\title{
SILVANA BIAGINI
}

Validação de um modelo experimental de transfusão de glóbulos vermelhos estocados homólogos em suínos e avaliação de seus efeitos cardiorrespiratórios e inflamatórios na hemorragia aguda

Tese apresentada à Faculdade de Medicina da Universidade de São Paulo para obtenção de título de Doutor em Ciências

Programa de Pneumologia

Orientador: Prof. Dr. Guilherme de Paula Pinto Schettino Coorientador: Prof. Dr. Luciano César Pontes de Azevedo

SÃO PAULO

2015 
Dados Internacionais de Catalogação na Publicação (CIP)

Preparada pela Biblioteca da

Faculdade de Medicina da Universidade de São Paulo

Creprodução autorizada pelo autor

\section{Biagini, Silvana}

Validação de um modelo experimental de transfusão de glóbulos vermelhos estocados homólogos em suínos e avaliação de seus efeitos cardiorrespiratórios e inflamatórios na hemorragia aguda / Silvana Biagini. -- São Paulo, 2015.

Tese(doutorado)--Faculdade de Medicina da Universidade de São Paulo.

Programa de Pneumologia.

Orientador: Guilherme de Paula Pinto Schettino.

Coorientador: Luciano César Pontes Azevedo.

Descritores: 1.Eritrócitos 2.Transfusão de sangue 3.Hipovolemia 4.Inflamação 5.Estudos de validação 6 .Suínos 7 .Hemorragia

USP/FM/DBD-129/15 
Dedicatória 

Dedico esta tese aos mens pais, Güuseppe Biagini e Lucia Naltin Biagini, pelo caráter e determinação que me transmitiram e que com muito sacrificio, me proporcionaram a oportunidade de me graduar em medicina e reatizar mew sonho de ser médica.

Aos meus irmãos que sempre incentivaram minha carreira profissional, obrigada pela amizade e confiança.

À minha fitha Livia Biagini Blanco por ter dividido minhas atençöes ao longo de 26 anos com a minha profissão e aperfeiçoamento, e ao pai dela que me deu todo $\sigma$ suporte e incentivo no inicio da minha carreira. 

Agradecimentos 

Gostaria de agradecer a todas as pessoas que colaboraram para a realização deste projeto, proporcionando-me frequentar e aprender na Faculdade de Medicina da Universidade de São Paulo, mais de duas décadas após a minha graduação.

Agradeço ao mew orientador Dr. Guitherme Schettino, pela confiança em mim depositada ao longo deste projeto, permitindo-me autonomia em seu desenvolvimento;

Ao men coorientador Dr. Luciano Azevedo, que participou de todos os experimentos práticos no decorrer desses anos, e por sempre estar disposto a me ajudar em todas as etapas para a realização deste projeto;

Ao Diretor médico e à Supervisora do Laboratório do Banco de Sangue do Sírío Libanês, Dr Sítvano Wendel e Dra. Rita Fontáo-Wendel, que acompanham minha carreira há mais de 24 anos incentivando e participando intensamente em mew crescimento profissional, além de grandes incentivadores deste projeto, inclusive emprestando-me sua expertise em Hemoterapia para validação das técnicas empregadas;

Ao Dr. Paulo Aguirre, que com sew amplo conhecimento experiência viabitizow a etapa inicial deste projeto;

Ao Dr. Marcelo Park e Dr. Eduardo Leite Vieira Costa, que sempre nos brindaram com sew conhecimento científico durante toda a etapa de elaboração do projeto e interpretação dos dados obtidos, mantendo minha empolgação pela pesquisa em momentos díficeis; 
Ao Dr. Andre L. Rosario que participou do experimento prático da primeira etapa deste projeto.

As colegas de trabalho do Instituto de Hemoterapia Sírio Libanês, Dra. Arlette Lazar, Dra. Sylvia Olyntho, Dra. Ruth Achkar e Dra. Patricia Scuracchio, que acompanham minha trajetória diária e sempre me apoiaram tanto neste projeto como em minha vida profissional, alegrando-me com sew adorável convívio e propiciando minha dedicação exclusiva a este projeto em vários momentos;

Ao colega Dr. Fausto Trigo que pacientemente ouviu, lew e relew este projeto muitas vezes durante todos esses anos, sempre disponivel e bem humorado, você fez a diferença.

Ao querido colega Marcelo Amaral, que com sua amizade, inestimável ajuda, paciência e bom humor, transformow diariamente minha experiência cientifica,

A Soane Mota, que além de todo suporte da anatise estatistica, se tornow uma grande amiga;

Aos colegas fisioterapentas por todos of sens valiosos ensinamentos e valiosissima paciência com minha pessoa;

Aa toda equipe do IEP pela oportunidade única em desenvolver este projeto em instalações de grande qualidade técnica e ambiente pessoal muito agradável;

Aos colegas médicos veterinários Dra. Andreza Conti Patara, Dra. Tabatha do Amaral Kalensky e Dr. Bruno G Pedron pelas importantes contribuiçöes científicas; 
As biologas Camila Dale e Eloisa de Sá Moreira e biomédica Jutiana Monte Real pelo suporte nas análises laboratoriais.

Aos colegas bioteristas pelo cuidado com os animais que sempre garantiram toda a assistência necessária ao bom desenvolvimento dos trabalhos;

Às queridas bibliotecárias Adriana Mara Fonseca, em especial Rita de Cassia Ortega, pela total disponibilidade, presteza, eficiência e amizade;

A Valería Lira que fez a ilustração gráfica deste projeto que além de sua competência profissional sempre foi muito atenciosa e disponivel.

Ao Renato Gabriel dos Santos e a todos os colegas que trabalham comigo pelo apoio durante o periodo dedicado a este projeto, evitando assim injustiças no reconhecimento de colegas não citados anteriormente. 

Normatização adotada 

Esta tese está de acordo com as seguintes normas, em vigor no momento de sua publicação:

Referências: adaptado de International Committee of Medical Journals Editors (Vancouver).

Universidade de São Paulo. Faculdade de Medicina. Divisão de Biblioteca e Documentação. Guia de apresentação de dissertações, teses e monografias. Elaborado por Anneliese Carneiro da Cunha, Maria Julia de A.L.Freddi, Maria F.Crestana, Marinalva de Souza Aragão, Suely Campos Cardoso, Valéria Vilhena. $3^{a}$ ed. São Paulo: Divisão de Biblioteca e Documentação; 2011.

Abreviatura dos títulos e periódicos de acordo com Lista of Journals Indexed in Index Medicus. 

Sumário 



\section{LISTA DE ABREVIATURAS}

\section{LISTA DE TABELAS}

LISTA DE FIGURAS

LISTA DE QUADRO

RESUMO

SUMMARY

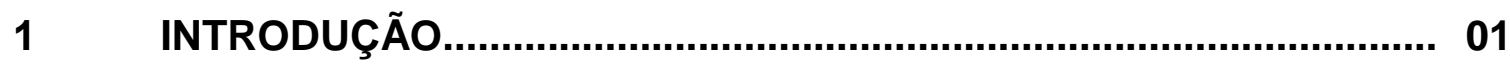

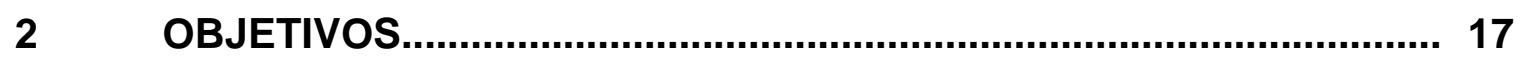

$2.1 \quad$ Objetivo primário..................................................................... 19

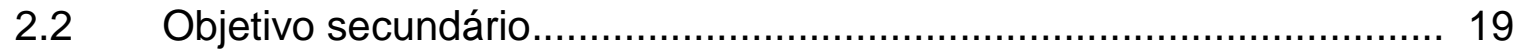

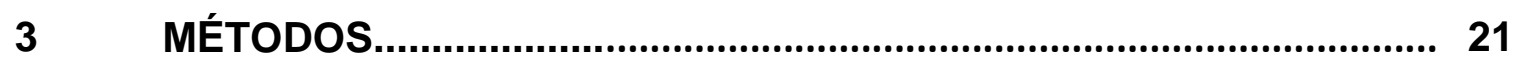

3.1 Delineamento Geral...................................................................... 23

3.1.1 Validação "in vitro" e "in vivo" da transfusão de concentrado de glóbulos vermelhos homólogos estocados por 14 dias em um modelo de suínos com hipovolemia aguda.

3.1.2 Avaliação dos efeitos agudos da transfusão na hemodinâmica, trocas gasosas, mecânica respiratória e resposta inflamatória pulmonar e sistêmica.

3.2 Hemorragia controlada e reposição volêmica..................................... 40

3.3 Coleta e Processamento das Unidades de Sangue Total................... 41

3.4 Avaliação Laboratorial - Hemograma, Variáveis Ventilatórias e de Oxigenação.

3.5 Avaliação da Resposta Inflamatória................................................ 42

3.5.1 Concentrações de citocinas no plasma e no tecido pulmonar.

3.5.2 Concentrações de nitrato no plasma e no tecido pulmonar.

3.5.3 Análise de expressão de RNAm (RNA mensageiro) para marcadores de resposta inflamatória em tecido pulmonar..................................... 46

3.6 Análise Estatística......................................................................... 50

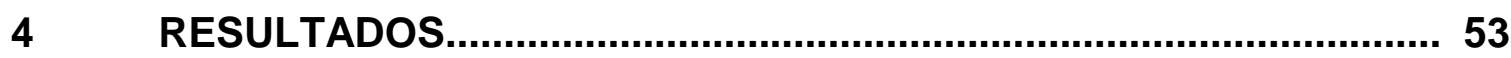


4.1 Etapa 1 - Validação da transfusão de concentrado de glóbulos vermelhos homólogos, estocados por 14 dias.

4.1.2 Validação “in vitro" das unidades de GV...................................... 55

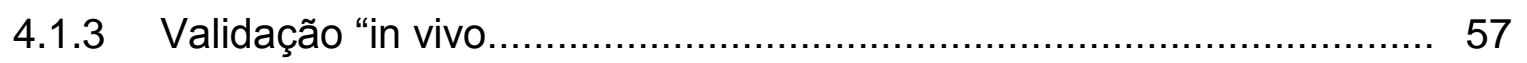

4.2 Etapa 2 - Avaliar os efeitos agudos da transfusão de glóbulos vermelhos estocados no transporte de oxigênio, mecânica respiratória e resposta inflamatória pulmonar e sistêmica da hipovolemia experimental.

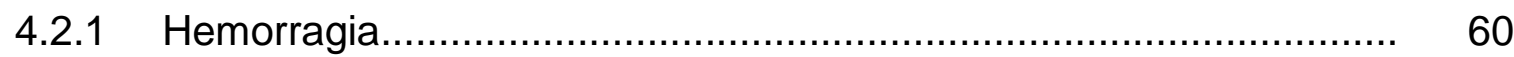

4.2.2 Parâmetros Hemodinâmicos e de Oxigenação................................ 60

4.2.3 Parâmetros Respiratórios...................................................... 79

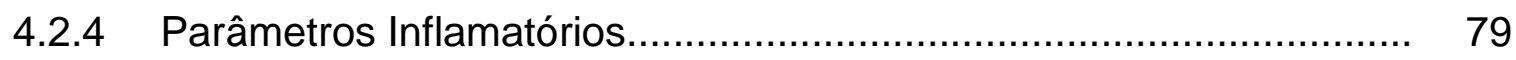

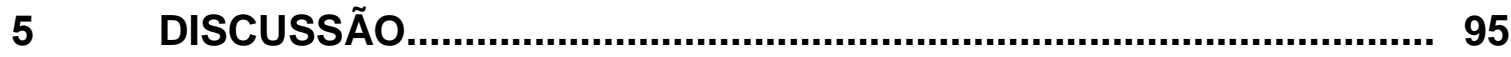

5.1 Validação da transfusão de GV estocados "in vitro" e "in vivo"............. 99

5.2 Avaliação do efeito agudo da transfusão de GV nas trocas gasosas, mecânica respiratória, hemodinâmica, assim como resposta inflamatória pulmonar e sistêmica em suínos hipovolêmicos sadios... 101

5.3 Efeitos Hemodinâmicos........................................................... 103

$5.4 \quad$ Efeito na Microcirculação................................................... 105

5.5 Efeito nas trocas gasosas e mecânica respiratória.......................... 106

5.6 Efeitos Inflamatórios............................................................... 109

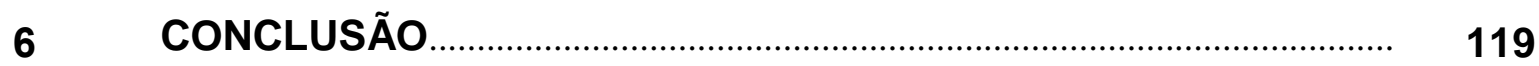

$7 \quad$ REFERÊNCIAS BIBLIOGRÁFICAS........................................... 123 
Listas 

$\Delta$ VS

ANOVA

APev

Codin

cDNA

CEUA

Cest

cpm

Curvas PV

DC

DCc

ELISA

$\mathrm{EtCO}_{2}$

FDA

$\mathrm{FIO}_{2}$

FR

GEDVI

GEF

GV

IL-1 $\beta$

IL-6

IL-10

IL-21

LBA

LPA

MDA

$\mathrm{Na}_{2}{ }^{51} \mathrm{CrO}_{4}$

NO

iNOS

PAM

PAop

PAP
Variação do volume sistólico

Análise de variância

Água pulmonar extravascular

Complacência dinâmica do sistema respiratório

DNA complementar

Comitê de Ética no Uso de Animais

Complacência estática do sistema respiratório

Contagem por minuto

Curva pressão volume (PV) do sistema

respiratório

Débito cardíaco

Débito cardíaco contínuo

Técnica de ensaio imunológico ligado à enzima

Gás carbônico no final da expiração

Food and Drug Administration

Fração inspiratória de oxigênio

Frequência respiratória

Volume diastólico final global indexado

Fração de ejeção global

Glóbulos vermelhos

Interleucina-1 beta

Interleucina-6

Interleucina-10

Interleucina-21

Lavado bronco-alveolar

Lesão pulmonar aguda

Malondialdeído

Cromato de sódio radioativo

Óxido nítrico

Óxido nítrico sintetase induzida

Pressão arterial média

Pressão de artéria pulmonar ocluída

Pressão de artéria pulmonar 
PAPm

PEEP

$\mathrm{PiCCO}^{(}$

Pmva

Ppico

Pplat

PVC

qRT- PCR

Rsr

RN

RNAm

SDMO

SDRA

$\mathrm{SvO}_{2}$

TAD

TRALI

(Transfusion Related

Acute Lung Injury)

TRIM

(Transfusion Related

Immunomodulation)

TRISS

VDFVD

$\mathrm{VnCl} 4$

VPT

VT
Pressão de artéria pulmonar média

Pressão expiratória final positiva

Pulse index Contour Continuous Cardiac Output

Pressão média de vias aéreas

Pressão de pico inspiratório

Pressão de platô inspiratório

Pressão venosa central

Reação em cadeia da polimerase em tempo real

Resistência do sistema respiratório

Recém-nascidos

RNA mensageiro

Síndrome de Disfunção de Múltiplos Órgãos

Síndrome do Desconforto Respiratório Agudo

Saturação Venosa Mista de Oxigênio

Dispneia associada à transfusão

Lesão pulmonar aguda relacionada à transfusão

Síndrome da imunomodulação relacionada à

transfusão

Transfusion requirements in septic shock

(Necessidade transfusional em choque séptico)

Volume Diastólico Final de Ventrículo Direito

Cloreto de Vanádio

Viabilidade pós transfusional

Volume corrente 
Tabela 1 Concentração de anticorpos e proteína utilizados na detecção por ensaio imunoenzimático dos mediadores IL-1 $1 \beta$, IL-6, IL-10 e IL-21

Tabela 2 Iniciadores e sondas utilizadas na detecção da expressão de RNAs mensageiros por PCR em tempo real.

Tabela 3 Validação das unidades de GV "in vitro". 56

Tabela 4 Grupos sanguíneos e provas de compatibilidade.................. 56

Tabela 5 Controle de qualidade "in vitro" das unidades de GV 59

Tabela 6 Tipagem Sanguínea e Provas de Compatibilidade. 59

Tabela 7 Animal excluído do estudo. 61

Tabela 8 Variáveis Hemodinâmicas e Laboratoriais dos Grupos Durante o Período do Estudo.

Tabela 9 Parâmetros Respiratórios dos Grupos durante o Período do Estudo. 
Figura 1 Validação "in vivo" ........................................................... 30

Figura 2 Linha do tempo..............................................................

Figura 3 Exemplo da construção da curva PV e calculo das energias inspiratória, expiratória e histerese.......................................... 39

Figura 4 Viabilidade "in vivo" de hemácias marcadas com cromato de sódio radioativo até 24 horas pós-infusão............................... 58

Figura 5 Parâmetros Hemodinâmicos Evolutivos dos grupos durante o estudo

Figura 6 Parâmetros de Oxigenação e Perfusão Tissular evolutivos dos grupos durante o estudo

Figura $7 \quad$ Parâmetros Respiratórios................................................... 91

Figura 8 Parâmetros inflamatórios em ambos os grupos durante 0

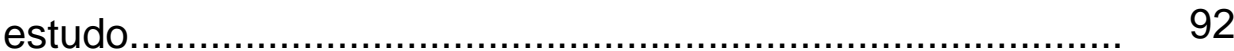

Figura 9 RNAm para citocinas e iNOS no tecido pulmonar.................... 93

Figura 10 Concentração de nitrato em ambos os grupos durante o estudo 
Quadro 1 Lesão de Estocagem................................................ 09 


Biagini S. Validação de um modelo experimental de transfusão de glóbulos vermelhos estocados homólogos em suínos e avaliação de seus efeitos cardiorrespiratórios e inflamatórios na hemorragia aguda [Tese]. São Paulo: Faculdade de Medicina, Universidade de São Paulo; 2015.

Objetivos: Transfusão de sangue é fundamental para a sobrevida de pacientes selecionados, porém é associada a complicações. A literatura é controversa em relação aos efeitos pulmonares, hemodinâmicos e inflamatórios da transfusão de glóbulos vermelhos (GV). Este estudo teve dois objetivos principais: 1- validar um modelo de transfusão homologa de GV estocados em suínos com hipovolemia aguda por hemorragia controlada; 2avaliar os efeitos agudos da transfusão de GV nas trocas gasosas, mecânica respiratória, hemodinâmica e na resposta inflamatória pulmonar e sistêmica.

Métodos: Este estudo foi dividido em duas etapas: 1.Coleta, processamento e estocagem por 14 dias de GV provenientes de um suino Agroceres ${ }^{\circledR}$, avaliado antes (in vitro) e após (in vivo - marcação com cromato de sódio radioativo) à sua transfusão em suínos sadios, um autólogo e quatro homologos ( $\mathrm{n}=$ cinco); 2. Outro grupo de suínos foi submetido à hemorragia aguda controlada $(25 \%$ de sua volemia) e então dividido em dois grupos: grupo transfusão ( $n=$ oito) recebeu duas unidades de GV e solução de ringer lactato ( $R L$ ) para restabelecer a volemia; grupo controle ( $n=0$ ito) que recebeu somente $R L$. Ambos os grupos foram seguidos até 6horas após o final da ressuscitação volêmica. Dados hemodinâmicos e respiratórios foram coletados a cada hora após o inicio do estudo. Mediadores inflamatórios e expressão de RNAmensageiro(RNAm) foram medidos no plasma e no tecido pulmonar.

Resultados: Houve recuperação de 97,5\% $\pm 19 \%$ dos GV marcados com cromato de sódio radioativo 24 horas após a transfusão. Houve aumento significativo da saturação venosa mista, conteúdo arterial de oxigênio e dos níveis de hemoglobina e hematócrito no grupo transfundido comparado ao controle. Os parâmetros medidos para a avaliação da microcirculação e as trocas gasosas foram similares em ambos os grupos. Observou-se um aumento significativo na energia gasta na histerese pulmonar no grupo controle quando comparado ao grupo transfundido $(p=0,002)$, bem como uma tendência 
á diminuição da energia inspiratória no grupo transfusão. As concentrações plasmáticas das diversas citocinas avaliadas antes e após a transfusão de GV mostraram-se abaixo dos limites de detecção do teste ELISA na maioria dos animais estudados em ambos os grupos; não houve diferença significativa nas concentrações de nitrato no plasma e no tecido pulmonar. Observou-se uma diferença discreta, porem estatisticamente significativa, entre os grupos na quantificação do RNAm da oxido nítrico sintetase induzida (iNOS) e da IL-21 no tecido pulmonar (aumento de 50\% na iNOS e decréscimo de 50\% na IL-21 no grupo transfundido comparado com o controle).

Conclusão: Demonstramos a viabilidade "in vitro" e "in vivo" de GV suínos, estocados por até 14 dias. A transfusão de GV homólogos não causou alterações significativas na hemodinâmica, função pulmonar e resposta inflamatória nas primeiras 6 horas após a transfusão.

Descritores: eritrócitos; transfusão de sangue; hipovolemia; inflamação, estudos de validação; suínos; hemorragia. 
Abstract 

Biagini S. Validation of homologous stored red blood cell transfusion in swine and evaluation of cardiorespiratory and inflammatory effects in acute hemorrhage [Thesis]. São Paulo: "Faculdade de Medicina, Universidade de São Paulo"; 2015.

Objectives: Blood transfusion is critical to the survival of selected patients, but may be associated with complications. Previous data related to pulmonary, hemodynamic and inflammatory effects of red blood cells (RBC) are still controversial. This study has two main objectives: 1- Validate a homologous stored red blood cell transfusion model in swine with acute hypovolemia by controlled bleeding; 2- Assess the acute effects of RBC transfusion on gas exchange, respiratory mechanics and hemodynamics, pulmonary and systemic inflammatory response.

Methods: This study was divided into two phases: 1. Collection, processing and storing RBC from Agroceres ${ }^{\circledR}$ swines for 14 days and evaluation before (in vitro) and after (in vivo - labelling with radioactive sodium chromate) transfusion in one autologous and four homologous healthy swines ( $n=$ five); 2 . Controlled acute hemorrhage ( $25 \%$ of blood volume) of sixteen pigs and then allocation in two groups: transfusion group ( $\mathrm{n}=$ eight) received two units of $\mathrm{RBC}$ and Lactaded Ringer's solution $(R L)$ to restore blood volume; control group $(n=$ eight) that received only LR. Both groups were followed up to 6 hours after the end of resuscitation. Hemodynamic and respiratory data were collected hourly after the start of the study. Inflammatory mediators and messenger $\mathrm{RNA}(\mathrm{mRNA})$ expression were measured in plasma and lung tissue.

Results: The 24-hour recovery of $\mathrm{RBC}$ labeled with radioactive sodium chromate was $97.5 \% \pm 19 \%$. We found significant increase of mixed venous oxygen saturation, oxygen arterial content, and hemoglobin and hematocrit levels in the transfused group compared to control. There were no significant differences between the two groups in microcirculation and gas exchange. There was a significant increase in the energy spent in lung hysteresis in the control group compared to the transfused group $(p=0,002)$, as well as a tendency to decrease inspiratory energy in the transfusion group. The concentrations of the various cytokines evaluated before and after RBC 
transfusions were below the ELISA detection limit in most animals studied; there were no significative difference in nitrate concentrations in plasma and lung tissue. There was a statistically significant difference between groups in the quantification of mRNA induced nitric oxide synthase (iNOS) and IL-21 in lung tissue (increase in iNOS 50\% and 50\% decrease in IL-21 in the transfused group as compared to control).

Conclusion: We demonstrated in this study the viability of 14-days stored swines RBC "in vitro" and "in vivo". Homologous stored red blood cell transfusion in swine did not cause significant hemodynamic changes in the pulmonary function and inflammatory response within the first six hours after transfusion.

Descriptors: erythrocytes; blood transfusion; hypovolemia; inflammation; validation studies; swine; hemorrhage. 
1. Introdução 

A transfusão de glóbulos vermelhos (GV) é uma das mais frequentes e antigas terapias celulares utilizadas na prática médica, assumindo um papel inconteste na manutenção da vida de muitos pacientes graves. A despeito do avanço em diferentes técnicas de ressuscitação volêmica, a transfusão de GV ainda permanece como terapia de escolha em grupos específicos de pacientes, particularmente naqueles com trauma e cirurgias de grande porte ${ }^{163,145}$. Ainda hoje, ao redor de $30 \%$ dos pacientes de terapia intensiva e $50 \%$ dos pacientes submetidos à cirurgia cardíaca, recebem transfusão de GV durante sua permanência no hospital ${ }^{201}, 29,202$. Estima-se que 85 milhões de unidades de GV sejam transfundidas anualmente em todo o mundo ${ }^{97,}{ }^{172}$; não obstante, sua utilização não está completamente estabelecida no que se refere à indicação precisa, dose, frequência, benefícios e riscos ${ }^{156,63,145,203,64}$.

Apesar da crescente segurança transfusional, a prática da transfusão ainda está associada a uma série de eventos adversos, por vezes graves, usualmente classificados como infeciosos e não infeciosos. A busca pela segurança transfusional determina altos custos pela tecnologia empregada ${ }^{155,192}$, bem como na limitação de estoque ${ }^{131,203}$. Os avanços na triagem sorológica de doadores nos últimos 20 a 30 anos levaram a uma sensível redução na transmissão de patógenos (viral, bacteriano e outros agentes) por transfusão ${ }^{38}$. A despeito deste sucesso persistem os eventos não infecciosos, denominados imuno-inflamatórios associados às transfusões. Tais eventos são responsáveis por significativa morbimortalidade em receptores de sangue e representam um grande desafio para melhora na terapia transfusional $^{70,191,201,190,209}$. 
Nas últimas duas décadas, evidências crescentes na literatura vêm alertando que a transfusão, mais especificamente de GV, pode estar associada a complicações clínicas importantes, tais como: lesão pulmonar ${ }^{62,26,134,220,27,185}$; aumento de tempo de ventilação mecânica ${ }^{52}$, aumento da permanência hospitalar; elevação da taxa de infecção pós-operatória e síndrome de disfunção de múltiplos órgãos $(\mathrm{SDMO})^{126}$ maior mortalidade ${ }^{62}$, principalmente em pacientes $\operatorname{críticos}^{70,201,29}$, na sepse ${ }^{143}$, politrauma, pós-operatório de cirurgias cardíacas ${ }^{48,66,137}$ e oncológicos ${ }^{193}$.

Cumpre salientar, contudo, que os pacientes com as condições acima descritas geralmente apresentam também um maior risco de SDMO, dificultando desta maneira a correta interpretação dos resultados ${ }^{198,109}$. Além disto, vários fatores relacionados às unidades de GV transfundidos, tais como diferentes soluções, métodos de processamento tempos de estocagem, número de unidades transfundidas e utilização de filtros para redução de leucócitos (leucorredução) também dificultam a interpretação destes estudos.

Os efeitos adversos, pró-inflamatórios e/ou imunossupressores vêm sendo atribuídos a uma ação "imunomodulatória" da transfusão conhecida como Síndrome da Imunomodulação Relacionada à Transfusão (Transfusion Related Immunomodulation - TRIM) ${ }^{191,141}$.

A evidência clínica da existência da imunomodulação foi inicialmente descrita em 1973 com a melhora da sobrevida de enxertos renais em pacientes que haviam recebido transfusão de sangue prévia ao transplante; tal melhora ocorreu de forma dose dependente ${ }^{136}$. Na década de 1980, inúmeros estudos relataram associação da transfusão com aumento de recorrência de tumores em pacientes transfundidos durante as cirurgias oncológicas ${ }^{54,14,17}$, aumento na 
incidência de infecção no perioperatório ${ }^{175}$, decréscimo de aborto espontâneo de repetição ${ }^{129}$ e diminuição de sintomatologia em algumas doenças inflamatórias ${ }^{220,195}$.

Uma explicação biológica plausível para justificar a pior evolução destes pacientes fundamenta-se na conhecida ocorrência de um conjunto de alterações bioquímicas, metabólicas e estruturais nas unidades de GV decorrentes de sua estocagem "ex- vivo", denominada "lesão de estocagem," que pode comprometer a segurança e a eficácia transfusional ${ }^{135,10,02,96}$. Durante a estocagem ocorre queda dos níveis de 2,3 difosfoglicerato, de ATP, diminuição progressiva do $\mathrm{pH}$, produção de lactato, consumo de glicose, aumento dos níveis de potássio e hemoglobina livre no plasma e vesiculação da membrana eritrocitária, além de alterações morfológicas e reológicas incluindo adesão dos GV ao endotélio. Estas alterações levariam a um prejuízo da função dos GV “in vivo" e menor sobrevida dos GV transfundidos ${ }^{196}$.

Evidências crescentes na literatura demonstraram ainda a ativação de neutrófilos e presença de substâncias bioreativas acumuladas no plasma durante o período de estocagem ${ }^{157,68,217,75,73}$. Tais processos podem também estar implicados nas alterações imuno-inflamatórias observadas após a

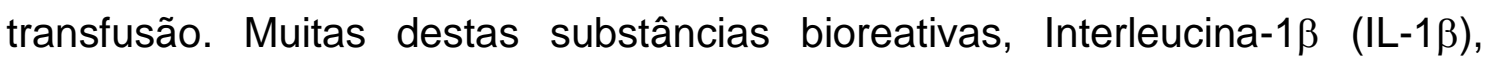
Interleucina-6 (IL-6), Interleucina-10 (IL- 10), Interleucina-21 (IL-21) e fator de necrose tumoral (TNF) são provenientes dos leucócitos presentes nos concentrados de glóbulos vermelhos. A remoção parcial de leucócitos, através da utilização de um filtro especifico, reduz o acúmulo destes mediadores bioreativos nas unidades de $\mathrm{GV}^{157,218,217,13,69,3,87}$. No entanto, pacientes recebendo GV leucorreduzidos ainda continuam a apresentar efeitos adversos, 
sugerindo a presença de outros fatores relacionados à imunomodulação ${ }^{199,41,46,161}$. Outra variável que vem sendo associada a pior evolução clínica de pacientes transfundidos é o tempo de estocagem dos

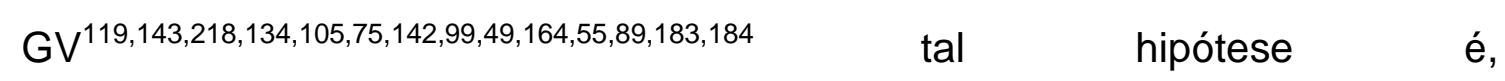
controversa ${ }^{194,208,144,197,211,202,221,108,183,198,212,210,103,47,206,169}$.

Mais recentemente estas alterações inflamatórias vêm sendo atribuídas a presença de hemoglobina livre, ferro, lipídios e fragmentos de membrana celular, acumuladas no plasma durante a estocagem ${ }^{95,37,59,7,91,76,77,78,110,166}$ (Quadro 1) .

Os GV estocados por maior tempo são mais susceptíveis à hemólise “in vivo” após a transfusão ${ }^{58,198,107}$. A hemoglobina livre no plasma e a encapsulada em microparticulas, provenientes da hemólise durante a estocagem, têm uma avidez pelo oxido nítrico (NO) muito superior à da hemoglobina encapsulada em eritrócitos intactos ${ }^{37,111}$. Tal característica seria responsável pela diminuição da biodisponibilidade do óxido nítrico (insufficient nitric oxide bioavailability - INOBA), que poderia explicar a ocorrência de vasoconstrição microvascular, atividade inflamatória pró-oxidante e ativação plaquetária descrita em pacientes transfundidos ${ }^{107}$. Redução similar da biodisponibilidade do NO devido ao aumento de concentração de hemoglobina no plasma tem sido relatado em pacientes com doenças hemolíticas como anemia falciforme ${ }^{101}$ e malária ${ }^{214,151}$. De fato, outros estudos corroboram a hipótese de que a presença da hemoglobina livre no plasma pode ser responsável pela alteração da homeostasia vascular secundária à atividade ligante do $\mathrm{NO}^{95,37}$. Todavia, ainda há dúvidas se esta alteração per si tem tradução clinica ou se ocorreria apenas em efeito sinérgico a outros fatores de 
risco inerentes ao receptor (diabetes, dieta rica em gordura e choque hemorrágico $)^{216,107}$. Esta avidez aumentada da hemoglobina livre pelo NO vem sendo largamente responsabilizada pela hipertensão, aumento da resistência vascular sistêmica e pulmonar e consequente morbimortalidade associada à administração de carreadores artificiais de oxigênio compostos de moléculas de hemoglobina ${ }^{179,215}$.

Uma série de estudos em modelos experimentais avaliou o papel do NO nos eventos adversos relacionados à transfusão de GV estocados. Estudo em ovinos de transfusão de GV autólogo estocado demonstrou aumento transitório das pressões de artéria pulmonar e resistência vascular pulmonar indexada, atenuado pela inalação de NO e potencializado pela inibição da oxido nítrico sintetase $(\mathrm{NOS})^{8}$. Outro estudo publicado recentemente, em modelo suíno de circulação extracorpórea, demonstrou associação entre transfusão de GV estocados e alteração significativa da função renal e da resposta inflamatória ${ }^{140}$. No entanto, estes autores utilizaram um tempo de armazenamento do GV muito longo; de acordo com a literatura, os GV suínos transfundidos tem vida média menor quando comparada ao dos humanos ${ }^{130}$. Além disso, expectativa de vida média dos GV suínos é menor do que os humanos (86 vs 120 dias) ${ }^{43}$, o que sugere que os efeitos observados neste estudo podem ter sido superestimados. O mesmo grupo, em estudo posterior com suínos, demonstrou diminuição significativa na complacência pulmonar 1,5 e 24 horas após a transfusão de GV homólogos com 14 e 42 dias de estocagem e evidências histológicas de lesão pulmonar aguda; tais efeitos foram exacerbados após circulação extracorpórea ${ }^{139}$. 
Em outros estudos, a transfusão também é avaliada como um "segundo evento", uma vez que os animais estudados tenham sofrido um “insulto" inicial para lesão pulmonar ${ }^{186,185}$, ou choque hipovolêmico ${ }^{107,50}$. Estudo em modelo "ex-vivo" de anéis aórticos de ratos publicado em novembro de 2013 postulou que a transfusão de GV estocados tem atividade vasoinibidora através de outro mecanismo além do proposto anteriormente, que não envolve a retirada do NO pela hemoglobina livre ${ }^{01}$. Ainda nesta linha de raciocínio, um estudo em modelo murino demonstrou que fatores de risco conhecidos para disfunção vasomotora, incluindo diabetes e dieta rica em gordura ${ }^{216}$, amplificaram o efeito adverso da estocagem de GV nestes animais. Seja qual for o mecanismo dominante, muitas linhas diferentes de investigação relacionam a hemólise do sangue armazenado como responsável, em última analise, pelas complicações observadas após transfusão de GV estocados ${ }^{146 .}$ Na prática clínica, estes estudos corroboram os achados de pior evolução em pacientes com fatores de risco preexistentes para doença cardiovascular quando transfundidos. Esta hipótese também explicaria porque estudos com transfusão de GV estocados em voluntários sadios não ocasionaram alteração vascular aparente $e^{60,12}$

Tamanho número de possibilidades etiológicas talvez possa ser explicado pela variação dos métodos de coleta, processamento e estocagem de GV utilizados nos diversos estudos experimentais em relação aos realizados em humanos, dificultando desta maneira a comparação dos dados ${ }^{56,205,185,216}$. 
Quadro 1- Lesão de Estocagem

\begin{tabular}{|c|c|}
\hline Alterações durante a estocagem & Consequências \\
\hline Decréscimo do 2,3-DPG, Acidose & $\uparrow$ Afinidade da Hemoglobina pelo $\mathrm{O}_{2}$ \\
\hline Depleção do ATP & $\begin{array}{l}\text { Alterações formato, aumento fragilidade } \\
\text { osmótica e decréscimo da deformabilidade } \\
\text { eritrocitária. }\end{array}$ \\
\hline $\begin{array}{l}\text { Microvesiculação e perda de } \\
\text { lípides da membrana }\end{array}$ & Decréscimo da viabilidade eritrocitária \\
\hline Peroxidação lipídica & Dano e morte celular \\
\hline $\begin{array}{l}\text { Geração de substâncias bioativas: } \\
\text { citocinas, lipídios, etc. }\end{array}$ & $\begin{array}{l}\text { RFNH, Recrutamento de neutrófilos, } \\
\text { ativação endotelial, lesão celular, TRALI, } \\
\text { IMOS? }\end{array}$ \\
\hline $\begin{array}{l}\text { Depleção do S-nitroso } \\
\text { hemoglobina (SNO) }\end{array}$ & Vasoconstrição, inflamação e trombose. \\
\hline
\end{tabular}

TRALI = Transfusion Related Acute Lung Injury

IMOS = Insuficiência de Múltiplos Órgãos

RFNH = Reação Febril não Hemolítica

Por outro lado, os efeitos benéficos primordialmente associados à transfusão de GV têm sido cada vez mais questionados $^{70,118,156,66,200,79,209,80,149,64}$. Muitos estudos clínicos que avaliam a eficácia da transfusão de glóbulos vermelhos utilizam marcadores indiretos ou desfechos substitutos para avaliar a oxigenação tecidual e o consumo de oxigênio tissular tais como a tonometria, dosagem de lactato sérico ou saturação venosa da hemoglobina pelo oxigênio ${ }^{117,208,152}$. Outros estudos avaliam dados mais gerais e indiretos como mortalidade, morbidade ou tempo de internação ${ }^{62,118,27,66,200,79,80,209,137,176}$. Todos são mais propensos a erros de 
conclusão devido à dependência destes marcadores a inúmeras variáveis não controladas, portanto dificultando ainda mais a interpretação crítica dos resultados $^{194,201,81}$.

Sabe-se que a oxigenação tecidual pode ser mantida mesmo com uma grande variabilidade do nível de hemoglobina através de vários mecanismos fisiológicos compensatórios como o aumento do débito cardíaco e da extração tecidual de oxigênio ${ }^{138,156}$. Estudos realizados em pacientes com choque hipovolêmico ${ }^{35}$ e séptico ${ }^{112,45}$ observaram ausência de melhora na oferta de oxigênio após a transfusão de glóbulos vermelhos com elevação dos níveis de hemoglobina para valores acima de $10 \mathrm{~g} / \mathrm{dL}$.

Pouco se sabe também sobre as mudanças da mecânica respiratória, após a transfusão de glóbulos vermelhos. Estudo realizado em recém-nascidos (RN) pré-termo identificou importantes alterações da mecânica respiratória, com redução da complacência e aumento da resistência do sistema respiratório e do trabalho respiratório após transfusão. Os autores sugerem que estas alterações podem ser devidas ao aumento da volemia, decorrente do aumento do hematócrito e consequente elevação da pressão hidrostática na microvasculatura pulmonar ${ }^{150}$. Do mesmo modo, um estudo realizado com a finalidade de avaliar o aumento do consumo de oxigênio após transfusão de glóbulos vermelhos em pacientes sépticos também demonstrou aumento significativo da resistência do sistema respiratório quando comparado à infusão de albumina ${ }^{45}$.

Dentre as complicações relacionadas à transfusão, aquelas envolvendo o sistema respiratório estão entre as principais causas de 
morbimortalidade ${ }^{154,187}$. Entretanto a literatura é pobre em dados sobre a resposta inflamatória e mecânica pulmonar após transfusão sanguínea ${ }^{150,68,52,26,62,220}$. Estudo realizado em $\mathrm{RN}$ prematuros sob ventilação mecânica ${ }^{26}$ observou uma correlação entre o volume de sangue transfundido e o pico de malondialdeído (MDA), marcador inespecífico de estresse oxidativo, no lavado bronco-alveolar (LBA). O aumento do MDA foi observado logo após a primeira hora da transfusão com posterior queda e novo aumento após a segunda transfusão, sendo este comportamento então consistente com uma relação causal entre transfusão e produção de MDA. Outro estudo ${ }^{68}$ no qual foram comparadas as concentrações de interleucina 6 (IL-6) no soro e no LBA de crianças submetidas à cirurgia cardíaca identificou uma correlação entre o aumento da IL-6 com o volume de sangue transfundido no intraoperatório, uso de inotrópicos, ventilação mecânica e tempo de internação na terapia intensiva. Estudo recente em pacientes de terapia intensiva em ventilação mecânica, não encontrou diferença na função pulmonar, assim como no status inflamatório e na coagulação até 2 horas após transfusão de uma unidade de GV fresco ou estocado $^{103}$.

Desde meados de 1970, há relatos na literatura associando a transfusão de sangue em pacientes vítimas de trauma ao desenvolvimento da lesão pulmonar e insuficiência respiratória aguda, chamada nesta época de "Síndrome do Pulmão Branco"16,11. Estudos mais atuais têm demonstrado também uma piora da função pulmonar em pacientes com SDRA (síndrome do desconforto respiratório agudo) já instaladas que são submetidos à transfusão de sangue, independente da prática ou não de leucorredução. Aumento da pressão hidrostática capilar pulmonar, mas principalmente lesão endotelial com 
aumento ainda maior da permeabilidade capilar pulmonar devem estar implicados no efeito deletério da função pulmonar de portadores de SDRA após transfusão. Adicionalmente os glóbulos vermelhos estocados parecem ser menos deformáveis, podendo impactar na microcirculação dificultando a circulação pulmonar e sistêmica ${ }^{133,19}$.

A partir de 1980 foi reconhecida a presença de edema agudo pulmonar não cardiogênico relacionado temporalmente à transfusão de sangue, síndrome esta batizada como TRALI (Transfusion Related Acute Lung Injury) ${ }^{98,61,181}$. Inicialmente considerado um fenômeno essencialmente imunológico, atualmente o TRALI também pode ser explicado através da interação entre condições inflamatórias prévias do receptor e/ou liberação de substância biologicamente ativas acumuladas na unidade de sangue durante a estocagem $^{101,159}$. TRALI, semelhante à SDRA, foi definido por uma conferência de consenso como hipoxemia $\left(\mathrm{PaO}_{2} / \mathrm{FiO}_{2}<300 \mathrm{~mm} \mathrm{Hg}\right)$ de início agudo, infiltrado pulmonar bilateral à radiografia torácica, pressão de artéria pulmonar ocluída menor que $18 \mathrm{~mm} \mathrm{Hg}$ e clara relação temporal com a transfusão (até 6 horas) $)^{98,61}$.

Vários estudos em pacientes críticos demonstraram a associação de transfusão de GV e lesão pulmonar aguda de forma dose dependente, porém sem a referida e necessária relação temporal. Desta forma, tem ocorrido grande dificuldade prática na demonstração dos critérios estabelecidos para o diagnóstico conclusivo de $\operatorname{TRALI}^{62,220,184,103}$. Outros demonstraram que a transfusão de GV resulta em lesão pulmonar moderada, não preenchendo os critérios estabelecidos para TRALI na referida conferência de consenso ${ }^{181,27}$, e não são portanto diagnosticadas e tratadas como tal ${ }^{33}$. Duas outras reações 
adversas à transfusão com predomínio de envolvimento pulmonar são sobrecarga circulatória associada à transfusão (Transfusion acute circulatory overload - TACO), definida por edema agudo pulmonar hidrostático até 6 horas após a transfusão ${ }^{53}$, e a dispneia associada à transfusão (transfused acute dyspnea - TAD) caracterizada por desconforto respiratório que ocorre nas primeiras 24h após a transfusão, que não preenchem os critérios para TRALI e $\mathrm{TACO}^{19}$. Desta forma, podemos então observar que a real incidência de morbidade pulmonar associada à transfusão é ainda incerta ${ }^{102}$ é provavelmente subestimada.

Um estudo em modelo experimental demonstrou associação entre transfusão de GV estocados e inflamação pulmonar ${ }^{205}$. Já um estudo realizado em humanos sadios demonstrou que a transfusão de GV autólogos, causa disfunção pulmonar súbita, evidenciada por piora das trocas gasosas, independente de condições previas do receptor e do tempo de estocagem do sangue ${ }^{212}$. Por outro lado, estudos clínicos para avaliar o papel da transfusão homóloga, isoladamente, em voluntários saudáveis seriam eticamente inaceitáveis.

Podemos assim dizer que os estudos, na sua maioria observacional, têm demonstrado uma possível associação entre transfusão e pior evolução clínica, incluindo lesão pulmonar, disfunção de órgãos e maior mortalidade, apesar de vários outros estudos questionarem estes achados ${ }^{132,23,184,156,36}$. A despeito do uso de várias técnicas estatísticas, para análise dos dados disponíveis nos estudos clínicos, vários são os "fatores de confusão" como, por exemplo: número de unidades transfundidas, diferentes estratégias transfusionais, diferentes tempos de estocagem, cuidados especiais com o 
sangue (ex.: leucorredução) e comorbidades associadas (ex.: sepse, trauma, pós-operatório, uso de circulação extracorpórea e câncer), dificultando o estabelecimento de um papel independente da transfusão na pior evolução dos pacientes. Estudos recentes sugerem que as características do doador também possam estar relacionadas a possíveis efeitos deletérios da transfusão de $\mathrm{GV}^{25,222}$.

A literatura científica é ainda mais pobre em relação à transfusão sanguínea em suínos ${ }^{173}$. Relatos anedóticos na literatura demonstraram a importância de realizar transfusão compatível no sistema AO para evitar reações adversas quando utilizadas transfusões de sangue total ${ }^{84,158}$. Hoje são reconhecidos 16 grupos sanguíneos em suínos e sabe-se que os anticorpos naturais pertencem ao grupo sanguíneo $(A-O)^{162}$. O antígeno $A$ suíno é encontrado primariamente no plasma e posteriormente é absorvido pelas hemácias. Portanto a possibilidade de hemólise (A-O) não parece ser importante nos suíno devido à baixa densidade de antígenos nas hemácias. As reações adversas mais comumente observadas são hipertensão pulmonar e coagulação intravascular disseminada, quando utilizada transfusão de sangue total. Todavia, estas reações não parecem ocorrer em animais que não foram previamente transfundidos, principalmente se utilizado concentrado de glóbulos vermelhos ao invés de sangue total ${ }^{162}$. Por outro lado, o modelo suíno tem sido bastante utilizado em situações que reproduzem condições clínicas de pacientes críticos por guardar boa correlação anatômica e funcional com os humanos, particularmente em relação à hemodinâmica, função respiratória e aparelho gastrointestinal. Neste contexto, experimentos com suínos poderiam 
evitar algumas das limitações biológicas e éticas verificadas em estudos com humanos relacionados à transfusão de sangue.

Não obstante, vários estudos em modelo animal que avaliam os efeitos adversos à transfusão de GV são realizados utilizando transfusão homóloga entre diferentes espécies ou entre animais singênicos, bem como transfusão autóloga, desta forma não traduzindo o que ocorre na nossa realidade. Adicionalmente, somente poucos e recentes estudos descrevem a validação da transfusão de GV em seu experimento ${ }^{8,139,22}$. Acreditamos ser de suma importância esta validação, com intuito de assegurar a relevância da transfusão para os efeitos estudados ante os problemas decorrentes de coleta, processamento ou estocagem inadequada. Em resumo, até o presente momento não está claro se a transfusão de GV tem um efeito causal ou é mais um fator de confusão na pior evolução dos pacientes ${ }^{137}$.

Em nosso estudo o objetivo principal foi desenvolver um modelo de transfusão em suínos saudáveis onde os diversos fatores de confusão pudessem ser controlados, iniciando-se pelos fatores relacionados com as bolsas de GV (coleta, processamento e estocagem) e os relacionados ao receptor. Acreditamos que a melhor compreensão das alterações hemodinâmicas e respiratórias, bem como da resposta inflamatória associada à transfusão de sangue, tem grande utilidade no aprimoramento do cuidado de pacientes que necessitem desta terapêutica. 

2. Objetivos 



\section{$2.1 \quad$ Objetivos primários}

- Validar um modelo de transfusão homologa de glóbulos vermelhos estocados em suínos com hipovolemia aguda por hemorragia controlada.

\subsection{Objetivos secundários}

- Avaliar os efeitos agudos da transfusão de glóbulos vermelhos estocados na hemodinâmica, trocas gasosas, mecânica respiratória e resposta inflamatória pulmonar e sistêmica. 

3. Métodos 

Esta pesquisa foi realizada no Laboratório de Pesquisa Experimental em Medicina Intensiva do Instituto de Ensino e Pesquisa do Hospital SírioLibanês (IEP). O projeto foi apoiado pelo Banco de Sangue e Departamento de Medicina Nuclear do Hospital Sírio Libanês.

O protocolo experimental foi submetido e aprovado pelo Comitê de Ética no Uso de Animais (CEUA) (Protocolo \#2007/11) e pelo Comitê de Ética em Pesquisa da Faculdade de Medicina da Universidade de São Paulo.

Realizado de acordo com o Protocolo do Instituto Nacional de Saúde dos Estados Unidos da América (NIH) para estudos experimentais em animais (http://www.ncbi.nlm.nih.gov/books/NBK24650).

\subsection{Delineamento Geral}

Inicialmente o Projeto foi dividido em duas etapas:

3.1.1 Etapa 1 - Validação "in vitro" e "in vivo" da transfusão de concentrado de glóbulos vermelhos homólogos estocados por 14 dias em um modelo de suínos com hipovolemia aguda.

3.1.2 Etapa 2: Avaliação dos efeitos agudos da transfusão na hemodinâmica, trocas gasosas, mecânica respiratória e resposta inflamatória pulmonar e sistêmica.

\section{Etapa 1 :}

Esta validação envolveu cinco porcos machos da raça Agroceres ${ }^{\circledR}$, sendo um deles o animal doador, e os demais receptores. O animal doador, com peso de $50 \mathrm{~kg}$, foi pré-anestesiado por via intramuscular com midazolam 
$(0,3 \mathrm{mg} / \mathrm{kg})$, submetido à anestesia inalatória com halotano na concentração de $2 \%$ administrado em mascara de oxigênio a 100\% (Conquest 3000, HB hospitalar). A seguir, foi instrumentado com cateter venoso central (7F) em condições assépticas e então submetido à hemorragia controlada de $25 \%$ da volemia (estimada como peso corpóreo $(\mathrm{kg}) \times 70 \mathrm{~mL})^{99} \mathrm{em} 40$ minutos. Foram coletados $1.033 \mathrm{~mL}$ equivalentes a duas unidades de sangue total. A coleta do sangue foi realizada utilizando-se bolsas duplas CPDA-1 (Fresenius Hemo Care ${ }^{\circledR}$, São Paulo, Brasil), contendo solução anticoagulante e preservativa com citrato de sódio desidratado, acido cítrico monoidratado, fosfato de sódio monobásico mono hidratado, dextrose mono hidratada e adenina, que permite o estoque dos GV por até 35 dias. Após a coleta destas unidades contendo em média $450 \mathrm{~mL}$ de sangue total, as bolsas foram centrifugadas a 3.300 rotações por minuto $(\mathrm{rpm})$ por 16 minutos a $4^{\circ} \mathrm{C}$ (centrífuga DAMON/IE Division ${ }^{\circledR}$ DPR6000 ), originando duas unidades de GV com hematócrito de 68\% armazenadas e estocadas por 14 dias em refrigerador com temperatura controlada ( $\left.2^{\circ} a 6^{\circ} \mathrm{C}\right)$ (Freze-Fridge Digital Thermometer with alarms "C/F" Alla France). Adicionalmente, as unidades de GV foram individualmente monitoradas para temperatura através de um sensor acoplado às bolsas (Ibuttom DS1921g, Maxim-Dallas, Califórnia, USA). Com a finalidade de garantir o suprimento ininterrupto de energia elétrica, as unidades de GV foram estocadas em uma sala do laboratório suprida com gerador. As unidades de plasma foram descartadas (Figura 1).

O animal foi ressuscitado com $3.000 \mathrm{~mL}$ de solução salina, a anestesia foi suspensa e o animal enviado para sobrevida no biotério. 


\section{Tipagem Sanguínea e Provas de Compatibilidade}

Para assegurar a compatibilidade eritrocitária da transfusão de GV entre os animais foi realizada a tipagem "direta" do sistema A-O, utilizando soro Anti-A monoclonal (DIAMED, São Paulo, Brasil), utilizado rotineiramente na pratica da clinica transfusional em humanos. Um volume de $50 \mu \mathrm{L}$ do reagente (Anti-A) foi adicionado a uma suspensão das hemácias suínas a 3\%. Estes tubos foram centrifugados a 3.400 rotações por minuto $(\mathrm{rpm})$ por 15 segundos (Sero-Fuge ${ }^{\circledR}$ 2002, Becton-Dickson, New Jersey, US) ${ }^{207,30}$.

Foi realizada a leitura imediata em temperatura ambiente, e a presença de aglutinação foi considerada como reação positiva. Adicionalmente, foi realizada prova de compatibilidade entre as hemácias do doador e o soro de cada animal, adicionando a $100 \mu \mathrm{L}$ do soro do receptor $50 \mu \mathrm{L}$ da suspensão de hemácias do doador. Estes tubos foram centrifugados por 15 segundos a 3.400 rpm (SERO-FUGE®2002, Becton Dickson, New Jersey, US) ${ }^{207}$. Foi realizada leitura imediata à temperatura ambiente e a presença de aglutinação foi considerada resultado positivo.

\section{Validacão "in vitro"}

A validação das bolsas "in vitro" foi realizada no dia da coleta (basal) e no 14ํ dia de estocagem através de mensuração dos seguintes parâmetros: volume das bolsas $(\mathrm{mL})$, concentrações de hemoglobina $(\mathrm{g} / \mathrm{dL})$ e hematócrito (\%) dosagem de hemoglobina livre $(\mathrm{mg} / \mathrm{dL})$ e determinação do índice de hemólise pelo método da peroxidase ${ }^{32}$. A porcentagem de hemólise foi 
determinada pela relação entre a hemoglobina livre liberada no plasma e o total de hemoglobina contida na amostra. O sobrenadante das amostras $(5 \mathrm{~mL})$ coletadas das unidades de GV foi obtido através da centrifugação a 3500rpm por 10 minutos e diluído em solução salina1:2. Na sequência, $10 \mu \mathrm{L}$ de amostra deste sobrenadante foi distribuído em duplicata e adicionado $500 \mu \mathrm{L}$ de benzidina e $500 \mu \mathrm{L}$ de peróxido de hidrogênio a $1 \%$, homogeneizado e incubado por seguido por incubação de 10 minutos. A reação foi interrompida com adição $5 \mu \mathrm{L}$ de solução de acido acético, seguido por incubação de 10 minutos. A absorbância das amostras foi determinada em espectrofotômetro (E2010D, CELM®) sob comprimento de onda de 515nm. O padrão de hemoglobina livre foi obtido através da diluição de $20 \mu$ de sangue controle comercial (Eightchek - 3WPX-TRA, Strech Laboratories USA) em 6,0 mL de água destilada.

Amostras de $1 \mathrm{~mL}$ foram coletadas para mensurar os níveis de hemoglobina e hematócrito. A hemoglobina livre e o índice de hemólise foram obtidos através dos cálculos:

- Hb livre $(\mathrm{mg} / \mathrm{dL})=$ [absorbância da amostra x conc. padrão $(\mathrm{mg} / \mathrm{dL})]$ x 10 / absorbância padrão

- Índice de Hemólise $(\%)=\mathrm{Hb}$ livre $(\mathrm{g} / \mathrm{L})$ x [100 - Ht(\%) ] / Hb total (gL-1)

Também foram mensuradas as concentrações de potássio, sódio, glicose e pH das unidades em analisador de gases sanguíneos (ABL 735, Radiometer Copenhagen, Dinamarca). Adicionalmente, para investigação de possível contaminação bacteriana nas unidades, foi realizada coleta de 
8mLdas bolsas de G.V para cultura (BacT Alert, Organon Teknica, New Hampshire, EUA).

\section{Validação "in vivo"}

Para este experimento, cinco animais machos Agroceres ${ }^{\circledR}$ (sendo um deles o animal submetido à hemorragia 14 dias antes) foram pré-anestesiados por via intramuscular com midazolam $(0,3 \mathrm{mg} / \mathrm{kg})$ e acepromazina $(0,5 \mathrm{mg} / \mathrm{kg})$. (Figura 1) Os animais foram intubados e mantidos sob anestesia geral com halotano (concentração média de $2 \%$ ) em oxigênio a $100 \%$ administrado por circuito semi-fechado do aparelho de anestesia (Conquest 3000, HB Hospitalar) e ventilados em modo volume controlado $(\mathrm{VT}=8 \mathrm{~mL} / \mathrm{kg})$ e frequência respiratória ajustada para uma $\mathrm{PaCO}_{2}$ em torno de 35 a $45 \mathrm{~mm} \mathrm{Hg}$. O bloqueio muscular foi realizado com infusão intermitente de $0,1 \mathrm{mg} / \mathrm{kg}$ de pancurônio. A analgesia foi realizada com a administração intravenosa de fentanil $(30 \mu \mathrm{g} / \mathrm{kg} / \mathrm{h})$. A adequação da profundidade anestésica durante todo o procedimento foi avaliada através da estabilização das variáveis fisiológicas (frequência cardíaca e pressão arterial), ausência de reflexos (corneal e resposta de flexão posterior dos membros) e ausência de resposta à manipulação. Um cateter venoso central (7F) foi inserido na veia jugular externa esquerda para coleta de amostras, administração de medicamentos e infusão de fluidos. Foi realizada a marcação de $100 \mathrm{~g}$ de GV proveniente de uma das duas unidades de G.V, estocadas há 14 dias, com $0,7 \mathrm{~mL}$ de cromato de sódio radioativo (lote $803 \mathrm{C}$ 20002 IPEN / CNEN / SP calibrado em 01/23/08 com prazo de validade 04/11/08, 185MBq de atividade). Este procedimento foi realizado à temperatura 
ambiente com agitação suave e contínua durante 20 minutos, e adição de ácido ascórbico (200 mg). A amostra foi posteriormente lavada com 1.000 mLde solução salina $(0,9 \%)$ e o material diluído $(1 / 50)$ em duplicata, para ser utilizada como referência do volume da "massa" eritrocitária injetada.

Foram injetados nos animais o equivalente a $2,5 \mathrm{~mL} / \mathrm{kg}(0,412 \mathrm{MBq} / \mathrm{kg}$ ou $0,01 \mathrm{mCi} / \mathrm{kg}$ ) da amostra marcada com o cromato de sódio, correspondendo a $16 \mathrm{~mL}$ nos quatro animais homólogos (peso $37-38 \mathrm{~kg}$ ) e $24 \mathrm{~mL}$ no animal autólogo (peso $60 \mathrm{~kg}$ ). As amostras para avaliação da viabilidade foram coletadas nos intervalos de tempo de 5 e 10 minutos e 2, 3, 6, 8, 12 e 24 horas após a transfusão de acordo com o método modificado "early time values average" (média dos valores iniciais), aonde o tempo "zero" que corresponde a $100 \%$ de sobrevida é obtido através da média das contagens iniciais (5 e 10 $\min )^{116}$. Três mililitros de cada uma das amostras e da amostra de referência foram contados durante 300 segundos em um contador gama automático (Assistente 3 Perkin Elmer, Waltham, MA, EUA). Os coeficientes de variação foram de $0,3 \%$.

As análises da viabilidade pós transfusional (VPT) foram realizadas através da porcentagem de sobrevida das hemácias marcadas com o material radioativo até 24 horas, que foi determinada como se segue:

- $\operatorname{VPT} 24$ horas $(\%)=[\mathrm{cpm} / \mathrm{mL}$ de hemácias $($ tempo $=24$ horas $) \mathrm{X} 100] /$ $\mathrm{cpm} / \mathrm{mL}$ de hemácias (tempo $=0$ horas)

Onde $\mathrm{cpm} / \mathrm{mL}$ é a contagem por minuto nos períodos prédeterminados, corrigidos pelos níveis de hemoglobina e hematócrito no tempo "zero" (média entre 5 e 10 minutos), quando ocorre a homogeneização no espaço intravascular do cromato de sódio radioativo ${ }^{128}$. 
Adicionalmente foi feito 0 controle da radioatividade livre no sobrenadante de todas as amostras coletadas dos animais utilizando-se a mesma metodologia descrita acima.

Após 24 horas foi realizada esplenectomia em todos os animais, sendo os baços submetidos à análise para identificação de sequestro esplênico por cintilografia em câmara de cintilação (Siemens Orbiter, Hoffman Estates, IL, EUA), com colimação para energia de $360 \mathrm{kev}$, fotopico centrado em $320 \mathrm{kev}$ e janela de $20 \%$, com processamento de imagem digitalizada. 


\section{FLUXOGRAMA}

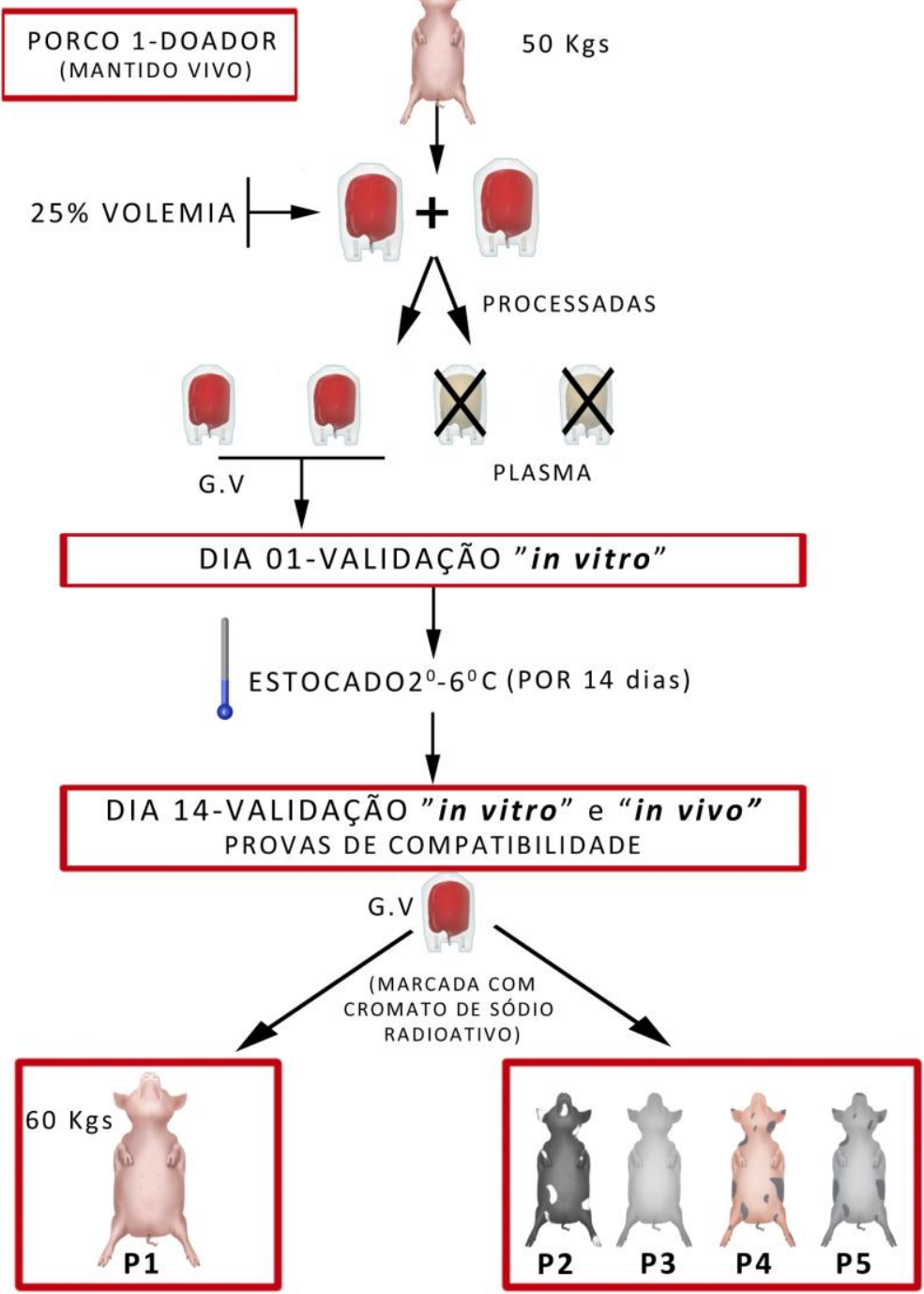

RECEPTOR AUTÓLOGO

RECEPTORES HOMÓLOGOS
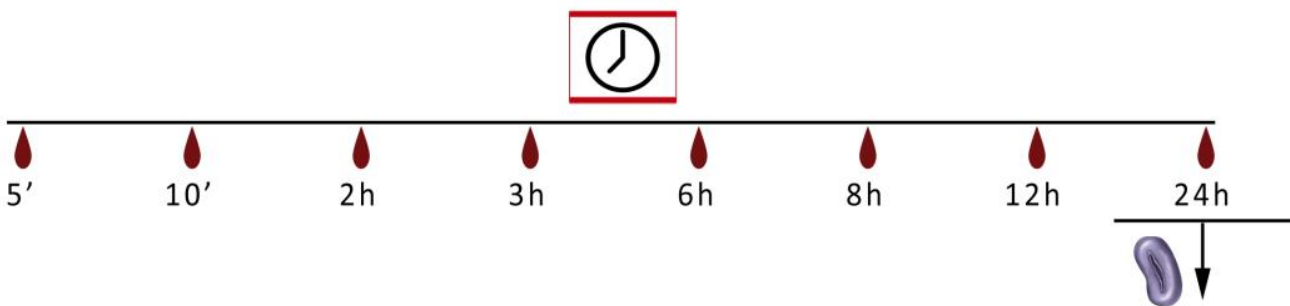

SACRIFICADOS

ESPLENECTOMIA

CINTILOGRAFIA BAÇO

Figura 1 - Validação "in vivo" 


\section{Etapa 2. : Avaliação dos efeitos agudos da transfusão na hemodinâmica, trocas gasosas, mecânica respiratória e resposta inflamatória - Preparação dos animais: (Figura 2).}

Dezoitos porcos, machos, da raça Agroceres ${ }^{\circledR}$, peso $68,5 \pm 3,5 \mathrm{Kg}(61$ $75 \mathrm{~kg}$ ) foram utilizados no estudo. Inicialmente, como o estudo seria realizado com transfusão de GV e não sangue total optou-se por utilizar os animais independentes da tipagem sanguínea. Todavia observamos que um animal com provas de compatibilidade positiva evoluiu com eventos adversos transfusionais, descritos em estudos que utilizavam unidades de sangue total. A partir deste momento, os animais foram escolhidos de acordo com a compatibilidade eritrocitária prévia com as bolsas de GV estocadas por 14 dias.

Os animais foram mantidos em jejum por 18 horas com livre acesso à água, pré-anestesiados por via intramuscular com midazolam $(0,3 \mathrm{mg} / \mathrm{kg})$ e acepromazina $(0,5 \mathrm{mg} / \mathrm{kg})$. A indução anestésica foi realizada com thionembutal $(12 \mathrm{mg} / \mathrm{kg})$ e o bloqueio neuromuscular inicial com brometo de pancurônio $(0,2$ $\mathrm{mg} / \mathrm{kg}$ ). A manutenção da analgesia e sedação foi realizada com fentanil (5 $\mu \mathrm{g} / \mathrm{kg} / \mathrm{h})$ e midazolam $(0,5 \mathrm{mg} / \mathrm{kg} / \mathrm{h})$, e o bloqueio muscular mantido ao longo do experimento com pancurônio (infusão contínua de $0,075 \mathrm{mg} / \mathrm{kg} / \mathrm{h}$ ). A adequação da profundidade anestésica durante todo o procedimento foi avaliada através da estabilização das variáveis fisiológicas (frequência cardíaca e pressão arterial), ausência de reflexos (corneal e resposta de flexão posterior dos membros) e ausência de resposta à manipulação. Quando necessário "bolus" de $5 \mu \mathrm{g} / \mathrm{kg}$ de fentanil e $0,125 \mathrm{mg} / \mathrm{kg}$ de midazolam foram administrados.

Os animais foram submetidos à intubação orotraqueal (tubo endotraqueal $n^{0}$ 7) e conectados a um ventilador mecânico (Evita XL- Draeger, 
Lubeck, Alemanha), modo volume controlado (VT= $8 \mathrm{~mL} / \mathrm{kg}$ e frequência respiratória ajustada para uma $\mathrm{PaCO}_{2}$ em torno de 35 a $45 \mathrm{~mm} \mathrm{Hg}$, pressão expiratória final positiva $(\mathrm{PEEP})=5 \mathrm{cmH}_{2} \mathrm{O}$ e $\mathrm{FiO}_{2}$ necessária para manter $\mathrm{SpO}_{2}$ $\geq 94 \%$.

Imediatamente antes da dissecção vascular e a seguir a cada 6 horas, os animais receberam um grama de cefalotina endovenosa como profilaxia antimicrobiana. Na sequência foi realizada a dissecção dos acessos vasculares, onde, através da veia jugular externa direita, foi introduzido um cateter de artéria pulmonar (774HF75, Edwards Lifescience, LLC, Irvine, Califórnia, EUA), que foi posicionado por visualização das curvas pressóricas. Este permitiu medidas de débito cardíaco (DC - L/min) por termodiluição, pressões da artéria pulmonar (mm Hg), pressão venosa central (PVC- mm Hg) , saturação venosa mista de oxigênio $\left(\mathrm{SvO}_{2}-\%\right)$, bem como do volume diastólico final de ventrículo direito (VDFVD - $m L$ ) (Vigilance VD®, Edwards Lifesciences, Irvine, Califórnia, EUA). A veia jugular externa esquerda foi dissecada para a introdução de um cateter (7F) para retirada de sangue durante a hemorragia controlada, administração de medicamentos, infusão de fluidos e injeção de solução salina resfriada para calibração do cateter. Um cateter (PV2015L20, \#5F, Pulsion Medical Systems, Munique, Alemanha) foi posicionado na artéria femoral direita para a coleta de amostras de sangue arterial, monitorização da pressão arterial sistêmica, mensuração da água pulmonar extravascular (APev), fração de ejeção global (GEF)(\%), volume diastólico final global indexado (GEDVI) $\left(\mathrm{mL} / \mathrm{m}^{2}\right)$ e da variação do volume sistólico ( $\triangle \mathrm{VS}$ ). (PiCCO® - Pulse Index Contour Continuous Cardiac Output; Infinity ${ }^{\circledR}$ PiCCO SmartPodTM XL; monitor - Infinity Delta XL, Drager). A 
calibração do sistema foi feita com a infusão de solução salina resfriada através de cateter venoso central. As pressões sistêmicas e pulmonares foram medidas com transdutores de quartzo (Edwards Critical Care, Irvine, CA, EUA) e visualizadas continuamente em um monitor multi-modular (Infinity Delta XL, Drager), que também forneceu os dados de frequência cardíaca (batimentos/min), saturação arterial de oxigênio $\left(\mathrm{SaO}_{2}-\%\right)$ e $\mathrm{EtCO}_{2}\left(\mathrm{CO}_{2}\right.$ no final da expiração - $\mathrm{mm} \mathrm{Hg}$ ).

Os parâmetros hemodinâmicos listados acima foram medidos imediatamente antes e 30 minutos após a hemorragia controlada, imediatamente após o término da ressuscitação volêmica, e a cada 60 minutos por até 6 horas.

Os dados respiratórios aferidos foram: complacência estática do sistema respiratório (Cest - $\mathrm{mL} . \mathrm{mm} \mathrm{Hg}^{-1}$ ), resistência do sistema respiratório (Rsr - mm Hg.L $\left.{ }^{-1} s^{-1}\right)$, pressão de pico inspiratório (Ppico $-\mathrm{cmH}_{2} \mathrm{O}$ ), pressão de platô inspiratório (Pplat $-\mathrm{cm} \mathrm{H}_{2} \mathrm{O}$ ), pressão média de vias aéreas (Pmva $-\mathrm{cm} \mathrm{H}_{2} \mathrm{O}$ ), PEEP $\left(\mathrm{cmH}_{2} \mathrm{O}\right)$, frequência respiratória ( $\mathrm{fr}$ - ciclos/min), volume corrente (VT $\mathrm{mL}), \mathrm{CO}_{2}$ no final da expiração $\left(\mathrm{EtCO}_{2}-\mathrm{mm} \mathrm{Hg}\right)$ e fração inspiratória de oxigênio $\left(\mathrm{FiO}_{2}\right.$ - \%), calculados pela média de 5 ciclos consecutivos.

As curvas de pressão-volume (PV) do sistema respiratório também foram avaliadas imediatamente antes da hemorragia controlada, uma, três e seis horas após a reposição volemica, através de método de baixo fluxo disponibilizado automaticamente pelo ventilador mecânico. Os parâmetros para realização das curvas PV foram os seguintes: fluxo inspiratório = 4L/min;

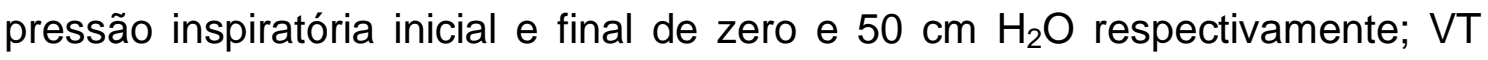


máximo $=2000 \mathrm{~mL}$. Foi estimado o trabalho inspiratório e expiratório através da analise das áreas abaixo das alças inspiratória e expiratória da curva PV (SigmaPlot 9). A diferença entre o trabalho expiratório e inspiratório foi considerada como a energia gasta com a histerese pulmonar. Todas as áreas foram normalizadas para a área do menor retângulo capaz de englobar toda a curva $\mathrm{PV}^{20,147}$. A área deste retângulo foi considerada como a energia potencial de "estiramento" pulmonar, e foi normalizada devido à heterogeneidade das propriedades visco-elásticas do sistema respiratório dos animais ${ }^{31}$ (Figura 3). 


\section{FLUXOGRAMA}

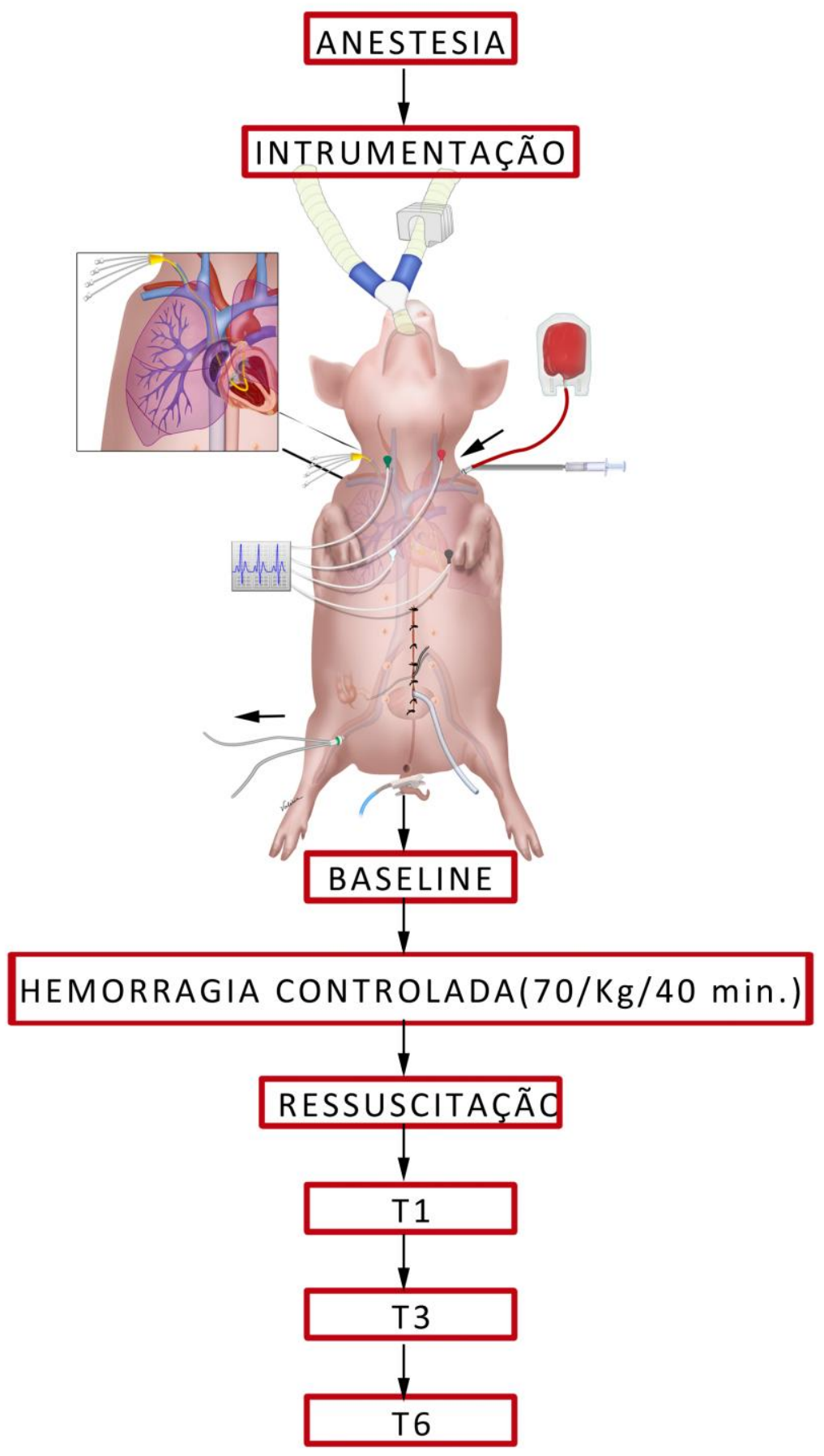

Figura 2 - Linha do tempo 
- Parâmetros respiratórios e hemodinâmicos: Baseline, hemorragia, ressuscitação e a cada hora até 6 horas após o termino da ressuscitação.

- Quantificação de citocinas por ELISA (IL-1ß; IL-6; IL-10 e IL-21); baseline, T3 e T6 (3 horas e 6 horas após ressuscitação, respectivamente)

- Dosagem de nitrato: baseline, T3 e T6 (3 horas e 6 horas após ressuscitação, respectivamente)

Pulmão

- Quantificação de citocinas por ELISA e RNAm por RT-qPCR para (IL-1 1 ; IL-10; IL-21 e TNF-alpha) e iNOS.

- Quantificação de nitrato 
Painel A - Alças Inspiratoria e Expiratoria

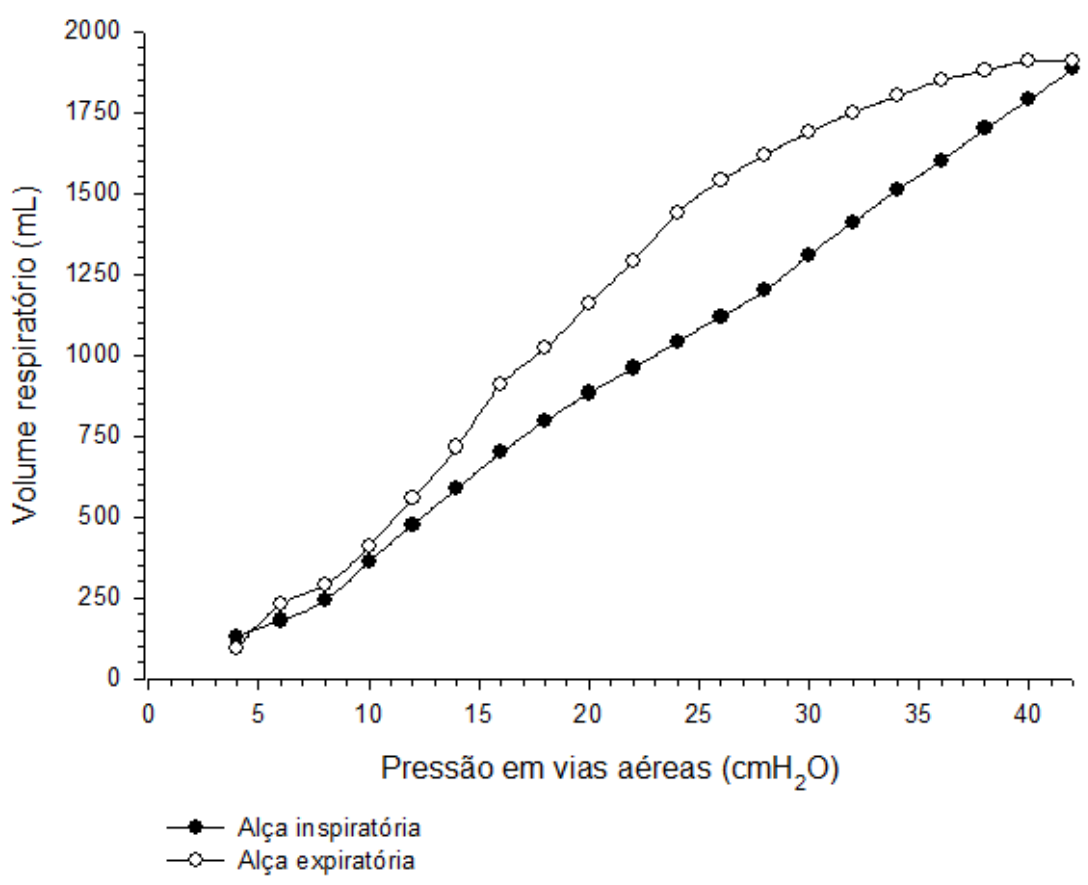

Painel B - Energia Inspiratória

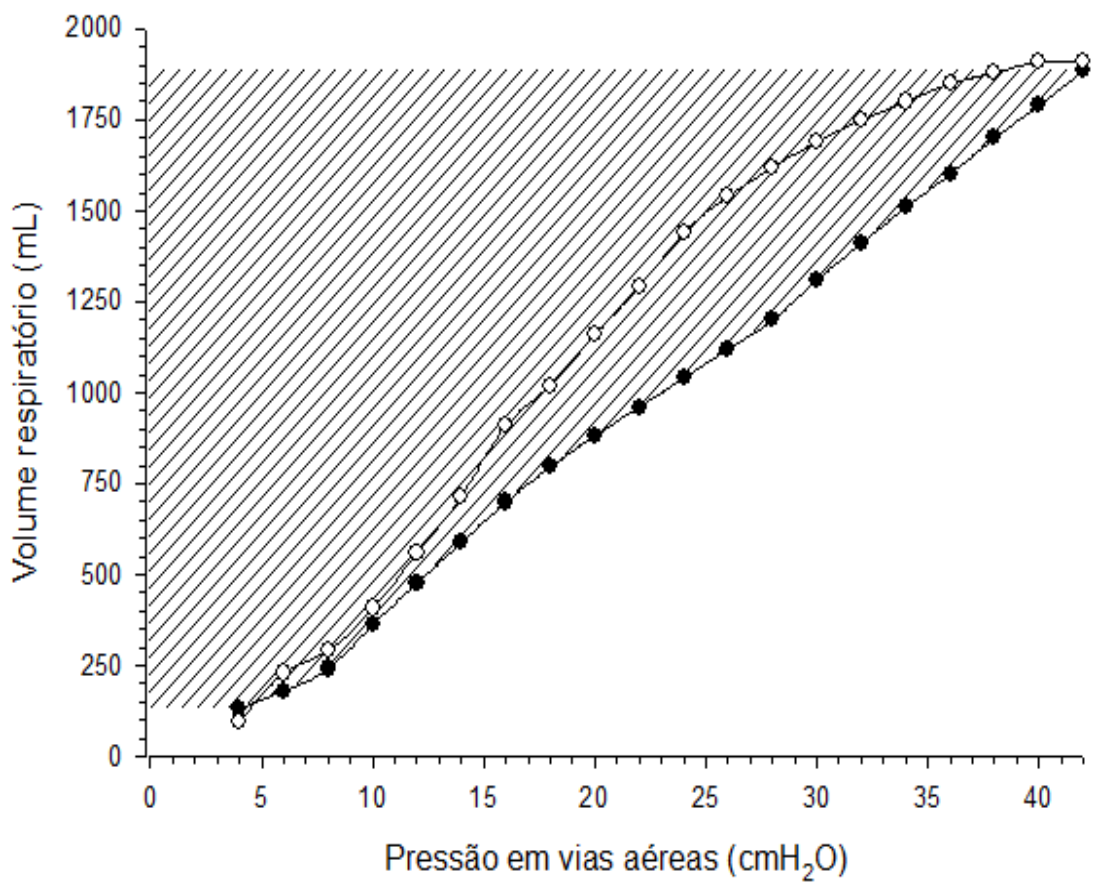


Painel C- Energia Expiratória

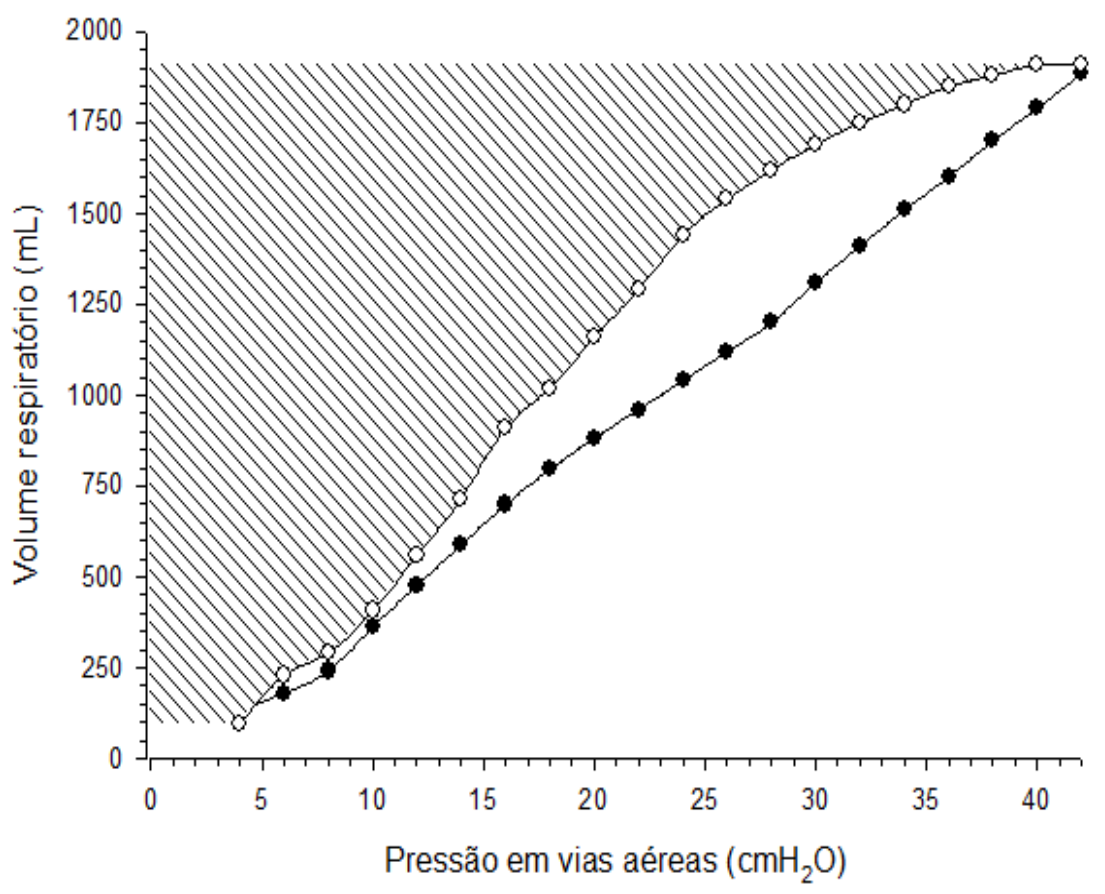

Painel D- Energia de Histerese

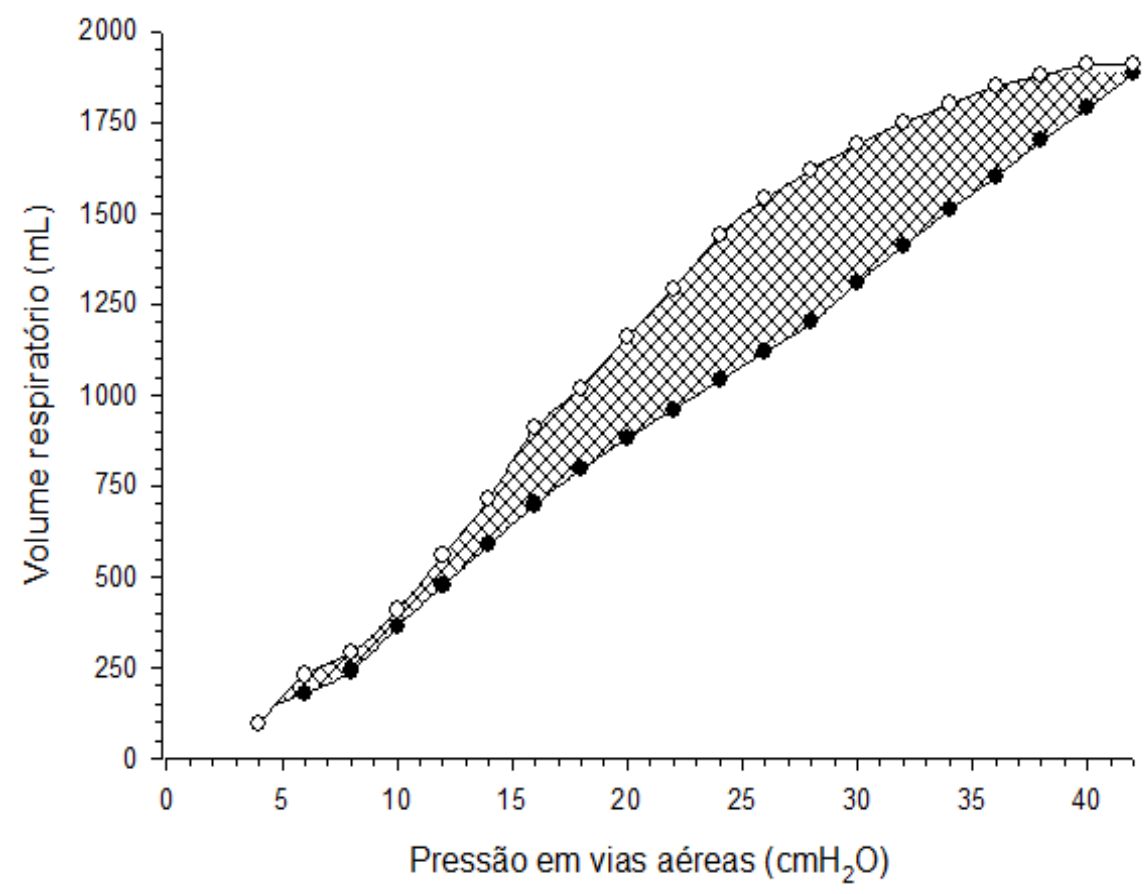


Painel E- Normalização das curvas

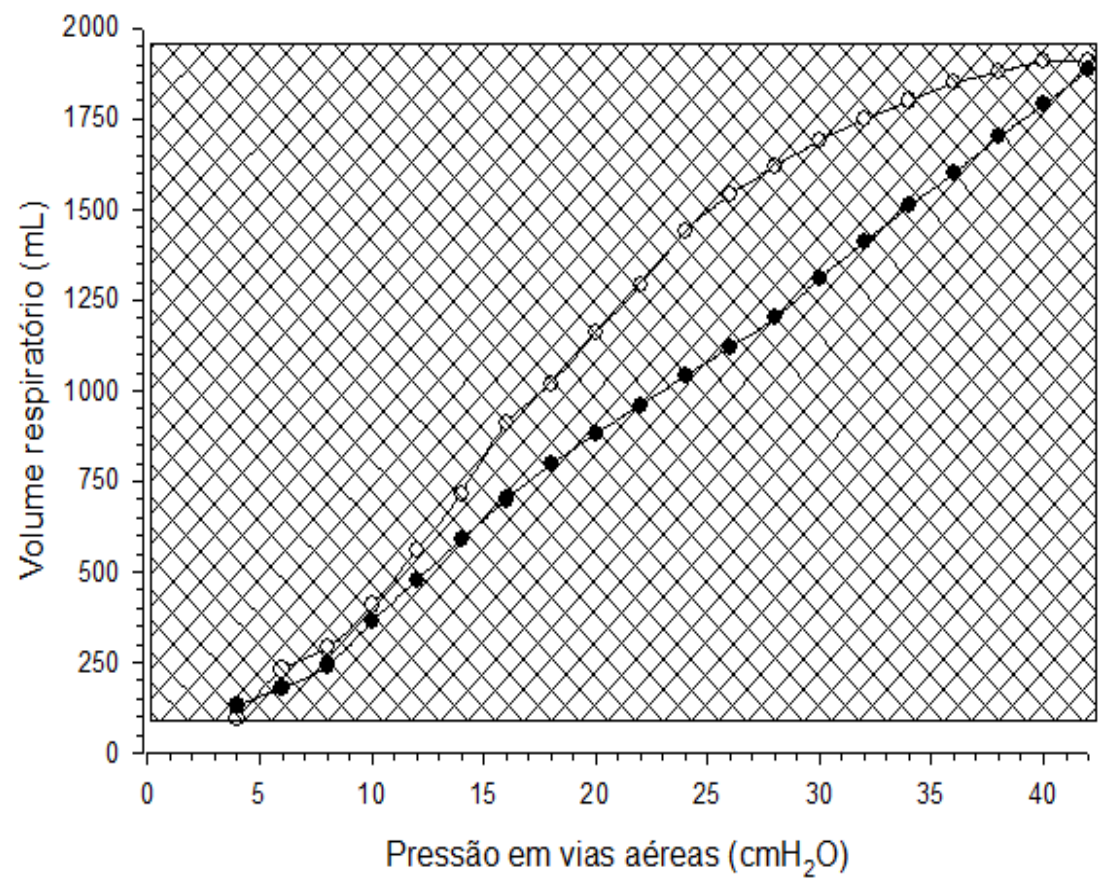

Figura 3 - Exemplo da construção da curva PV e calculo das energias inspiratória, expiratória e histerese

Imediatamente após a monitorização os animais foram submetidos à laparotomia mediana por uma incisão de cerca de seis centímetros e através de uma cistostomia foi inserido um cateter para monitorização do débito urinário. Um probe de Laser Doppler Fluxometria (Transonic Systems Inc., Ithaca, NY, USA) foi posicionado no íleo distal para mensuração da perfusão da microcirculação intestinal (unidades arbitrárias de microcirculação perfundidas) ${ }^{34,99}$.

Após o término do preparo os animais foram mantidos sem manipulação durante uma hora para estabilização. Durante o preparo cirúrgico e estabilização, receberam alíquotas de ringer lactato $(500 \mathrm{~mL}$ a cada 30 
minutos) com o objetivo de garantir normovolemia, a saber: pressão venosa central $(P \vee C) \geq 6 \mathrm{~mm} \mathrm{Hg}$, débito urinário $\geq 0,5 \mathrm{~mL} / \mathrm{kg} / \mathrm{h}$ e $\mathrm{SvO}_{2} \geq 70 \%$. Após o preparo, foi mantida infusão contínua de ringer lactato a $5 \mathrm{~mL} / \mathrm{kg} / \mathrm{h}$ durante todo o período do experimento.

\subsection{Hemorragia controlada e reposição volêmica}

Imediatamente após o período de estabilização, os animais foram submetidos à hemorragia controlada com retirada através do cateter venoso de $25 \%$ de sua volemia (estimada como peso em $\mathrm{kg} \times 70 \mathrm{~mL})^{99}$. O tempo médio para a hemorragia foi de 40 minutos. O sangue foi coletado de maneira asséptica em bolsas contendo solução anticoagulante (conforme descrito anteriormente). Após 30 minutos do término da hemorragia, a reposição volêmica foi realizada em aproximadamente 120 minutos, como descrito a seguir:

- Grupo controle ( $n=9)$ - reposição volêmica com ringer lactato com volume equivalente a três vezes o volume do sangue removido (ex: hemorragia de $900 \mathrm{~mL}$, reposição de $2700 \mathrm{~mL}$ de ringer lactato).

- Grupo transfusão ( $n=9)$ - reposição volêmica, durante sessenta minutos, com duas unidades de concentrado de glóbulos vermelhos estocados por 14 dias. Além disso, receberam ringer lactato na quantidade equivalente a três vezes da diferença entre o volume de sangue removido na hemorragia e aquele reposto na forma de concentrado de hemácias (ex: hemorragia de 900 
$\mathrm{mL}$ e reposição de $400 \mathrm{~mL}$ de concentrado de hemácias, mais infusão adicional de $1500 \mathrm{~mL}$ de ringer lactato).

Após o término da reposição volêmica, os animais de ambos os grupos foram observados e monitorizados por seis horas ou até o óbito.

\subsection{Coleta e Processamento das Unidades de Sangue Total}

As unidades de sangue total foram coletadas e identificadas com o número do animal em bolsas duplas CPDA-1 (conforme descrito anteriormente). No total, cada animal originou duas bolsas de sangue e duas unidades de plasma. As unidades de plasma foram descartadas e as unidades de hemácias armazenadas em refrigerador com temperatura controlada $\left(2^{\circ}\right.$ a 6ํㅡ. Cada animal transfundido recebeu os concentrados de hemácias do animal submetido à hemorragia controlada em experimento anterior.

\subsection{Avaliação Laboratorial - Hemograma, Variáveis Ventilatórias e de Oxigenação}

Imediatamente antes e 30 minutos após a indução da hipovolemia, imediatamente após o término da ressuscitação e a cada 60 minutos até 6 horas a seguir, foram coletadas amostras de sangue arterial para análise de variáveis ventilatórias e oxigenação $\left(\mathrm{pH}, \mathrm{PaO}_{2}, \mathrm{PaCO}_{2}, \mathrm{BE}\right)$ e mensuração do lactato (ABL 700 Radiometer, Copenhagen, Denmark). Adicionalmente foi coletado sangue venoso (veia jugular externa) antes da indução de hipovolemia e após a ressuscitação para calibração do sistema de medição contínua da 
saturação venosa. Antes da indução de hipovolemia e ao final do experimento foi coletada uma amostra de sangue para realização de hemograma.

\subsection{Avaliação da Resposta Inflamatória}

\section{Coleta do sangue}

Amostras de sangue periférico (4 mL) foram coletadas em tubo contendo EDTA ( $4 \mathrm{~mL}$ ) durante todo o experimento. Foram coletadas amostras nos seguintes momentos: antes da indução da hipovolemia, 3 e 6 horas após a ressuscitação volêmica (baseline, T3 e T6). O sangue ficou armazenado em gelo até centrifugação a $2.500 \times \mathrm{g}$ por $10 \mathrm{~min}$ a $4{ }^{\circ} \mathrm{C}$. O plasma foi armazenado a $-70{ }^{\circ} \mathrm{C}$.

Posteriormente, o plasma foi destinado à quantificação de proteínas da resposta inflamatória e de nitrado.

\section{Coleta dos Pulmões}

Ao final do experimento após o óbito por aprofundamento da anestesia, o tórax dos animais foi aberto, os pulmões excisados e uma fração do tecido pulmonar foi retirada do lobo médio pulmonar direito. O fragmento de tecido foi colocado em tubo eppendorf ( $2 \mathrm{~mL})$, mergulhado imediatamente em nitrogênio líquido e armazenado em freezer $-80^{\circ} \mathrm{C}$. As amostras de pulmão foram destinadas posteriormente à quantificação de proteínas inflamatórias. 


\subsubsection{Concentração de citocinas no plasma e tecido pulmonar}

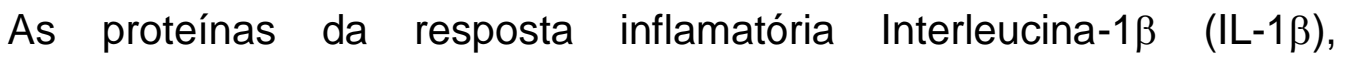
Interleucina-6 (IL-6), Interleucina-10 (IL- 10), e Interleucina-21 (IL-21), foram quantificadas pela técnica de ensaio imunológico ligado à enzima (ELISA) baseado em método "sanduíche". Os kits utilizados e as concentrações dos anticorpos e proteína estão listados na Tabela 1.

Tabela 1- Concentração de anticorpos e proteína utilizados na detecção por ensaio imunoenzimático dos mediadores IL-1 $\beta$, IL-6, IL-10 e IL-21

\begin{tabular}{lccc}
\hline \multicolumn{1}{c}{ Kit ELISA } & $\begin{array}{c}\text { Anticorpo de } \\
\text { Captura } \\
(\boldsymbol{\mu g} / \mathbf{m L})\end{array}$ & $\begin{array}{c}\text { Anticorpo de } \\
\text { Detecção }(\mathbf{n g} / \mathbf{m L})\end{array}$ & $\begin{array}{c}\text { Curva Padrão } \\
\text { Proteína } \\
(\mathbf{p g} / \mathbf{m L})\end{array}$ \\
\hline DuoSet IL1 $\beta$ porco (R\&D Systems \#DY681) & 2 & 50 & 4.000 a $15^{*}$ \\
DuoSet IL6 porco (R\&D Systems \#DY686) & 0,8 & 100 & 8.000 a $125^{*}$ \\
DuoSet IL10 porco (R\&D Systems \#DY693) & 2 & 200 & 1.000 a 31* \\
Human IL-21 ELISA (eBioscience \#88-7216) & $1 / 250$ & $1 / 250^{*}$ & 2.000 a 31* \\
\hline
\end{tabular}

*Sensibilidade de detecção

\section{Extracão de proteínas do pulmão}

Para avaliação dos mediadores inflamatórios por ELISA inicialmente foram extraidas as proteínas do pulmão. Para isso, cada 100mg do órgão foi homogeneizado usando o equipamento Tissueruptor (Qiagen) à baixa velocidade em $1 \mathrm{~mL}$ de uma solução contendo coquetel inibidor de proteases (Roche \#11836153001), diluído em PBS Tween 0,05\%. Em seguida, a 
suspensão foi centrifugada 2 vezes por 10 min à $4^{\circ} \mathrm{C}$, sendo a primeira centrifugação a $3.000 \times \mathrm{g}$ e a segunda a $10.000 \times \mathrm{g}$. O sobrenadante foi separado e armazenado a $-80^{\circ} \mathrm{C}$.

\section{Ensaio imunoenzimático (ELISA) - Protocolo de ELISA no plasma}

\section{e tecido pulmonar.}

A quantificação das proteínas inflamatórias IL-1ß; IL-6 e IL-10 foi realizada seguindo as instruções do fabricante (R\&D Systems).

Cada poço da placa de 96 "wells" (Nunc \#442424) foi sensibilizado com $50 \mu \mathrm{L}$ do anticorpo monoclonal diluído em PBS $(137 \mathrm{mM} \mathrm{NaCl}, 2,7 \mathrm{mM} \mathrm{KCl}$, $8,1 \mathrm{mM} \mathrm{Na}_{2} \mathrm{HPO}_{4}, 1,5 \mathrm{mM} \mathrm{KH}{ }_{2} \mathrm{PO}_{4}-\mathrm{pH} 7,2$ ), seguido por incubação "overnight" à 25드 (Agilent \#G2545A) sob agitação de 20 rpm (lka \#3319000). A fim de retirar o excesso de anticorpo não adsorvido, foram realizadas 5 lavagens sucessivas com $400 \mu \mathrm{L}$ de solução de lavagem (PBS 0,05\% Tween), realizado entre todas as etapas, exceto após a adição do substrato tetrametilbenzidina (TMB). Em seguida, adicionou-se $300 \mu \mathrm{L}$ de solução de bloqueio (PBS 1\% BSA) por 2 horas à $25^{\circ} \mathrm{C}$. Uma curva padrão foi construída a partir de diluições seriadas da proteína recombinante da citocina de interesse (Tabela 1). Amostras de soro (90\% em PBS 1\% BSA) foram distribuídas em duplicata

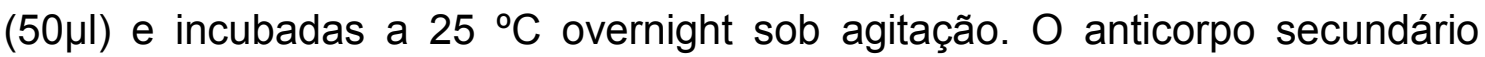
policlonal biotinilado, diluído em PBS 1\% BSA, foi então adicionado por 2 horas à 25ํㅡ sob agitação. Após incubação por 20 minutos com Estreptavidina (R\&D \#DY998) diluída 1:200 à 25ํㅡ sob agitação e ao abrigo da luz, a reação foi 
revelada com $50 \mu \mathrm{L}$ de TMB (mistura $1: 1 \mathrm{v} / \mathrm{v}$ de $\mathrm{H}_{2} \mathrm{O}_{2}$ e tetrametilbenzidina) (BD \#555214), durante 20 min de incubação à $25^{\circ} \mathrm{C}$ sob agitação e ao abrigo da luz. A reação foi interrompida com a adição de $25 \mu \mathrm{L}$ de ácido sulfúrico $2 \mathrm{~N}$ (Merck \#1.00731). A absorbância das amostras foi determinada em espectrofotômetro (Sunrise, Tecan) sob comprimento de onda de 450nm.

A quantificação da citocina plasmática IL-21 foi realizada com protocolo semelhante ao descrito acima seguindo as recomendações e soluções específicas fornecidas pelo fabricante (eBioscience).

Os valores encontrados de densidade óptica (DO) foram subtraídos da leitura do branco (PBS 1\% BSA). Os valores de DO encontrados nas amostras foram interpolados com a curva padrão através da regressão polinomial de $4^{\underline{a}}$ ordem (PRISM GraphPad Software versão 5.01). A curva padrão foi incluída em todas as placas considerando-se duplicata de cada ponto para melhor reprodutibilidade dos ensaios.

\subsubsection{Concentrações de nitrato no plasma e no tecido pulmonar}

Antes da indução da hipovolemia e após 3 e 6 horas da ressuscitação volêmica amostras foram coletadas para avaliar a produção de óxido nítrico (NO) no plasma através de um de seus metabólitos o nitrato. Para tal, utilizouse a técnica de quimiluminescência por meio do analisador de NO (Sievers, modelo NOA280, Colorado, EUA). Essa técnica requer a redução de nitrato a NO, o qual reage com ozônio para gerar luz, que é quantificada por fotomultiplicadoras. Para conversão do nitrato a NO, foi utilizada reação com 
cloreto de vanádio $(\mathrm{VnCl})$ em ácido clorídrico a $95^{\circ} \mathrm{C}$. A curva de calibração em níveis múltiplos foi realizada por padrão externo (nitrato de sódio - Aldrich, EUA). Esta técnica foi também utilizada para mensurar a concentração de nitrato no tecido pulmonar, em ambos os grupos, logo após a morte dos animais. Amostras de tecidos pulmonares foram coletadas do lobo médio pulmonar direito, homogeneizadas por lise tecidual com triturador, seguida de diluição em $2 \mathrm{~mL}$ de tampão Tris- $\mathrm{HCl} 50 \mathrm{mM}$ com PMSF $1 \mathrm{mM}$ e $0,1 \%$ mercaptoetanol. O tecido lisado foi submetido à centrifugação a 5000 rpm por 5 minutos, à $4^{\circ} \mathrm{C}$ para remoção de debris e células não lisadas. $\mathrm{O}$ sobrenadante foi recolhido e submetido à quantificação de proteínas por ensaio colorimétrico (Bradford, Bio-Rad, California, Estados Unidos). Todos os resultados foram normalizados para a concentração de proteínas das amostras.

\subsubsection{Análise de expressão de RNAm (RNA mensageiro) para marcadores de resposta inflamatória em tecido pulmonar}

\section{Extração de RNA do tecido pulmonar}

O RNA total foi extraído e purificado em colunas por meio do "RNAeasy Minikit" (Qiagen). Aproximadamente $10 \mathrm{mg}$ de tecido foram misturados com $600 \mu \mathrm{L}$ solução tampão do kit (RLT) e homogeneizados com auxílio do Tissueruptor (Qiagen). As amostras foram centrifugadas a $16.000 \mathrm{~g}$ por 3 minutos e o sobrenadante (lisado) transferido para um novo tubo. $600 \mu \mathrm{L}$ de etanol $100 \%$ foram adicionados ao volume recuperado, e aplicados em uma 
coluna com afinidade por RNA (miRNeasy) seguido por centrifugação a $8.000 \mathrm{~g}$ por 15 segundos. O RNA aderido à coluna foi lavado com $350 \mu \mathrm{L}$ de solução RPE seguido pela mesma centrifugação. 80ul de DNase mix foram aplicados diretamente à coluna para eliminação de uma eventual presença de DNA na coluna. Após 15 minutos de incubação à temperatura ambiente, $350 \mu \mathrm{L}$ de solução tampão (RW1) foram adicionados para lavagem da coluna, seguido por nova centrifugação de $8.000 \mathrm{~g}$ por 15 segundos. A coluna foi lavada mais duas vezes com $500 \mu \mathrm{L}$ da solução tampão (RPE). O RNA total foi eluído da coluna com $50 \mu \mathrm{L}$ de água livre de RNase e centrifugação a $8.000 \mathrm{~g}$ por 1 minuto. As amostras de RNA extraído ficaram estocadas em freezer a $-80^{\circ} \mathrm{C}$.

A quantificação do RNA extraído e a estimativa do grau de contaminação por proteínas e sal foram feitas por espectrofotometria nas absorbâncias de 260, 280 e 230nm, respectivamente no equipamento Nanovue (GE Healthcare). A qualidade da concentração do RNA obtido foi verificada através do fracionamento eletroforético de um $\mu \mathrm{g}$ de RNA de cada uma das amostras em gel de agarose 1\% ("microfluidic chip") com utilização do equipamento BioAnalyser (Agilent). Foram considerados RNAs de boa qualidade amostras que apresentavam as bandas correspondentes aos RNAs ribossomais 28 e 18S, e nos quais a intensidade da banda $28 S$ era maior ou igual à da banda $18 \mathrm{~S}$.

\section{Síntese de cDNA}

A primeira etapa é a síntese do cDNA (DNA complementar), que foi efetuada com o kit "SuperScript III First-Strand Synthesis System for RT-PCR" 
(Invitrogen). Três microgramas de cada um dos RNAs extraídos foram incubados a $65^{\circ} \mathrm{C}$ durante 5 minutos na presença de $1 \mu \mathrm{L}$ de oligo (dT), e $1 \mu \mathrm{L}$ de dNTP mix [10mM], em volume final de $10 \mu \mathrm{L}$. As amostras foram colocadas no gelo e em seguida foram adicionadas às mesmas: $2 \mu \mathrm{L}$ de RT Tampão [10X], $4 \mu \mathrm{L}$ de $\mathrm{MgCl}_{2}$ [25mM], $2 \mu \mathrm{L}$ de DTT $[0,01 \mathrm{M}], 1 \mu \mathrm{L}$ de RNAse OUT

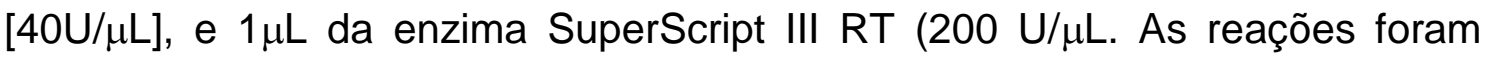
incubadas a $50^{\circ} \mathrm{C}$ por $50 \mathrm{~min}$ e depois a $85^{\circ} \mathrm{C}$ por $5 \mathrm{~min}$. Ao final da reação, foi adicionado $1 \mu \mathrm{L}$ de RNase $\mathrm{H}$ em cada amostra seguido por incubação a $37^{\circ} \mathrm{C}$ por 20 minutos. As amostras de cDNA foram armazenadas a $-20^{\circ} \mathrm{C}$.

\section{Ensaio de PCR em tempo real (Taqman)}

A avaliação da expressão de RNAm em tecido pulmonar foi realizada por reação em cadeia da polimerase em tempo real em equipamento SDS 7900 (qRT-PCR) utilizando a química Taqman® (Applied Biosystems). Os RNAm pesquisados, assim como as respectivas sondas (probes) e iniciadores (primers) estão descritos na tabela 2.

Cada cDNA $(2 \mu \mathrm{L})$ foi submetido à reação de PCR com $1 \mu \mathrm{L}$ de Assay 20X (conjunto de primers e sonda TaqMan), $10 \mu \mathrm{L}$ de Taqman Universal MasterMix [2x] em volume final de $20 \mu \mathrm{L}$. No termociclador ABI-7900 (Applied Biosystems) as reações aconteceram nas seguintes condições: $50^{\circ} \mathrm{C}$ por $2 \mathrm{~min}$, $95^{\circ} \mathrm{C}$ por $10 \mathrm{~min}, 40$ ciclos de $95^{\circ} \mathrm{C}$ por $15 \mathrm{~s} \mathrm{e} 60^{\circ} \mathrm{C}$ por $1 \mathrm{~min}$. 
Tabela 2 - Iniciadores e sondas utilizadas na detecção da expressão de RNAs mensageiros por PCR em tempo real

Iniciadores suíno-específicos utilizados na PCR em tempo real

\section{Sequência dos Iniciadores e Sondas confeccionados}

Sequiência (5'-3')

IL-1 $\beta$ sense GGTTTCTGAAGCAGCCATGG

IL-1 $\beta$ antisense GATTTGCAGCTGGATGCTCC

IL-1 $\beta$ Probe 5'(FAM)-AAAGAGATGAAGTGCTGCACCCAAAACCTG-(TAMRA)3'

IL-10 sense TTGGAGCTTGCTAAAGGCACT

IL-10 antisense CGGCGCTGTCATCAATTTCT

IL-10 Probe 5'(FAM)-CACCTCCTCCACGGCCTTGCTCTT-(TAMRA)3'

\section{Iniciadores e Sondas adquiridos comercialmente (Applied BioSystems)}

Assay ID

IL-21 Ss03384710_u1

TNF $\alpha \quad$ Ss03391318_g1

NOS2 Ss03374608_u1

HPRT1 Ss03388274_m1

GAPDH Ss03375629_u1

Legenda : Hprt - hipoxantina-guanina-fosforibosiltransferase; GAPDH - gliceraldeído-3-fosfato desidrogenase

As intensidades de fluorescência registradas ao longo de cada ciclo da PCR foram analisadas no programa SDS Software (versão 2.3). A partir de um gráfico de intensidade de fluorescência em função do número de ciclos de amplificação, definimos manualmente um limiar (threshold), onde a intensidade de fluorescência é estatisticamente diferente da fluorescência de fundo (background) e a curva encontra-se na fase logarítima de amplificação. O ciclo da reação onde à fluorescência da amostra intercepta o threshold é chamado Ct (cycle threshold), e a comparação da expressão gênica de diferentes amostras é feita através da comparação entre os Cts. Amostras com Cts 
maiores apresentam menores quantidades do gene alvo no cDNA molde inicial na reação.

\section{Cálculo da Expressão Gênica Diferencial}

A diferença entre os valores de $\mathrm{Ct}(\Delta \mathrm{Ct})$ entre as amostras, após normalização com genes de expressão estável, reflete sua expressão diferencial. Todas as reações foram realizadas em duplicata e foram consideradas aceitáveis reações cujo desvio padrão entre as duplicatas fosse menor que 0,5. A média dos valores de Ct das duplicatas foi considerada para o cálculo da expressão diferencial. Como normalizador das quantidades de cDNA molde, foi amplificado de todas as amostras o transcrito dos genes de expressão constitutiva Hprt (hipoxantina-guanina-fosforibosiltransferase) e GAPDH (gliceraldeído-3-fosfato desidrogenase). A normalização dos dados de expressão gênica foi realizado utilizando-se a média dos Cts encontrados para esses dois genes dentro de cada amostra.

\subsection{Análise Estatística}

Este foi o primeiro estudo em nosso meio validando a transfusão de glóbulos vermelhos estocados homólogos em modelo suíno e avaliando os efeitos agudos hemodinâmicos, respiratórios e inflamatórios da transfusão. Desta forma, este estudo foi considerado exploratório, sendo assim não foi realizado calculo do tamanho amostral. 
As variáveis evolutivas (hemodinâmicas e respiratórias) são apresentadas como média e desvio-padrão (DP) e gráficos apropriados, e analisados inferencialmente via análise não paramétrica para dados com medidas repetidas; a opção por esta metodologia deve-se ao fato de estudarmos um número pequeno de animais em cada grupo e realizarmos medidas repetidas. Esta metodologia é mais flexível e apresenta resultados robustos para as análises de diversos tipos de estudos longitudinais ${ }^{133}$. Além disso, esta metodologia possui vantagens como: a não necessidade da suposição de um modelo particular, a robustez quanto à presença de "outliers", relativa precisão quando há um tamanho amostral pequeno e a fácil interpretação das hipóteses ${ }^{133}$. Em todas as variáveis foram testadas as hipóteses que comparam os cinco momentos avaliados (baseline, póshemorragia, 1, 3 e 6 horas após ressuscitação volêmica). Nas comparações múltiplas foi aplicada a correção de Bonferroni para garantir maior controle do erro do tipo I. Para a interpretação dos resultados utilizamos os efeitos relativos de tratamento (RTE) e seus respectivos intervalos de confiança, com 95\% de confiança. Em que os valores dos RTE encontrados em determinado tempo e grupo podem ser interpretados como probabilidades. RTE maiores que 0,5 indicam que os valores observados naquele grupo (controle ou transfusão), naquele tempo (baseline, pós hemorragia, 1 hora, 3 horas ou 6 horas) tendem a ser maiores do que as respostas globais.

Os dados não evolutivos, como as citocinas inflamatórias pulmonares foram comparadas através do teste $t$ de Student. As concentrações de nitrato pulmonar e plasmático foram avaliadas com teste de Friedman e MannWhitney; a análise post-hoc foi realizada com teste de Tukey HSD. Os dados 
referentes à validação das bolsas de glóbulos vermelhos foram realizados com o teste não paramétrico de Wilcoxon para comparação de duas amostras pareadas. O nível de significância estatística considerado foi de $5 \%$ com testes bi caudais e as análises foram realizadas utilizando os softwares SPSS 13.0, R (versão2. 15.2) (http://www.ime.usp.br/ jmsinger/anova_npar.zip) e o pacote estatístico 2.0 SigmaStat comercialmente disponível (Systat Software, San Jose, CA, EUA) . 
4. Resultados 



\subsection{Etapa 1 - Validação da transfusão de concentrado de glóbulos vermelhos homólogos, estocados por 14 dias}

\subsubsection{Validação "in vitro" das unidades de GV}

A validação "in vitro" das 02 unidades de GV de suínos armazenados em bolsas de sangue utilizadas em humanos demonstrou que as unidades de glóbulos vermelhos estocadas por 14 dias mantiveram hematócrito constante $(68,4 \pm 0,64 \%$ e $68,2 \pm 1,41 \%)$, menor volume $(179,7 \mathrm{~mL} \pm 23,55)$ e concentração de hemoglobina $(22,4 \pm 0,14 \mathrm{~g} / \mathrm{dL})$ quando comparados aos obtidos em humanos $^{67,207,30}$.

Os valores de sódio (119 $\pm 1,41 \mathrm{mEq} / \mathrm{L})$, potássio $(32,1 \pm 1,06 \mathrm{mEq} / \mathrm{L}), \mathrm{pH}$ $(6,9 \pm 0,04)$ e índice de hemólise $(0,1 \pm 0,01 \%)$ encontrados no 14 dia de estocagem foram similares aos valores encontrados em glóbulos vermelhos humanos no último dia de estocagem ${ }^{67,207,30}$. Não houve queda nos níveis de glicose e o pH manteve-se constante.(Tabela 3). 
Tabela 3 - Validação das unidades de GV "in vitro"

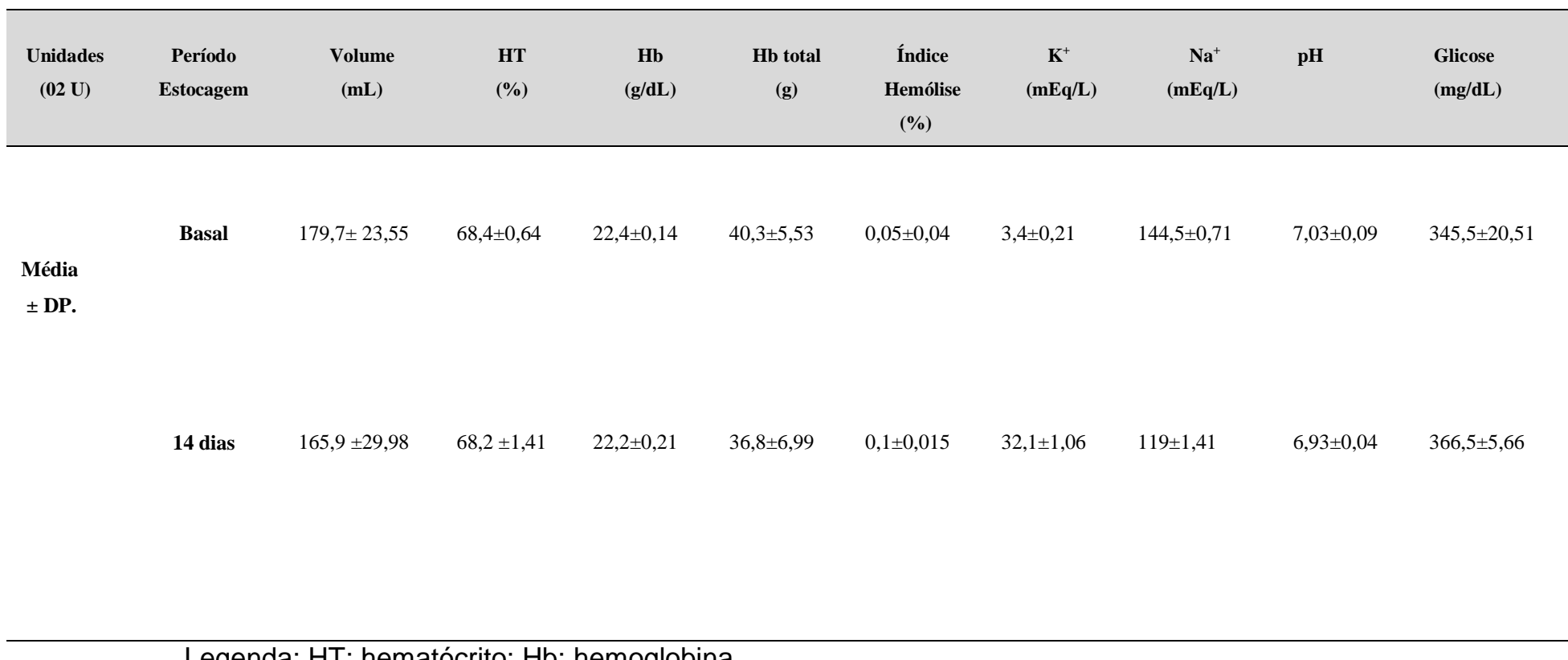

Legenda: HT: hematócrito; Hb: hemoglobina.

$\mathrm{Na}$ tabela 4 observamos os resultados dos grupos sanguíneos e as provas de compatibilidade do animal doador (animal 1) com os receptores (animais 2,3,4 e 5). As provas de compatibilidade resultaram negativas entre 0 doador e os cinco receptores em temperatura ambiente (um autólogo e quatro homólogos).

Tabela 4 - Grupos sanguíneos e provas de compatibilidade

\begin{tabular}{cccc}
\hline Soro & $\begin{array}{c}\text { DIAMED } \\
\text { Anti-A } \\
\text { Monoclonal }\end{array}$ & $\begin{array}{c}\text { Possivel Grupo } \\
\text { Sanguineo }\end{array}$ & $\begin{array}{c}\text { Prova de } \\
\text { Compatibilidade }\end{array}$ \\
\hline Animal 1* & Negativa & O ou nulo & Negativa \\
Animal 2 & $4+$ & A Forte & Negativa \\
Animal 3 & Negativa & O ou nulo & Negativa \\
Animal 4 & $4+$ & A Forte & Negativa \\
Animal 5 & $1+$ & A Fraco & Negativa \\
\hline
\end{tabular}




\subsubsection{Validação “in vivo”}

A figura 4 demonstra a sobrevida das hemácias marcadas com cromo 24 horas após a transfusão. Houve recuperação de 97,5\% \pm 19 das hemácias transfundidas.

Adicionalmente foi realizada a dosagem de radioatividade livre no sobrenadante das amostras, a qual foi negativa. A porcentagem de radioatividade livre no sobrenadante nas amostras de 5, 10, 120, 180, 360, 480, 720 e 1440 minutos foi de $1,1 \pm 0,1 \%, 1,1 \pm 0,2 \%, 1,0 \pm 0,2 \%, 0,9 \pm 0,2 \%$, $0,7 \pm 0,1 \%, \quad 1,3 \pm 1,2 \%, \quad 0,8 \pm 0,3 \%$ e $0,9 \pm 0,4$ ( $p=$ não significativo), respectivamente.

Os resultados foram negativos para sequestro esplênico em todos os animais analisados.

As culturas bacterianas das bolsas foram negativas. 


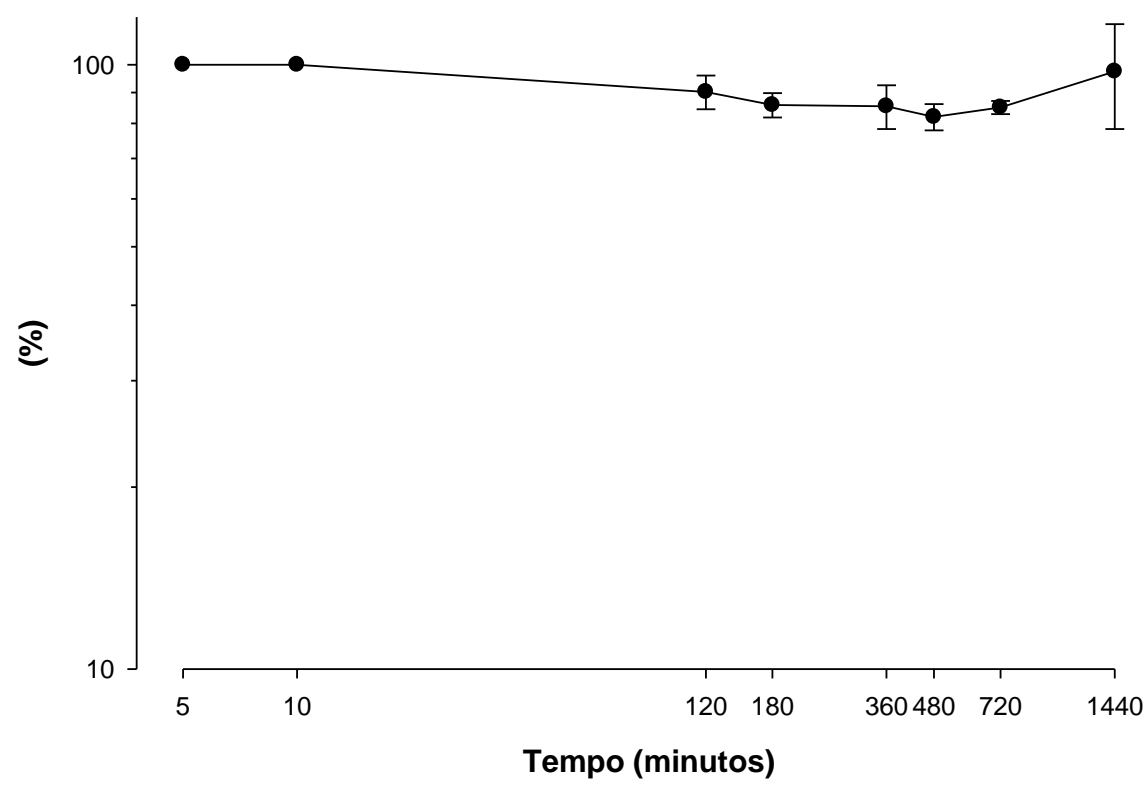

Figura 4 - Viabilidade "in vivo" de hemácias marcadas com cromo até 24 horas pós-injeção

4.2 Etapa 2 - Avaliar os efeitos agudos da transfusão de glóbulos vermelhos estocados no transporte de oxigênio, mecânica respiratória e resposta inflamatória pulmonar e sistêmica da hipovolemia experimental

Foi realizado controle de qualidade das unidades "in vitro" das 16 unidades de

GV estocadas no dia da coleta e no $14^{\circ}$ dia de estocagem. O volume médio das unidades transfundidas foi de $235,2 \pm 22,5 \mathrm{~mL}$, com hematócrito de $71(\%)$

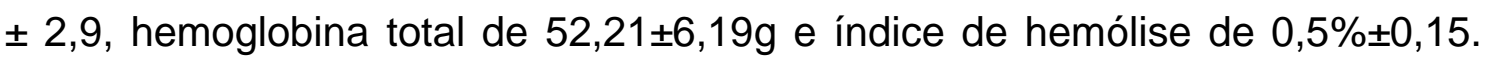

(Tabela 5)

Foram realizadas tipagens sanguíneas de todos os doadores e receptores (Tabela 6). Todas as provas de compatibilidade resultaram negativas. 
Tabela 5 - Controle de qualidade "in vitro" das unidades de GV

\begin{tabular}{l|cccccc}
\hline $\begin{array}{l}\text { Parâmetros } \\
\text { Analisados }\end{array}$ & Período & $\mathbf{N}$ & Valor & \multicolumn{3}{c}{ Percentil } \\
\cline { 5 - 7 } & & & & $\mathbf{2 5}$ & $\begin{array}{c}\mathbf{5 0} \\
\text { (Mediana) }\end{array}$ & $\mathbf{7 5}$ \\
\hline $\begin{array}{l}\text { Volume } \\
\text { (mL) }\end{array}$ & Baseline & 16 & $249,3 \pm 44$ & 221,6 & 249,3 & 259,6 \\
HT (\%) & 14 dias & 16 & $235,2 \pm 22,55$ & 215,5 & 245,7 & 249,6 \\
& Baseline & 16 & $73,3 \pm 3,46$ & 70,4 & 74,1 & 76,3 \\
Hb (g/dL) & 14 dias & 16 & $71,1 \pm 2,92$ & 68,1 & 71,5 & 73,9 \\
& Baseline & 16 & $23,3 \pm 1,41$ & 22,3 & 23,5 & 24,3 \\
Hb total (g) & Baseline & 16 & $55,8 \pm 6,59$ & 51,1 & 58,1 & 60,7 \\
& 14 dias & 16 & $52,2 \pm 6,19$ & 48,0 & 52,3 & 57,5 \\
Hb livre & Baseline & 16 & $31 \pm 9,31$ & 22,8 & 29,4 & 40,7 \\
(mg/dL) & 14 dias & 16 & $112,5 \pm 31,43$ & 84,0 & 111,8 & 129,9 \\
Índice de & Baseline & 16 & $0,1 \pm 0,04$ & 0,1 & 0,1 & 0,1 \\
hemólise & 14 dias & 16 & $0,5 \pm 0,15$ & 0,4 & 0,5 & 0,6 \\
(\%) & & & & & & \\
\hline
\end{tabular}

Legenda: HT: hematócrito; Hb: hemoglobina.

Tabela 6 - Tipagem Sanguínea e Provas de Compatibilidade

\begin{tabular}{lcccc}
\hline Soro & DIAMED & Possivel Grupo & Possivel Grupo & Prova de \\
& Anti-A & Sanguineo & Sanguineo & Compatibilidade \\
& Monoclonal & Receptor & Doador & \\
\hline
\end{tabular}

$\begin{array}{lcccc}\text { Animal 4 } & \text { Positiva } & \text { A } & \text { A } & \text { Negativa } \\ \text { Animal 5 } & \text { Positiva } & \text { A } & \text { A } & \text { Negativa } \\ \text { Animal 9 } & \text { Positiva } & \text { A } & \text { O ou nulo } & \text { Negativa } \\ \text { Animal 10 } & \text { Positiva } & \text { A } & \text { A } & \text { Negativa } \\ \text { Animal 13 } & \text { Positiva } & \text { A } & \text { O ou nulo } & \text { Negativa } \\ \text { Animal 14 } & \text { Positiva } & \text { A } & \text { A } & \text { Negativa } \\ \text { Animal 15 } & \text { Negativa } & \text { O ou nulo } & \text { O ou nulo } & \text { Negativa } \\ \text { Animal 16 } & \text { Positiva } & \text { A } & \text { A } & \text { Negativa }\end{array}$




\subsubsection{Hemorragia}

O volume de hemorragia media dos animais foi de $1083,7 \pm 100,8 \mathrm{~mL}$ que correspondeu a $22,6 \pm 1,69 \%$ da volemia estimada. Isto resultou em um pequeno decréscimo dos níveis de hemoglobina de $10,36 \pm 0,78 \mathrm{~g} / \mathrm{dL}$ para $9,99 \pm$ $1,17 \mathrm{~g} / \mathrm{dL}$ e de $\mathrm{HT}$ de $32,3 \pm 2,67$ para $30,9 \pm 3,55 \%$.

\subsubsection{Parâmetros Hemodinâmicos e de Oxigenação}

Apenas 16 dos 18 animais analisados foram incluídos neste estudo. Um dos animais do grupo controle foi excluído devido a dificuldades técnicas com os equipamentos de monitorização durante o experimento. Um animal com tipo sanguíneo não $A$ (O ou nulo) recebeu duas unidades de GV do tipo $A$ (tabela 7) com prova de compatibilidade positiva, evoluiu 1 hora após a ressuscitação volêmica com queda de $86 \%$ da $\mathrm{PaO}_{2} / \mathrm{FiO}_{2}$ ( $48 \mathrm{~mm} \mathrm{Hg}$ ), $57 \%$ da complacência do sistema respiratório $\left(21,1 \mathrm{~mL} \cdot \mathrm{mm} \mathrm{Hg}^{-1}\right)$ e aumento de 110 $\%$ da resistência do sistema respiratório (14,5 mm Hg. $\left.\mathrm{L}^{-1} \cdot \mathrm{s}^{-1}\right)$, e $60 \%$ da pressão de artéria pulmonar média $(48 \mathrm{~mm} \mathrm{Hg})$ em relação ao baseline, evoluindo com insuficiência respiratória, hematúria, anuria, sangramento lacrimal e queda na contagem plaquetária, sem sinais de hemólise até o final do procedimento. (Tabela 7) 
Tabela 7 - Animal excluído do estudo*

\begin{tabular}{|c|c|c|c|c|c|}
\hline Variáveis & Baseline & Hemorragia & $\begin{array}{c}\text { 1hora } \\
\text { Após } \\
\text { Ressuscitação } \\
\text { volêmica }\end{array}$ & $\begin{array}{c}3 \text { horas após } \\
\text { Ressuscitação } \\
\text { volêmica }\end{array}$ & $\begin{array}{c}6 \text { horas após } \\
\text { Ressuscitação } \\
\text { volêmica }\end{array}$ \\
\hline PAM (mm Hg) & 80 & 75 & 119 & 115 & 102 \\
\hline PVC (mm Hg) & 14 & 12 & 14 & 16 & 16 \\
\hline PAPm (mm Hg) & 30 & & 48 & 50 & 53 \\
\hline $\mathrm{SVO}_{2}(\%)$ & 79 & 41 & 13 & 22 & 9 \\
\hline $\mathrm{FiO}_{2}(\%)$ & 0,25 & 0,25 & 100 & 100 & 100 \\
\hline $\mathrm{PaO}_{2}(\%)$ & 85,5 & 83 & 47,7 & 69,7 & 38,5 \\
\hline $\mathrm{PaO}_{2} / \mathrm{FiO}_{2}$ & 342 & 332 & 48 & 69,7 & 38,5 \\
\hline Cest (mL.mm Hg $\left.g^{-1}\right)$ & 48,2 & - & 21,1 & 21,8 & 18 \\
\hline $\operatorname{Rsr}\left(m L . m m H g L-1 s^{-1}\right)$ & 6,8 & - & 14,5 & 14,4 & 14 \\
\hline $\mathbf{H b}$ & 9,4 & - & - & 11,8 & 12,8 \\
\hline Ht $(\%)$ & 30,9 & - & - & 36,8 & 40,9 \\
\hline Plaquetas & 352 & - & - & 86 & 78 \\
\hline
\end{tabular}

*Provas de Compatibilidade Eritrocitárias Positivas

Legenda: $\mathrm{PAM}=$ pressão arterial média; $\mathrm{PVC}=$ pressão venosa central; $\mathrm{PAPm}=$ pressão de arteria pulmonar média; $\mathrm{SvO}_{2}$ = saturação venosa mista de oxigênio; $\mathrm{FiO}_{2}=$ fração inspirada de oxigênio; $\mathrm{PaO}_{2}$ pressao arterial de oxigênio; Cest: Complacência estática do sistema respiratório; Rsr= resistência do sistema respiratório.

Os demais animais $(n=16)$ foram analisados. Demonstramos nas figuras 5 e 6 e na tabela 8, os efeitos da transfusão de GV nos parâmetros hemodinâmicos, de oxigenação, perfusão e laboratoriais. Como esperado a hipovolemia foi associada à redução significativa do índice sistólico $(p<0,001)$, pressão arterial média $(p<0,001), \mathrm{SvO}_{2} \%(p<0,001), P V C(p=0,05)$, ITSVD $(p<0,001)$ e ITSVE $(p<0,001)$ (Figura 5, Painel A, B, C, D, E, F) em ambos os grupos. Adicionalmente, a hipovolemia aumentou significantemente a $\Delta \mathrm{VS}$ $(p<0,001)$ (Figura 5, Painel G). Em ambos os grupos a reposição de 
cristalóides, associado ou não a transfusão de GV, levou à recuperação parcial ou completa dos parâmetros hemodinâmicos. Entretanto, o grupo tratado com transfusão de GV apresentou um aumento dos valores de $\mathrm{SvO}_{2}$ (Figura 5 Painel C) e $\mathrm{CaO}_{2}$ (Figura 6 Painel A). Adicionalmente houve um aumento significativo do nível de hemoglobina e hematócrito $(\mathrm{p}<0,001)$ (Figura 6 Painel B, C) do grupo transfundido comparado ao controle após a transfusão e durante todo o experimento mostrando assim a viabilidade dos GV estocados. A transfusão não influenciou significativamente a microcirculação avaliada através da técnica de Laser Doppler fluxometria. (Figura 6 Painel D) e da dosagem de lactato (Figura 6 Painel E). 
Painel A - Índice Sistólico $\left(\mathrm{mL} / \mathrm{bat} / \mathrm{m}^{2}\right)$

Perfis individuais de cada animal por grupo
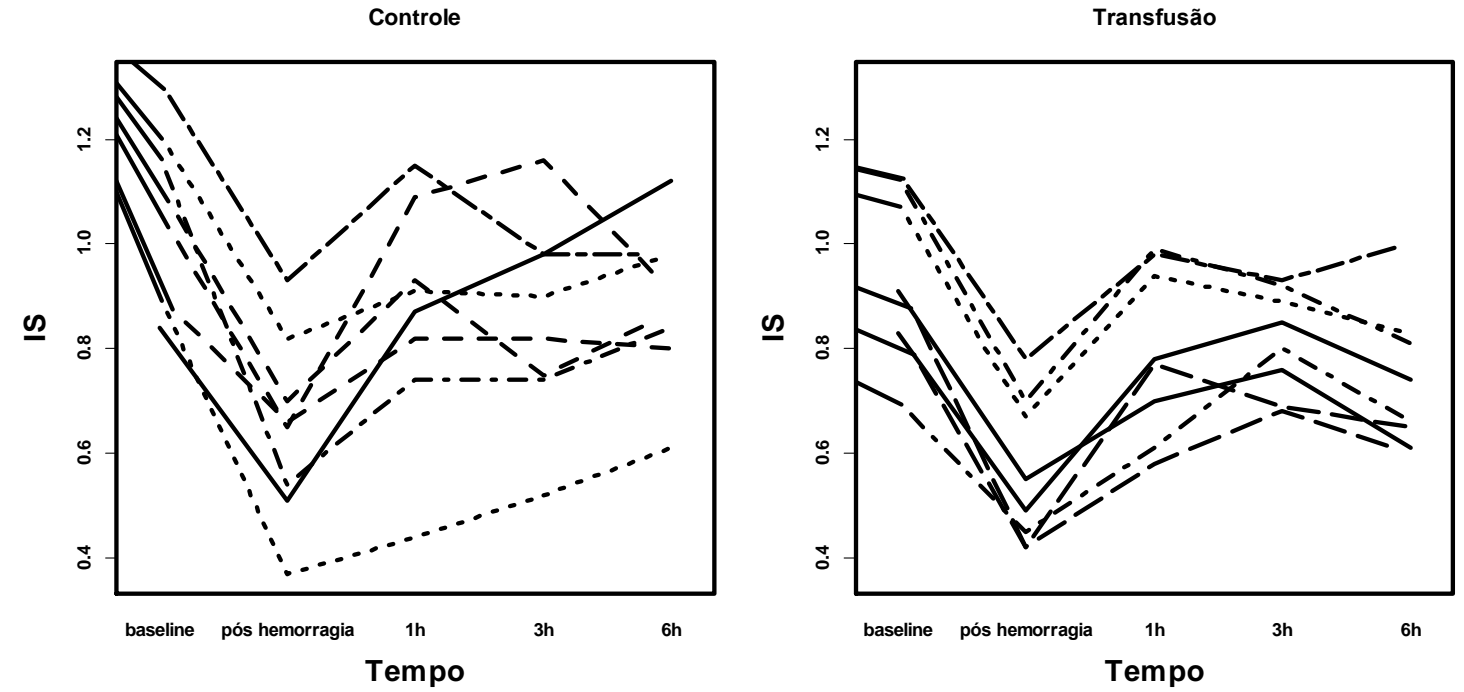

Efeito Relativo de Tratamento (RTE)

\section{Índice Sistólico $\left(\mathrm{mL} / \mathrm{bat} / \mathrm{m}^{2}\right)$}

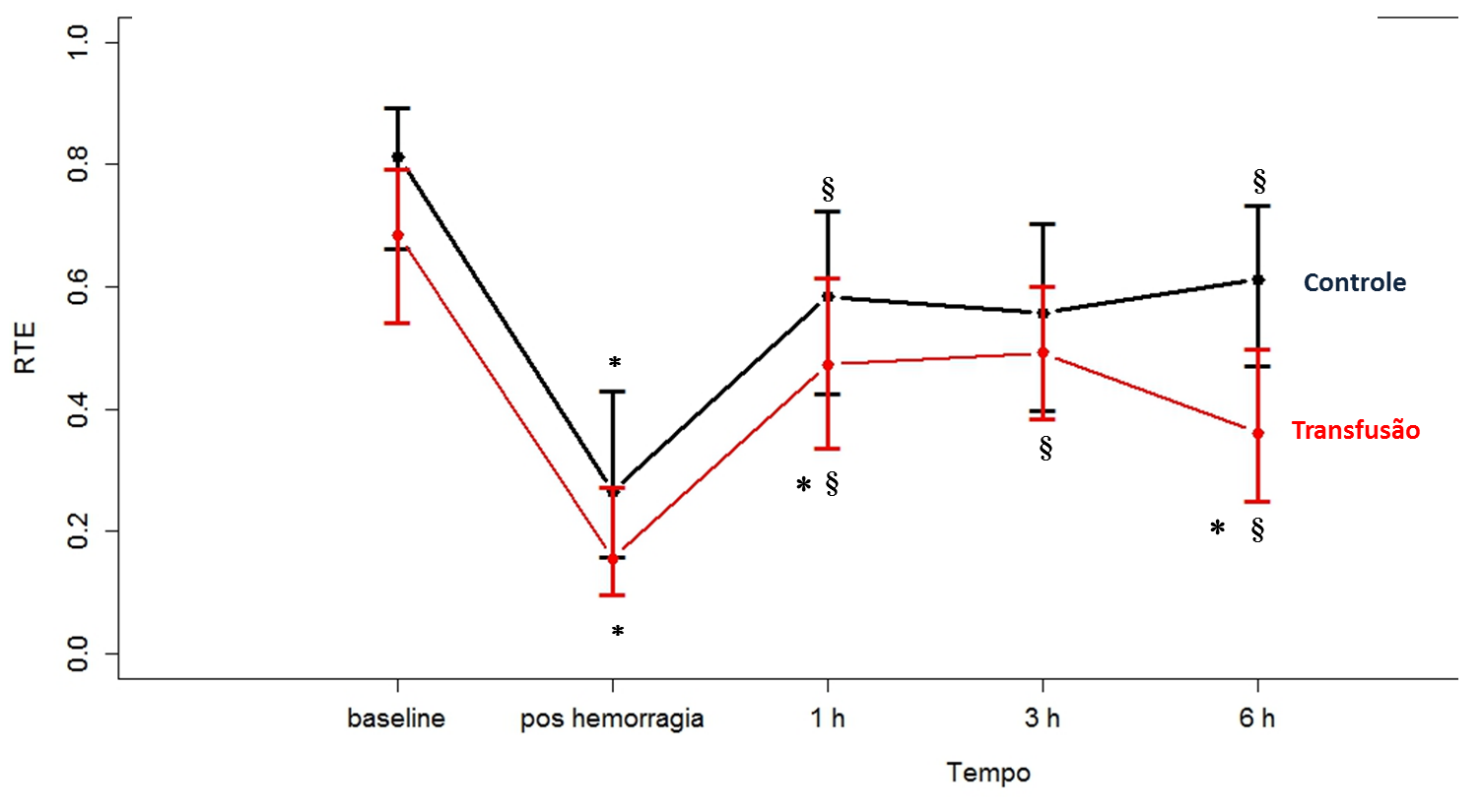

$* \mathrm{P}<0.05$ vs baseline $\quad{ }^{\S} \mathrm{P}<0.05$ vs hemorragia 
Painel B - Pressão Arterial Média (PAM) $(\mathrm{mm} \mathrm{Hg})$

Perfis individuais de cada animal por grupo
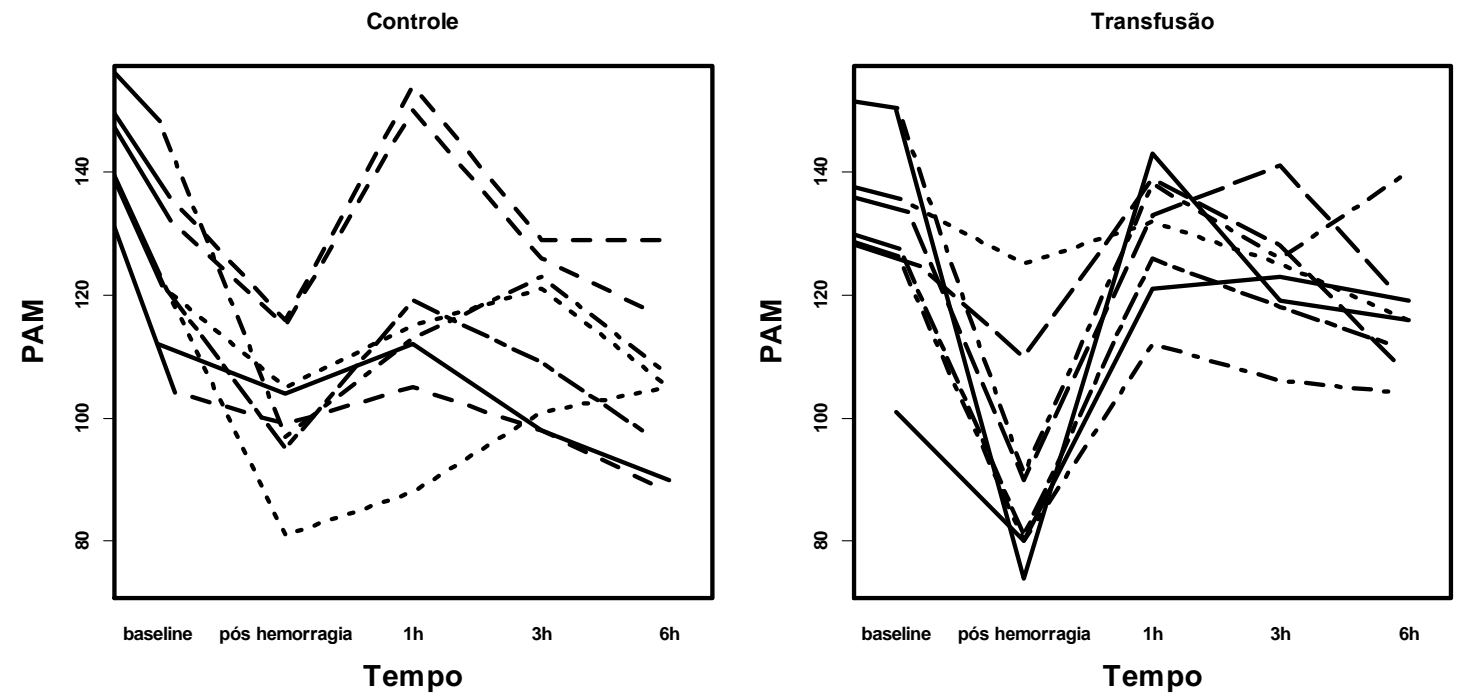

Efeito Relativo de Tratamento (RTE)

$\operatorname{PAM}(\mathrm{mmHg})$

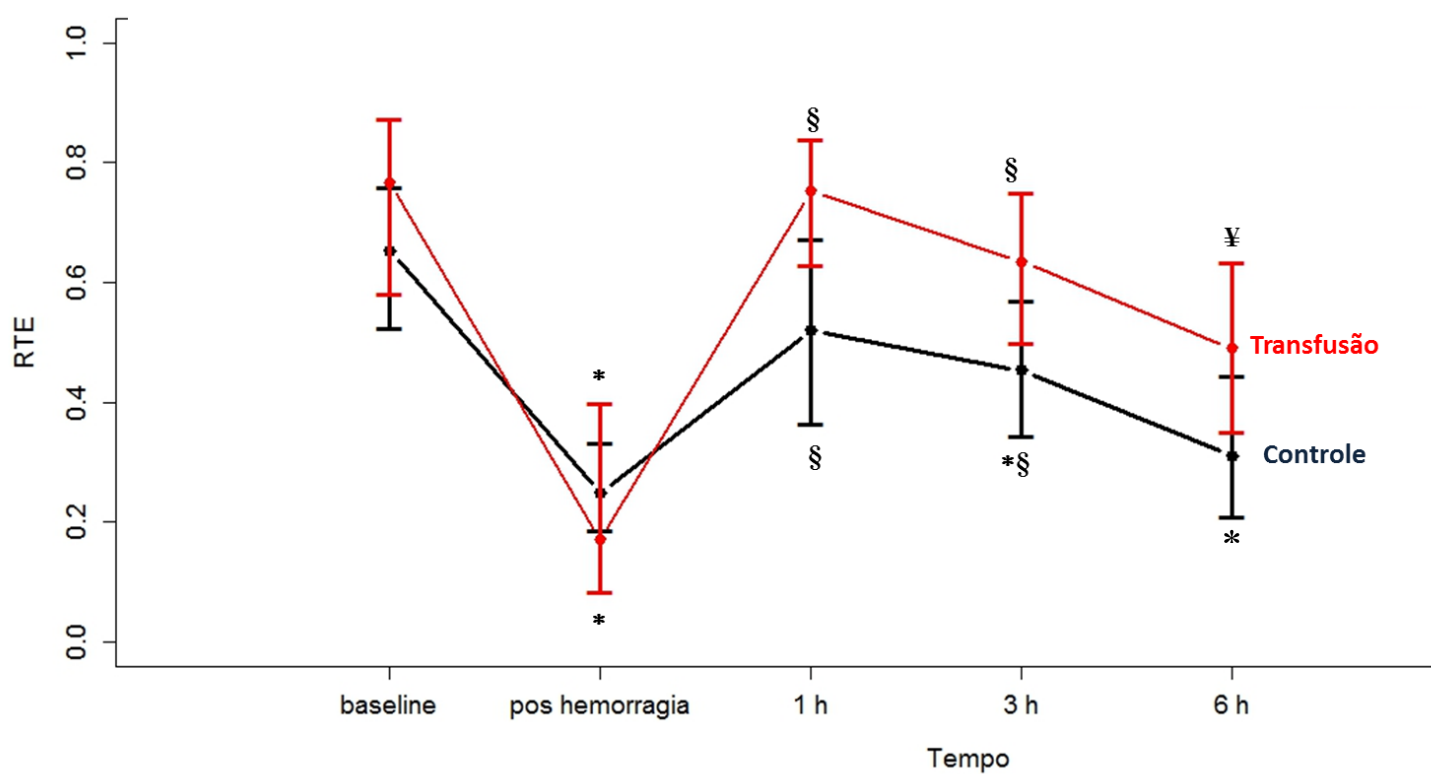

* $\mathrm{P}<0.05$ vs baseline $\quad{ }^{\S} \mathrm{P}<0.05$ vs hemorragia $\quad{ }^{¥} \mathrm{P}<0.05$ vs 1 hora 
Painel C - Saturação Venosa Mista de Oxigênio (\%)

Perfis individuais de cada animal por grupo
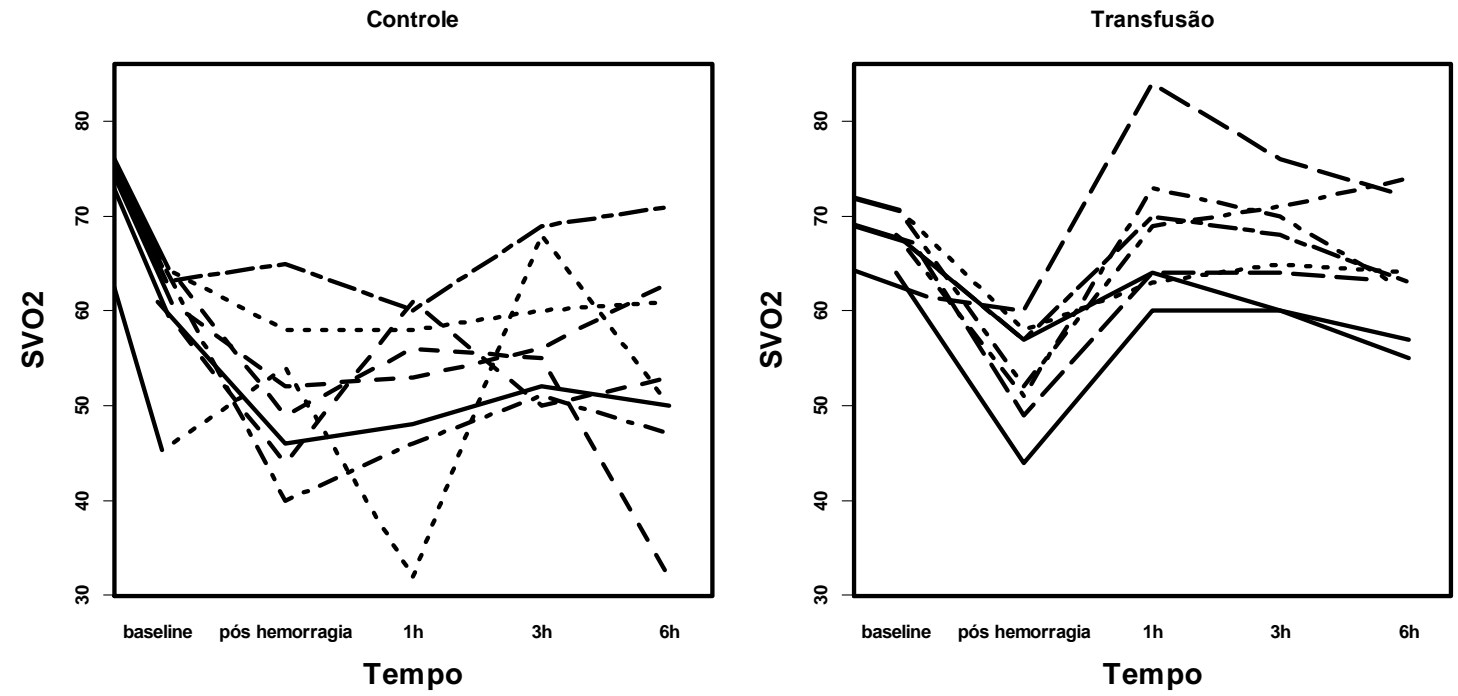

Efeito Relativo de Tratamento (RTE)

$\mathrm{SVO}_{2}$

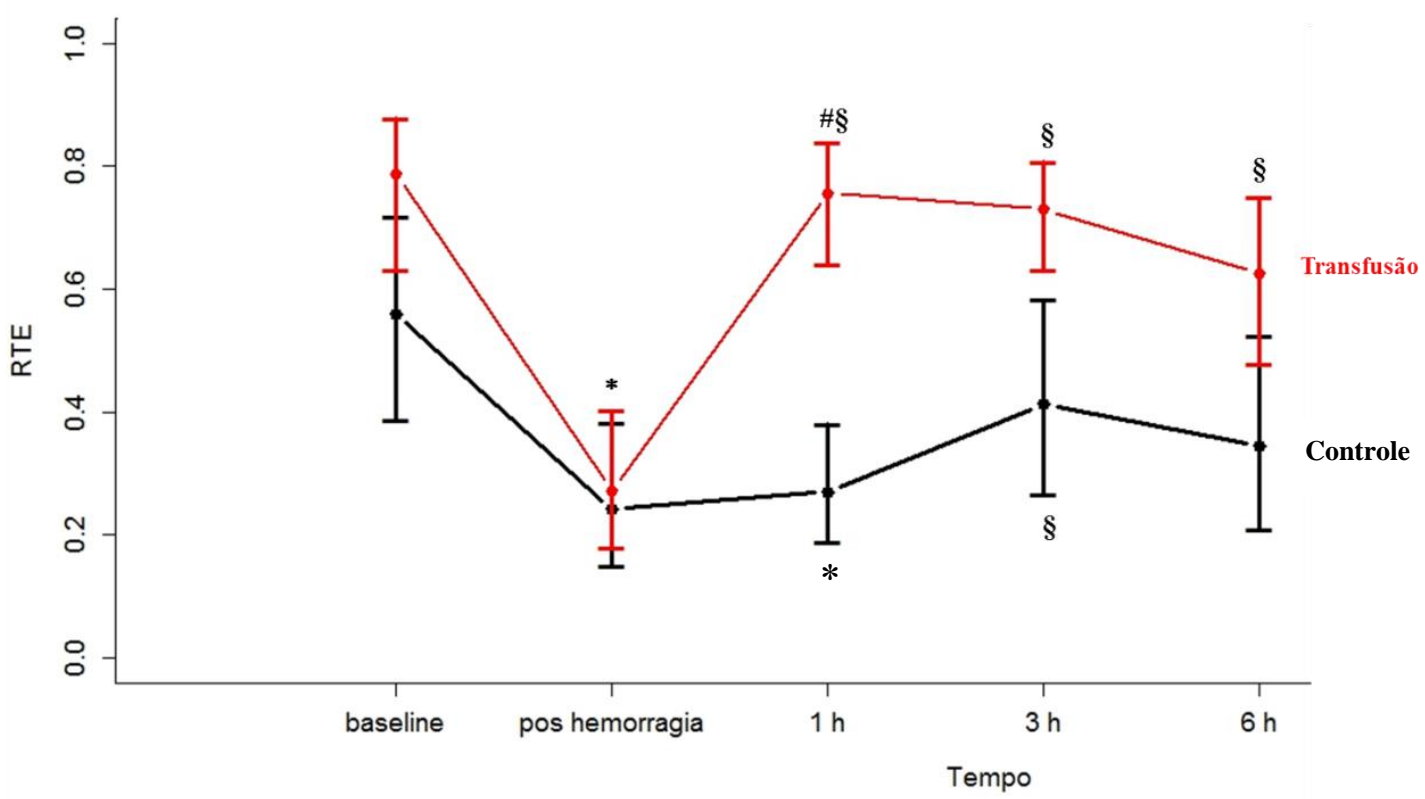

* $\mathrm{P}<0.05$ vs baseline $\quad{ }^{\S} \mathrm{P}<0.05$ vs hemorragia $\quad{ }^{\#} \mathrm{P}<0.05$ vs controle 
Painel D - Pressão Venosa Central (PVC) $(\mathrm{mm} \mathrm{Hg})$

Perfis individuais de cada animal por grupo
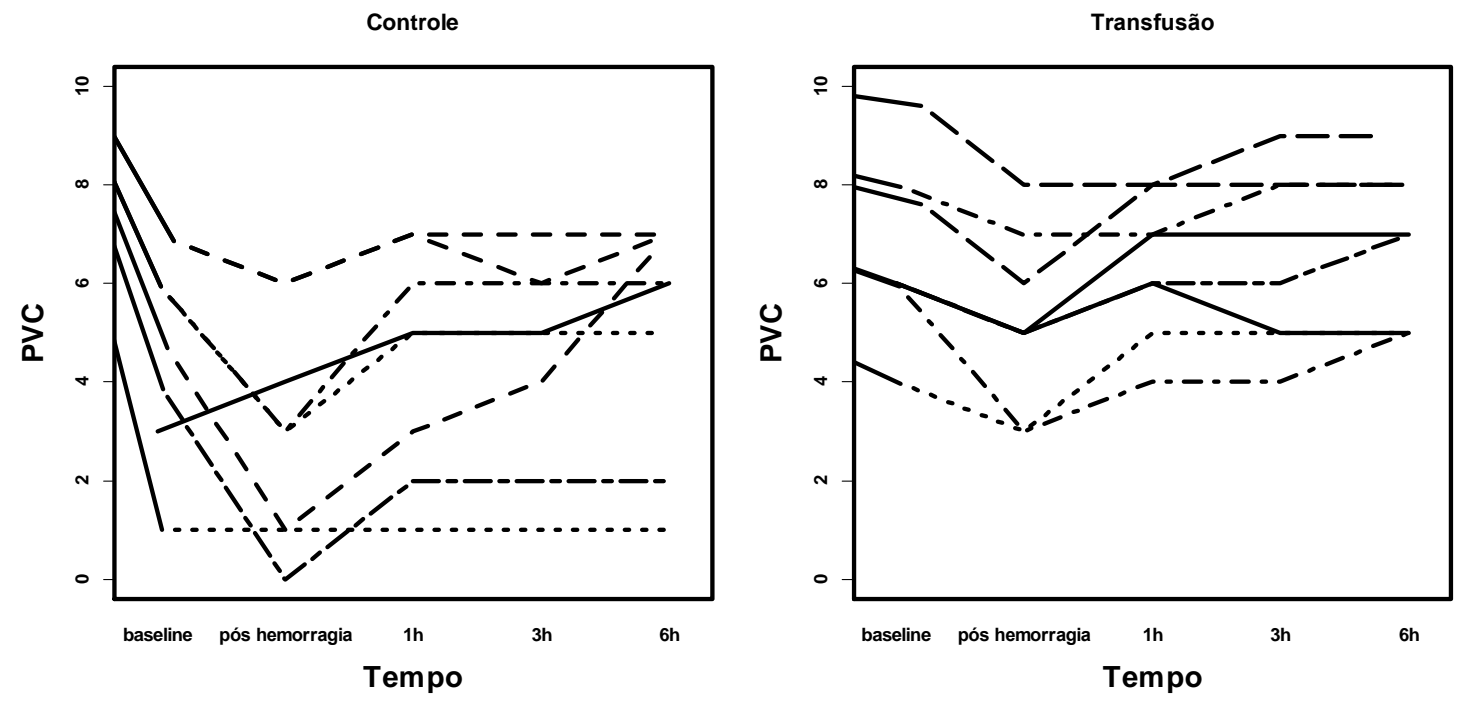

Efeito Relativo de Tratamento (RTE)

PVC(mmHg)

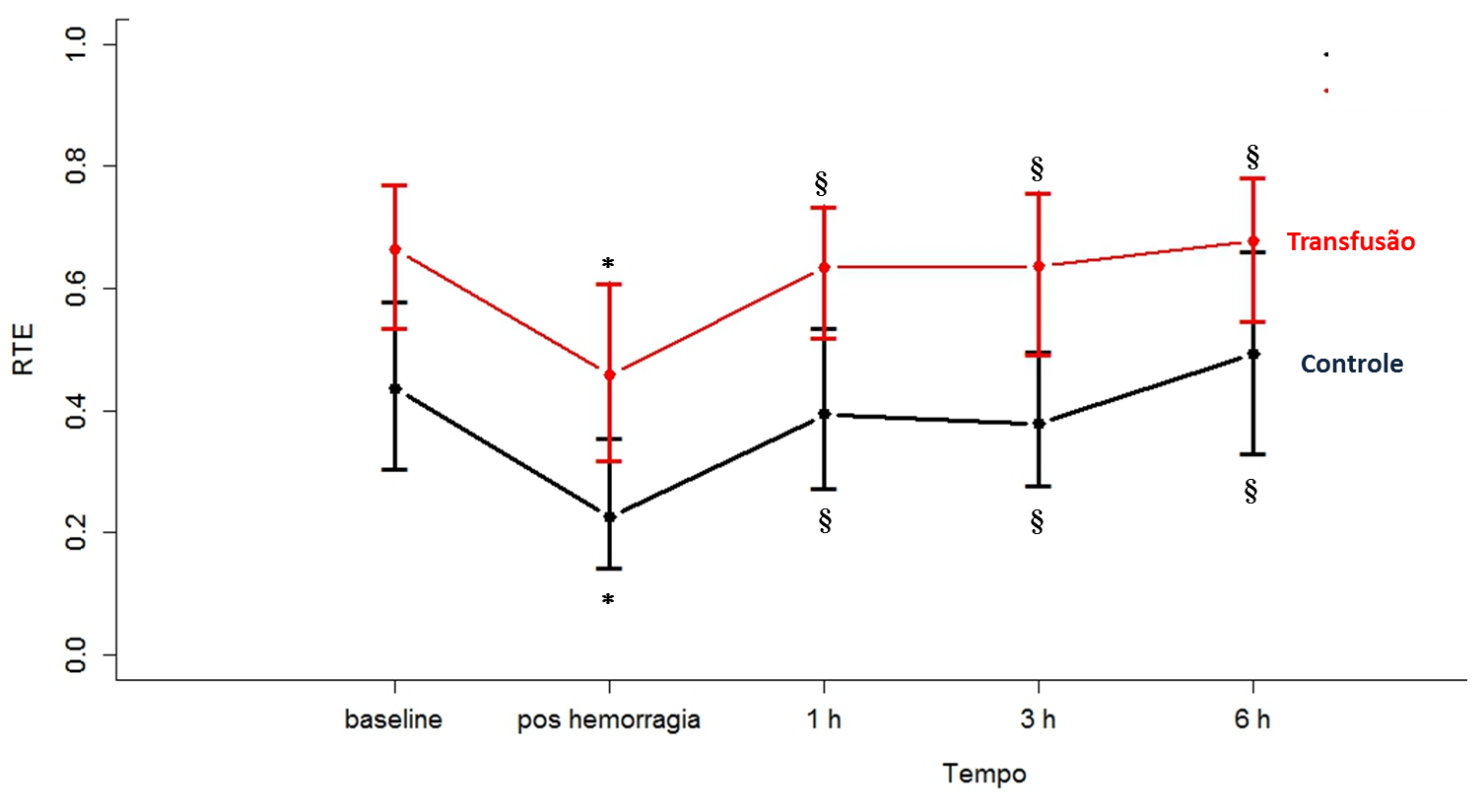

* $\mathrm{P}<0.05$ vs baseline $\quad{ }^{\S} \mathrm{P}<0.05$ vs hemorragia 
Painel E - $\quad$ ITSVE [(mL.mm Hg)/kg.bat $)]$

Perfis individuais de cada animal por grupo
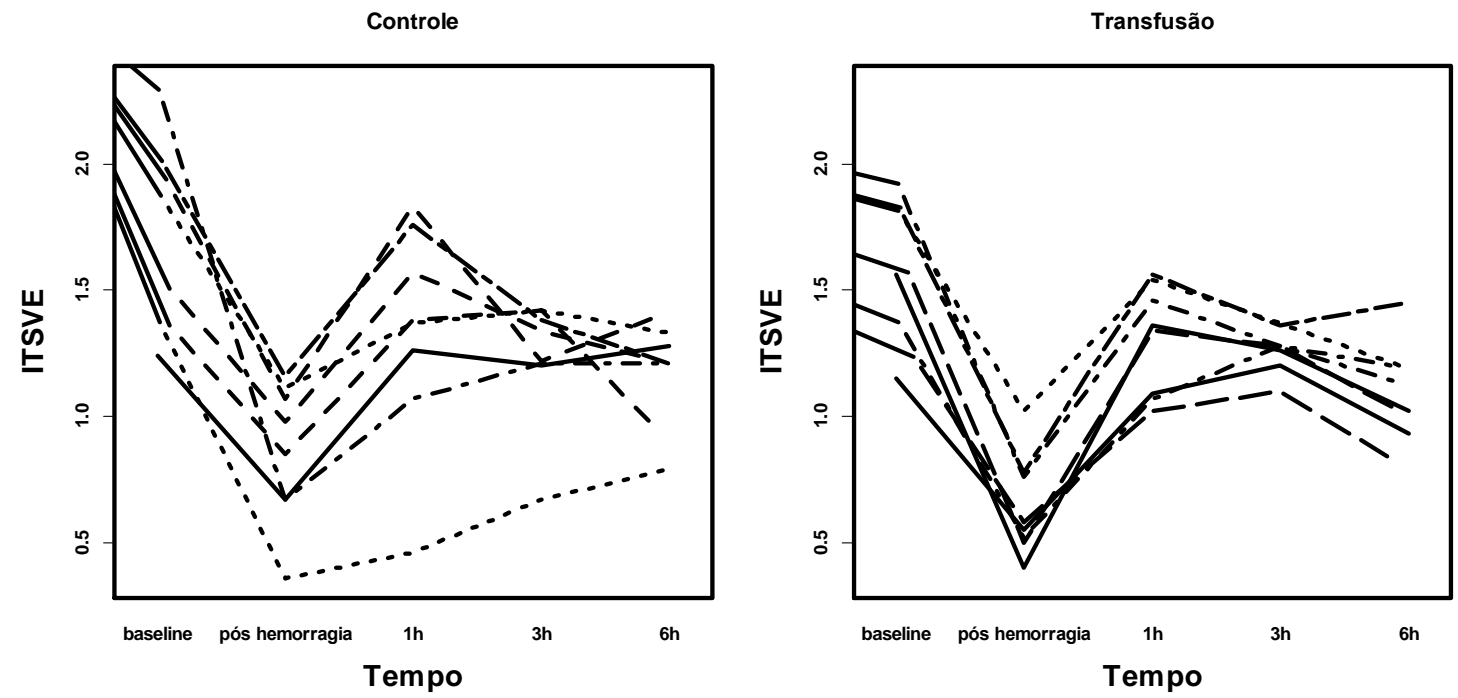

Efeito Relativo de Tratamento (RTE)

\section{ITSVE}

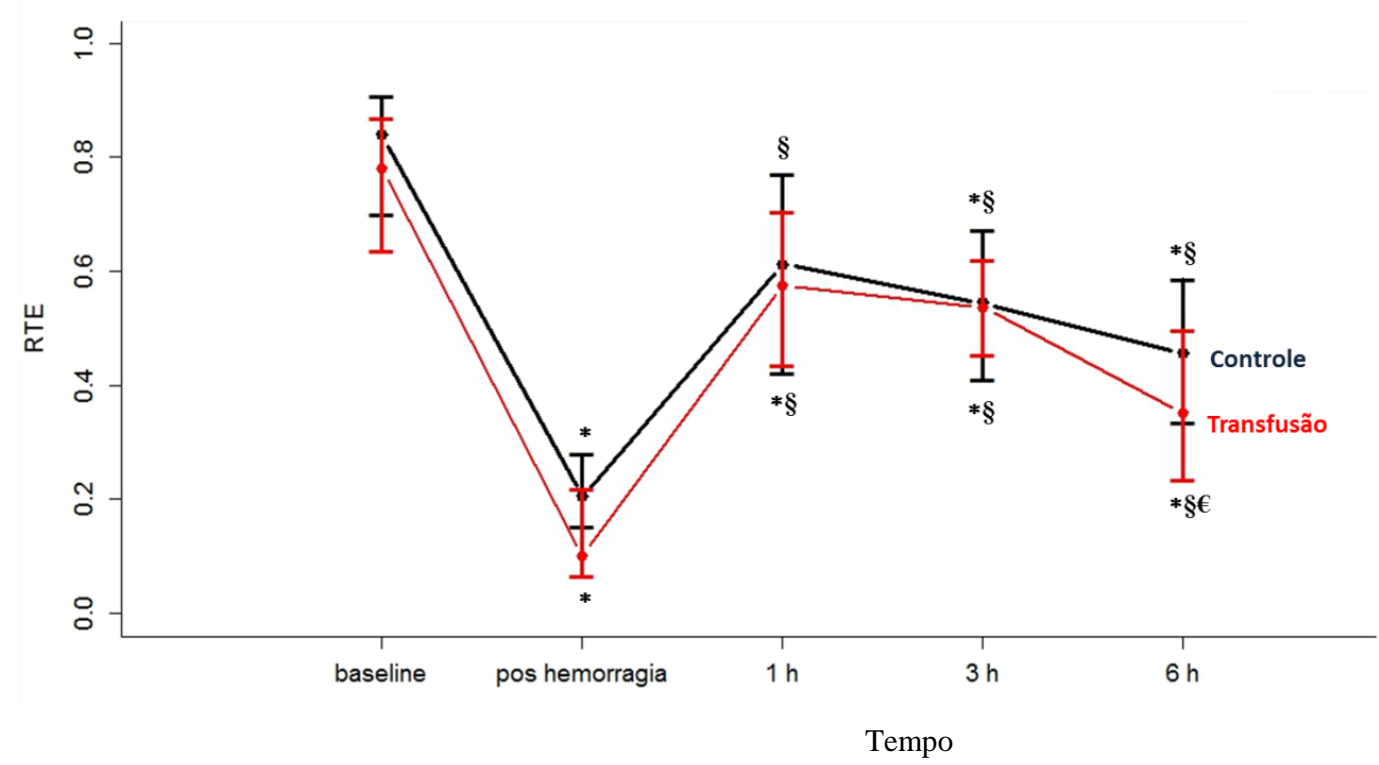

* $\mathrm{P}<0.05$ vs baseline $\quad{ }^{\S} \mathrm{P}<0.05$ vs hemorragia $\quad{ }^{\epsilon} \mathrm{P}<0,05$ vs $3 \mathrm{~h}$ 
Painel F - $\quad$ ITSVD [(mL.mm Hg) $/ \mathrm{kg}$. bat $)]$

Perfis individuais de cada animal por grupo
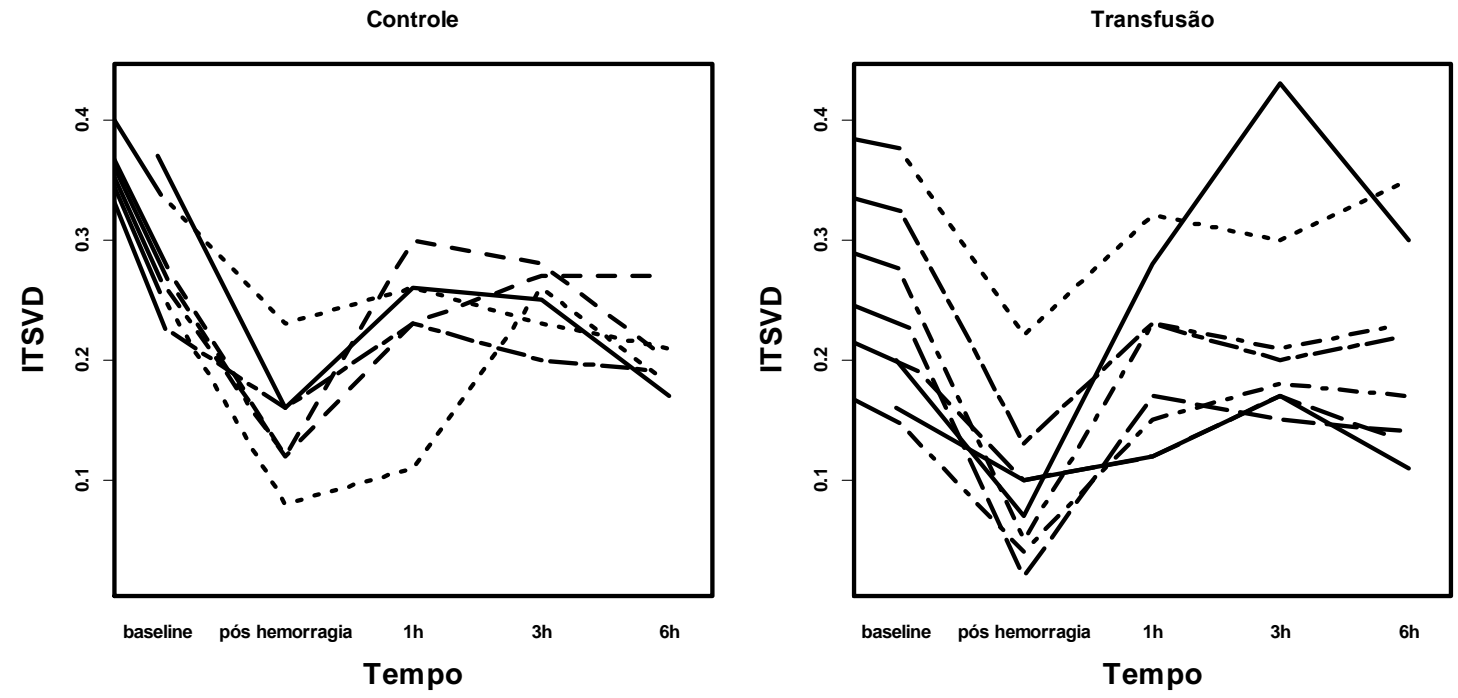

Efeito Relativo de Tratamento (RTE)

ITSVD

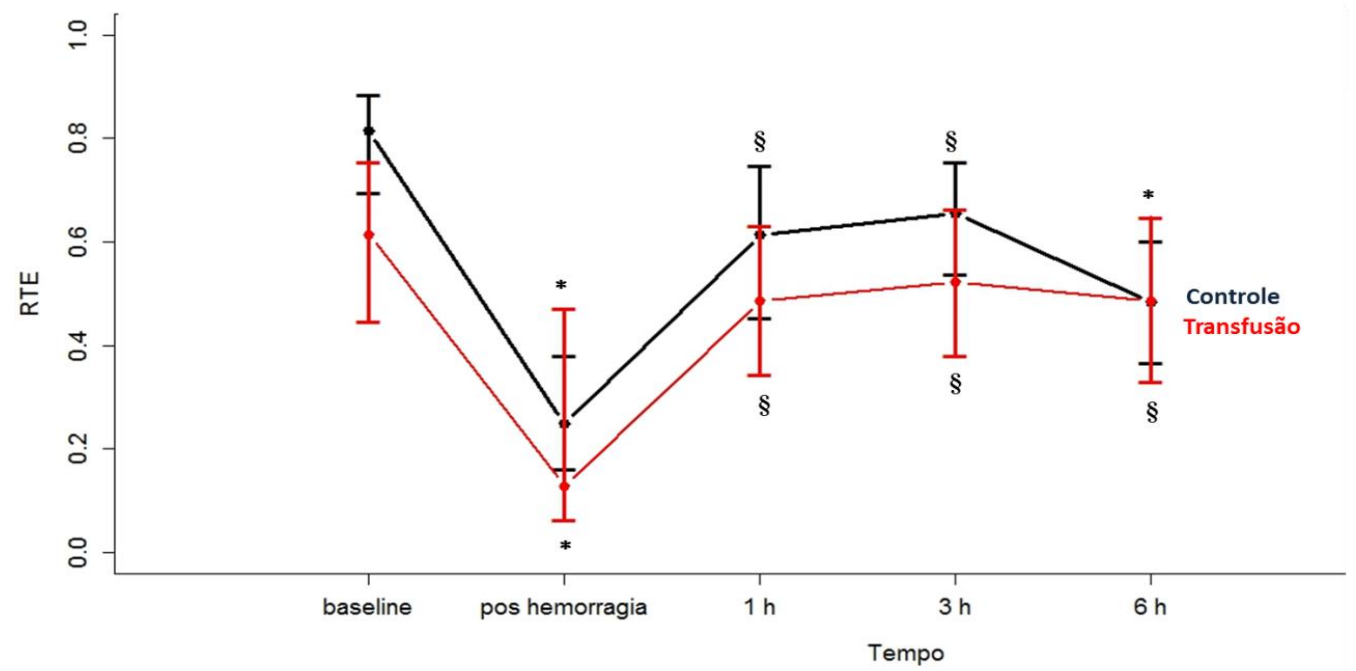

${ }^{*} \mathrm{P}<0.05$ vs baseline $\quad{ }^{\S} \mathrm{P}<0.05$ vs hemorragia 
Painel G - Variação de Volume Sistólico ( $\Delta$ VS) (\%)

Perfis individuais de cada animal por grupo
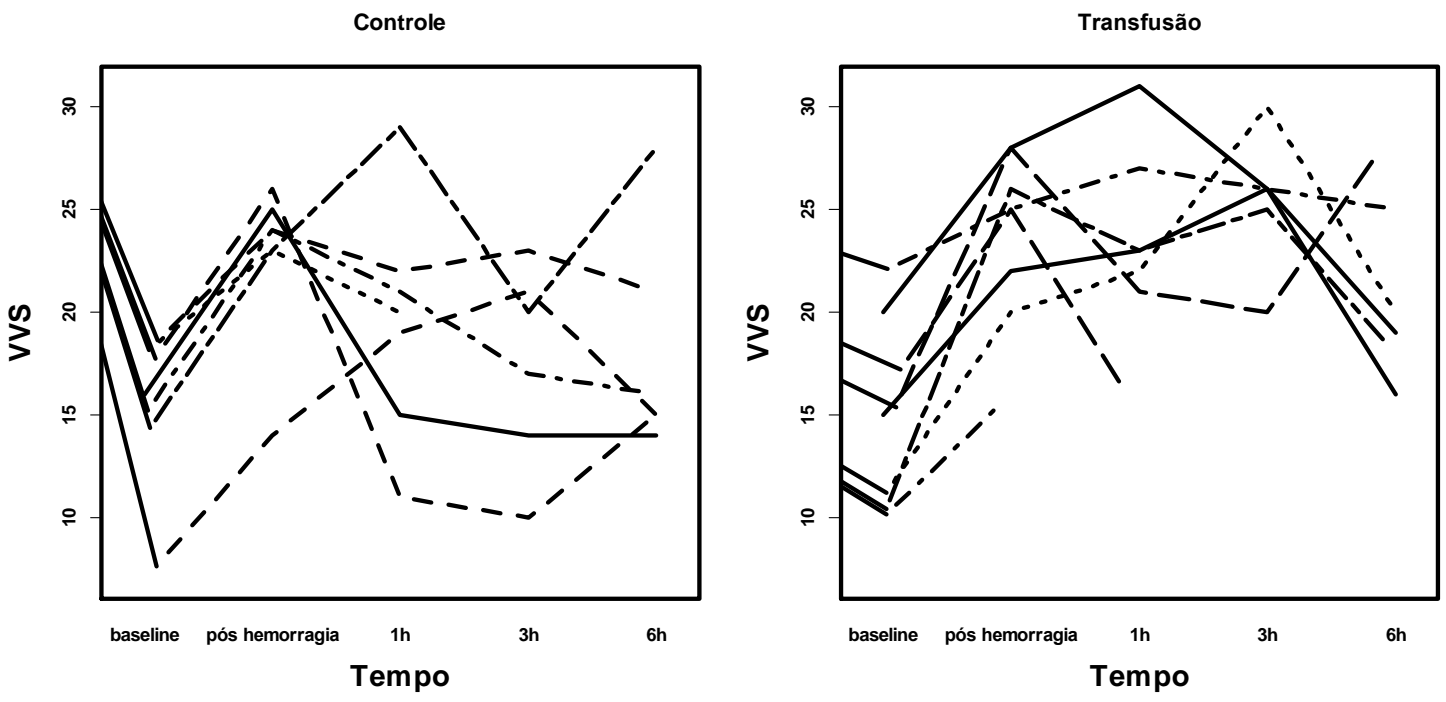

Efeito Relativo de Tratamento (RTE)

\section{$\Delta \mathbf{V S}$}

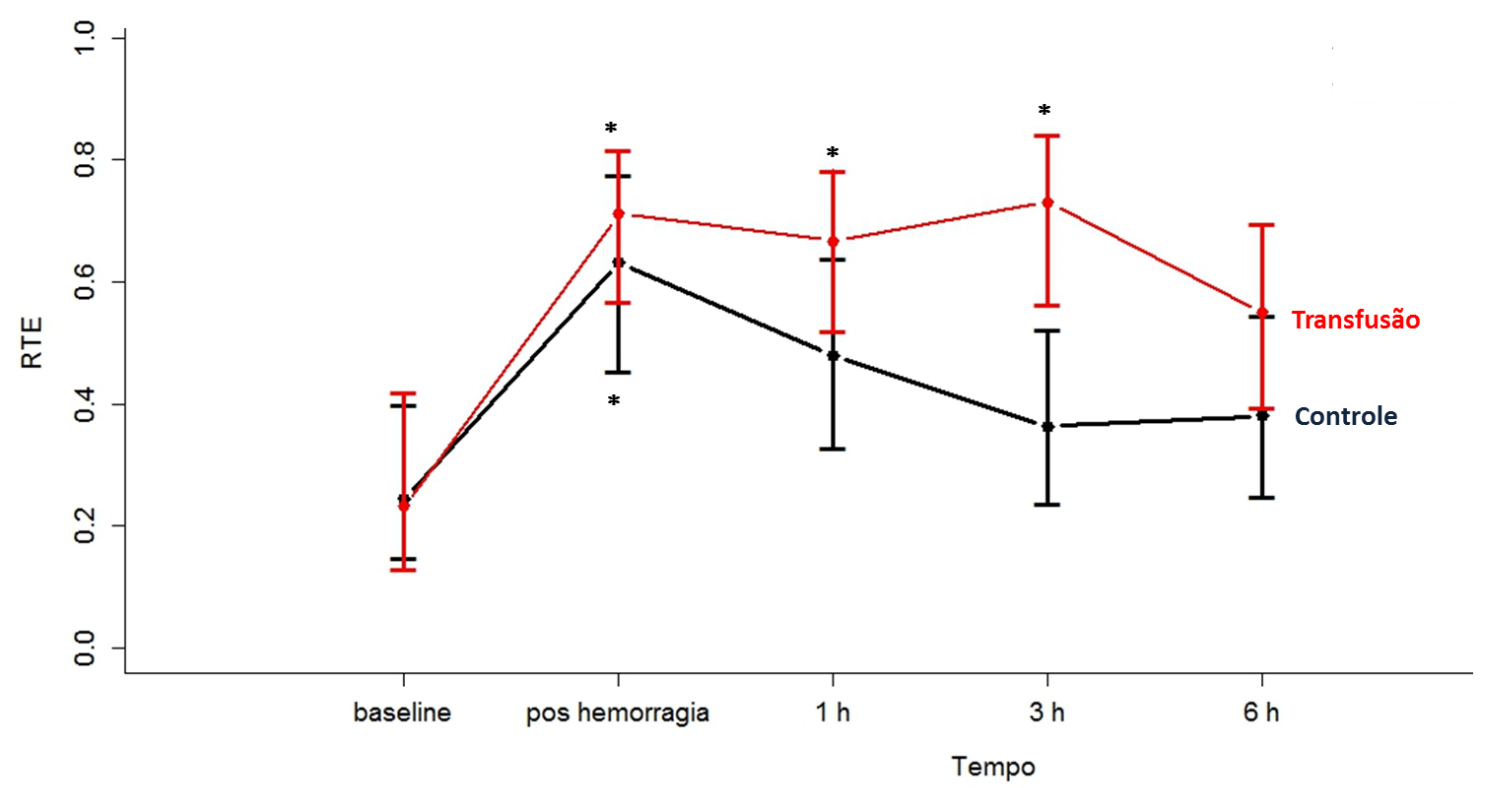

$* \mathrm{P}<0.05$ vs baseline

Figura 5 - Parâmetros Hemodinâmicos Evolutivos dos grupos durante 0 estudo 
Painel A - Conteúdo Arterial de Oxigênio $\left(\mathrm{CaO}_{2}\right)(\mathrm{mL} / \mathrm{dL})$

Perfis individuais de cada animal por grupo
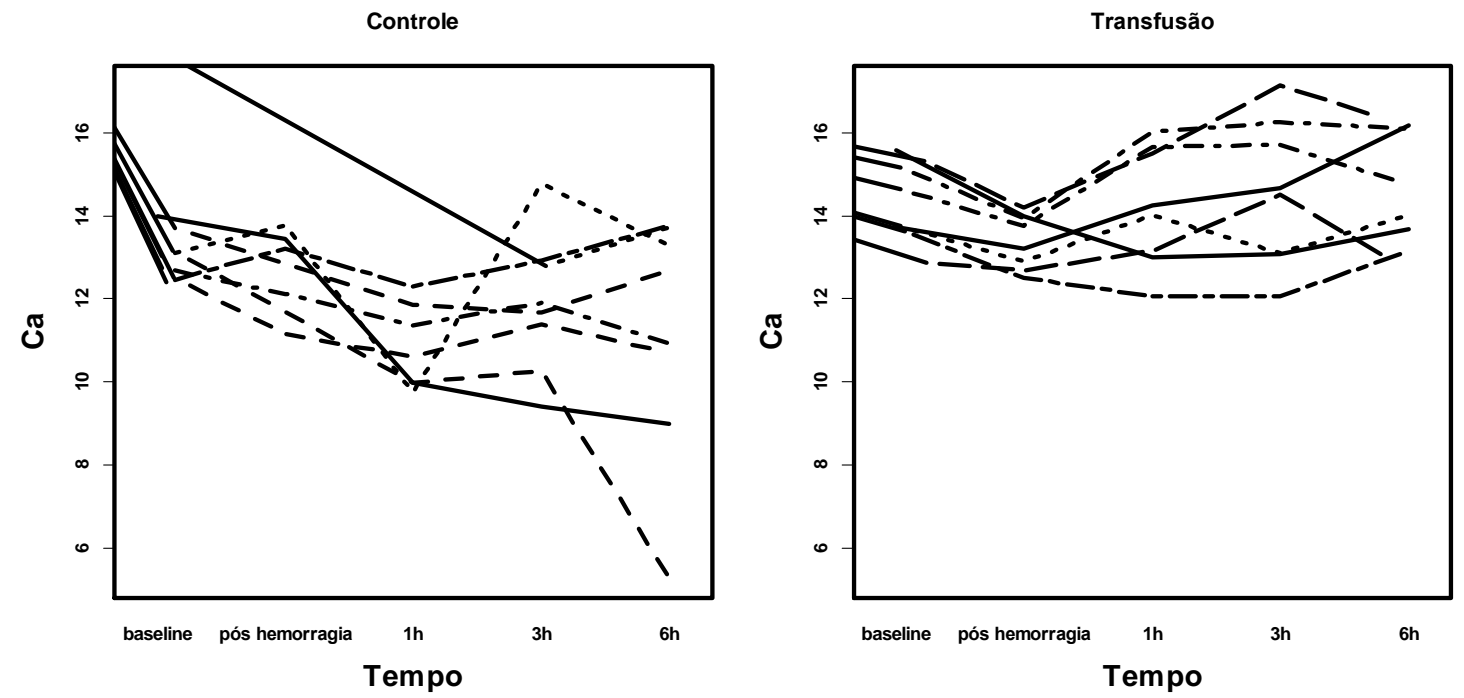

Efeito Relativo de Tratamento (RTE)

\section{Conteúdo arterial de oxigênio $(\mathrm{mL} / \mathrm{dL})$}

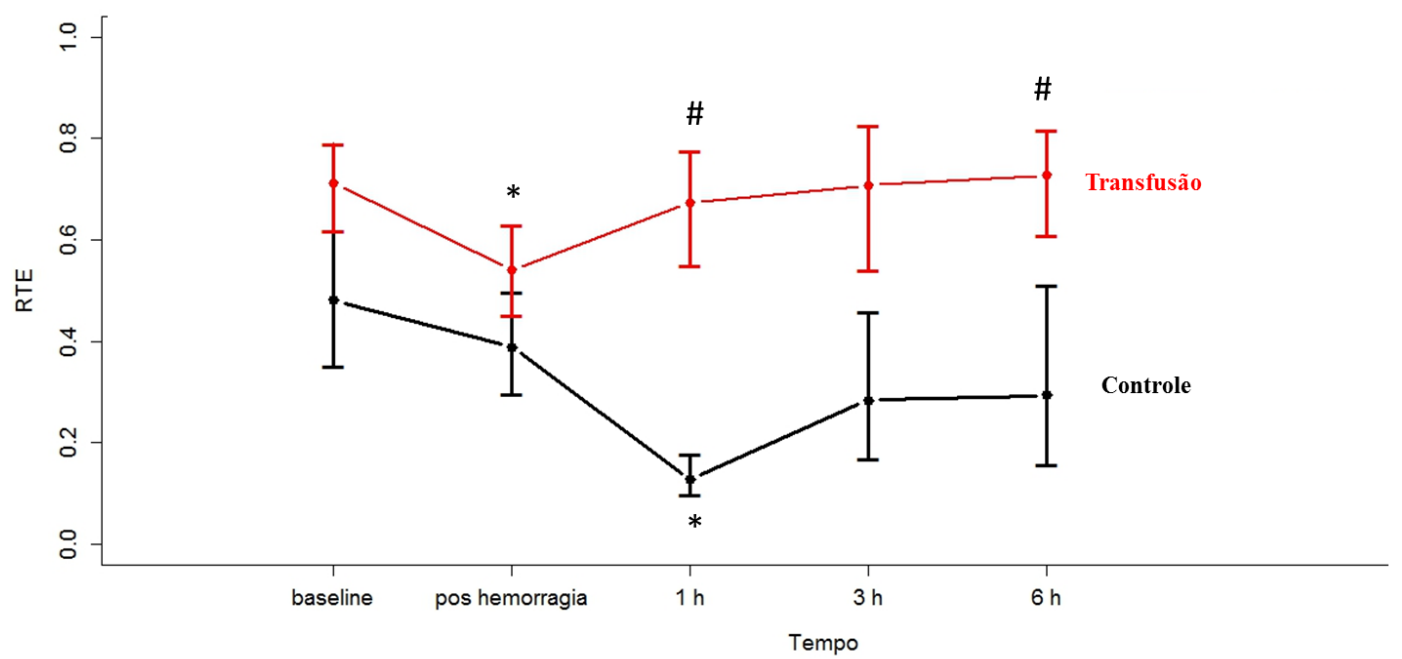

* $\mathrm{P}<0.05$ vs baseline $\quad$ \# $\mathrm{P}<0.05$ vs controle 
Painel B - Hemoglobina ( $\mathrm{g} / \mathrm{dl})$

Perfis individuais de cada animal por grupo
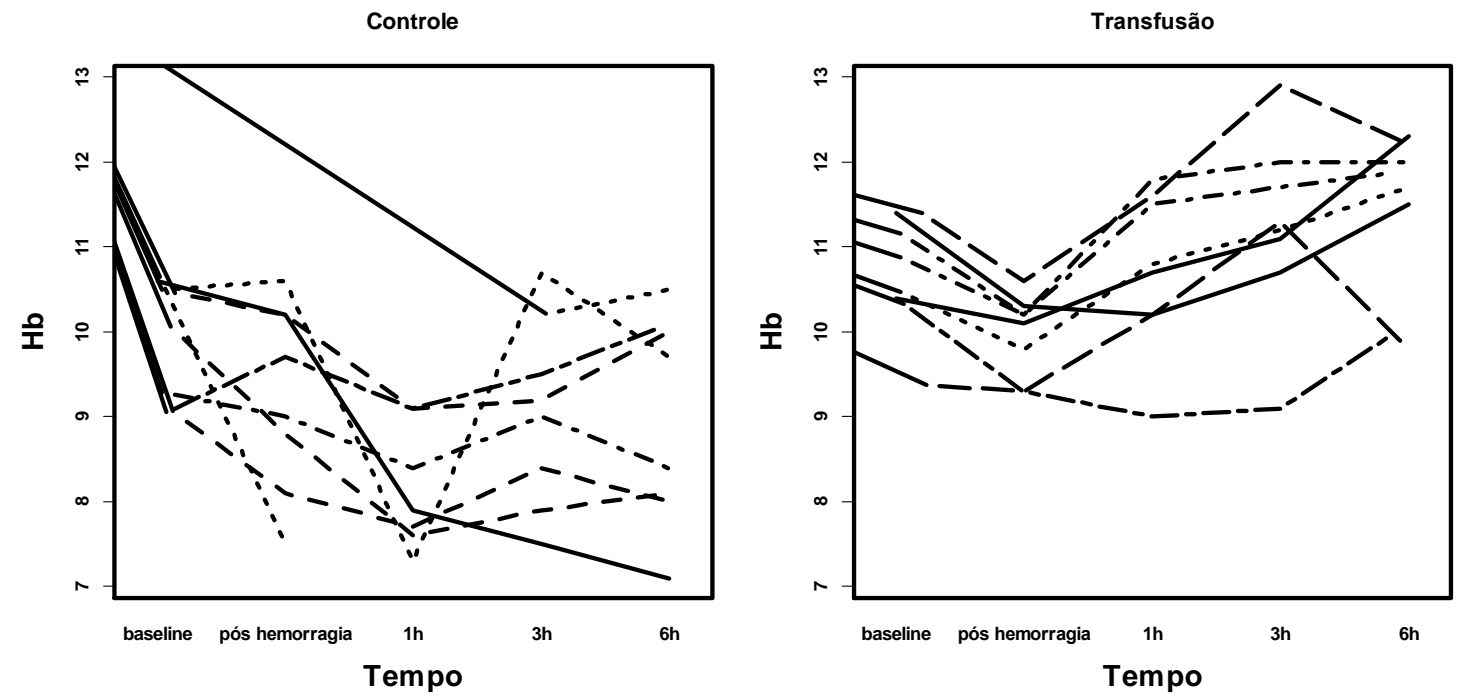

Efeito Relativo de Tratamento (RTE)

\section{Hemoglobina (g/dL)}

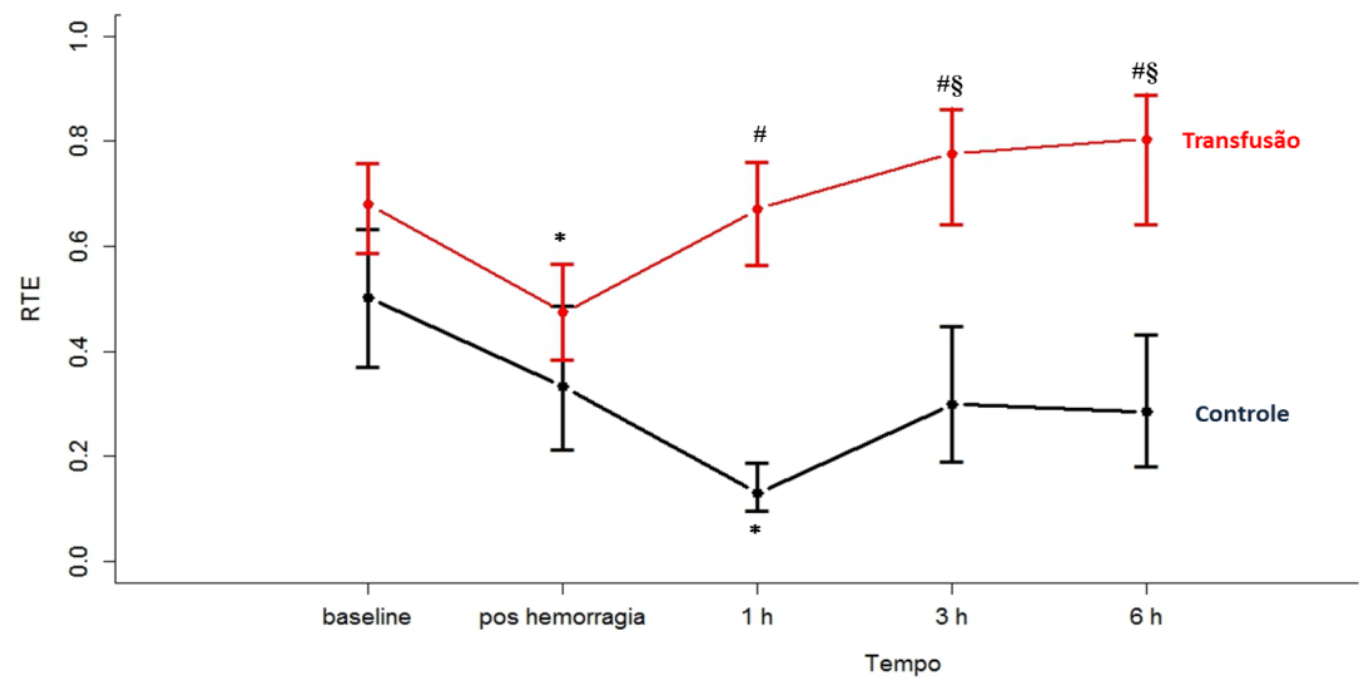

* $\mathrm{P}<0.05$ vs baseline $\quad{ }^{\S} \mathrm{P}<0.05$ vs hemorragia $\quad$ \# $\mathrm{P}<0.05$ vs controle 
Painel C - Hematócrito (\%)

Perfis individuais de cada animal por grupo
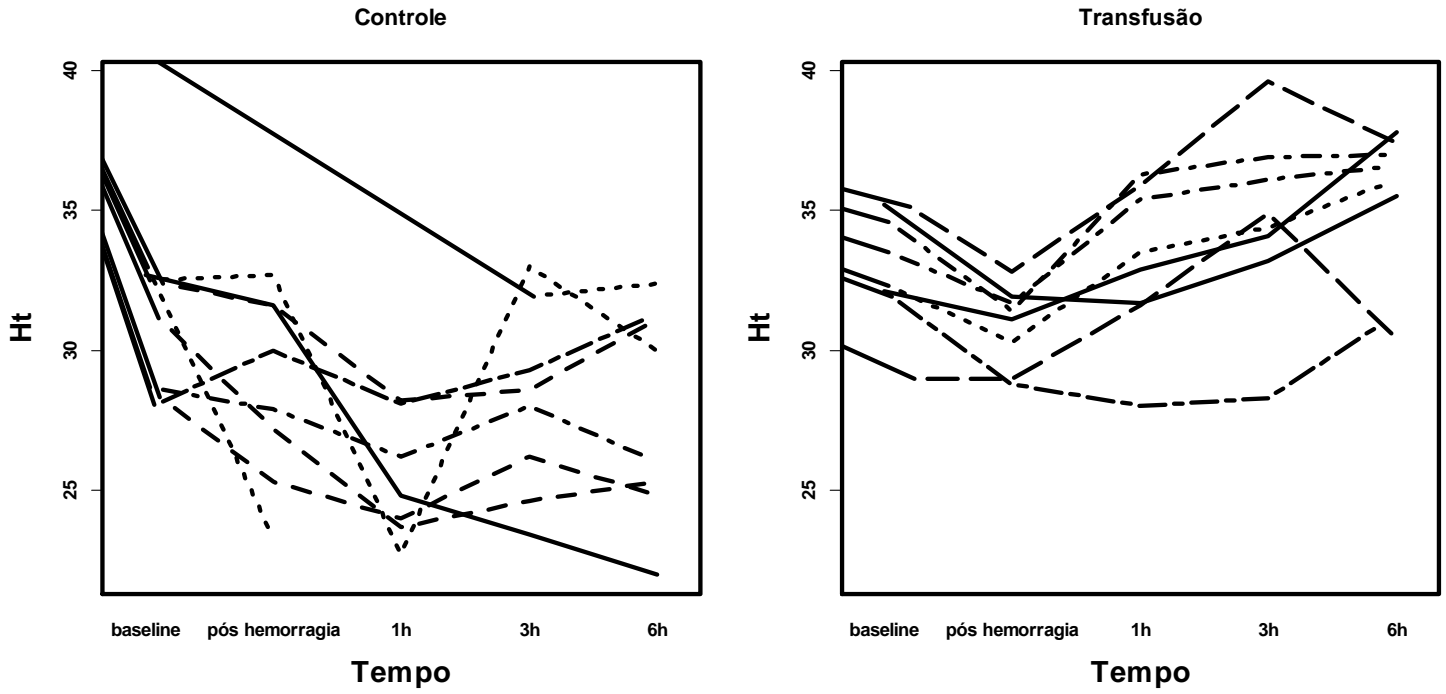

Efeito Relativo de Tratamento (RTE)

\section{Hematócrito (\%)}

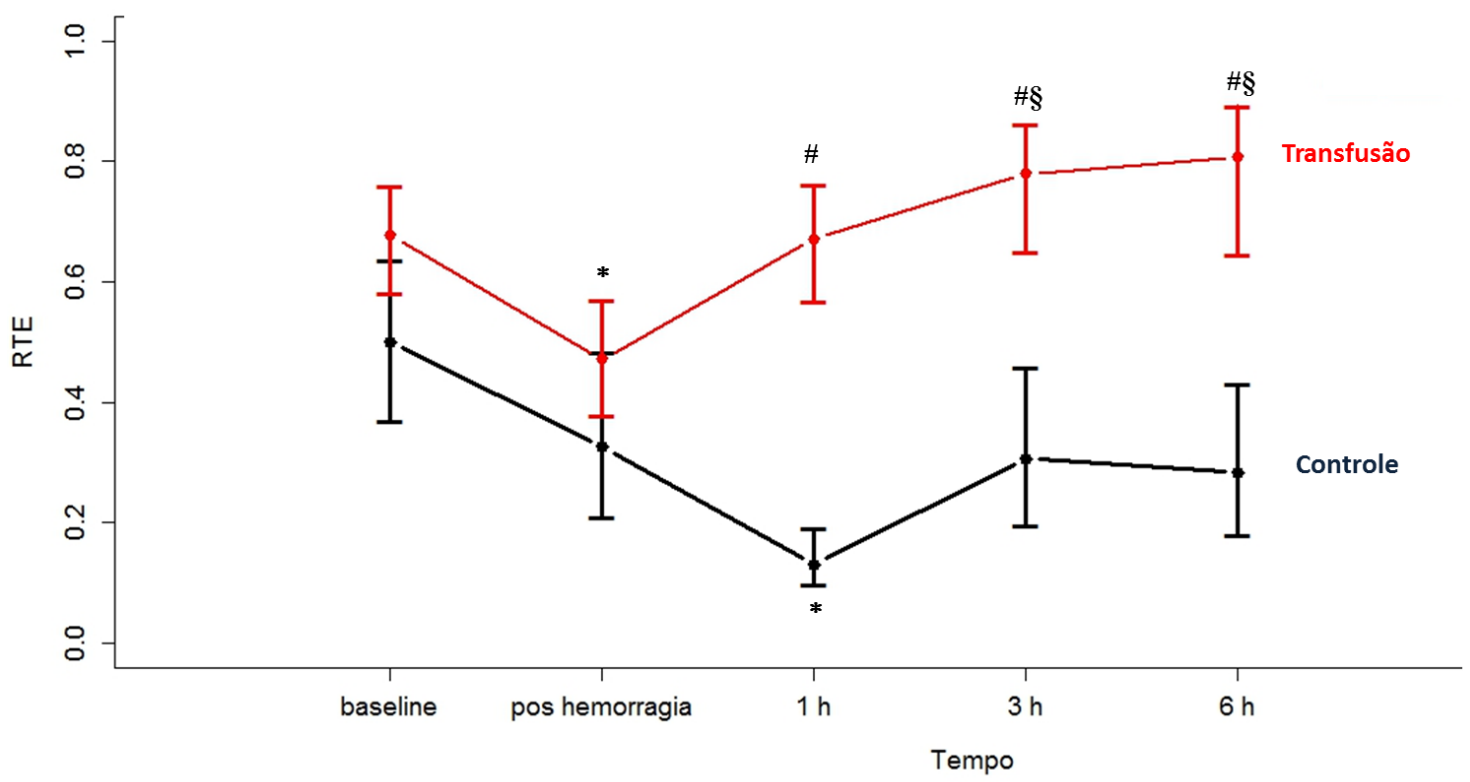

* $\mathrm{P}<0.05$ vs baseline $\quad{ }^{\S} \mathrm{P}<0.05$ vs hemorragia $\quad{ }^{\#} \mathrm{P}<0.05$ vs controle 
Painel D - Unidades de Microcirculação Perfundidas (UMcP)

Perfis individuais de cada animal por grupo
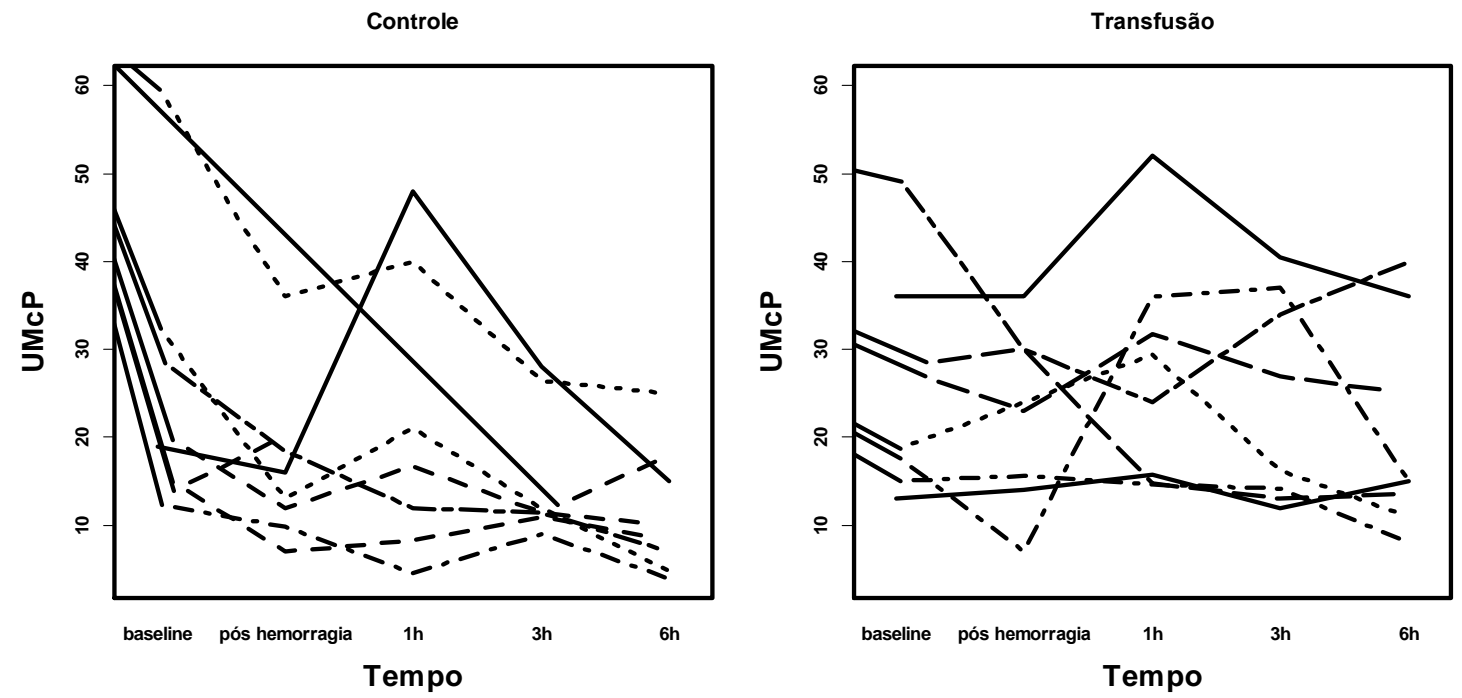

Efeito Relativo de Tratamento (RTE)

Unidades de Microcirculação Perfundidas (UMcP)

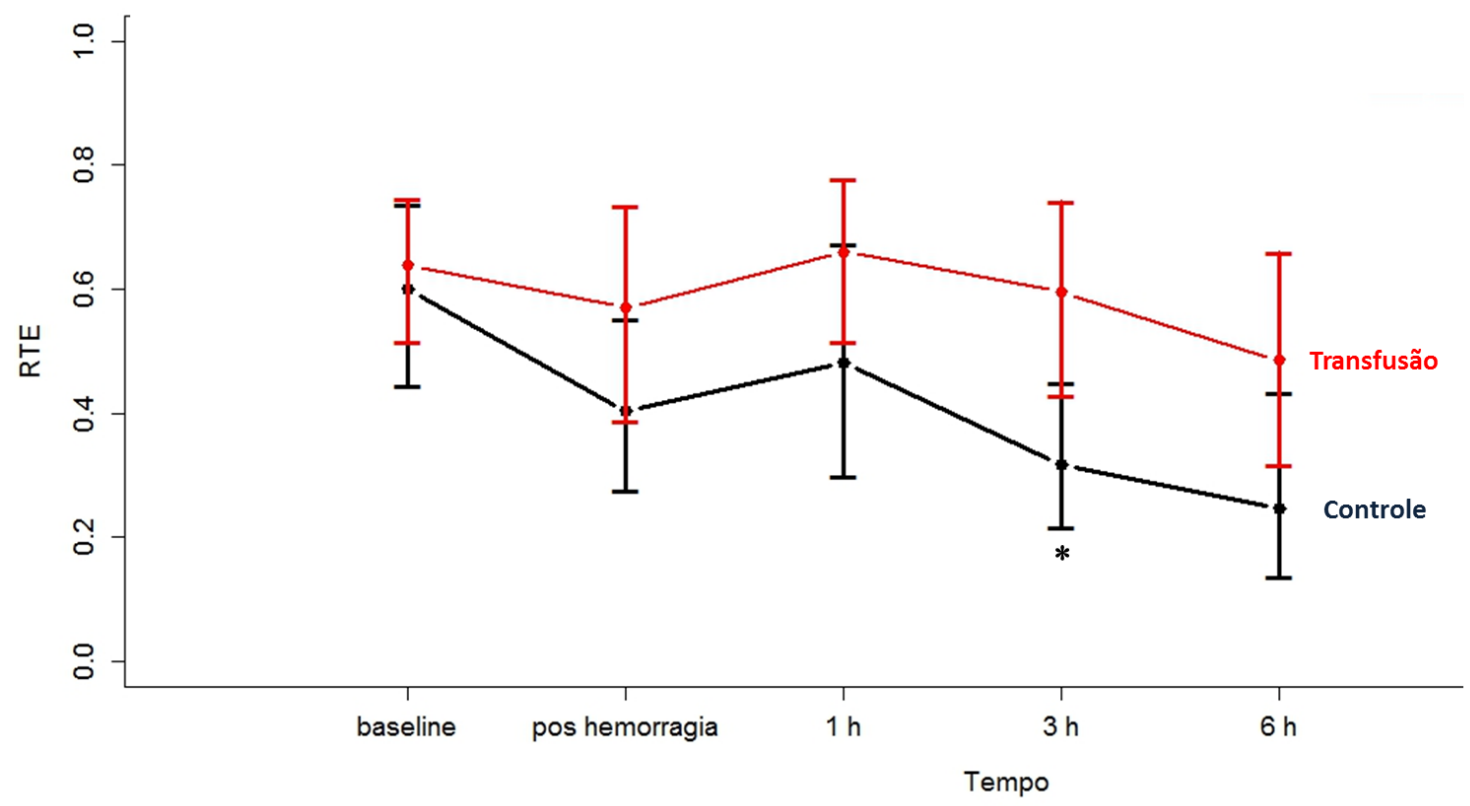


Painel E - Lactato (mEq/L)

Perfis individuais de cada animal por grupo
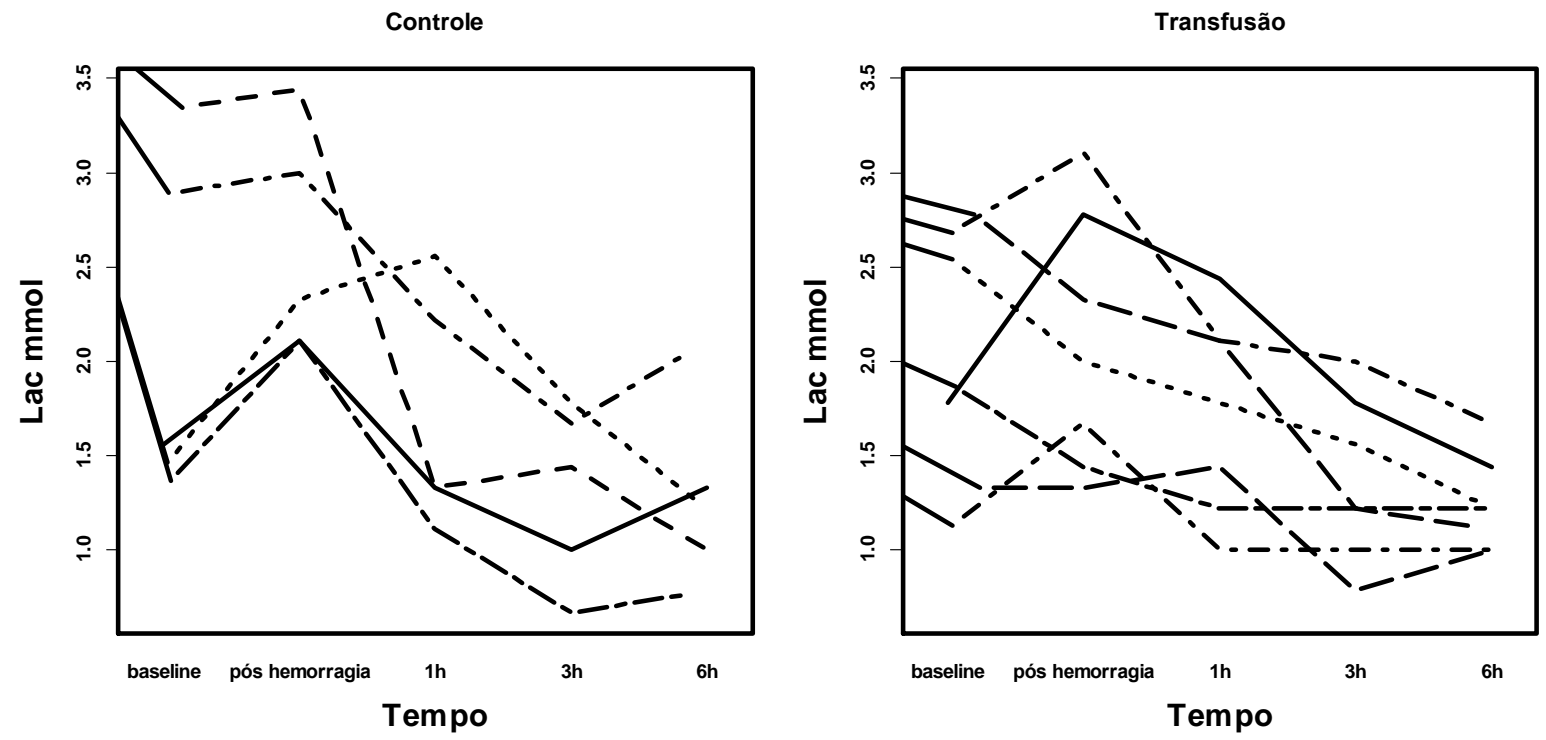

Efeito Relativo de Tratamento (RTE)

\section{Lactato(mEq/L)}

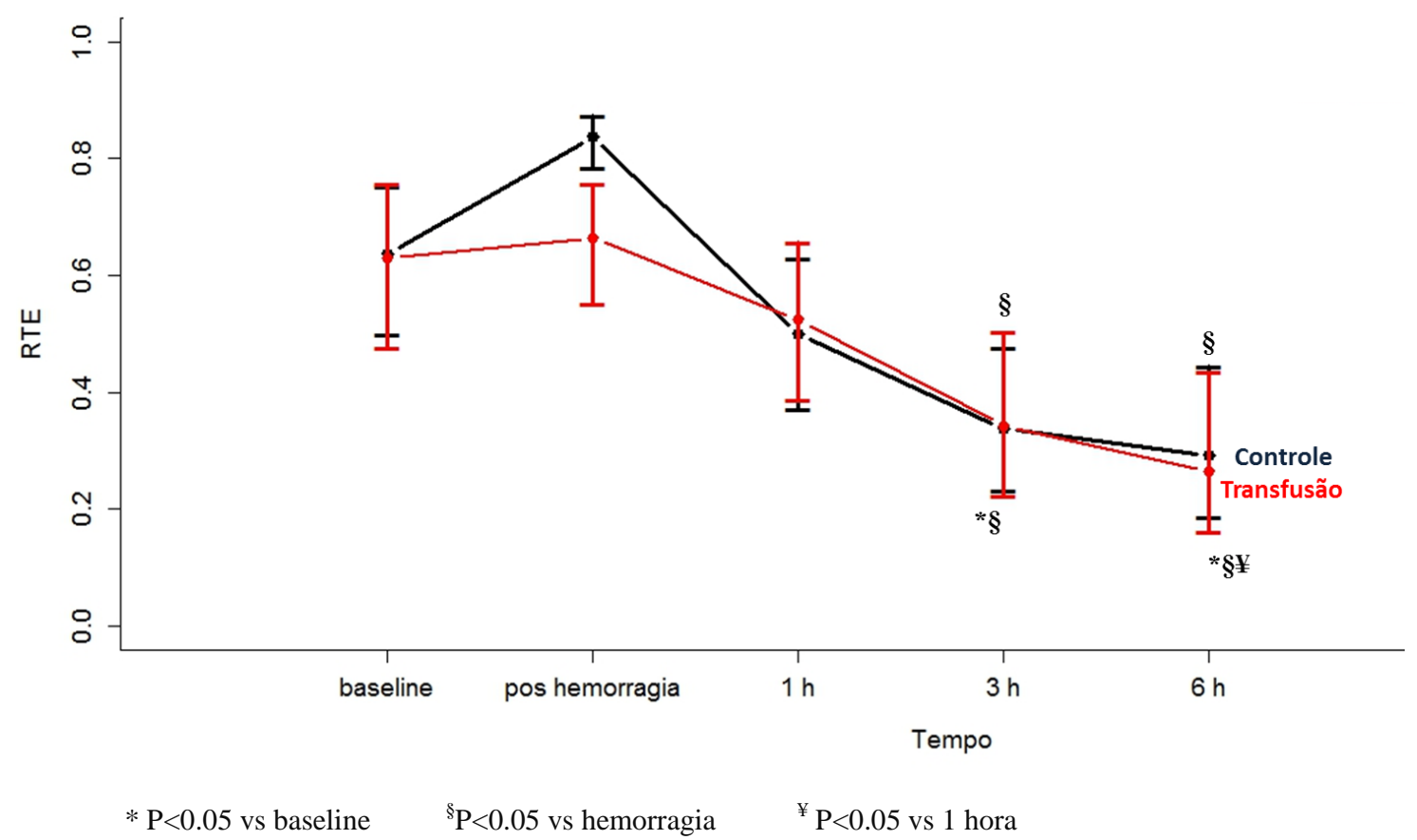

Figura 6 - Parâmetros de Oxigenação e Perfusão Tissular evolutivos dos grupos durante o estudo 
Tabela 8 - Variáveis Hemodinâmicas e Laboratoriais dos Grupos Durante o Período do Estudo

\begin{tabular}{|c|c|c|c|c|c|c|c|}
\hline Variável & Grupo & Baseline & $\begin{array}{c}\text { Hemorragia } \\
\text { Controlada }\end{array}$ & $\begin{array}{c}1 \text { hora } \\
\text { ressuscitação }\end{array}$ & $\begin{array}{c}3 \text { horas } \\
\text { ressuscitação }\end{array}$ & $\begin{array}{c}6 \text { horas } \\
\text { ressuscitação }\end{array}$ & Valor de p \\
\hline FC (bpm) & $\begin{array}{c}\text { Transfusão } \\
\text { Controle }\end{array}$ & $\begin{array}{l}112 \pm 16 \\
109 \pm 27\end{array}$ & $\begin{array}{l}118 \pm 18 \\
134 \pm 33\end{array}$ & $\begin{array}{l}115 \pm 12 \\
131 \pm 30\end{array}$ & $\begin{array}{l}119 \pm 12 \\
141 \pm 31\end{array}$ & $\begin{array}{l}124 \pm 14 \\
135 \pm 24\end{array}$ & $\begin{array}{l}0,006^{\text {I }} \\
0,269^{\&}\end{array}$ \\
\hline PAM (mm Hg) & $\begin{array}{c}\text { Transfusão } \\
\text { Controle }\end{array}$ & $\begin{array}{l}133 \pm 16 \\
126 \pm 14\end{array}$ & $\begin{array}{l}91 \pm 18^{*} \\
102 \pm 11^{*}\end{array}$ & $\begin{array}{l}131 \pm 10^{\S} \\
120 \pm 22^{\S}\end{array}$ & $\begin{array}{l}123 \pm 10 \\
113 \pm 13^{* \S}\end{array}$ & $\begin{array}{l}116 \pm 11^{¥} \\
104 \pm 14^{*}\end{array}$ & $\begin{array}{l}0,001^{\mathbb{I}} \\
0,156^{\&}\end{array}$ \\
\hline$\Delta \operatorname{VS}(\%)$ & $\begin{array}{c}\text { Transfusão } \\
\text { Controle }\end{array}$ & $\begin{array}{l}15 \pm 5 \\
15 \pm 4\end{array}$ & $\begin{array}{l}24 \pm 4^{*} \\
22 \pm 4^{*}\end{array}$ & $\begin{array}{l}23 \pm 5^{*} \\
20 \pm 6\end{array}$ & $\begin{array}{l}21 \pm 1^{*} \\
17 \pm 5\end{array}$ & $\begin{array}{l}21 \pm 5 \\
18 \pm 5\end{array}$ & $\begin{array}{r}<0,001^{\mathbb{\Phi}} \\
0,037^{\&}\end{array}$ \\
\hline Fração Ejeção Global & $\begin{array}{c}\text { Transfusão } \\
\text { Controle }\end{array}$ & $\begin{array}{l}32 \pm 4 \\
30 \pm 5\end{array}$ & $\begin{array}{l}25 \pm 5^{\S} \\
23 \pm 4\end{array}$ & $\begin{array}{l}33 \pm 6 \\
32 \pm 5^{\S}\end{array}$ & $\begin{array}{l}31 \pm 3^{\S} \\
32 \pm 3^{\S}\end{array}$ & $\begin{array}{l}28 \pm 7 \\
28 \pm 3^{* \S}\end{array}$ & $\begin{array}{r}<0,001^{\mathbb{I}} \\
0,284^{\&}\end{array}$ \\
\hline VDFGI & $\begin{array}{c}\text { Transfusão } \\
\text { Controle }\end{array}$ & $\begin{array}{l}557 \pm 99 \\
630 \pm 139\end{array}$ & $\begin{array}{l}449 \pm 87 \\
507 \pm 148^{*}\end{array}$ & $\begin{array}{l}512 \pm 60 \\
552 \pm 131\end{array}$ & $\begin{array}{l}504 \pm 79 \\
530 \pm 119^{*}\end{array}$ & $\begin{array}{l}499 \pm 44,3 \\
529 \pm 131\end{array}$ & $\begin{array}{c}<0,001^{\mathbb{I}} \\
0,165^{\&}\end{array}$ \\
\hline PAPO (mm Hg) & $\begin{array}{c}\text { Transfusão } \\
\text { Controle }\end{array}$ & $\begin{array}{l}8 \pm 4 \\
7 \pm 2\end{array}$ & $\begin{array}{l}7 \pm 4 \\
5 \pm 2\end{array}$ & $\begin{array}{l}9 \pm 3 \\
8 \pm 3\end{array}$ & $\begin{array}{l}8 \pm 3 \\
7 \pm 2\end{array}$ & $\begin{array}{l}8 \pm 4 \\
7 \pm 4\end{array}$ & $\begin{array}{l}0,030^{\text {I }} \\
0,394^{\&}\end{array}$ \\
\hline
\end{tabular}


Tabela 8 - Variáveis Hemodinâmicas e Laboratoriais dos Grupos Durante o Período do Estudo (Continuação)

\begin{tabular}{|c|c|c|c|c|c|c|c|}
\hline Variável & Grupo & Baseline & $\begin{array}{c}\text { Hemorragia } \\
\text { Controlada }\end{array}$ & $\begin{array}{l}1 \text { hora } \\
\text { ressuscitação }\end{array}$ & $\begin{array}{l}3 \text { horas } \\
\text { ressuscitação }\end{array}$ & $\begin{array}{l}6 \text { horas } \\
\text { ressuscitação }\end{array}$ & Valor de $p$ \\
\hline \multirow{2}{*}{$\begin{array}{c}\text { RVSI } \\
{\left[\text { dynas. }^{-1} \cdot\left(\mathrm{cm} 5^{-1} \cdot \mathrm{kg}^{-1}\right]\right.}\end{array}$} & Transfusão & $101 \pm 32$ & $110 \pm 31$ & $115 \pm 30$ & $98 \pm 17$ & $99 \pm 22^{\#}$ & $0,003^{\mathbb{\pi}}$ \\
\hline & Controle & $90 \pm 25$ & $101 \pm 33$ & $87 \pm 26$ & $77 \pm 18^{\S}$ & $69 \pm 18^{* \$ \sharp}$ & $0,05^{\&}$ \\
\hline \multirow{2}{*}{$\begin{array}{c}\text { ITSVE } \\
[(\mathrm{mL} \cdot \mathrm{mm} \mathrm{Hg}) / \mathrm{kg} \cdot \text { bat })]\end{array}$} & Transfusão & $1,6 \pm 0,3$ & $0,6 \pm 0,2^{*}$ & $1,3 \pm 0,2^{* \S}$ & $1,3 \pm 0,1^{* \S}$ & $1,1 \pm 0,2^{* \S}$ & $<0.001^{\mathbb{\pi}}$ \\
\hline & Controle & $1,7 \pm 0,3$ & $0,8 \pm 0,3^{*}$ & $1,3 \pm 0,4^{\S}$ & $1,2 \pm 0,2^{* \S}$ & $1,2 \pm 0,2^{* \S}$ & $0,417^{\&}$ \\
\hline \multirow[t]{2}{*}{ PAPm } & Transfusão & $26 \pm 3$ & $17 \pm 7^{*}$ & $25 \pm 5$ & $27 \pm 8^{\S}$ & $27 \pm 6^{\S}$ & $0,001^{\mathbb{I}}$ \\
\hline & Controle & $26 \pm 6$ & $19 \pm 5$ & $23 \pm 4$ & $26 \pm 8$ & $22 \pm 7$ & $0,571^{\&}$ \\
\hline \multirow[t]{2}{*}{ PVC (mm Hg) } & Transfusão & $7 \pm 2$ & $5 \pm 2^{*}$ & $6 \pm 1^{\S}$ & $7 \pm 2^{\S}$ & $7 \pm 2^{\S}$ & $<0,001^{\mathbb{\Psi}}$ \\
\hline & Controle & $5 \pm 2$ & $3 \pm 2^{*}$ & $5 \pm 2^{\S}$ & $5 \pm 2^{\S}$ & $5 \pm 2^{\S}$ & $0,062^{\&}$ \\
\hline$\frac{\text { RVPI }}{\left[\operatorname{dynas}^{-1} \cdot\left(\mathrm{cm}^{5}\right)^{-1} \cdot \mathrm{kg}^{-1}\right]}$ & $\begin{array}{c}\text { Transfusão } \\
\text { Controle }\end{array}$ & $\begin{array}{l}13 \pm 3 \\
13 \pm 5\end{array}$ & $\begin{array}{l}12 \pm 6 \\
14 \pm 7\end{array}$ & $\begin{array}{l}14 \pm 3 \\
11 \pm 4\end{array}$ & $\begin{array}{l}15 \pm 7 \\
14 \pm 9\end{array}$ & $\begin{array}{l}17 \pm 2 \\
10 \pm 5\end{array}$ & $\begin{array}{l}0,587^{\pi} \\
0,168^{\text {\& }}\end{array}$ \\
\hline
\end{tabular}


Tabela 8 - Variáveis Hemodinâmicas e Laboratoriais dos Grupos Durante o Período do Estudo (Continuação)

\begin{tabular}{|c|c|c|c|c|c|c|c|}
\hline Variável & Grupo & Baseline & $\begin{array}{c}\text { Hemorragia } \\
\text { Controlada } \\
\end{array}$ & $\begin{array}{c}1 \text { hora } \\
\text { ressuscitação }\end{array}$ & $\begin{array}{l}3 \text { horas } \\
\text { ressuscitação }\end{array}$ & $\begin{array}{c}6 \text { horas } \\
\text { ressuscitação }\end{array}$ & Valor de p \\
\hline \multirow{2}{*}{$\begin{array}{c}\text { ITSVD } \\
[(\mathrm{mL} . \mathrm{mm} \mathrm{Hg}) / \mathrm{kg} . \text { bat. })]\end{array}$} & Transfusão & $0,25 \pm 0,08$ & $0,09 \pm 0,06^{*}$ & $0,20 \pm 0,07^{\S}$ & $0,23 \pm 0,09^{\S}$ & $0,21 \pm 0,09^{\S}$ & $<0,001^{\mathbb{I}}$ \\
\hline & Controle & $0,29 \pm 0,05$ & $0,14 \pm 0,05^{*}$ & $0,23 \pm 0,07^{\S}$ & $0,25 \pm 0,03^{\S}$ & $0,20 \pm 0,04^{*}$ & $0,209^{\&}$ \\
\hline \multirow[t]{2}{*}{$\mathrm{SVO}_{2}$} & Transfusão & $67,8 \pm 3,2$ & $53,5 \pm 5,4^{*}$ & $68,4 \pm 7,6^{\# \S}$ & $66,8 \pm 5,6^{\S}$ & $63,8 \pm 6,5^{\S}$ & $<0,001^{\text {I }}$ \\
\hline & Controle & $61,1 \pm 6,8$ & $50,9 \pm 8$ & $51,7 \pm 9,6^{*}$ & $57,7 \pm 7,4^{\S}$ & $53,4 \pm 11,8$ & $<0,001^{\&}$ \\
\hline \multirow{2}{*}{$\begin{array}{l}\text { Fluxo urinário } \\
\text { (mL/kg/h) }\end{array}$} & Transfusão & $1,7 \pm 0.9$ & $0,7 \pm 0.6$ & $2,3 \pm 0.9^{\S}$ & $2,4 \pm 1.7^{\S}$ & $1,8 \pm 0.8^{\S}$ & $0,001^{\text {f }}$ \\
\hline & Controle & $3,4 \pm 1.7$ & $1,5 \pm 0.9^{*}$ & $3,0 \pm 2.1$ & $2,6 \pm 1.7$ & $1,9 \pm 0.9$ & $0,128^{\&}$ \\
\hline \multirow[t]{2}{*}{ Balanço hídrico cumulativo (mL/Kg) } & Transfusão & $20 \pm 6$ & - & $28 \pm 7^{* \#}$ & $37 \pm 6^{* \# ¥}$ & $46 \pm 6^{*} €$ & $<0,001^{\text {It }}$ \\
\hline & Controle & $20 \pm 3$ & - & $43 \pm 4^{*}$ & $50 \pm 8^{* ¥}$ & $59 \pm 11^{* ¥ €}$ & $<0,001^{\&}$ \\
\hline \multirow{2}{*}{$\begin{array}{l}\text { Lactato } \\
(\mathbf{m E q} / \mathbf{L})\end{array}$} & Transfusão & $2,0 \pm 0,7$ & $2,1 \pm 0.7$ & $1,7 \pm 0,5^{*}$ & $1,4 \pm 0,4^{* \S}$ & $1,2 \pm 0,2^{* \S}$ & $<0,001^{\mathbb{I}}$ \\
\hline & Controle & $2,1 \pm 0.9$ & $2,6 \pm 0.6$ & $1,7 \pm 0,6$ & $1,3 \pm 0,5^{\S}$ & $1,3 \pm 0,5^{\S}$ & $0,767^{\&}$ \\
\hline
\end{tabular}


Tabela 8 - Variáveis Hemodinâmicas e Laboratoriais dos Grupos Durante o Período do Estudo (Continuação)

\begin{tabular}{|c|c|c|c|c|c|c|c|}
\hline Variável & Grupo & Baseline & $\begin{array}{c}\text { Hemorragia } \\
\text { Controlada }\end{array}$ & $\begin{array}{c}1 \text { hora } \\
\text { ressuscitação }\end{array}$ & $\begin{array}{c}3 \text { horas } \\
\text { ressuscitação }\end{array}$ & $\begin{array}{c}6 \text { horas } \\
\text { ressuscitação }\end{array}$ & Valor de p \\
\hline $\begin{array}{c}\mathrm{BE} \\
(\mathrm{mEq} / \mathrm{L})\end{array}$ & $\begin{array}{c}\text { Transfusão } \\
\text { Controle }\end{array}$ & $\begin{array}{l}4,1 \pm 3,6 \\
5,7 \pm 1,8\end{array}$ & $\begin{array}{l}1,5 \pm 4,3 \\
4,4 \pm 2,2^{*}\end{array}$ & $\begin{array}{l}3,8 \pm 2.6 \\
5,0 \pm 1,7\end{array}$ & $\begin{array}{l}3,9 \pm 3,2 \\
5,7 \pm 2,0\end{array}$ & $\begin{array}{l}4,3 \pm 2,7 \\
6,3 \pm 2,2^{\S}\end{array}$ & $\begin{array}{l}0,004^{\pi} \\
0,202^{\&}\end{array}$ \\
\hline pH & $\begin{array}{c}\text { Transfusão } \\
\text { Controle }\end{array}$ & $\begin{array}{l}7,48 \pm 0,05 \\
7,49 \pm 0.05\end{array}$ & $\begin{array}{l}7,46 \pm 0.05 \\
7,47 \pm 0.04\end{array}$ & $\begin{array}{l}7,47 \pm 0.04 \\
7,48 \pm 0.03\end{array}$ & $\begin{array}{l}7,46 \pm 0.05 \\
7,46 \pm 0.04\end{array}$ & $\begin{array}{l}7,47 \pm 0.05 \\
7,49 \pm 0.03\end{array}$ & $\begin{array}{l}0,357^{\mathbb{\pi}} \\
0,594^{\&}\end{array}$ \\
\hline Hematócrito & $\begin{array}{c}\text { Transfusão } \\
\text { Controle }\end{array}$ & $\begin{array}{l}33,1 \pm 2,2 \\
30,3 \pm 5,1\end{array}$ & $\begin{array}{l}30,9 \pm 1.4^{*} \\
23,1 \pm 4,2\end{array}$ & $\begin{array}{l}33,2 \pm 2,8^{\#} \\
31,5 \pm 5,2^{*}\end{array}$ & $\begin{array}{l}34,7 \pm 3,3^{\# \S} \\
31,5 \pm 3,01\end{array}$ & $\begin{array}{l}35,3 \pm 2,8^{\# \S} \\
28,1 \pm 2,9\end{array}$ & $\begin{array}{l}<0,001^{\mathbb{\Phi}} \\
<0,001^{\&}\end{array}$ \\
\hline \multirow[t]{2}{*}{ Hemoglobina } & Transfusão & $10,7 \pm 0,7$ & $9,9 \pm 0,5^{*}$ & $10,7 \pm 0,9^{\#}$ & $11,3 \pm 1,1^{\# \S}$ & $11,4 \pm 1,0^{\# \S}$ & $<0,001^{\&}$ \\
\hline & Controle & $10,0 \pm 0,7$ & $9,3 \pm 1.1$ & $7,1 \pm 0,7^{*}$ & $9,0 \pm 1,1$ & $9,0 \pm 1,2$ & $0,001^{\&}$ \\
\hline
\end{tabular}

Análise não paramétrica para dados com medidas repetidas ${ }^{\text {II }}$ efeito tempo; ${ }^{\&}$ efeito grupo;

Interação grupo X tempo: RVSI P = 0,037; RVPI p=0,032; Hb e HT p<0,001; Balanço hídrico cumulativo p <0,001

Analise post-hoc com correção de Bonferroni: ${ }^{*} \mathrm{P}<0.05$ vs baseline ${ }^{\S} \mathrm{P}<0.05$ vs hemorragia $\quad{ }^{\#} \mathrm{P}<0.05$ vs controle ${ }^{¥} \mathrm{P}<0.05$ vs 1 hora pós ressuscitação e ${ }^{€} \mathrm{P}<0.05$ vs 3 horas pós ressuscitação.

FC: Frequência cardíaca; PAM: Pressão arterial média; $\Delta$ VS: Variação de Volume Sistólico; VDFGI: Volume diastólico final global indexado; PAPO: Pressão artéria pulmonar ocluída; RVSI: Resistencia vascular sistêmica indexada; ITSVE: Índice de trabalho de ventrículo esquerdo; PAPm: Pressão de artéria pulmonar média; PVC: Pressão Venosa Central; RVPI: Resistência vascular pulmonar indexada; ITSVD : índice de trabalho de ventrículo direito; $\mathrm{SVO}_{2}$ : saturação venosa de oxigênio e BE: Excesso de base 


\subsubsection{Parâmetros Respiratórios}

Na tabela 9 e Figura 7, Painel A, B,C, D e E descrevemos os efeitos da transfusão de GV na função respiratória. Não houve diferença na relação $\mathrm{PaO}_{2} / \mathrm{FiO}_{2}$ entre os grupos. Não foi possível identificar qualquer efeito agudo significativo da transfusão de GV na função pulmonar nos diversos parâmetros avaliados.

Não foi também observado alteração na mecânica respiratória avaliada através da complacência estática e resistência respiratória entre os grupos estudados (Figura 7 Paínel D, E). Houve uma diminuição significativa da energia de histerese (Figura 7, Paínel G) $(p=0,002)$ no grupo transfusão quando comparado ao controle 6 horas após a ressuscitação (Tabela 9). Observamos ainda uma tendência à diminuição da energia inspiratória após a primeira hora da ressuscitação volêmica no grupo transfusão (Figura 7, Painel F). Não obsevamos diferença significativa na agua extravascular pulmonar durante os tempos e entre os grupos (Figura 7, Painel H). Interessantemente 0 grupo controle apresentou um aumento significativo no balanço hídrico cumulativo (Figura 7 Painel I) 1 e 3 horas após a ressuscitação normalizando 6 horas após a transfusão.

\subsubsection{Parâmetros Inflamatórios}

As concentrações plasmáticas das diversas citocinas avaliadas antes e após a transfusão de GV mostraram-se abaixo dos limites de detecção do teste ELISA na maioria dos animais estudados sugerindo ausência de inflamação 
sistêmica significativa. Na Figura 8 Painéis A - D encontram-se as concentrações de citocinas dosadas no tecido pulmonar. Novamente não foram encontradas diferenças entre os grupos transfundidos e não transfundidos. Observamos uma pequena diferença, mas estatisticamente significante entre os grupos transfundido e controle na quantificação do mRNA da iNOS ((oxido nítrico sintetase induzida) e IL-21 no tecido pulmonar, com o dobro de aumento no primeiro e um decréscimo de $50 \%$ no último no grupo transfundido (Figura $9)$.

A concentração de nitrato no plasma está demonstrada na figura 10 , Painel $\mathrm{A}$ e o único efeito observado encontrado foi uma modesta diminuição após 3 horas apenas no grupo transfundido (Figura 10, Painel B). 
Tabela 9 - Parâmetros Respiratórios dos Grupos durante o Período do Estudo

\begin{tabular}{|c|c|c|c|c|c|c|c|}
\hline Variável & Grupo & Baseline & $\begin{array}{c}\text { Hemorragia } \\
\text { Controlada }\end{array}$ & $\begin{array}{c}1 \text { hora } \\
\text { ressuscitação }\end{array}$ & $\begin{array}{c}3 \text { horas } \\
\text { ressuscitação }\end{array}$ & $\begin{array}{c}6 \text { horas } \\
\text { ressuscitação }\end{array}$ & $\begin{array}{c}\text { Valor de } \\
\qquad p\end{array}$ \\
\hline $\begin{array}{c}\mathrm{PaO}_{2} \\
(\mathrm{~mm} \mathrm{Hg})\end{array}$ & $\begin{array}{c}\text { Transfusão } \\
\text { Controle }\end{array}$ & $\begin{array}{l}94 \pm 14 \\
90 \pm 15\end{array}$ & $\begin{array}{l}94 \pm 12 \\
87 \pm 14\end{array}$ & $\begin{array}{l}83 \pm 15 \\
85 \pm 14\end{array}$ & $\begin{array}{c}78 \pm 17^{\S ¥} \\
86 \pm 24\end{array}$ & $\begin{array}{l}73 \pm 13^{\star \S} \\
77 \pm 26\end{array}$ & $\begin{array}{l}0.011^{\text {II }} \\
0.974^{\&}\end{array}$ \\
\hline $\mathrm{FiO}_{2}$ & $\begin{array}{c}\text { Transfusão } \\
\text { Controle }\end{array}$ & $\begin{array}{l}0.25 \pm 0.03 \\
0.26 \pm 0.03\end{array}$ & $\begin{array}{l}0.25 \pm 0.02 \\
0.26 \pm 0.03\end{array}$ & $\begin{array}{c}0.26 \pm 0.02 \\
0.3 \pm 0.08\end{array}$ & $\begin{array}{l}0.27 \pm 0.04 \\
0.33 \pm 0.12\end{array}$ & $\begin{array}{r}0.35 \pm 0.26 \\
0.31 \pm 0.07\end{array}$ & $\begin{array}{l}0.006^{\mathrm{I}} \\
0.213^{\&}\end{array}$ \\
\hline $\mathrm{PaO}_{2} / \mathrm{FiO}_{2}$ & $\begin{array}{c}\text { Transfusão } \\
\text { Controle }\end{array}$ & $\begin{array}{l}381 \pm 44 \\
344 \pm 70\end{array}$ & $\begin{array}{l}373 \pm 31 \\
332 \pm 80\end{array}$ & $\begin{array}{c}317 \pm 49^{\S} \\
293 \pm 78\end{array}$ & $\begin{array}{c}289 \pm 69^{*} ¥ ¥ \\
269 \pm 65^{\S}\end{array}$ & $\begin{array}{l}255 \pm 86^{*} \S \\
248 \pm 74^{\pi \S}\end{array}$ & $\begin{array}{l}<0,001^{\text {II }} \\
0,232^{\&}\end{array}$ \\
\hline $\begin{array}{c}\mathrm{PaCO}_{2} \\
(\mathrm{~mm} \mathrm{Hg})\end{array}$ & $\begin{array}{c}\text { Transfusão } \\
\text { Controle }\end{array}$ & $\begin{array}{l}37 \pm 6 \\
38 \pm 8\end{array}$ & $\begin{array}{l}35 \pm 4 \\
38 \pm 2\end{array}$ & $\begin{array}{l}37 \pm 4 \\
38 \pm 5\end{array}$ & $\begin{array}{l}39 \pm 3 \\
42 \pm 4\end{array}$ & $\begin{array}{l}39 \pm 4 \\
39 \pm 4\end{array}$ & $\begin{array}{l}0.081^{\mathbb{q}} \\
0.196^{\&}\end{array}$ \\
\hline $\begin{array}{c}\mathrm{CO}_{2} \text { expirado } \\
(\mathrm{mm} \mathrm{Hg})\end{array}$ & $\begin{array}{c}\text { Transfusão } \\
\text { Controle }\end{array}$ & $\begin{array}{l}34 \pm 4 \\
39 \pm 3\end{array}$ & $\begin{array}{l}34 \pm 5 \\
38 \pm 3\end{array}$ & $\begin{array}{l}36 \pm 3 \\
37 \pm 5\end{array}$ & $\begin{array}{l}38 \pm 2 \\
39 \pm 2\end{array}$ & $\begin{array}{l}38 \pm 3 \\
37 \pm 6\end{array}$ & $\begin{array}{l}0.123^{\text {II }} \\
0.084^{\&}\end{array}$ \\
\hline $\begin{array}{c}\text { Frequência } \\
\text { Respiratória (rpm) }\end{array}$ & $\begin{array}{c}\text { Transfusão } \\
\text { Controle }\end{array}$ & $\begin{array}{l}16 \pm 2 \\
17 \pm 4\end{array}$ & $\begin{array}{l}16 \pm 2 \\
18 \pm 3\end{array}$ & $\begin{array}{l}15 \pm 2 \\
18 \pm 3\end{array}$ & $\begin{array}{l}15 \pm 2 \\
17 \pm 3\end{array}$ & $\begin{array}{l}15 \pm 2 \\
17 \pm 2\end{array}$ & $\begin{array}{l}0.204^{\mathbb{q}} \\
0.291^{\&}\end{array}$ \\
\hline Ppi $\left(\mathrm{cmH}_{2} \mathrm{O}\right)$ & $\begin{array}{c}\text { Transfusão } \\
\text { Controle }\end{array}$ & $\begin{array}{l}21 \pm 1 \\
25 \pm 5\end{array}$ & $\begin{array}{l}20 \pm 2 \\
23 \pm 5\end{array}$ & $\begin{array}{l}22 \pm 4 \\
24 \pm 4\end{array}$ & $\begin{array}{c}25 \pm 7^{\S ¥} \\
26 \pm 7\end{array}$ & $\begin{array}{l}26 \pm 8^{\S} \\
27 \pm 5\end{array}$ & $\begin{array}{l}0.001^{\mathrm{g}} \\
0.229^{\&}\end{array}$ \\
\hline Pplatô $\left(\mathrm{cmH}_{2} \mathrm{O}\right)$ & $\begin{array}{c}\text { Transfusão } \\
\text { Controle }\end{array}$ & $\begin{array}{l}18 \pm 1 \\
18 \pm 4\end{array}$ & $\begin{array}{l}17 \pm 2 \\
18 \pm 4\end{array}$ & $\begin{array}{l}18 \pm 4 \\
18 \pm 3\end{array}$ & $\begin{array}{l}19 \pm 5^{\ddagger} \\
20 \pm 4\end{array}$ & $\begin{array}{l}20 \pm 6^{\ddagger} \\
20 \pm 4\end{array}$ & $\begin{array}{l}0.015^{\text {I }} \\
0,831^{\&}\end{array}$ \\
\hline
\end{tabular}


Tabela 9 - Parâmetros Respiratórios dos Grupos durante o Período do Estudo (Continuação)

\begin{tabular}{|c|c|c|c|c|c|c|c|}
\hline Variável & Grupo & Baseline & $\begin{array}{c}\text { Hemorragia } \\
\text { Controlada }\end{array}$ & $\begin{array}{c}1 \text { hora } \\
\text { ressuscitação }\end{array}$ & $\begin{array}{l}3 \text { horas } \\
\text { ressuscitação }\end{array}$ & $\begin{array}{l}6 \text { horas } \\
\text { ressuscitação }\end{array}$ & $\begin{array}{c}\text { Valor de } \\
\mathbf{p}\end{array}$ \\
\hline $\begin{array}{l}\text { Pressão Média } \\
\quad\left(\mathrm{cmH}_{2} \mathrm{O}\right)\end{array}$ & $\begin{array}{l}\text { Transfusão } \\
\text { Controle }\end{array}$ & $\begin{array}{l}10 \pm 0.4 \\
11 \pm 1,6\end{array}$ & $\begin{array}{l}10 \pm 0.5 \\
11 \pm 1,7\end{array}$ & $\begin{array}{c}10 \pm 1 \\
11 \pm 1,4\end{array}$ & $\begin{array}{l}10 \pm 1,6 \\
11 \pm 1,6\end{array}$ & $\begin{array}{c}11 \pm 2,7 \\
12 \pm 1\end{array}$ & $\begin{array}{l}0.036^{\pi} \\
0.065^{\text {\& }}\end{array}$ \\
\hline $\begin{array}{c}\text { Complacência } \\
\text { estática } \\
\left(\mathbf{m L} \cdot \mathbf{m m ~ H} \mathbf{H g}^{-1}\right)\end{array}$ & $\begin{array}{l}\text { Transfusão } \\
\text { Controle }\end{array}$ & $\begin{array}{c}44 \pm 5 \\
46 \pm 15\end{array}$ & $\begin{array}{l}49 \pm 9 \\
44 \pm 9\end{array}$ & $\begin{array}{c}46 \pm 10 \\
41 \pm 8\end{array}$ & $\begin{array}{l}43 \pm 12^{\S} \\
38 \pm 10\end{array}$ & $\begin{array}{c}42 \pm 13^{\S} \\
37 \pm 10\end{array}$ & $\begin{array}{l}0.018^{\mathbb{\pi}} \\
0.304^{\text {\& }}\end{array}$ \\
\hline $\begin{array}{c}\text { Resistência } \\
\text { Respiratória } \\
\left(\mathbf{m m ~ H g} \mathbf{~ L}^{-1} \cdot \mathbf{s}^{-1}\right)\end{array}$ & $\begin{array}{c}\text { Transfusão } \\
\text { Controle }\end{array}$ & $\begin{array}{l}7,1 \pm 1,9 \\
7,6 \pm 1,4\end{array}$ & $\begin{array}{l}6,6 \pm 1,8 \\
7,5 \pm 2,2\end{array}$ & $\begin{array}{c}7,7 \pm 2 \\
7,7 \pm 2,1\end{array}$ & $\begin{array}{l}8,1 \pm 2,5 \\
8,7 \pm 2,7^{\S}\end{array}$ & $\begin{array}{l}8,7 \pm 2,6 \\
9,4 \pm 2,8\end{array}$ & $\begin{array}{l}0.020^{\mathbb{\pi}} \\
0.579^{\&}\end{array}$ \\
\hline $\begin{array}{c}\text { Energia } \\
\text { Inspiratória (\%) }\end{array}$ & $\begin{array}{l}\text { Transfusão } \\
\text { Controle }\end{array}$ & $\begin{array}{l}56 \pm 2 \\
57 \pm 3\end{array}$ & ---- & $\begin{array}{l}56 \pm 2 \\
57 \pm 2\end{array}$ & $\begin{array}{l}54 \pm 2^{¥} \\
57 \pm 6\end{array}$ & $\begin{array}{c}53 \pm 1 *^{*} \\
57 \pm 5\end{array}$ & $\begin{array}{l}0.02^{\mathbb{I I}} \\
0.172^{\text {\& }}\end{array}$ \\
\hline $\begin{array}{c}\text { Energia } \\
\text { Expiratória (\%) }\end{array}$ & $\begin{array}{l}\text { Transfusão } \\
\text { Controle }\end{array}$ & $\begin{array}{l}43 \pm 4 \\
40 \pm 7\end{array}$ & ---- & $\begin{array}{l}43 \pm 3 \\
42 \pm 6\end{array}$ & $\begin{array}{l}41 \pm 2 \\
36 \pm 4\end{array}$ & $\begin{array}{c}40 \pm 3^{\#} \\
35 \pm 4\end{array}$ & $\begin{array}{l}0.007^{\mathbb{\pi}} \\
0.002^{\&}\end{array}$ \\
\hline $\begin{array}{c}\text { Energia de } \\
\text { Histerese (\%) }\end{array}$ & $\begin{array}{l}\text { Transfusão } \\
\text { Controle }\end{array}$ & $\begin{array}{l}13 \pm 4 \\
17 \pm 7\end{array}$ & ---- & $\begin{array}{l}13 \pm 3 \\
15 \pm 5\end{array}$ & $\begin{array}{c}13 \pm 2^{\S} \\
21 \pm 7\end{array}$ & $\begin{array}{l}13 \pm 3^{\#} \\
21 \pm 5\end{array}$ & $\begin{array}{l}0.246^{\mathbb{\pi}} \\
0,006^{\&}\end{array}$ \\
\hline \multicolumn{8}{|c|}{ Volume Extravascular } \\
\hline $\begin{array}{c}\text { APev } \\
(\mathbf{m L} \cdot \mathbf{K g}-1)\end{array}$ & $\begin{array}{c}\text { Transfusão } \\
\text { Controle }\end{array}$ & $\begin{array}{c}6.3 \pm 1 \\
8 \pm 2\end{array}$ & $\begin{array}{l}5.4 \pm 0,7 \\
7.3 \pm 2.1\end{array}$ & $\begin{array}{l}6.4 \pm 1.2 \\
7.9 \pm 2.8\end{array}$ & $\begin{array}{c}6.8 \pm 1.6^{\S} \\
8 \pm 2.6\end{array}$ & $\begin{array}{l}6.5 \pm 0.9^{\S} \\
7.9 \pm 2.5\end{array}$ & $\begin{array}{l}0.004^{\text {Tl }} \\
0,037^{\&}\end{array}$ \\
\hline
\end{tabular}

Análise não paramétrica para dados com medidas repetidas "I efeito tempo; \& efeito grupo;

Não houve interação grupo $\mathrm{x}$ tempo. Analise post-hoc com correção de Bonferroni * $\mathrm{P}<0.05$ vs baseline ${ }^{\S} \mathrm{P}<0.05$ vs hemorragia ${ }^{\#} \mathrm{P}<0.05$ vs controle ${ }^{\sharp} \mathrm{P}<0.05$ vs 1 hora pós ressuscitação. A energia inspiratória, energia expiratória e energia de histerese foram calculadas utilizandoa curva Pressão Volume do sistema respiratório através da área do retângulo contendo a curva PV. Todas as áreas foram normalizadas para a área do menor retângulo capaz de englobar toda a curva PV. Ppi: pressão de pico; Pplatô: pressão de platô; Cestat: Complacência estática do sistema respiratório; APev água extravascular pulmonar indexada. 
Painel A - Relação $\mathrm{PaO}_{2} / \mathrm{FiO}_{2}(\mathrm{~mm} \mathrm{Hg})$

Perfis individuais de cada animal por grupo
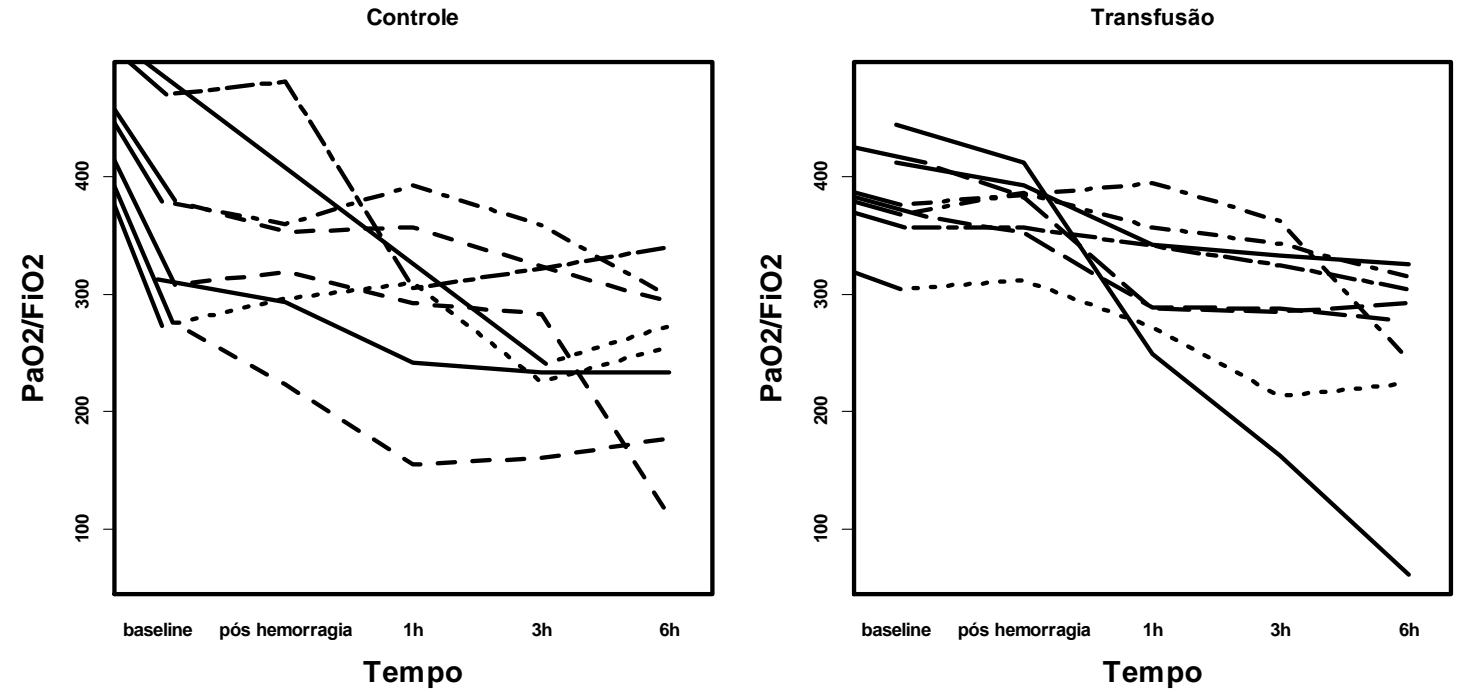

Efeito Relativo de Tratamento (RTE)

$\mathrm{PaO}_{2} / \mathrm{FiO}_{2}$

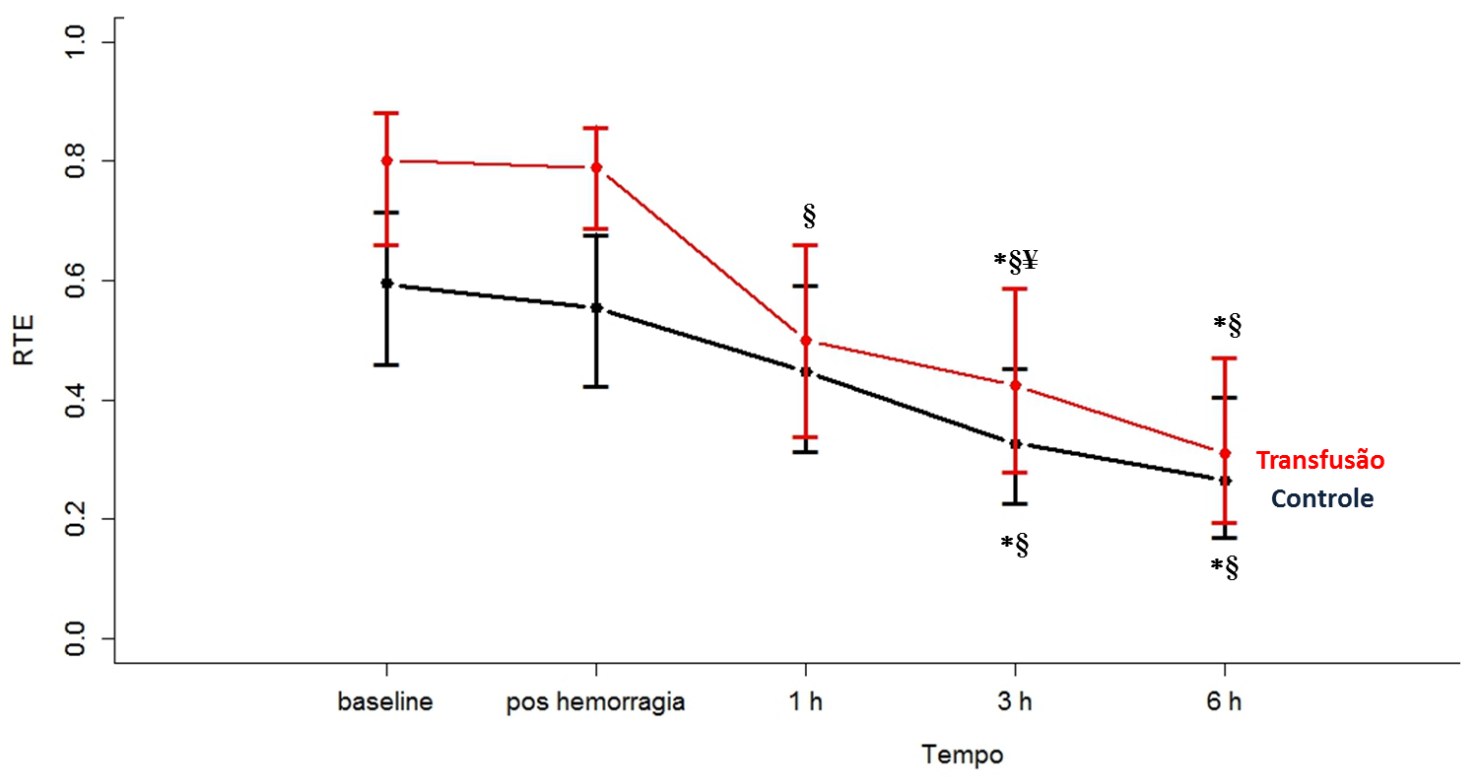

* $\mathrm{P}<0.05$ vs baseline $\quad{ }^{\S} \mathrm{P}<0.05$ vs hemorragia $\quad{ }^{\ddagger} \mathrm{P}<0.05$ vs 1 hora 
Painel B - $\quad \mathrm{PaCO}_{2}$ expirado $(\mathrm{mm} \mathrm{Hg})$

Perfis individuais de cada animal por grupo.
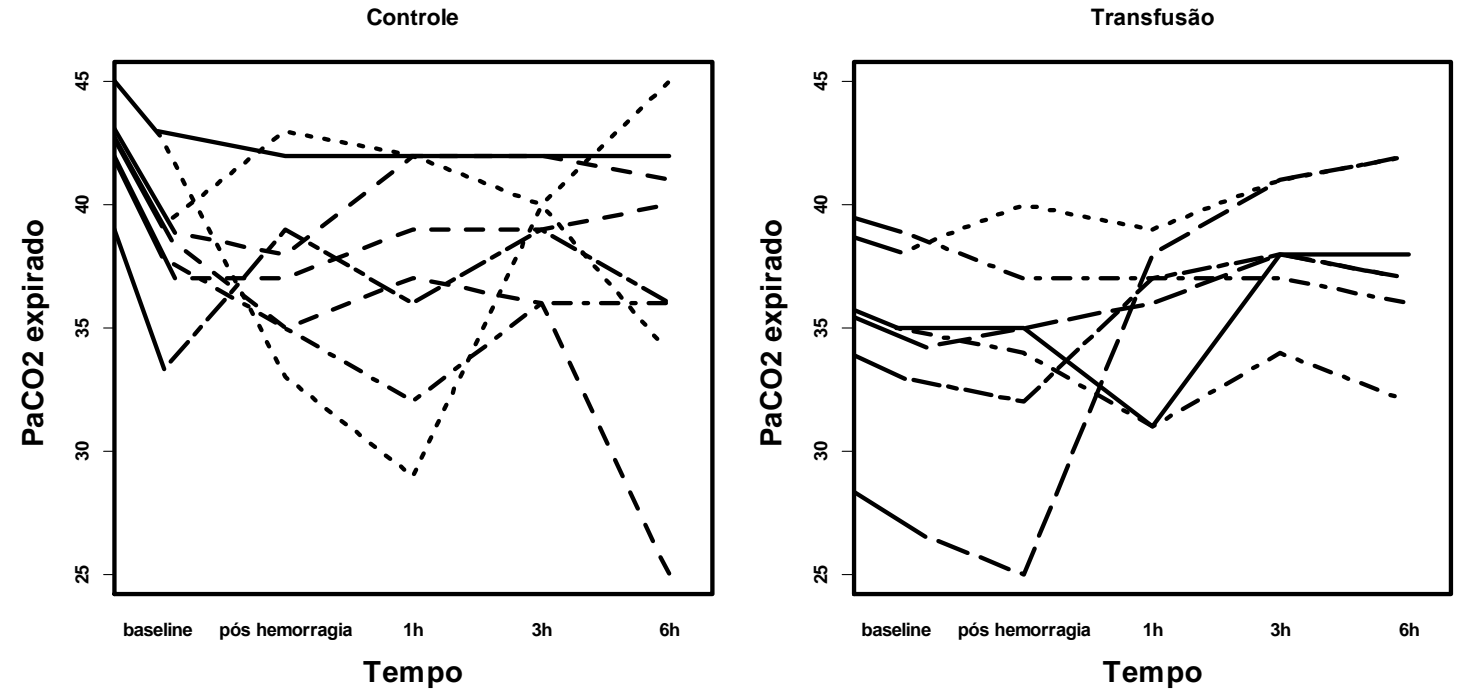

Efeito Relativo de Tratamento (RTE)

$\mathrm{CO}_{2}$ expirado $(\mathrm{mmHg})$

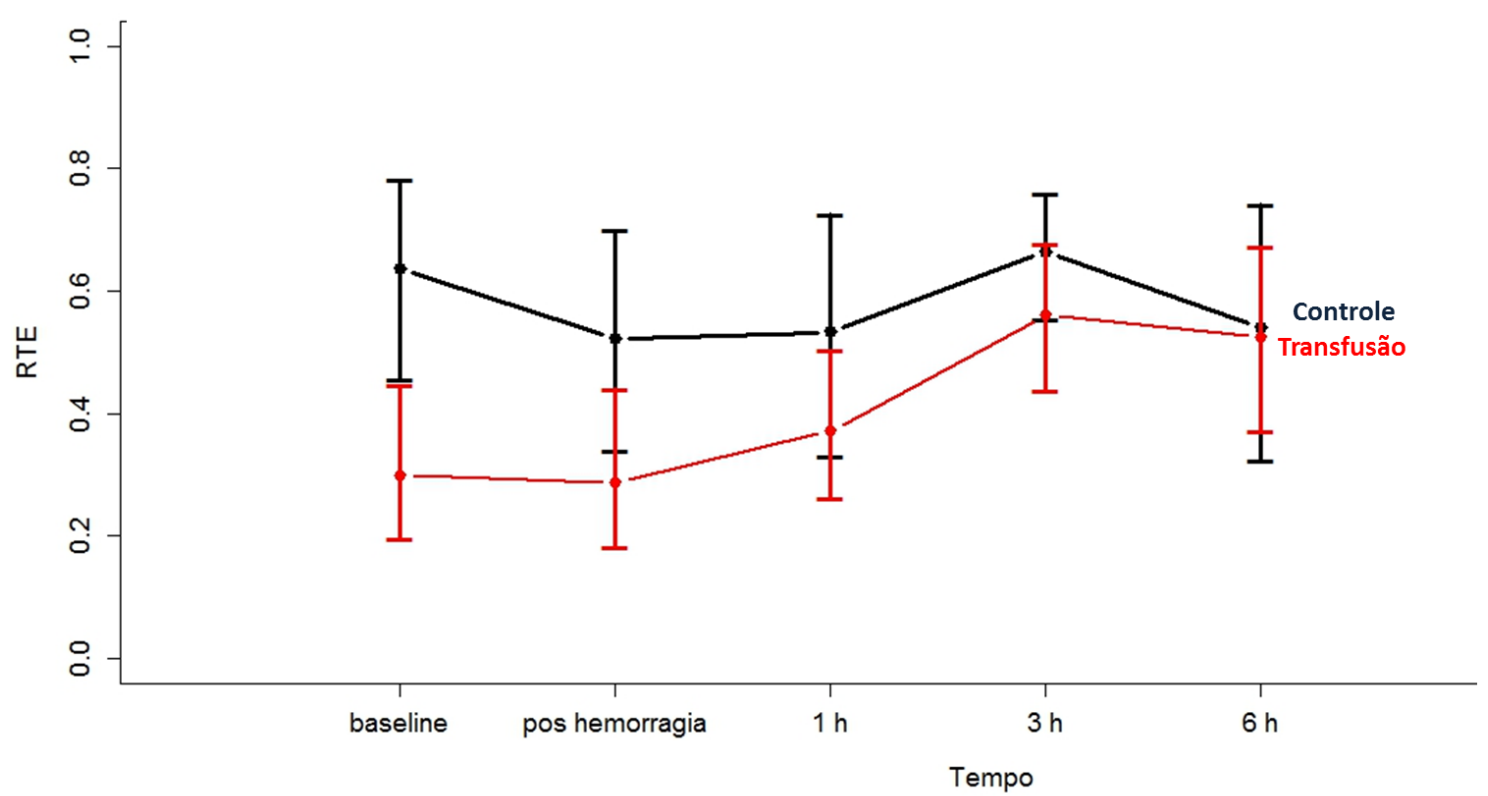


Painel C - Pressão de Pico Inspiratório $\left(\mathrm{cm} \mathrm{H}_{2} \mathrm{O}\right)$

Perfis individuais de cada animal por grupo.
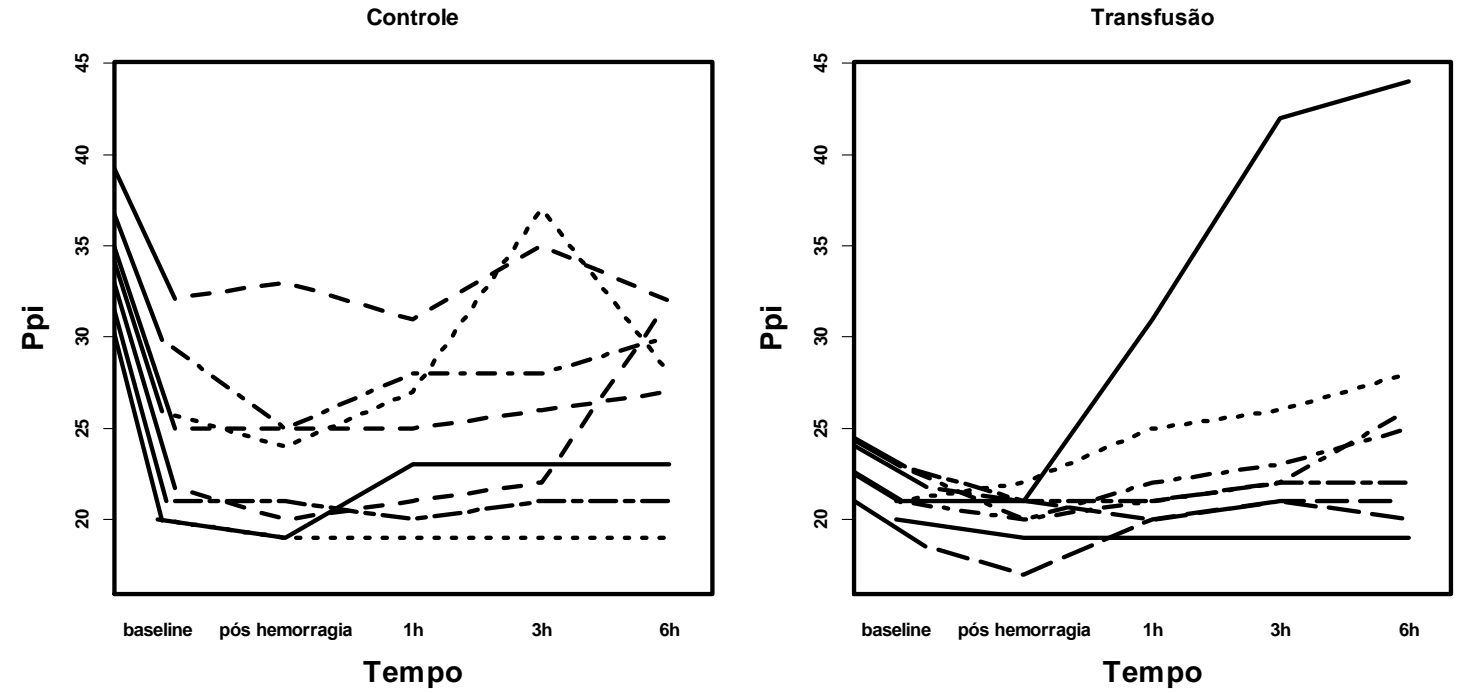

Efeito Relativo de Tratamento (RTE)

\section{Pressão de Pico Inspiratório $\left(\mathrm{cm} \mathrm{H}_{2} \mathrm{O}\right)$}

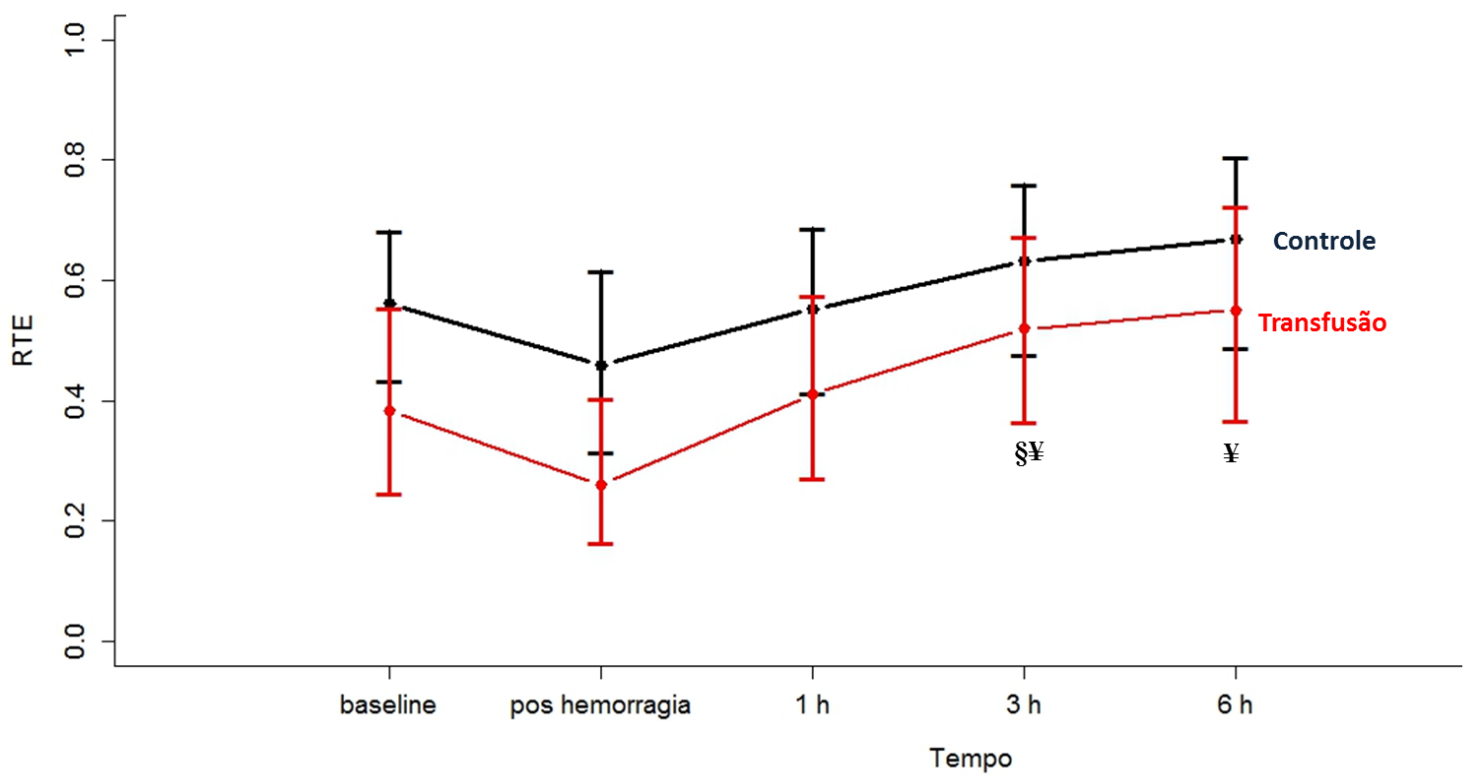

${ }^{\S} \mathrm{P}<0.05$ vs hemorragia $\quad{ }^{\ddagger} \mathrm{P}<0.05$ vs 1 hora 
Painel D - Complacência Estática do Sistema Respiratório ( $\mathrm{mL} \cdot \mathrm{mm} \mathrm{Hg}^{-1}$ )

Perfis individuais de cada animal por grupo.
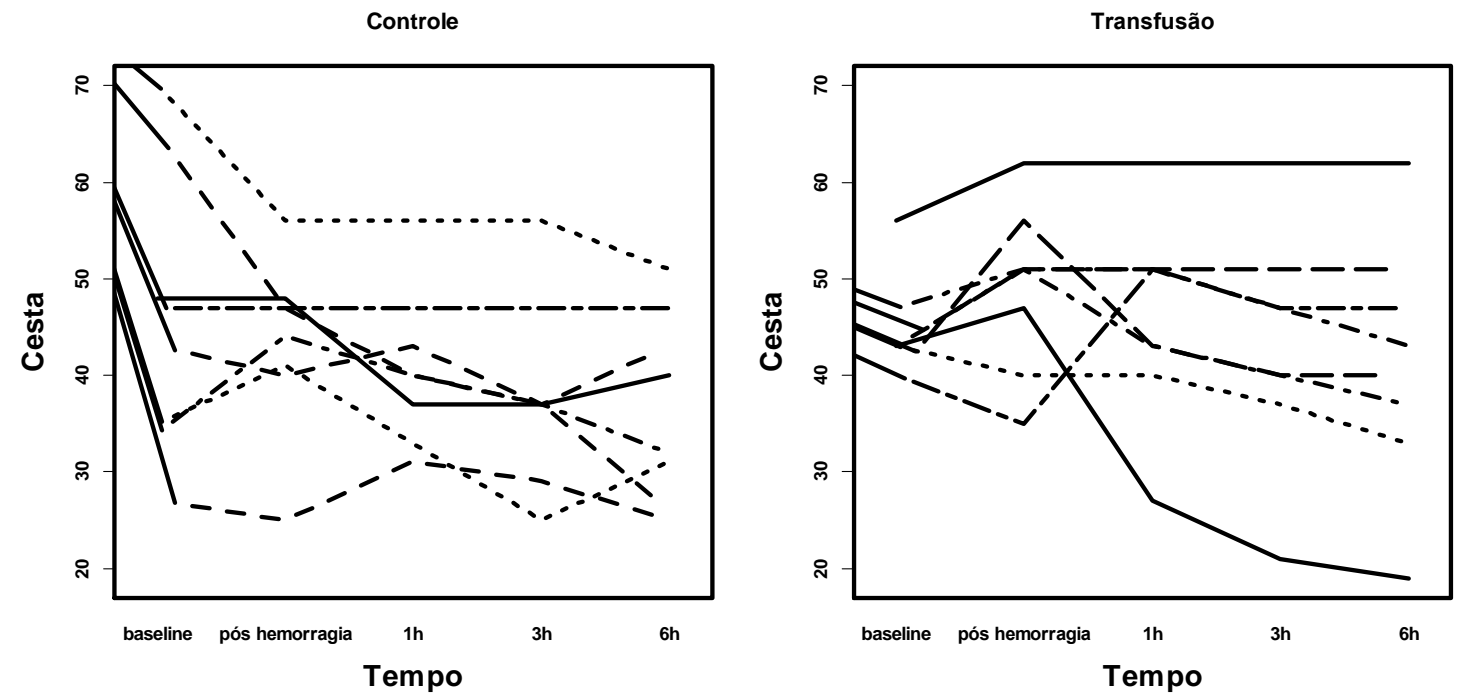

Efeito Relativo de Tratamento (RTE)

\section{Complacência Estática do Sistema Respiratório (mL.mmHg ${ }^{-1}$ )}

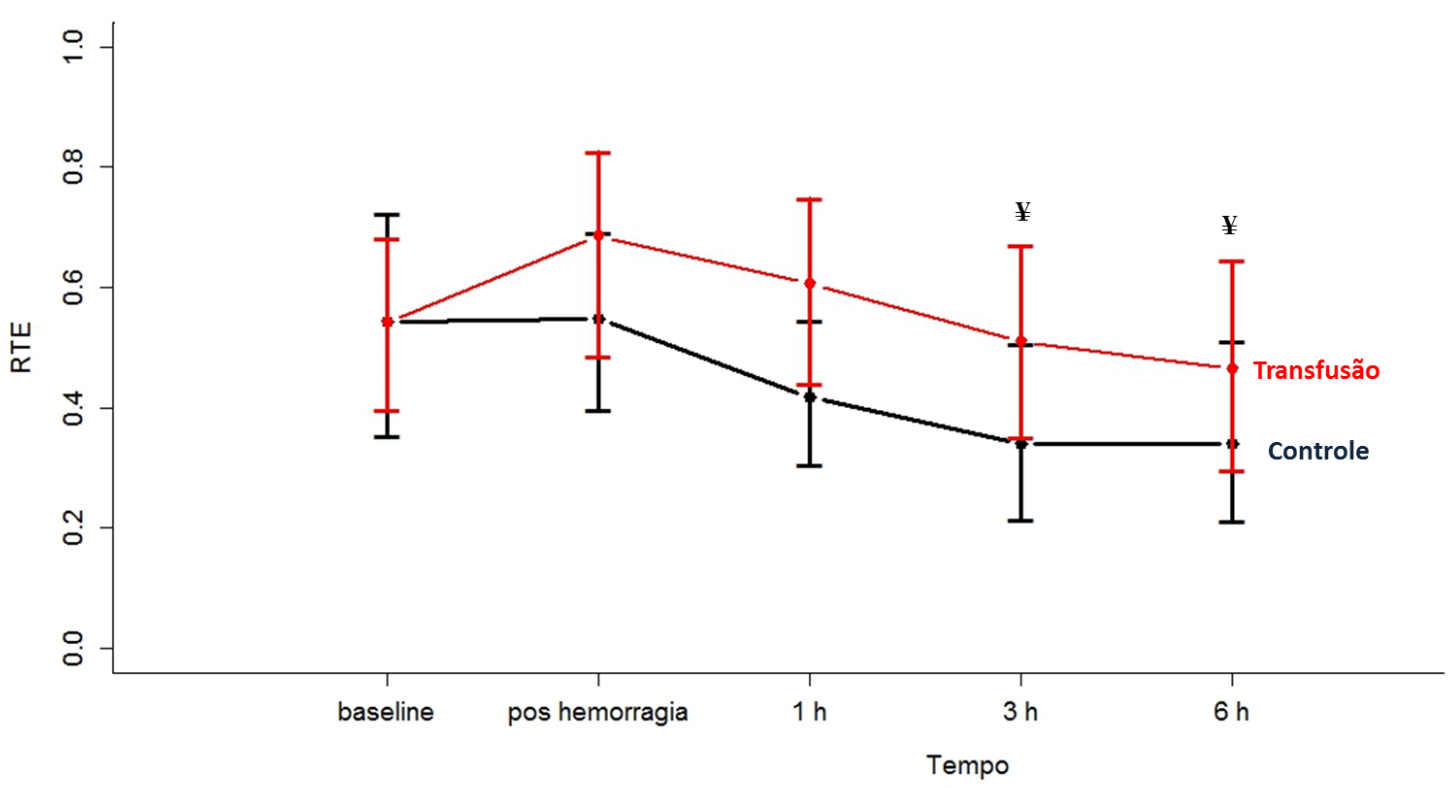

${ }^{¥} \mathrm{P}<0.05$ vs 1 hora 
Painel E - Resistência do Sistema Respiratório (mm Hg.L-1s ${ }^{-1}$ )

Perfis individuais de cada animal por grupo.
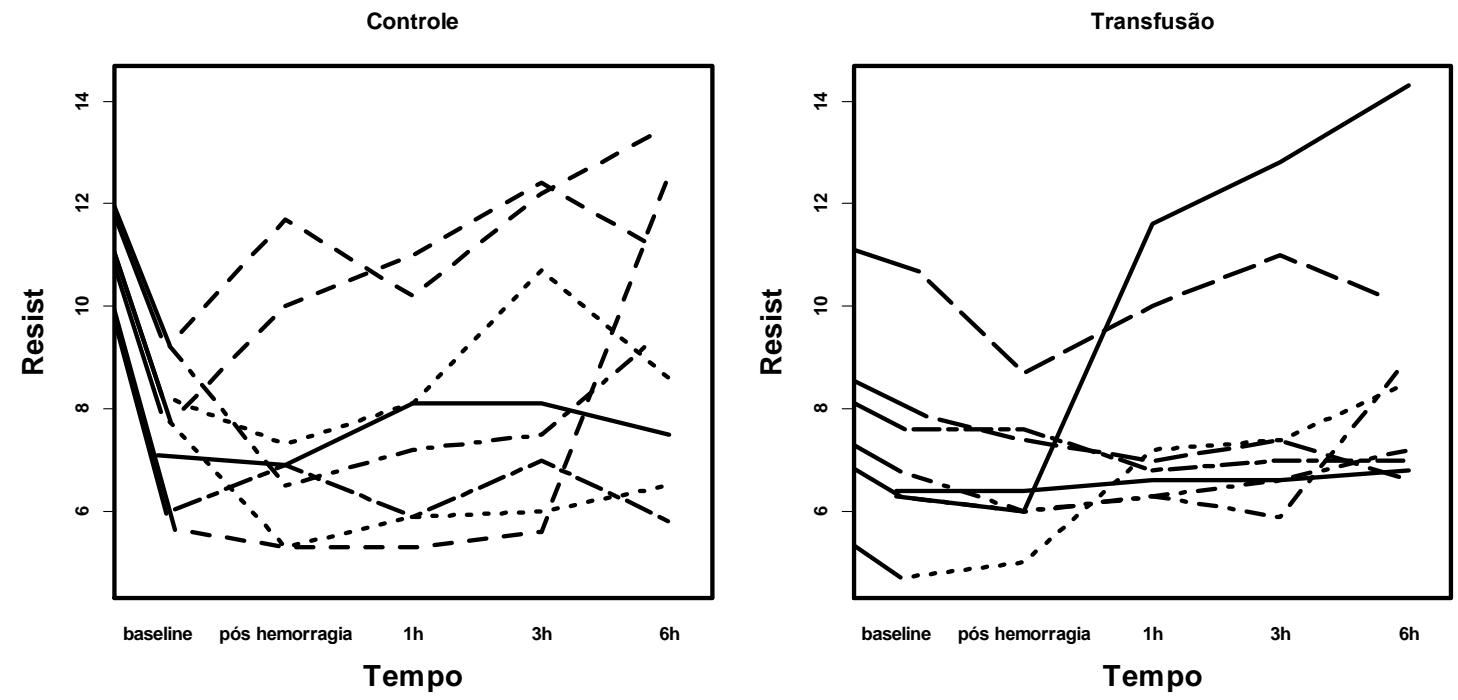

Efeito Relativo de Tratamento (RTE)

Resistência do Sistema Respiratório (mmHg. $\left.\mathrm{L}^{-1} \mathrm{~s}^{-1}\right)$

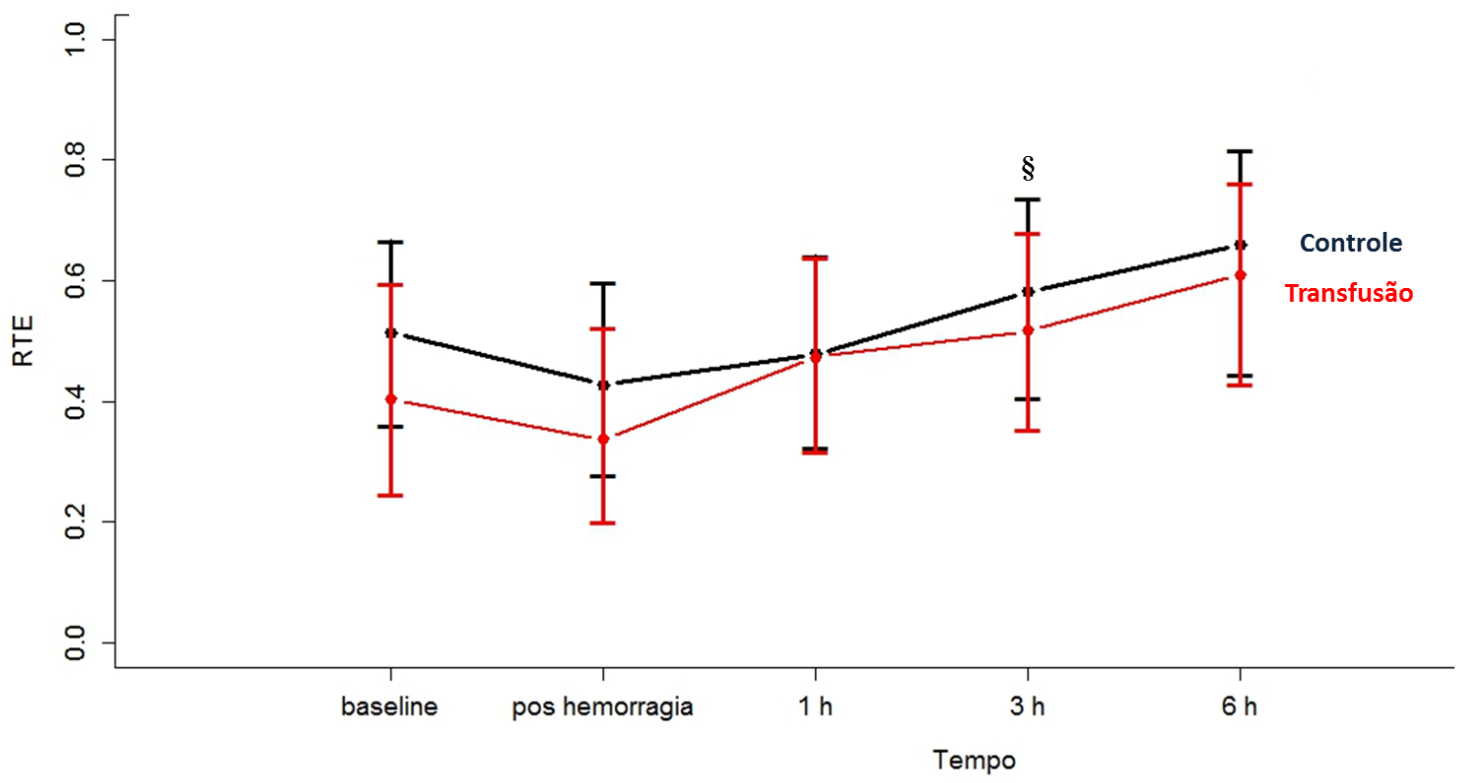

${ }^{\S} \mathrm{P}<0.05$ vs hemorragia 
Painel F - Energia inspiratória ( \%)

Perfis individuais de cada animal por grupo.
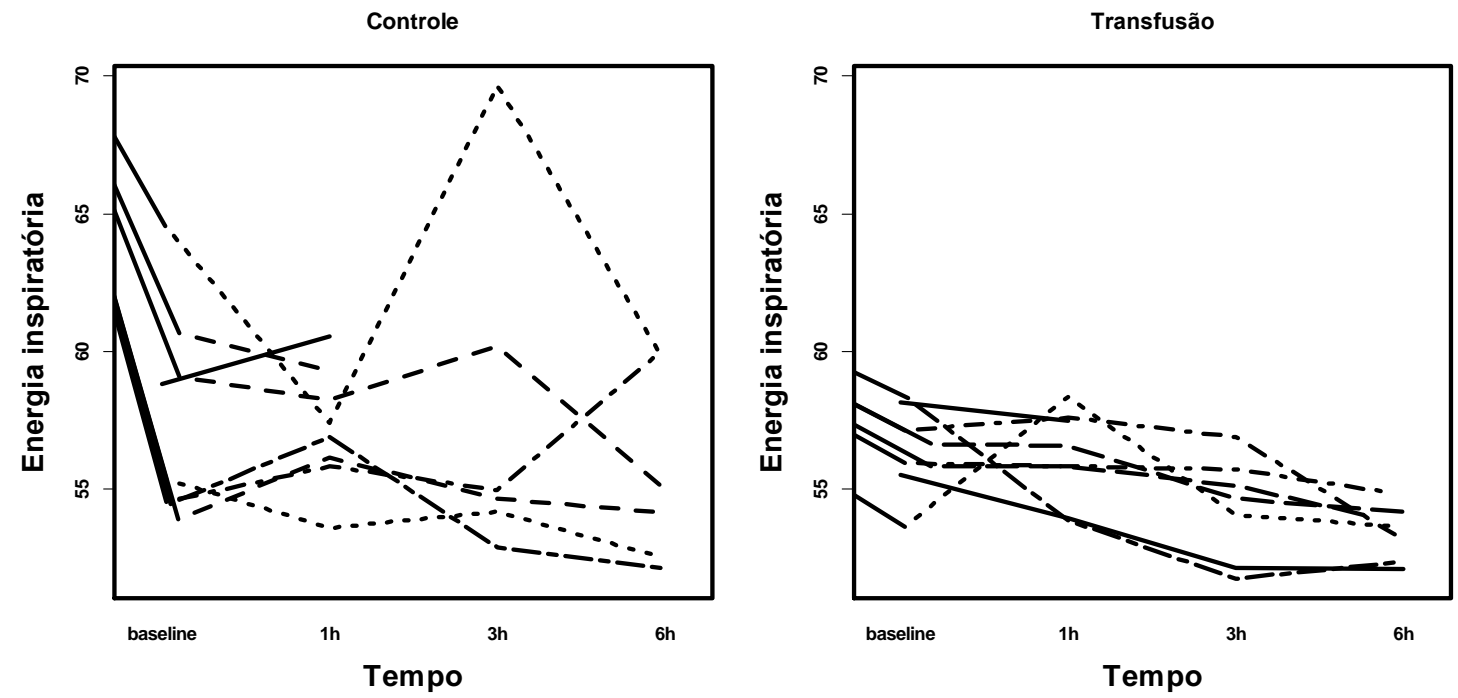

Efeito Relativo de Tratamento (RTE)

\section{Energia inspiratória}

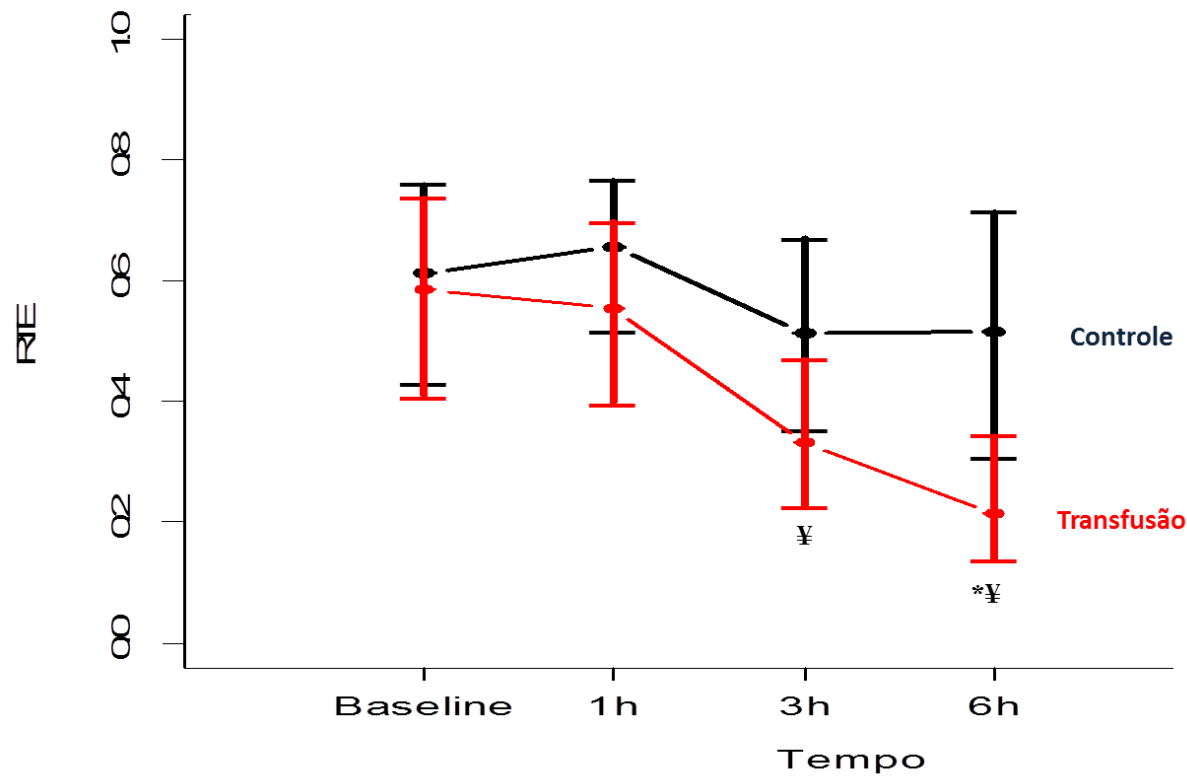

${ }^{*} \mathrm{P}<0.05$ vs baseline $\quad{ }^{¥} \mathrm{P}<0.05$ vs 1 hora 
Painel G - Energia Histerese (\%)

Perfis individuais de cada animal por grupo
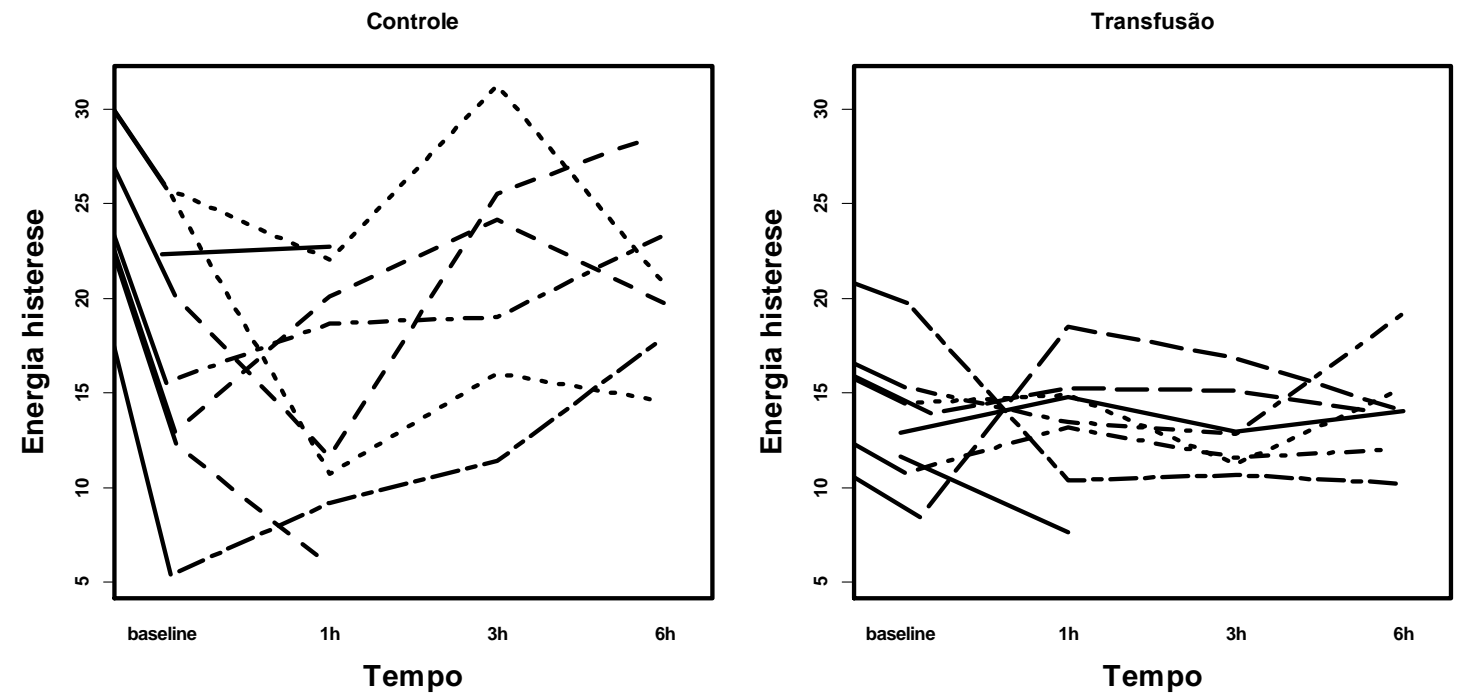

Efeito Relativo de Tratamento (RTE)

\section{Energia Histerese}

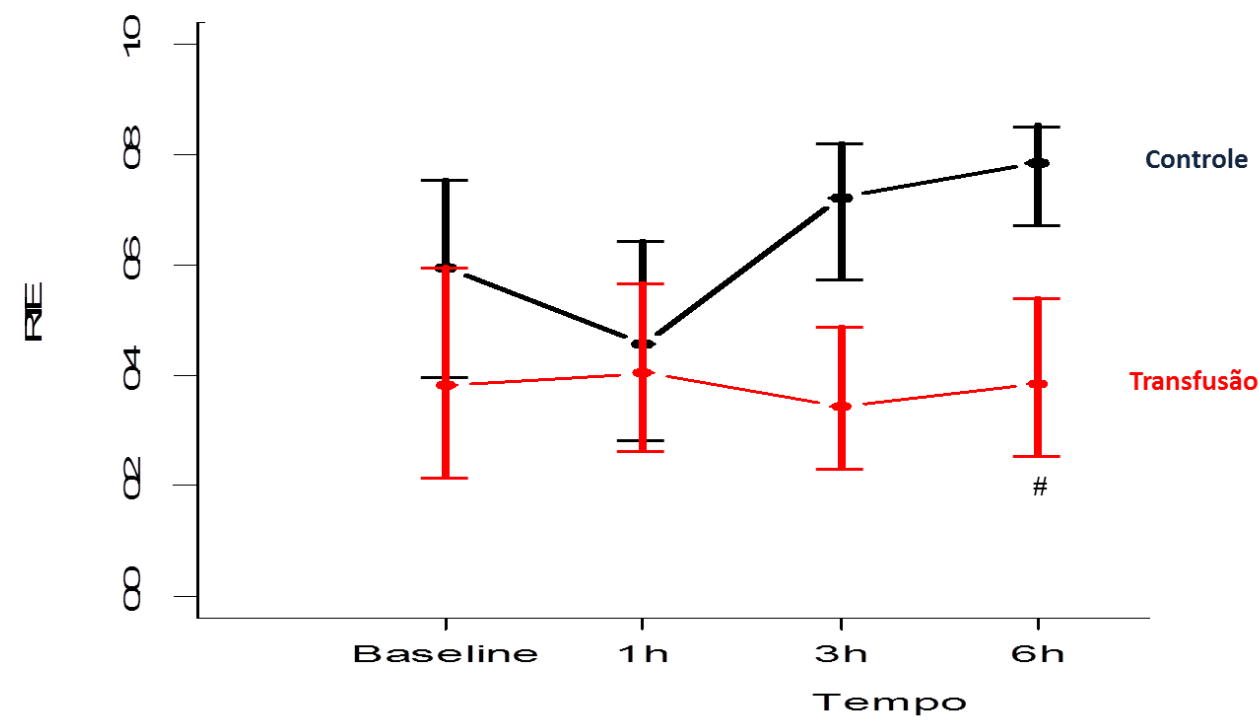

${ }^{\#} \mathrm{P}<0.05$ vs controle 
Painel H - Água Extra Vascular Pulmonar (APev) $\left(\mathrm{mL} . \mathrm{kg}^{-1}\right)$

Perfis individuais de cada animal por grupo.
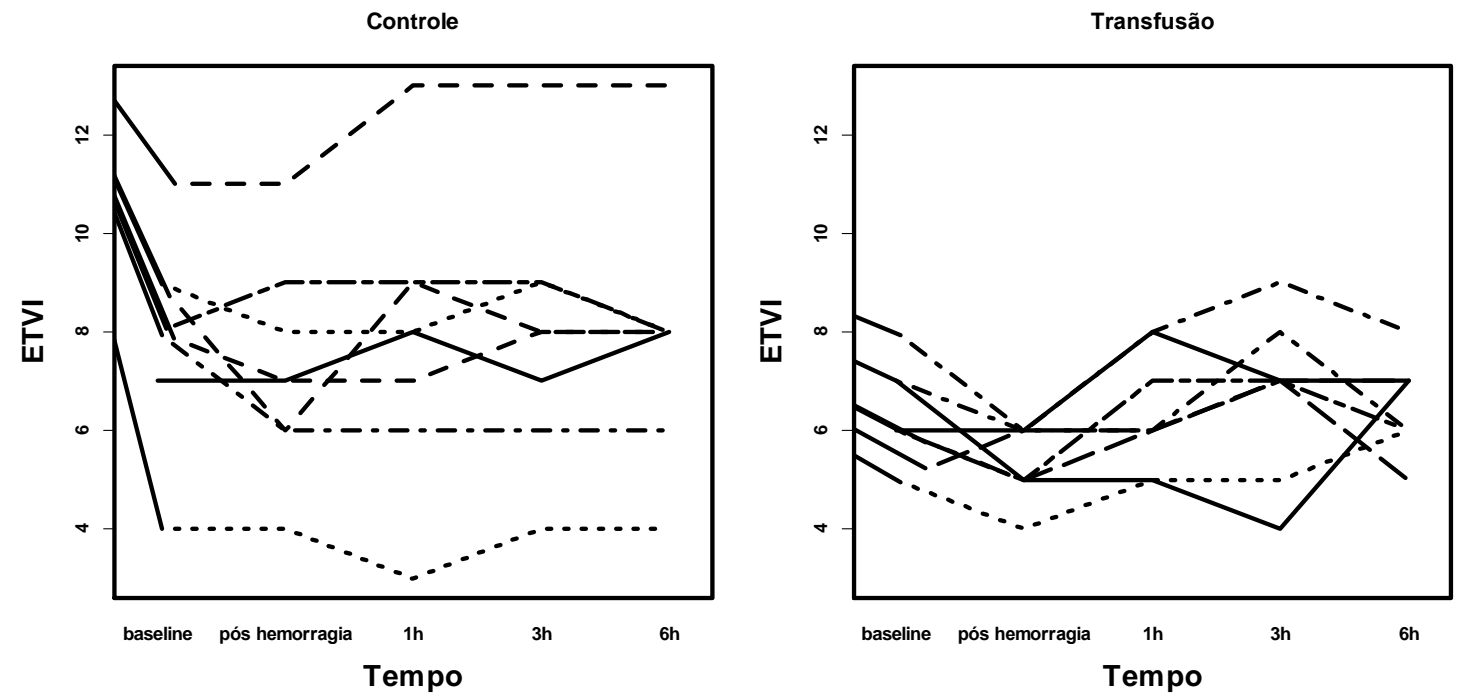

Efeito Relativo de Tratamento (RTE)

\section{Água Extra Vascular Pulmonar (mL.kg-1)}

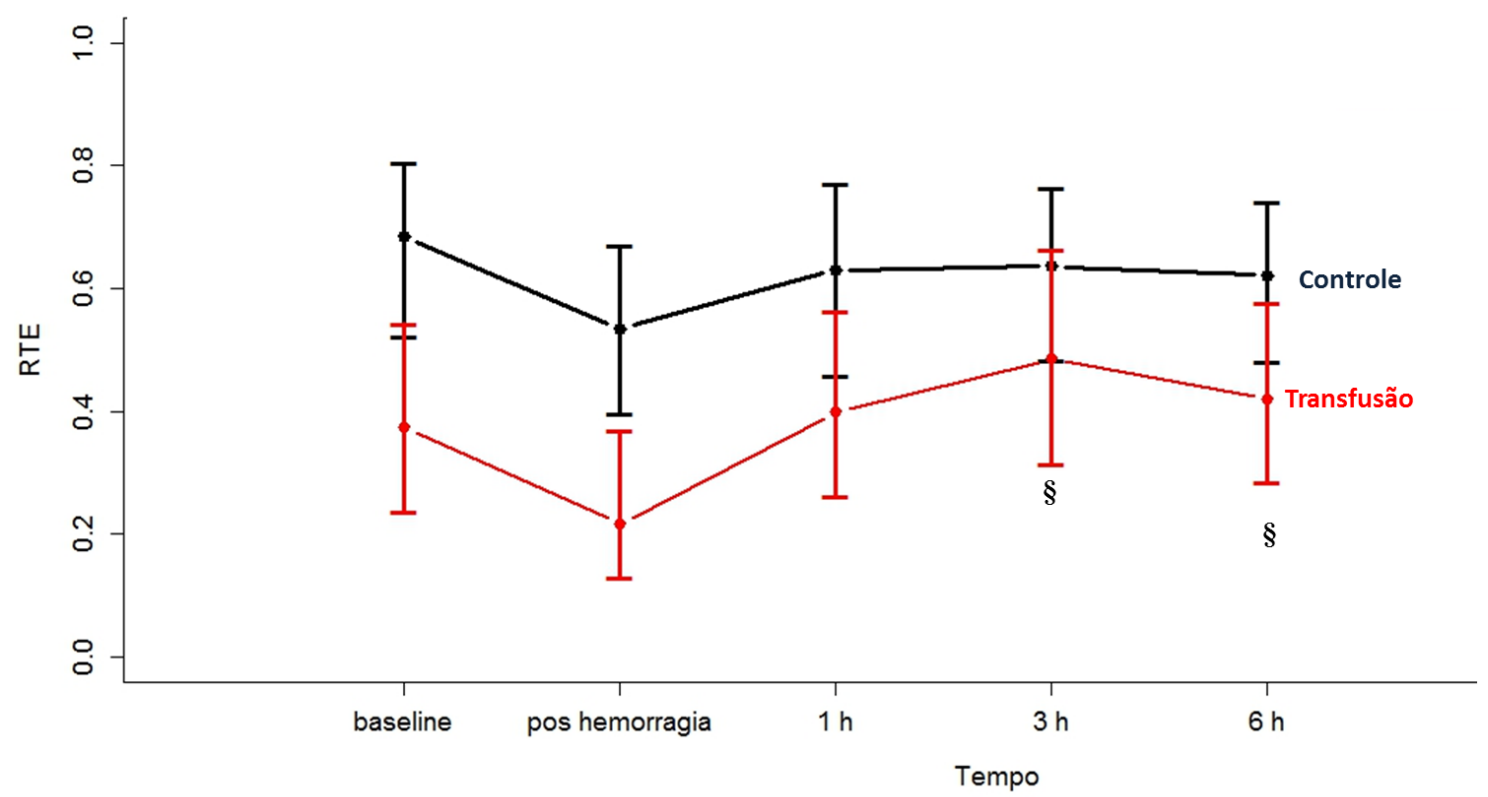

${ }^{\S} \mathrm{P}<0.05$ vs hemorragia 
Painel I - Balanço hídrico /peso (cumulativo)

Perfis individuais de cada animal por grupo

Controle

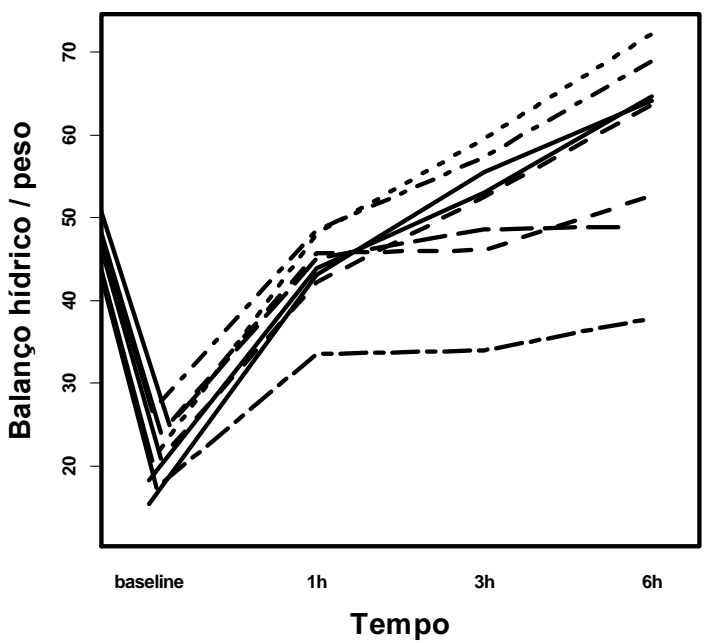

Efeito Relativo de Tratamento (RTE)
Transfusão

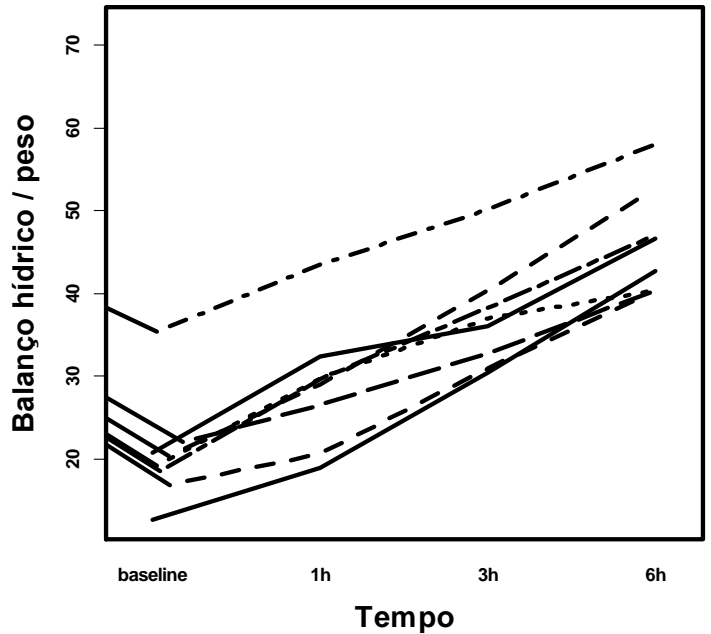

\section{Balanço Hídrico/Peso}

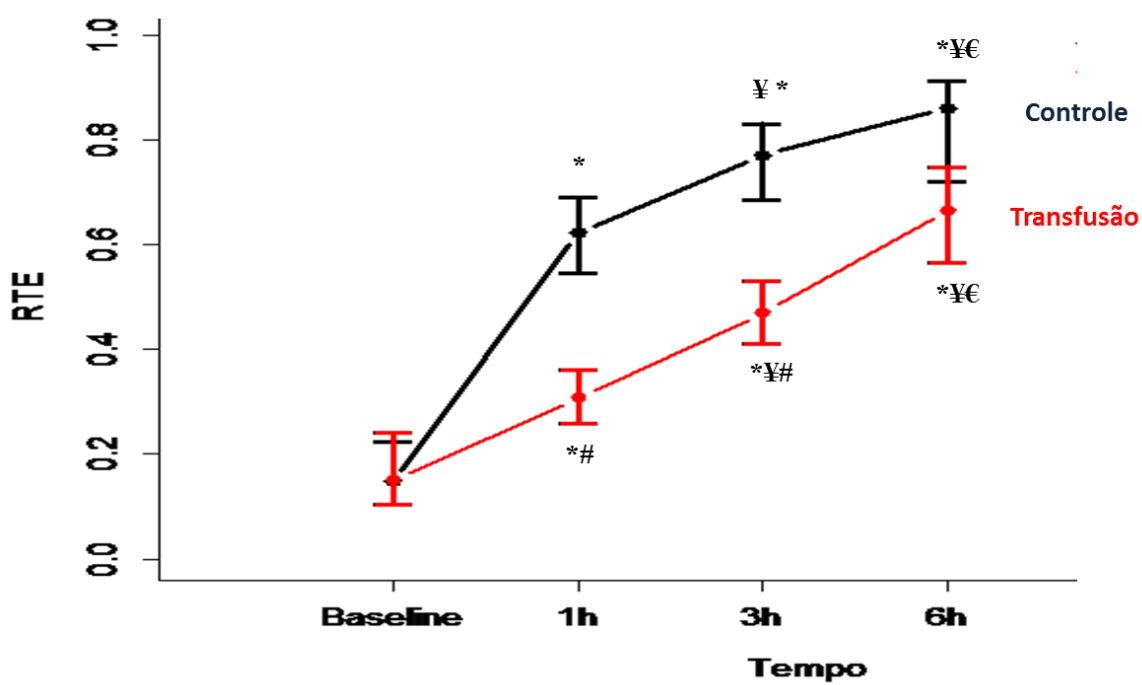

${ }^{*} \mathrm{P}<0.05$ vs baseline $\quad{ }^{*} \mathrm{P}<0.05$ vs controle

${ }^{¥} \mathrm{P}<0.05$ vs 1 hora $\quad{ }^{€} \mathrm{P}<0.05$ vs 3 horas

Figura 7 - Parâmetros Respiratórios 
Painel A - Concentração pulmonar de IL-6 em ambos os grupos

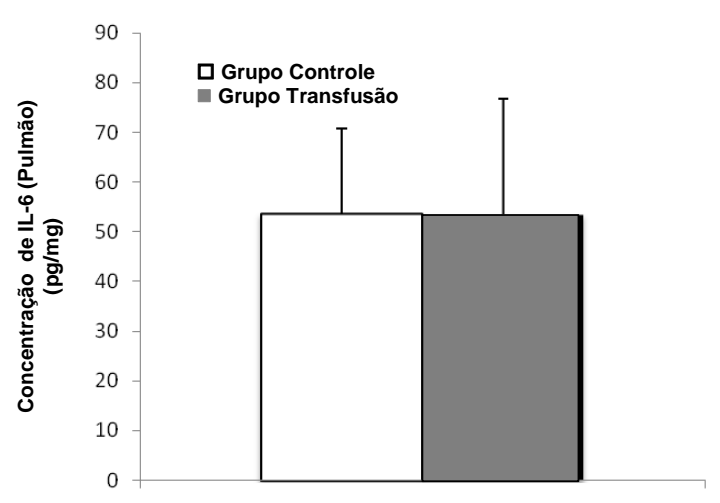

$\mathrm{P}=0.401$ (Teste $\mathrm{t}$ de Student)

Painel C - $\quad$ Concentração pulmonar de IL-1 $\beta$ Em ambos os grupos

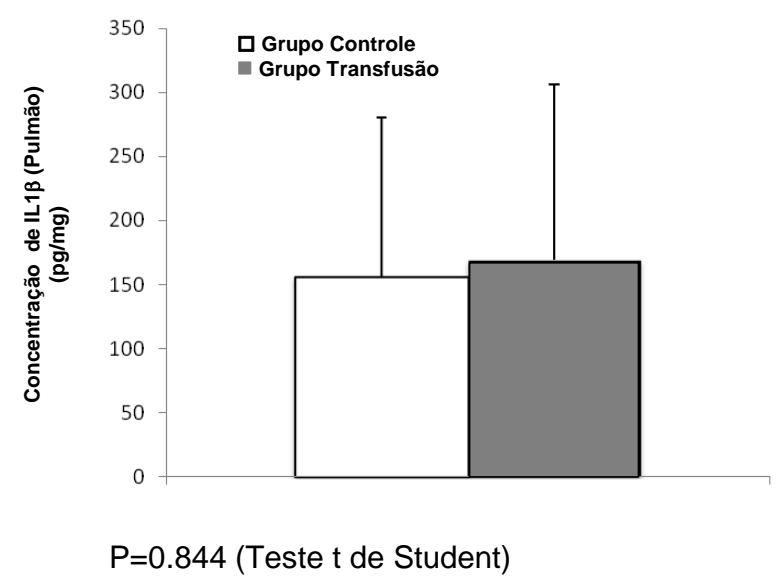

Painel B - Concentração pulmonar de IL-10 em ambos os grupos

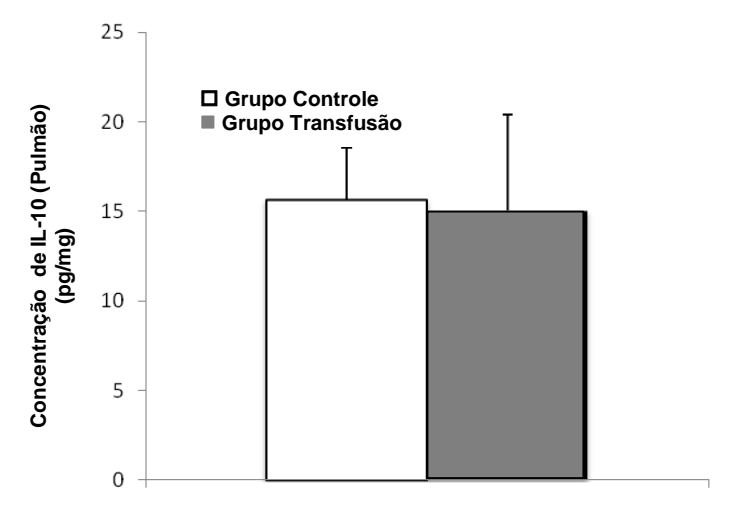

$\mathrm{P}=0.817$ (Teste $\mathrm{t}$ de Student)

Painel D - Concentração pulmonar de IL-21 em ambos os grupos

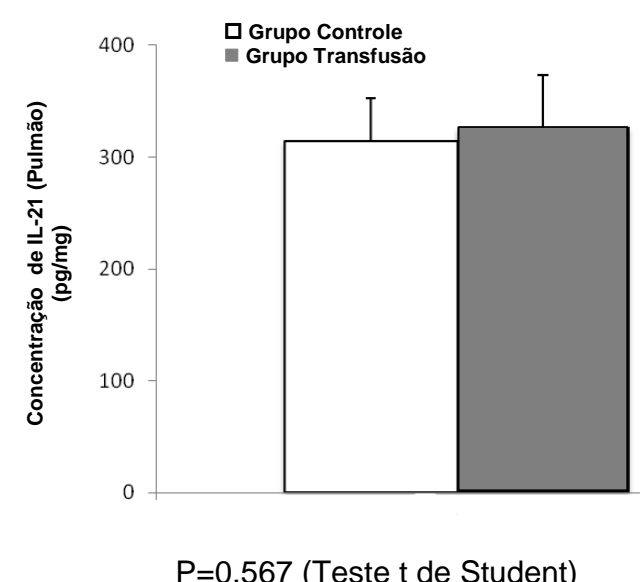

Figura 8 - Parâmetros inflamatórios em ambos os grupos durante o estudo 


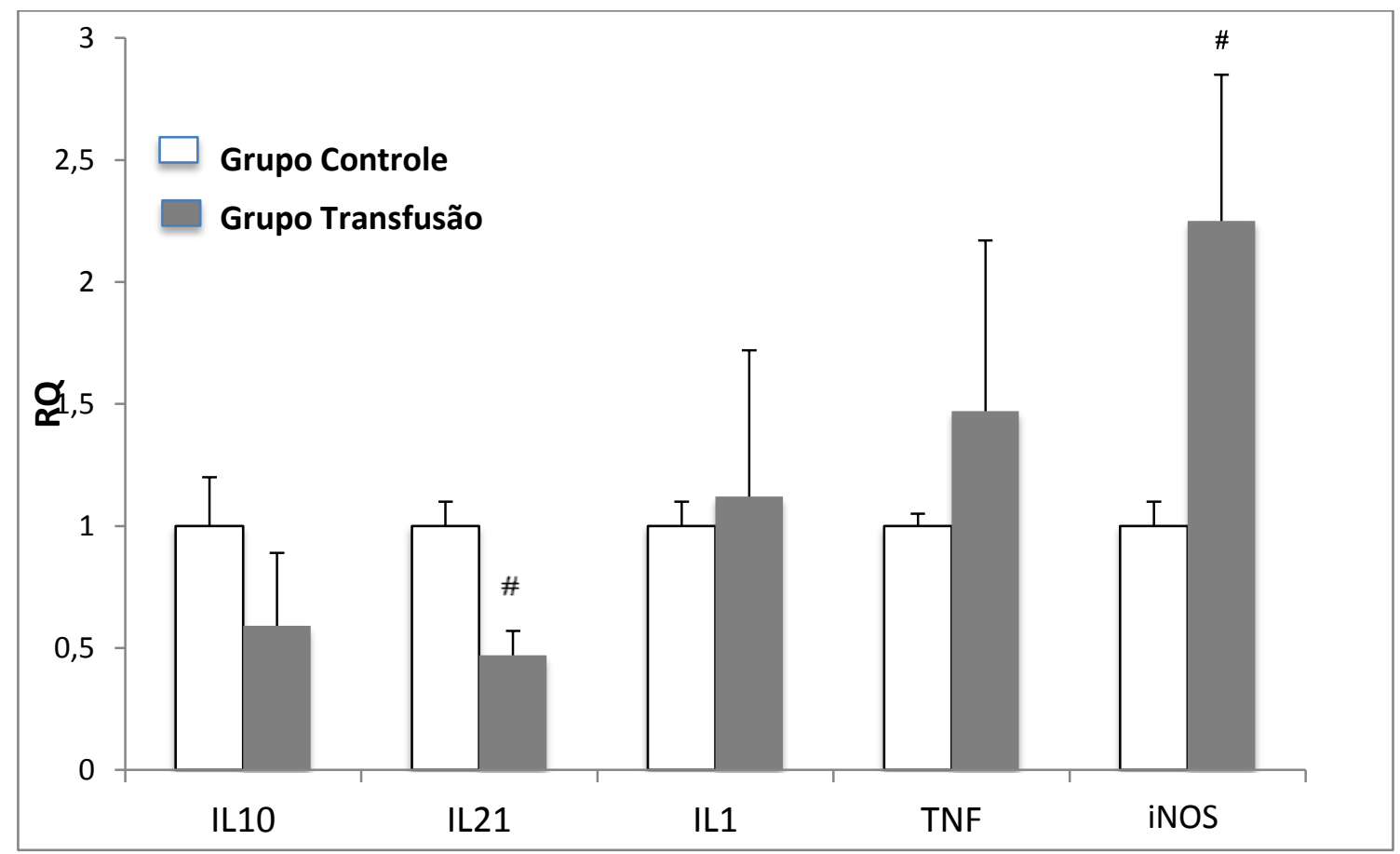

${ }^{\#} \mathrm{P}<0.05$ vs controle (Test-t de student). RQ: relative quantification

Figura 9 - RNAm para citocinas e iNOS no tecido pulmonar 
Painel A - Concentração de nitrato plasmático em ambos os grupos

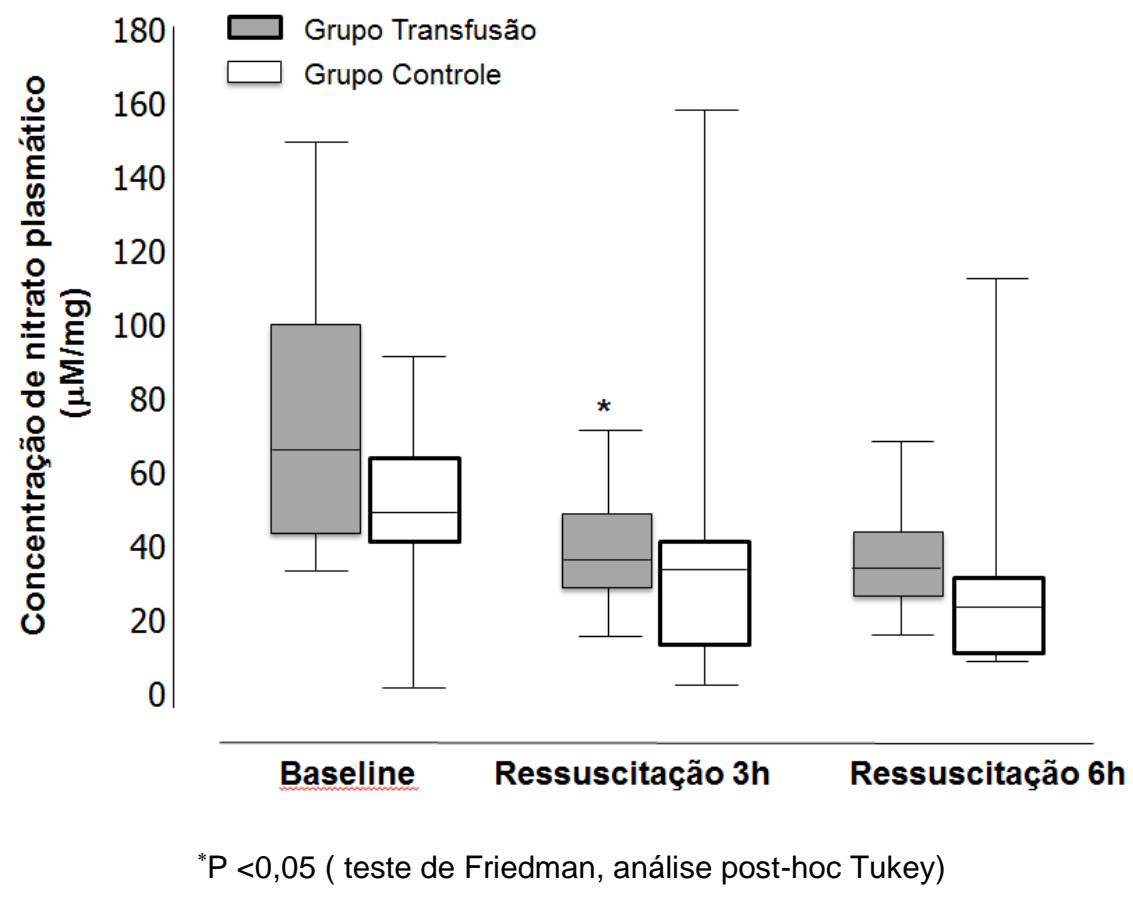

Painel B - Nitrato pulmonar em ambos os grupos

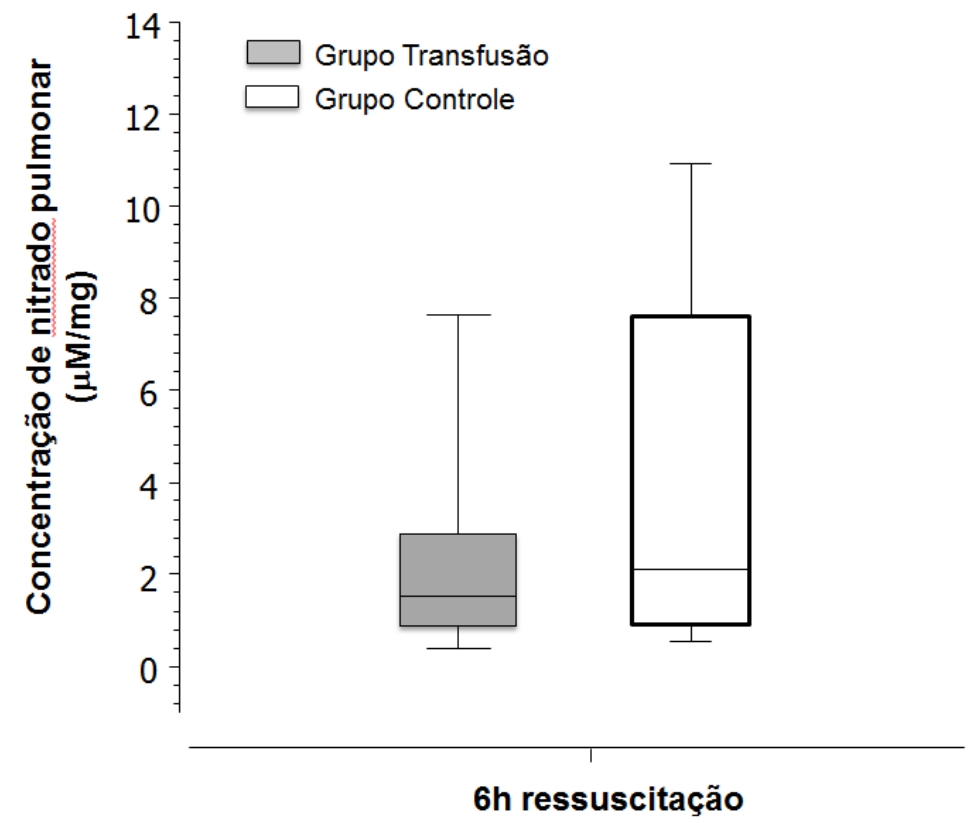

Figura 10 - Concentração de nitrato em ambos os grupos durante o estudo 

Nas últimas duas décadas vêm sendo discutido amplamente na literatura uma possível associação independente entre transfusão de glóbulos vermelhos estocados e pior evolução clínica dos pacientes. Durante a estocagem "ex vivo", os GV sofrem uma série de alterações denominadas de "lesão de estocagem". Os sistemas de estocagem aprovados pelo FDA requerem um mínimo de $75 \%$ de sobrevida de GV no receptor 24 horas após a transfusão e hemólise $<1 \%$, no último dia de estocagem ${ }^{39}$. Estes dois critérios podem não assegurar a segurança e eficácia da transfusão de GV e refletir parcialmente as alterações progressivas dos GV durante a estocagem. Múltiplos mecanismos estão sendo responsabilizados pela alta incidência de complicações e mortalidade nestes pacientes, porém ainda não estão completamente entendidos $^{143,126,70,201,62,134,60,84}$. Todavia, os pacientes avaliados para estas condições geralmente apresentam também um maior risco de SDMO, dificultando desta maneira a correta interpretação dos resultados ${ }^{198,109}$.

Até o presente momento, a despeito do grande número de estudos, concentrando-se principalmente em pacientes vítimas de trauma, cirurgia cardíaca e pacientes críticos, resultados divergentes vêm sendo relatados, impossibilitando qualquer consenso sobre este tema.

Modelos animais para transfusão são relevantes em varias áreas de pesquisa e permitem avaliações muitas vezes impossíveis de serem realizadas em humanos ${ }^{223}$. A validade clínica de tais modelos é dependente de uma avaliação precisa das limitações de cada modelo animal específico. As vantagens da utilização de pequenos animais têm sido bem documentadas e, portanto tem sido amplamente utilizados em estudos de transfusão ${ }^{108,7}$. No 
entanto, diferenças anatômicas, fisiológicas e imunológicas inerentes a cada espécie não devem ser ignoradas. Adicionalmente devem ser levadas em conta as diferenças entre vida média e sobrevida dos GV transfundidos entre as espécies, assim como os métodos de coleta e estocagem destes glóbulos vermelhos ${ }^{56,72,04,185,216,107,216,160}$. Outros aspectos a serem avaliados são transfusão de sangue entre espécies ${ }^{144,186,185}$, ou ex-vivo ${ }^{189}$ em outros, a transfusão é avaliada como um "segundo evento", uma vez que os animais estudados tenham sofrido um "insulto" inicial para lesão pulmonar ${ }^{186,185}$, ou choque hipovolêmico ${ }^{107,9,50}$.

O modelo suíno é frequentemente utilizado em estudos experimentais de transplante de órgãos, tecidos e investigações em terapia intensiva, devido à similaridade da anatomia e fisiologia com o humano. Entretanto há poucos estudos que avaliam o efeito na mecânica pulmonar após a transfusão de GV, principalmente devido às dificuldades em encontrar um modelo animal que seja semelhante ao humano ${ }^{140}$. Adicionalmente, entre os estudos que avaliaram os efeitos da transfusão de sangue em modelo experimental, poucos realizaram a validação do processo transfusional e até onde temos conhecimento poucos estudos avaliaram 0 papel isolado da transfusão $8,139,50,160$.

Neste estudo, desenvolvemos e validamos um modelo experimental de transfusão de glóbulos vermelhos homólogos estocados em suínos. A transfusão realizada neste estudo foi de duas unidades de GV homólogos estocados, estratégia comumente utilizada na prática clinica, em suínos hipovolêmicos para avaliar o efeito isolado da transfusão de GV nas trocas 
gasosas, mecânica respiratória, hemodinâmica, assim como resposta inflamatória pulmonar e sistêmica em suínos hipovolêmicos sadios.

Com a finalidade de determinar a homologia entre as unidades de GV porcinas e humanas estocadas foram realizados testes de controle de qualidade "in vitro" e "in vivo" à semelhança dos utilizados para validar a transfusão destes hemocomponentes em humanos ${ }^{30}$.

\subsection{Validação da transfusão de GV estocados “in vitro"e "in vivo"}

O tempo de estocagem de 14 dias foi escolhido baseado em estudos prévios, os quais demonstraram que a vida média potencial dos eritrócitos homólogos suínos, marcados com cromato de sódio radioativo, transfundidos na literatura é de 14 a 20 dias $^{18,130}$ e de eritrócitos autólogos até 28 dias $^{174}$, menor do que a humana (110 -120 dias $)^{122,170}$. Portanto, o tempo de estocagem de 14 dias representaria o tempo equivalente ao de estocagem usual de uma unidade de GV humano estocado em banco de sangue ${ }^{139}$. Os valores dos diversos parâmetros bioquímicos analisados no $14^{\circ}$ dia de estocagem (sódio, pH e concentração de potássio) foram similares aos valores encontrados em GV humanos no último dia de estocagem ${ }^{30,51}$ e está de acordo com os valores encontrados em estudo em modelo suíno de transfusão de GV homólogos $^{140,139}$. O menor hematócrito encontrado nestas unidades, quando comparado ao humano, reflete o encontrado no sangue venoso destes animais $^{139}$. O índice de hemólise encontrado no 14ํำ dia de estocagem também está dentro dos parâmetros estabelecidos para GV humanos (<1\%). Não houve queda dos níveis de glicose durante o período de estocagem, redução 
do $\mathrm{pH}$ ou aumento do lactato. Os eritrócitos suínos, diferente da maioria dos mamíferos, não parecem utilizar a glicose durante a estocagem, fato este já relatado em outros estudos ${ }^{113,138}$

Os métodos utilizados para avaliar a viabilidade "in vitro" comumente são insuficientes para predizer a viabilidade "in vivo", definida, arbitrariamente, como a sobrevida dos GV humanos estocados após 24 horas da transfusão acima de $75 \%{ }^{187}$ e níveis de hemólise inferiores a $1 \%{ }^{188,123,97,4}$.

A sobrevida dos eritrócitos marcados com $\mathrm{Na}_{2}{ }^{51} \mathrm{CrO}_{4}$ foi descrita pela primeira vez na década de 50 por Ebaugt e col. ${ }^{42}$ utilizando técnica proposta por Gray e Sterling ${ }^{65}$. O cromato liga-se predominantemente nas cadeias $\beta$ da hemoglobina, tem baixa emissão de energia, baixo índice de eluição e vida média longa (27.7 dias) ${ }^{124}$. O isótopo, incorporado à hemoglobina, permanece marcando o eritrócito até o momento em que o mesmo seja destruído. Ao ser liberado do GV, por ocasião da hemólise, o cromo sob a forma trivalente não consegue marcar novo eritrócito. Adicionalmente, os sítios de sequestros dos GV podem ser identificados utilizando um contador de superfície e o grau de hemólise intravascular pode ser estimado com pequenos volumes de GV marcados.

Até o presente momento, o teste padrão ouro utilizado para avaliar a eficácia da transfusão de GV, ainda é a marcação de hemácias com cromato de sódio radioativo, descrito por Moroff e col ${ }^{127}$ associado a níveis de hemólise inferiores a $1 \%$ no último dia de estocagem ${ }^{74}$. Em nosso estudo a sobrevida "in vivo" dos glóbulos vermelhos marcados com cromato de sódio radioativo demonstrou viabilidade próxima a 90\%, valor este considerado satisfatório para o tempo de estocagem, principalmente levando-se em conta a sobrevida de 
GV suínos descrita na literatura ${ }^{18,130}$. Observamos uma grande variabilidade inter doadores, o que é corroborado por estudos na literatura ${ }^{39}$. Outro resultado que corrobora para o nível insignificante de hemólise é a baixa radioatividade livre encontrada no sobrenadante das amostras e a falta de reatividade no baço dos animais, sugerindo que a vasta maioria dos eritrócitos estava intacta na circulação após 24 horas da transfusão.

A análise do "in vitro" das 16 unidades de GV coletadas e transfundidas nos 8 animais do grupo transfusão mostrou achados similares aos encontrados na análise das 02 unidades de GV utilizadas para a validação deste estudo.

\subsection{Avaliação do efeito agudo da transfusão de GV nas trocas gasosas, mecânica respiratória, hemodinâmica, assim como resposta inflamatória pulmonar e sistêmica em suínos hipovolêmicos sadios}

Dos dezoito suínos que inicialmente foram utilizados neste estudo, apenas dezesseis foram analisados. Estudos prévios ${ }^{84}$ demonstraram reações adversas quanto realizada transfusão de sangue total incompatível no Sistema A-O, todavia não há descrição de reações adversas, independente da compatibilidade, após transfusão de $\mathrm{GV}^{162}$, em animais que não foram previamente transfundidos. Desta forma, devido ao exposto e à logística, optamos por iniciar os experimentos independentes dos resultados das provas de compatibilidade, com posterior avaliação. Um animal do tipo sanguíneo não A ou nulo recebeu GV de doador do tipo A, com provas de compatibilidade positiva e evoluiu com hipertensão pulmonar, insuficiência respiratória, hematúria, anuria e sinais de coagulopatia de consumo (CID). A possível explicação para estas alterações seria a reação entre os anticorpos anti-A do 
plasma do receptor que poderiam reagir com a substância $A$ no plasma do doador e ativação do sistema complemento, porem sem sinais de hemólise ${ }^{162}$.

Diferente dos humanos e vários outros mamíferos, o antígeno $\mathrm{A}$ não é constitucional dos eritrócitos suínos e, sim adsorvidos do plasma, portanto a transfusão de GV com volume reduzido de plasma seria insuficiente para suscitar reação imunológica hemolítica ${ }^{162}$. Na experiência de Smith $D$ em transfusão de GV e plaquetas em suínos submetidos à TMO não foi encontrada nenhuma reação adversa, independente dos testes de compatibilidade, em animais não transfundidos previamente.

NOTA: Smith D. Blood groups and transfusion in pigs [online]. Acesso em 22 jan. 2007. Comunicação via e-mail.

Com a finalidade de evitar qualquer viés na interpretação dos resultados, estes dois animais foram excluídos do estudo e a partir deste momento todos os animais foram transfundidos com unidades compatíveis no sistema A-O.

Optou-se por um modelo de hipovolemia por hemorragia controlada para evitar os efeitos inflamatórios que poderiam ocorrer secundários ao choque hipovolêmico, ${ }^{107,50}$ e mascarar os eventos adversos secundários exclusivamente à transfusão dos GV homólogos estocados.

A redução significativa do índice sistólico, pressão arterial média, précarga, e o aumento significativo da variação de volume sistólico em ambos os grupos na hipovolemia em relação ao baseline demonstrou a eficácia do modelo. $\mathrm{O}$ aumento significativo dos níveis de $\mathrm{Hb}, \mathrm{Ht} 1,3$ e 6 horas após $\mathrm{O}$ termino da transfusão de $\mathrm{GV}$ e $\mathrm{SVO}_{2}$ no grupo transfundido comparado ao controle após a ressuscitação imediata e durante todo o procedimento mostra a eficácia e a viabilidade da transfusão dos GV estocados. 


\subsection{Efeitos Hemodinâmicos}

Observamos que a transfusão de hemácias armazenadas por 14 dias levou a aumento transitório da pressão média de artéria pulmonar nos oito animais estudados no grupo transfusão imediatamente após o início da ressuscitação volêmica, em média $12,57 \pm 12,62 \%(p=0,028)$ quando comparado ao baseline, e retornaram próximo aos níveis basais em até 1 hora após o termino da transfusão. Nossos achados corroboram estudos recentes realizados em modelo ovino ${ }^{50}$, que encontraram aumento transitório da pressão de artéria pulmonar durante a ressuscitação com GV estocados, quando comparados com salina ou sangue fresco $(p<0,01$ e $p<0,05)$, retornando a níveis basais em até 4 horas após a transfusão, porem sem diferença significativa na relação $\mathrm{PaO}_{2} / \mathrm{FiO}_{2}$. Outro estudo ${ }^{8}$ também demonstrou aumento transitório da pressão de artéria pulmonar e aumento do índice de resistência vascular pulmonar após transfusão de GV estocados, que retornou ao normal uma hora após o termino da transfusão. Neste último estudo o aumento do tônus vascular pulmonar foi associado ao aumento de hemoglobina livre no plasma, potencializado pelo bloqueio parcial da NOS pelo L-NAME (inibidor da oxido nítrico sintetase). Ainda a vasoconstrição pulmonar induzida pela transfusão de sangue estocado foi prevenida pela inalação concomitante de 80ppm de óxido nítrico. Adicionalmente, estas alterações não foram encontradas no grupo que foi transfundido com GV frescos. Até o momento, estudos na literatura associam a hipertensão pulmonar à presença de hemoglobina livre em pacientes que recebem transfusão de GV estocados 
versus transfusão de GV frescos ${ }^{8}$, assim como em pacientes falciformes ${ }^{106,114}$, entretanto o papel da inativação do oxido nítrico pela hemoglobina livre ainda é controverso. Embora em nosso estudo o controle de qualidade "in vivo" (marcação com cromato de sódio radioativo) demonstrou que os GV estocados por 14 dias comportaram-se semelhante à GV humanos frescos ou com menor tempo de estocagem, ainda observamos alteração súbita e transitória da pressão de artéria pulmonar média nos animais transfundidos quando comparados ao grupo controle. Aliado a este fato, transfundimos apenas duas unidades de GV, talvez transfusões de maior volume pudessem levar a aumento persistente de hemoglobinemia devido à destruição dos GV durante a estocagem, e após a transfusão, acarretando diminuição da biodisponibilidade do NO e vasoconstrição.

Não foram encontradas alterações sistêmicas no grupo transfundido quando comparado ao grupo controle, o que corrobora estudos recentes realizados em modelos ovinos ${ }^{8,50,160}$. Outro estudo experimental ${ }^{216}$ demonstrou que transfusão de GV estocado ou seu sobrenadante pode induzir vasoconstrição e hipertensão sistêmica aguda apenas em ratos com disfunção endotelial prévia (diabéticos) e que pode ser prevenida através da inalação com NO, propondo que ratos com disfunção endotelial são mais susceptíveis aos efeitos vasoconstritores da hemoglobina livre liberada durante a estocagem dos GV. Estes estudos sugerem uma possível interação entre a transfusão de GV e predisponibilidade do receptor. Entretanto, estudo em ratos sadios que receberam sobrenadante de sangue humano estocado, mostrou aumento significativo da PAM (pressão arterial média) quando comparado com sobrenadante de sangue fresco 40 minutos após a transfusão $(p=0,003)$ com 
significante correlação de hemoglobina livre no sobrenadante ${ }^{37}$. Cabe salientar que neste estudo a transfusão foi interespécies, não sendo possível afastar possíveis causas imunológicas, dificultando desta forma a extrapolação destas conclusões para humanos.

Estudos em pacientes críticos também não observaram alterações significativas na hemodinâmica imediatamente, $2 h^{103}, 24 h$ e 48 horas após a transfusão de GV estocados ${ }^{27}$.

\subsection{Efeito na Microcirculação}

Também não foi observada alteração da microcirculação, avaliada através da utilização de Laser Doppler Fluxometria ${ }^{34,99}$, diferente do encontrado em estudos em modelo animal ${ }^{178,21}$, quando a transfusão de sangue estocado reduziu significativamente a perfusão local, sem no entanto apresentar alterações sistêmicas evidentes. Outros estudos sugerem que as alterações na microcirculação ocorrem em associação a danos endoteliais prévios $^{21,216}$. 


\subsection{Efeito nas trocas gasosas e mecânica respiratória}

A abrangente avaliação da mecânica pulmonar realizada neste estudo não demonstrou alteração significativa da complacência pulmonar e resistência respiratória após transfusão de GV estocados, alteração de troca gasosa e presença de edema agudo pulmonar. Interessantemente observou-se um aumento da energia gasta na histerese $(p<0,001)$ no grupo controle 6 horas após o término da ressuscitação quando comparado ao grupo transfusão e uma tendência à diminuição da energia gasta no trabalho inspiratório no grupo transfundido. Os efeitos pulmonares da transfusão, incluindo avaliação da "mecânica" foram investigados anteriormente em poucos estudos. Um estudo inicial realizado em prematuros anêmicos demonstrou que a transfusão induziu uma redução na complacência respiratória, incrementos na resistência vascular pulmonar e aumento do trabalho respiratório. Todavia os autores ponderam que estas alterações podem ter ocorrido devido à sobrecarga de volume ou o aumento do conteúdo de água nos pulmões ${ }^{150}$. Estes efeitos deletérios não foram reproduzidos em outros estudos em humanos, uma vez que a transfusão diminuiu o trabalho respiratório, sem qualquer efeito nocivo para a troca gasosa, tanto em pacientes com doença pulmonar obstrutiva crônica como em controles anêmicos $^{153}$. Estudo em pacientes sob ventilação mecânica também não demonstrou alteração na função pulmonar e mecânica respiratória após transfusão de uma unidade de GV fresco ou estocado ${ }^{103}$. Entretanto, um estudo recente em modelo suíno demonstrou diminuição significativa na complacência pulmonar 1,5 e 24 horas após a transfusão de GV homólogos e 
evidências histológicas de lesão pulmonar aguda, caracterizada por infiltração neutrofílica e ativação endotelial do pulmão após 24 horas, que foi exacerbada quando associada à circulação extracorpórea ${ }^{139}$, sem sinais de sobrecarga volêmica.

Em nosso estudo não observamos uma piora da troca gasosa durante 0 tempo avaliado. Sabe-se que o desenvolvimento de disfunção respiratória "per si" compromete a recuperação de pacientes graves e pode contribuir para maior morbimortalidade. Adicionalmente, várias são as reações adversas transfusionais que têm 0 pulmão como órgão alvo, todavia o diagnóstico diferencial por vezes não é uma tarefa fácil. O prejuízo na troca gasosa, diminuição da complacência pulmonar e alterações radiológicas, são isoladamente ou em conjunto, indicadores de edema agudo pulmonar de diversas etiologias. Com a finalidade de diferenciar alteração de permeabilidade pulmonar (TRALI) secundária à transfusão de GV, de sobrecarga volêmica $(\mathrm{TACO})^{53}$ utilizamos uma técnica de monitorização cardiovascular $\mathrm{PiCCO}^{\circledR}$, (Pulse index Contour Continuous Cardiac Output, Pulsion Medical Systems, Germany). Esta técnica fornece informação precisa sobre o status volêmico e edema pulmonar, através da combinação das técnicas de termodiluição transpulmonar e análise de contorno de pulso ${ }^{219,127}$. Vários estudos demonstraram que a transfusão resulta em lesão pulmonar moderada, não preenchendo os critérios estabelecidos para TRALI e, portanto não diagnosticados e tratados como tal ${ }^{181,33}$, muitas vezes dose dependente sem relação com o tempo de estocagem, em uma população heterogênea de pacientes críticos $^{27}$. Outras reações adversas à transfusão de GV, tais como sobrecarga volêmica ${ }^{53}$ e dispneias associadas à transfusão (TAD) também 
estão relacionadas à maior morbidade, porém sua real incidência ainda não é bem conhecida ${ }^{102}$. Estudo em pacientes submetidos concomitantemente à circulação extracorpórea e múltiplas transfusões de GV não identificou alterações significativas na troca gasosa pulmonar, quando comparados a pacientes não transfundidos ou que receberam menor numero de unidades de $\mathrm{GV}^{184}$. Adicionalmente, um estudo em doadores humanos sadios observou alterações pulmonares agudas subclínicas na primeira hora após transfusão de GV autólogos, frescos e estocados, definida por diferença alvéolo-arterial da pressão parcial de oxigênio, com normalização após 24 horas, porem sem diferença clínica significativa na pressão arterial de oxigênio ${ }^{212}$. As unidades de GV transfundidas neste estudo eram autólogas, sugerindo que alterações agudas subclínicas possam ocorrer independentes do status do receptor. Excetuando-se os diversos estudos que avaliam a ocorrência de $\operatorname{TRALI}^{98} \mathrm{O}$ efeito da transfusão de hemácias na resposta inflamatória pulmonar foi objeto de poucos estudos na literatura e estes resultados são discordantes ${ }^{181}$.

Para mostrar a importância da associação entre transfusão sanguínea e efeito adverso pulmonar, uma revisão recente sobre a SDRA relatou a diminuição da incidência desta síndrome no período entre 2001-2008 comparado com o período de 1999-2000, e entre os diversos motivos avaliados estão o uso mais conservador da transfusão de hemocomponentes ${ }^{120}$. 


\subsection{Efeitos Inflamatórios}

Neste estudo não observamos alteração na dosagem de citocinas inflamatórias no plasma e também na mensuração de seus precursores no tecido pulmonar através da técnica de PCR - real time pra RNAm, corroborando o estudo realizado em modelo ovino ${ }^{8}$. Um estudo em modelo murino mostrou resultados similares ao nosso, em animais sadios a transfusão de sangue estocado não induziu resposta inflamatória pulmonar ${ }^{115}$. Entretanto, o pré-tratamento destes animais com endotoxina amplificou significativamente os efeitos inflamatórios da transfusão, incluindo aumento na contagem de leucócitos e na concentração de citocinas no lavado bronco-alveolar.

Estudos em humanos que avaliaram o status inflamatório após transfusão de GV mostram resultados controversos. Um estudo em recémnascidos pré-termo mostrou evidências de resposta inflamatória 2 e 4 horas após a transfusão ${ }^{93}$, já um estudo realizado em pacientes pós cirurgias cardíacas com circulação extracorpórea relatou aumento de IL-8 apenas no lavado broncoalveolar 6 horas após transfusão de $\mathrm{GV}^{204}$. Por outro lado, um estudo em pacientes de terapia intensiva em ventilação mecânica, não encontrou diferença no status inflamatório e na coagulação até 2 horas após transfusão ${ }^{103}$, o mesmo ocorreu após transfusão de 01 unidade de GV autólogo estocado ${ }^{77}$.

Estudos experimentais em ratos demonstraram rápida resposta próinflamatória, com aumento de citocinas após transfusão de 02 unidades de GV estocados por 42 dias (interleucina -6 [IL-6], fator de necrose tumoral $\alpha[$ TNF- $\alpha$ ], proteína quimiotática de monócitos 1 (MCP-1) e proteína inflamatória de 
monócitos 1 beta [MIP-1 $1 \beta])^{76}$, todavia o tempo de estocagem utilizado para este modelo animal foi muito longo ${ }^{56,9}$ o que pode ter superestimado os resultados, outro estudo também demonstrou aumento da IL-6 em ratos 2 horas após a transfusão de GV estocados por 2 semanas $^{216}$. Outro estudo em modelo canino também demonstrou (aumento da proteína quimiotática de monócitos 1 (MCP-1), 6 horas após a transfusão de GV estocados por 28 dias, independente da leucorredução $0^{22}$. Interessantemente, estes dados não foram confirmados em estudo recente realizado com voluntários sadios após transfusão de GV autólogos estocados (40-42 dias) ${ }^{76}$.

Em nosso estudo o único efeito significativo da transfusão de glóbulos vermelhos na inflamação pulmonar foram alterações modestas na expressão do gene de iNOS (óxido nítrico sintetase induzida) e IL-21 no tecido pulmonar. A iNOS tem sido consistentemente correlacionada com a inflamação ${ }^{6}$. Adicionalmente, vários estudos experimentais relatam uma diminuição da biodisponibilidade do NO após transfusão de GV estocados, com repercussão clínica, e em alguns estudos a inalação de NO atenuou o quadro ${ }^{107}$. Em 2009, foi proposto por Gladwin e Kim-Shapiro que vários eventos adversos (vasoconstrição, inflamação, trombose) atribuídos à transfusão de GV estocados são decorrentes da diminuição da biodisponibilidade do NO secundário a um desequilíbrio entre a sua produção e destruição. A regulação do tônus vascular é controlada por NOS através de uma regulação parácrina dos níveis de NO. Três são as isoformas de NOS, neuronal, induzível e endotelial. A NOS endotelial é provavelmente a maior fonte de regulação do tônus vascular, mas NOS neuronal e possivelmente a NOS induzível também desempenham este papel ${ }^{146}$. No entanto, apesar de ocorrer decréscimo nos 
níveis de NO nos GV horas após a estocagem, estes níveis são restaurados rapidamente após a transfusão. Além disto, a hemoglobina livre proveniente da lise dos GV é rapidamente ligada à haptoglobina e filtrada pelos rins, sugerindo que estes efeitos do NO sejam transitórios, com rápida restauração de sua biodisponibilidade ${ }^{180}$. A maioria dos estudos avalia o "consumo" do NO indiretamente através da melhora dos sinais de vasoconstrição com inalação de óxido nítrico ${ }^{215,216,8,107}$ e intensificação destes sinais com a inibição da NOS com a L-NAME ${ }^{8}$, da dosagem de seus metabólitos nitrato/ nitrito ${ }^{8}$; outro estudo avaliou através da dosagem do precursor da Hemeoxigenase $-1(\mathrm{HO}-1)^{107}$. Em nosso estudo a ideia inicial era avaliar a produção de NOS induzida, que estaria associada à possível alteração inflamatória desencadeada pela transfusão de GV estocado. Não observamos alteração significativa dos níveis de nitrato plasmático entre os grupos estudados corroborando com o estudo em modelo ovino sadio ${ }^{8}$, sugerindo que pacientes com redução do nível vascular de NO, secundário à disfunção endotelial são mais susceptíveis a efeitos adversos provenientes da estocagem de GV por períodos prolongados. Salientando que ${ }^{8}$ também encontraram aumento da PAP na primeira hora após a transfusão sugerindo uma relação entre diminuição da biodisponibilidade de NO e vasoconstrição.

A IL-21 é uma citocina recentemente estudado que aumenta após a exposição à endotoxina ${ }^{57}$, e tem sido relatada interagir com IL-10 na regulação da resposta anti-inflamatória ${ }^{167}$. No entanto, estas alterações não foram seguidas por mudanças significativas nos "produtos" destes mediadores, já que não foi possível identificar variações na concentração de proteína IL-21 ou nitrato no tecido pulmonar. É possível que o efeito da transfusão de GV na 
inflamação fosse aumentado com a exposição a um insulto concomitante como sepses ou lesão pulmonar ou em um período mais longo de observação. $O$ stress oxidativo da inflamação pode estar associado com diversas condições patológicas prévias dos receptores, incluindo obesidade, resistência à insulina, hipertensão e doença coronariana ${ }^{59}$.

Em relação aos estudos em humanos, ensaio clínico prévio detectou um aumento nas concentrações plasmáticas de IL-6 e IL-8 após a transfusão de hemácias em pacientes $\operatorname{críticos}^{88}$. Além disso, estudo recente que avaliou mais especificamente os efeitos pulmonares da transfusão em pacientes submetidos concomitantemente à circulação extracorpórea e transfusão de sangue, demonstrou que transfusões múltiplas foram associadas ao aumento das concentrações de citocinas e fatores de coagulação no lavado broncoalveolar ${ }^{184}$. Outro estudo avaliou o efeito agudo da transfusão de sangue na permeabilidade pulmonar em pacientes no pós operatório de cirurgia cardíaca e observou aumento do PLI (pulmonary leak index) sem queda significativa da relação $\mathrm{PaO}_{2} / \mathrm{FIO}_{2}{ }^{204}$. Por outro lado, uma investigação em pacientes críticos demonstrou que a transfusão de RBC "velho" (média do tempo de armazenamento de 26 dias) não induziu efeitos significativos sobre a função respiratória, imunológica e de coagulação, em comparação com RBC fresco ${ }^{102}$. Estes resultados demonstram a controvérsia desta questão.

Estudo publicado recentemente, em modelo suíno de circulação extracorpórea, demonstrou associação entre transfusão de GV estocados (média 37 dias) e alteração significativa da função renal e da resposta inflamatória ${ }^{140}$. No entanto, estes autores utilizaram um tempo de armazenamento do GV muito longo, tendo em vista que a meia-vida de RBC 
transfundido homóloga em suínos é de 20 dias $^{130}$. Além disso, expectativa de vida média dos RBC suínos e menor do que em humanos (86 vs 120 dias) ${ }^{43}$ o que sugere que os efeitos observados neste estudo podem ser superestimados. O mesmo grupo em estudo posterior com suínos demonstrou evidencias histológicas de lesão pulmonar aguda, caracterizada por infiltração neutrofílica e ativação endotelial do pulmão após 24 horas, que foi exacerbada quando associada à circulação extracorpórea ${ }^{139}$.

Levando-se em conta o exposto até o momento, podemos observar que esta relação risco versus benefício da transfusão de glóbulos vermelhos ainda está longe de ser esclarecida. Vários são os fatores de confusão, incluindo: características dos GV transfundidos (tempo de estocagem, solução preservativa, utilização de filtros de leucorredução, características do doador), número de unidades transfundidas e características inerentes aos pacientes (comorbidades) que dificultam uma relação de associação independente entre a transfusão e pior evolução destes pacientes. Portanto estudo em animais tem a vantagem de se controlar os diversos fatores de confusão descritos acima.

Para mostrar a importância da associação entre transfusão sanguínea e efeito adverso pulmonar, uma revisão recente sobre a SDRA relatou a diminuição da incidência desta síndrome no período entre 2001-2008 comparado com o período de 1999-2000, e entre os diversos motivos avaliados estão o uso mais conservador da transfusão de hemocomponentes ${ }^{120}$. Aliado a este fato as complicações transfusionais relacionadas ao sistema respiratório estão entre os principais eventos graves da transfusão $26,53,133,220,27,184,211$ e uma das principais causas de fatalidade associada à transfusão $0^{62,19,117,189,153,186}$ 
Em resumo há na literatura evidências substanciais de estudos préclínicos que transfusão de GV estocados altera a microcirculação e a liberação de oxigênio ${ }^{177,10,144,28}$. Estudos clínicos têm demonstrado resultados conflitantes $^{168,108,198,190,60,165}$. Razões para esta pior evolução permanecem incertas no que diz respeito à sua mera existência, magnitude, associação causal e fatores envolvidos e tem sido recentemente revisadas ${ }^{198,190,60,165,198,137}$. Estas incluem o tipo de desenho dos estudos clínicos, na grande maioria observacional e retrospectiva, a falta de comparação entre os grupos estudados, diferenças geográficas na produção e estocagem das unidades de GV (por ex leucorredução, buffy-coat, lavagem etc.), diferentes tempos de estocagem, indicações transfusionais e diferentes desfechos. Estudos em indivíduos sadios, com a finalidade de afastar os fatores de confusão inerente ao paciente, por motivos éticos só podem ser realizados com sangue autólogo e, portanto não traduzindo o que ocorre na prática clínica. Por outro lado, estudos em pacientes com diferentes comorbidades são ótimos para entender a fisiopatologia, mas são limitados por vieses de indicação e fatores de confusão. Além dos fatores expostos acima, recentemente tem sido bastante discutido que fatores inerentes ao doador, tais como idade, sexo, paridade e ate mesmo tipo sanguíneo podem estar relacionados a complicações adversas agudas e em longo prazo à transfusão de sangue ${ }^{182,24}$. Uma revisão sistemática está sendo realizada para avaliar esta associação ${ }^{25}$. Muitos estudos experimentais por sua vez esbarram em diferenças interespécie, nas propriedades de estocagem das unidades de GV e resposta imunológica. Até o momento, nenhuma prova conclusiva de relação causal entre transfusão de GV estocado e evento adverso foi estabelecido. 
Na tentativa de identificar a possível fisiopatologia dos eventos adversos associados à transfusão de GV estocados, vários estudos estão sendo realizados. Com a finalidade de afastar variáveis de confusão, estudos controlam o receptor e avaliam diferentes características relacionadas à unidade de GV transfundida, tais como: tempos diferentes de estocagem, presença de células integras, fragmentos celulares, substancias liberadas pela degeneração das células (leucorredução) e acumuladas no plasma (lavagem). Para mostrar a importância e a atualidade deste estudo, atualmente, vários estudos controlados randomizados estão sendo conduzidos no Canadá, Estados Unidos e Austrália para verificar se GV estocados por maior período estão relacionados à maior morbimortalidade em várias situações clínicas $^{104,72,92}$, outros dois recentemente concluídos não encontraram associação entre tempo de estocagem e maior morbimortalidade ${ }^{168,47}$

Este experimento é o primeiro realizado em nosso centro envolvendo a avaliação de transfusão em um modelo suíno. Optamos por utilizar em nosso experimento unidades de GV estocadas por 14 dias, que é similar a unidades próximas ao período maior de estocagem em humanos (42 dias) conforme o controle de qualidade descrito previamente, para maior homologia ao que ocorre rotineiramente nos serviços transfusionais em nosso país. A opção de utilização de unidades não leucorreduzidas corrobora a mesma filosofia, tendo em vista que em nosso país não é obrigatória a leucorredução universal dos hemocomponentes, sendo esta mandatória apenas para indicações específicas (Brasil, 2013).

Nossos resultados devem ser interpretados com as considerações apropriadas dos limites de um modelo pré clinico. Devido ao tamanho da 
amostra temos a possibilidade de erros de tipo II, que podem ter influenciado o resultado. Outra limitação é o período relativamente curto de observação após a transfusão de sangue. É possível que os efeitos deletérios da transfusão de glóbulos vermelhos possam ocorrer mais tardiamente, embora estudos anteriores em humanos demonstrassem que efeitos deletérios da transfusão ocorreram até 6 horas após a administração de GV $^{204,184}$ e estudos experimentais em até 4 horas após a transfusão ${ }^{8,185,139}$. Outro ponto a ser discutido é pequeno número de número de unidades transfundidas (duas), a toxicidade dos GV estocados parece estar relacionada á quantidade de bolsas transfundidas. Estudo clínico relatou que o risco de insuficiência renal aguda foi diretamente proporcional ao numero de unidades transfundidas em pacientes submetidos à cirurgia cardíaca ${ }^{90}$. Todavia, observamos um crescente número de estudos na literatura associando a transfusão de até 2 unidades de GV e aumento de morbimortalidade em pacientes de cirurgia cardíaca ${ }^{171,86,137}$.

Nosso estudo tem alguns pontos fortes, como o desenvolvimento de um modelo transfusional que se assemelha a transfusão realizada na pratica clínica em pacientes agudamente hipovolêmicos. Adicionalmente os critérios de processamento, estocagem e testes de compatibilidade das unidades de GV mimetizam o que ocorre em humanos, e o modelo suíno tem ótima correlação em termos de anatomia, bioquímica, fisiologia, e tamanho com humanos ${ }^{147}$. Além disso, foi realizada uma ampla avaliação da função pulmonar, incluindo a avaliação dos possíveis caminhos mecanicistas associada a efeitos relacionados com a transfusão de pulmão.

Além disso, avaliamos o efeito da transfusão de hemácias isoladamente, isto é em animais sadios, pois sabemos que em pulmões previamente 
"ativados", o efeito da transfusão de sangue pode ser potencializado ${ }^{186,107,185,50}$. Importante salientar que durante o período estudado (até 6 horas após a transfusão) não observamos nenhum sinal de hipóxia neste modelo, principal achado de TRALI. Neste estudo o nosso principal objetivo foi avaliar o efeito independente da transfusão de sangue em pulmões saudáveis. Acreditamos que este modelo, uma vez que foi concebido, abre um campo de pesquisa toda para avaliar os efeitos da transfusão durante o trauma, cirurgia ou outras condições inflamatórias.

Pontos a serem discutidos na comparação de "efeitos" de estocagem no modelo suíno com humano: o controle de qualidade "in vitro" dos GV suínos foi realizado a semelhança do realizado em humanos assim como o controle "in vivo" com a marcação de cromato de sódio radioativo, entretanto não há na literatura até o momento dados comparando a lesão de estocagem entre GV humano e suíno. Apesar do resultado do controle de qualidade "in vitro" das unidades transfundidas com 14 dias de estocagem ter evidenciado equivalência com unidades de GV humano no último dia de estocagem, a sobrevida das hemácias "in vivo" marcadas com cromato de sódio, demonstrou viabilidade das mesmas acima de 90\%, não esperado para hemácias humanas.

Levando-se em conta o exposto até agora parece haver uma "interação" entre fatores do receptor e da transfusão de GV na explicação dos efeitos adversos imune-inflamatórios, aonde a transfusão se comportaria como a injúria adicional. Desta forma, as alterações sofridas pelo GV na circulação podem ser induzidas mais por fatores relacionados ao receptor do que da lesão de estocagem. A transfusão de sangue é uma terapia rotineira de "transplante" 
de células homólogas e introdução de antígenos solúveis que frequentemente induzem a uma resposta aloimune tanto imunossupressiva quanto próinflamatória ${ }^{82,40,44,71,85,25}$. O nosso maior objetivo neste estudo foi desenvolver um modelo transfusional de GV estocados que apresentasse homologia com a transfusão em humanos e avaliar o efeito independente da transfusão de GV em animais "sadios". Acreditamos que este modelo de transfusão homologa em suínos contribuirá para futuros estudos relacionados aos efeitos da transfusão, tais como cuidados especiais (leucorredução), tempo de estocagem, interações entre transfusão, comorbidades no receptor e características do doador que não são possíveis em humanos devido a aspectos éticos e logísticos. 
6. Conclusão 

Este estudo demonstrou que o modelo suíno pode ser utilizado para coleta, processamento, estocagem e transfusão de glóbulos vermelhos utilizando os mesmos processos realizados na rotina em humanos, doadores de sangue e pacientes. Adicionalmente demonstra a importância dos testes de compatibilidade eritrocitária, que muitas vezes não é utilizado rotineiramente em modelos animais, principalmente para investigar efeitos adversos à transfusão de sangue homólogo.

O modelo experimental de transfusão de GV em suínos desenvolvido neste estudo pode ser utilizado para realizar a pesquisa mecanistica visando à função cardiovascular e respiratória, controlando possíveis fatores de confusão inerentes ao receptor e a unidade transfundida. Este estudo demonstrou ainda que a transfusão homóloga de GV armazenado durante 14 dias em modelo de receptores saudáveis não foi associada a alterações do sistema cardiocirculatório e respiratório e alterações inflamatórias agudas em porcos saudáveis submetidos à hipovolemia controlada.

Estudos posteriores são necessários para avaliar as consequências fisiopatológicas da transfusão de GV em modelos experimentais com doenças concomitantes. 

7. Referências Bibliográficas 

1. Alexander JT, El-Ali AM, Newman JL et al. Red Blood cells stored for increasing periods produce progressive impairments in nitric oxide-mediated vasodilation. Transfusion. 2013;53:2619-28.

2. Almac $\mathrm{E}$, Ince $\mathrm{C}$. The impact of storage on red cell function in blood transfusion. Best Pract Res Clin Anaesthesiol. 2007; 21:195-208.

3. Anniss AM, Sparrow RL. Storage duration and white blood cell content of red blood cell (RBC) products increases adhesion of stored RBCs to endothelium under flow conditions. Transfusion. 2006; 46:1561-7.

4. AuBuchon JP, Dumont LJ, Herschel L, Roger J, Beddard RL, Taylor HL, Whitley PH, Sawyer SL, Graminske S, Martinson K, Dora R, Heldke S, Adamson J, Rose LE. Automated collection of double red blood cell units with a variable-volume separation chamber. Transfusion. 2008;48:147-52.

5. Australian and New Zealand Intensive Care Research Centre. Standard issue transfusion versus fresher red cell use in intensive care: a randomized controlled trial (TRANSFUSE). [cited $2014 \quad$ Dez] http://clinicaltrials.gov/ct2/show/NCT01638416.Accessed.

6. Azevedo LC, Janiszewski M, Soriano FG, Laurindo FR. Redox mechanisms of vascular cell dysfunction in sepsis. Endocr Metab Immune Disord Drug Targets. 2006; 6:159-64.

7. Baek JH, D'Agnillo F, Vallelian F, Pereira CP, Williams MC, Jia Y, Schaer DJ, Buehler PW. Hemoglobin-driven pathophysiology is an in vivo consequence of the red blood cell storage lesion that can be attenuated in guinea pigs by haptoglobin therapy. J Clin Invest. 2012;122:1444-58.

8. Baron DM, Yu B, Lei C, Bagchi A, Beloiartsev A, Stowell CP, Steinbicker AU, Malhotra R, Bloch KD, Zapol WM. Pulmonary hypertension in lambs transfused with stored blood is prevented by breathing nitric oxide. Anesthesiology. 2012; 116:637-47.

9. Belizaire RM, Prakash PS Richter JR, Robinson BR, MD, Edwards MJ, Caldwell CC, Lentsch AB, Pritts TA. Microparticles from stored red blood cells activate neutrophils and cause lung injury after hemorrhage and resuscitation $J$ Am Coll Surg. 2012; 214: 648-657. 
10. Bennett-Guerrero E, Veldman TH, Doctor A, Telen MJ, Ortel TL, Reid TS, Mulherin MA, Zhu H, Buck RD, Califf RM, McMahon TJ. Evolution of adverse changes in stored RBCs. Proc Natl Acad Sci USA. 2007;104(43):17063-8.

11. Berman IR, Iliescu $\mathrm{H}$, Ranson JH, Eng K. Pulmonary capillary permeability: a transfusion lesion. J Trauma. 1976; 16:471-80.

12. Berra L, Coppadoro A, Yu B, Lei C, Spagnolli E, Steinbicker AU, Bloch KD, Lin T, Sammy FY, Warren HS, Fernandez BO, Feelisch M, Dzik WH, Stowell CP, Zapol WM. Transfusion of stored autologous blood does not alter reactive hyperemia index in healthy volunteers. Anesthesiology. 2012; 117:56-63.

13. Biffl WL, Moore EE, Offner PJ, Ciesla DJ, Gonzalez RJ, Silliman CC. Plasma from aged stored red blood cells delays neutrophil apoptosis and primes for cytotoxicity: abrogation by poststorage washing but not prestorage leukoreduction. J Trauma. 2001; 50:426-31; discussion 432.

14. Blumberg N, Agarwal M, Chuang C . Relations between recurrence of cancer of the colon and blood transfusion. Br Med J. 1985;290:1037-9.

15. Brasil. Ministério da Saúde. Portaria no 2.712, Redefine o regulamento técnico de procedimentos hemoterápicos de 12 de novembro de 2013. Diário Oficial da União, Brasília. 13 nov. 2013; n.221, Seção 1, p.106. Disponível em: http://pesquisa.in.gov.br/imprensa/jsp/visualiza/index.jsp?jornal=1 \&pagina=106 $\underline{\text { \&data }=13 / 11 / 2013}$

16. Brown HS, Turk LN 3rd, Hopkins WA. Management of the white lung syndrome. Ann Thorac Surg. 1972; 13:411-9.

17. Burrows L, Tartter $P$, Aufses A. Increased Recurrence Rates in Perioperatively Transfused Colorectal Malignancy Patients. Cancer Detect Prev. 10:361-9,1987

18. Bush JA, Jensen WN, Athens JW, Ashenbrucker H, Cartwright GE, Wintrobe MM. Studies on copper metabolism. XIX. The kinetics of iron metabolism and erythrocyte life-span in copper-deficient swine. J Exp Med. 1956;103:701-12.

19. Bux J, Sachs UJ. Pulmonary transfusion reactions. Transfus Med Hemother. 2008;35:337-45. 
20. Cabello B, Mancebo J. Work of breathing. Intensive Care Med. 2006; 32:13114.

21. Cabrales $P$, Tsai AG, Intaglietta M. Modulation of perfusion and oxygenation by red blood cell oxygen affinity during acute anemia. Am J Respir Cell Mol Biol. 2008; 38:354-61.

22. Callan MB, Patel RT, Rux AH, Bandyopadhyay S, Sireci AN, O'Donnell PA, Ruane T, Sikora T, Marryott K, Sachais BS, Hod EA. Transfusion of 28-day-old leucoreduced or non-leucoreduced stored red blood cells induces an inflammatory response in healthy dogs. Vox Sanguinis. 2013;105:319-27.

23. Carson JL, Reynolds RC, Klein HG. Bad bad blood? Crit Care Med. 2008; 36:2707-8.

24. Chapman CE, Williamson LM: National Blood Service TRALI reduction policies: implementation and effect. Transfus Med Hemother. 2008;35:93-6.

25. Chassé M, English SW, Mclntyre L, Knoll G, Shehata N, Forster A, Wilson $\mathrm{K}$, van Walraven $\mathrm{C}$, Tinmouth $\mathrm{A}$, Fergusson DA. Effect of blood donor characteristics on transfusion outcomes: a protocol for systematic review and meta-analysis. Syst Rev. 2014;3:28.

26. Collard KJ, Godeck S, Holley JE. Blood transfusion and pulmonary lipid peroxidation in ventilated premature babies. Pediatr Pulmonol. 2005;39:257-61.

27. Cornet AD, Zwart E, Kingma SD, Groeneveld AB. Pulmonary effects of red blood cell transfusion in critically ill, non-bleeding patients. Transfus Med. 2010; 20:221-6.

28. Cortés-Puch I, Wang D, Sun J, Solomon SB, Remy KE, Fernandez M, Feng J, Kanias T, Bellavia L, Sinchar D, Perlegas A, Solomon MA, Kelley WE, Popovsky MA, Gladwin MT, Kim-Shapiro DB, Klein HG, Natanson C. Washing older blood units before transfusion reduces plasma iron and improves outcomes in experimental canine pneumonia. Blood. 2014;123:1403-11. 
29. Corwin HL, Gettinger A, Pearl RG, Fink MP, Levy MM, Abraham E, Maclntyre NR, Shabot MM, Duh MS, Shapiro MJ. The CRIT Study: Anemia and blood transfusion in the critically ill--current clinical practice in the United States. Crit Care Med. 2004; 32:39-52.

30. Council of Europe. European Directorate for the Quality of Medicines and Healthcare. Guide to the preparation, use and quality assurance of blood components. $16^{\text {th }}$ ed. Strasbourg, France; 2011.

31. da Silva Almeida JR, Machado FS, Schettino GP, Park M, Azevedo LC. Cardiopulmonary effects of matching positive end-expiratory pressure to abdominal pressure in concomitant abdominal hypertension and acute lung injury. J Trauma. 2010; 69:375-83.

32. Dacie JV Sir, Lewis SM. Practical haematology. $5^{\text {th }}$ ed. Edinburgh: Churchill Livingstone; 1975.

33. Davis A, Mandal R, Johnson M, Makar R, Stowell C, Dzik S. A touch of TRALI. Transfusion. 2008; 48:541-5.

34. De Backer D, Dubois MJ. Assessment of the microcirculatory flow in patients in the intensive care unit. Curr Opin Crit Care. 2001; 7:200-3.

35. Dietrich KA, Conrad SA, Hebert CA, Levy GL, Romero MD. Cardiovascular and metabolic response to red blood cell transfusion in critically ill volumeresuscitated nonsurgical patients. Crit Care Med. 1990; 18:940-4.

36. Dixon B, Santamaria JD, Reid D, Collins M, Rechnitzer T, Newcomb AE., Nixon I, Yii ML, Rosalion A, Campbell DJ. The association of blood transfusion with mortality after cardiac surgery: cause or confounding? Transfusion. 2013;53:19-27.

37. Donadee C, Raat NJ, Kanias T, Tejero J, Lee JS, Kelley EE, Zhao X, Liu C, Reynolds H, Azarov I, Frizzell S, Meyer EM, Donnenberg AD, Qu L, Triulzi D, Kim-Shapiro DB, Gladwin MT: Nitric oxide scavenging by red blood cell microparticles and cell-free hemoglobin as a mechanism for the red cell storage lesion. Circulation. 2011. 124:465-76. 
38. Dood RY, Notari EP, Stramer SL. Current prevalence and incidence of infectious diseae markers and estimated window -period risk in the American Red Cross blood donor population [comment]. Transfusion. 2002; 42: 975-9.

39. Dumont LJ and AuBuchon $P$, for the Biomedical Excellence for Safer Transfusion (BEST) Collaborative. Transfusion 2008;48:1053-1060

40. Dutcher JP, Schiffer CA, Aisner J, Wiernik PH. Alloimmunization following platelet transfusion: the absence of a dose-response relationship. Blood. 1981; 57:395-8.

41. Dzik WH, Anderson JK, O'Neill EM, Assmann SF, Kalish LA, Stowell CP. A prospective, randomized clinical trial of universal WBC reduction. Transfusion. 2002; 42:1114-22.

42. Ebaugh FG Jr, Emerson CP, Ross JF. The use of radioactive chromium 51 as an erythrocyte tagging agent for the determination or red cell survival in vivo. $\mathrm{J}$ Clin Invest. 1953;32:1260-76.

43. Eckermann JM, Buhler LH, Zhu A, Dor FJ, Awwad M, Cooper DK. Initial investigation of the potential of modified porcine erythrocytes for transfusion in primates. Xenotransplantation. 2004; 11:18-26.

44. Fauchet $R$, Genetet $B$, Gueguen $M$, Leguerrier A, Rioux C, Logeais $Y$. Transfusion therapy and HLA antibody response in patients undergoing open heart surgery. Transfusion. 1982; 22:320-2.

45. Fernandes CJ Jr, Akamine N, De Marco FV, De Souza JA, Lagudis S, Knobel E. Red blood cell transfusion does not increase oxygen consumption in critically ill septic patients. Crit Care. 2001; 5:362-7.

46. Fergusson D, Khanna MP, Tinmouth A, Hébert PC. Transfusion of leukoreduced red blood cells may decrease postoperative infections: two metaanalyses of randomized controlled trials. Can J Anaesth. 2004; 51:417-24. 
47. Fergusson DA, Hébert $P$, Hogan DL, LeBel L, Rouvinez-Bouali N, Smyth JA, Sankaran K, Tinmouth A, Blajchman MA, Kovacs L, Lachance C, Lee S, Walker CR, Hutton B, Ducharme R, Balchin K, Ramsay T, Ford JC, Kakadekar A, Ramesh K, Shapiro S. Effect of fresh red blood cell transfusions on clinical outcomes in premature, very low- birth -weight infants. the ARIPI randomized trial. JAMA. 2012; 308:1443-51.

48. Fransen E, Maessen J, Dentener M, Senden N, Buurman W. Impact of blood transfusions on inflammatory mediator release in patients undergoing cardiac surgery. Chest. 1999; 116:1233-9.

49. Frenzel T, Westphal-Varghese B, Westphal M. Role of storage time of red blood cells on microcirculation and tissue oxygenation in critically ill patients. Curr Opin Anaesthesiol. 2009; 22:275-80.

50. Fung YL, Tung JP, Foley SR, Simonova G, Thom O, Staib A, Collier J, Dunster KR, Solano C, Shekar K, Chew MS, Fraser JF. Stored blood transfusion induces transient pulmonary arterial hypertension without impairing coagulation in an ovine model of nontraumatic haemorrhage. Vox Sang. 2013; 105:150-8.

51. Fung MK, Grossman BJ, Hillyer C, Westhoff $\mathrm{CM}$, editors. AABB technical manual. $18^{\text {th }}$ ed. Bethesda (MD): AABB; 2014.

52. Gajic O, Dara SI, Mendez JL, Adesanya AO, Festic E, Caples SM, Rana R, St Sauver JL, Lymp JF, Afessa B, Hubmayr RD. Ventilator-associated lung injury in patients without acute lung injury at the onset of mechanical ventilation. Crit Care Med. 2004; 32:1817-24.

53. Gajic O, Gropper MA, Hubmayr RD. Pulmonary edema after transfusion: how to differentiate transfusion-associated circulatory overload from transfusion-related acute lung injury. Crit Care Med. 2006; 34(5 Suppl):S109-13.

54. Gantt CL. Red Blood Cells for Cancer Patients. Lancet. 2:363,1981. 
55. Gauvin F, Spinella PC, Lacroix J, Choker G, Ducruet T, Karam O, Hébert PC, Hutchison JS, Hume HA, Tucci M; Canadian Critical Care Trials Group and the Pediatric Acute Lung Injury and Sepsis Investigators (PALISI) Network. Association between length of storage of transfused red blood cells and multiple organ dysfunction syndrome in pediatric intensive care patients. Transfusion. 2010; 50:1902-13.

56. Gilson CR, Kraus TS, Hod EA, Hendrickson JE, Spitalnik SL, Hillyer CD, Shaz $\mathrm{BH}$, Zimring JC. A novel mouse of red blood cell storage and posttransfusion in vivo survival. Transfusion. 2009;49:1546-53.

57. Glader P, Smith ME, Malmhäll C, Balder B, Sjöstrand M, Qvarfordt I, Lindén A. Interleukin-17-producing T-helper cells and related cytokines in human airways exposed to endotoxin. Eur Respir J. 2010; 36:1155-64.

58. Gladwin MT, Kim-Shapiro DB. Storage lesion in banked blood due to hemolysis-dependent disruption of nitric oxide homeostasis. Curr Opin Hematol. 2009; 16:515-23.

59. Gladwin MT, Kanias T, Kim-Shapiro DB. Hemolysis and cell-free hemoglobin drive an intrinsic mechanism for human disease. J Clin Invest. 2012; 122:12058.

60. Glynn SA. The red blood cell storage lesion: a method to the madness. Transfusion. 2010; 50:1164-9.

61. Goldman M, Webert KE, Arnold DM, Freedman J, Hannon J, Blajchman MA; TRALI Consensus Panel. Proceedings of a consensus conference: towards an understanding of TRALI. Transfus Med Rev. 2005; 19:2-31.

62. Gong MN, Thompson BT, Williams P, Pothier L, Boyce PD, Christiani DC. Clinical predictors of and mortality in acute respiratory distress syndrome: potential role of red cell transfusion. Crit Care Med. 2005; 33:1191-8. 
63. Goodnough LT, Shander A. Patient blood management. Anesthesiology. 2012; 116:1367-76.

64. Goodnough LT, Maggio P, Hadhazy E, Shieh L, Hernandez-Boussard T, Khari $P$, Shah N. Restrictive blood transfusion practices are associated with improved patient outcomes. Transfusion. 2014;54:2753-9.

65. Gray SJ, Sterling K. The tagging of red blood cells and plasma proteins with radioactive chromium. J Clin Invest. 1950;29:818.

66. Hajjar LA, Vincent JL, Galas FR, et al: Transfusion requirements after cardiac surgery: The TRACS randomized trial. JAMA 2010;304:1559-1567.

67. Hannon JP, Bossone CA, Wade CE. Normal physiological values for conscious pigs used in biomedical research. Lab Anim Sci. 1990; 40:293-8.

68. Hauser GJ, Ben-Ari J, Colvin MP, Dalton HJ, Hertzog JH, Bearb M, Hopkins RA, Walker SM. Interleukin-6 levels in serum and lung lavage fluid of children undergoing open heart surgery correlate with postoperative morbidity. Intensive Care Med. 1998; 24:481-6.

69. Hébert PC, Fergusson D, Blajchman MA, Wells GA, Kmetic A, Coyle D, Heddle N, Germain M, Goldman M, Toye B, Schweitzer I, vanWalraven C, Devine D, Sher GD; Leukoreduction Study Investigators. Clinical outcomes following institution of the Canadian universal leukoreduction program for red blood cell transfusions. JAMA. 2003; 289:1941-9.

70. Hébert PC, Wells G, Blajchman MA, Marshall J, Martin C, Pagliarello G, Tweeddale M, Schweitzer I, Yetisir E. A multicenter, randomized, controlled clinical trial of transfusion requirements in critical care. Transfusion Requirements in Critical Care Investigators, Canadian Critical Care Trials Group. N Engl J Med. 1999;340:409-17.

71. Heddle NM, Cook RJ, Arnold DM, et al. The effect of blood storage duration on in-hospital mortality: a randomized controlled pilot feasibility trial. Transfusion. 2012;52:1203-12. 
72. Heddle NM, Cook RJ, Arnold DM, et al. The effect of blood storage duration on in-hospital mortality: a randomized controlled pilot feasibility trial. Transfusion. 2012;52:1203-12.

73. Hess JR. An update on solutions for red cell storage. Vox Sang. 2006; 91:13-9.

74. Hess JR; Biomedical Excellence for Safer Transfusion (BEST) Collaborative. Scientific problems in the regulation of red blood cell products. Transfusion. 2012;52:1827-35.

75. Ho J, Sibbald WJ, Chin-Yee IH. Effects of storage on efficacy of red cell transfusion: when is it not safe? Crit Care Med. 2003; 31(12 Suppl):S687-97.

76. Hod EA, Zhang N, Sokol SA, Wojczyk BS, Francis RO, Ansaldi D, Francis KP, Della-Latta P, Whittier S, Sheth S, Hendrickson JE, Zimring JC, Brittenham GM, Spitalnik SL. Transfusion of red blood cells after prolonged storage produces harmful effects that are mediated by iron and inflammation. Blood. 2010;115(21):4284-92.

77. Hod EA, Brittenham GM, Billote GB et al. Transfusion of human volunteers with older, stored red blood cells produces extravascular hemolysis and circulating non transferrin-bound iron. Blood. 2011; 118:6675-6682.

78. Hod EA, Spitalnik SL. Stored red blood cell transfusions: iron, inflammation, immunity, and infection. Transfus Clin Biol. 2012; 19:84-9.

79. Holst LB, Haase N, Wetterslev J, Wernerman J, Aneman A, Guttormsen AB, Johansson PI, Karlsson S, Klemenzson G, Winding R, Nebrich L, Albeck C, Vang ML, Bülow HH, Elkjær JM, Nielsen JS, Kirkegaard P, Nibro H, Lindhardt A, Strange D, Thormar K, Poulsen LM, Berezowicz P, Bådstøløkken PM, Strand K, Cronhjort M, Haunstrup E, Rian O, Oldner A, Bendtsen A, Iversen S, LanGVa JA, Johansen RB, Nielsen N, Pettilä V, Reinikainen M, Keld D, Leivdal S, Breider JM, Tjäder I, Reiter N, Gøttrup U, White J, Wiis J, Andersen LH, Steensen M, Perner A. Transfusion requirements in septic shock (TRISS) trial comparing the effects and safety of liberal versus restrictive red blood cell transfusion in septic shock patients in the ICU: protocol for a randomised controlled trial. Trials. 2013;14:150. 
80. Holst LB, Haase N, Wetterslev J, Wernerman J, Guttormsen AB, Karlsson S, Johansson PI, Aneman A, Vang ML, Winding R, Nebrich L, Nibro HL, Rasmussen BS, Lauridsen JRM, Nielsen JS, Oldner A, Pettilä V, Cronhjort M, Andersen LH, Pedersen Ulf G, Reiter N, Wiis J, White JO, Russel L, Thornberg KJ, Hjortrup PB, Müller RG, Møller MH, Steensen M, Tjäder I, Kilsand K, Odeberg- Werneman S, Bjøbø B, Bundgaard H, Thy MA, Lodahl .D., Maerkedahl R, Albeck C, Illum D, Kruse M, Winkel P and, Perner A, for the TRISS Trial Group* and the Scandinavian Critical Care Trials Group). Lower versus higher hemoglobin threshold for transfusion in septic shock. $N$ Eng $J$ Med. 2014; 371;15: 1381-91.

81. Hopewell S, Omar O, Hyde C, Yu LM, Doree C, Murphy MF. A systematic review of the effect of red blood cell transfusion on mortality: evidence from large-scale observational studies published between 2006 and 2010. BMJ Open. 2013;3(5). doi: 10.1136/bmjopen-2012-002154.

82. Howard JE, Perkins HA. The natural history of alloimmunization to platelets. Transfusion. 1978;18:496-503.

83. Hult A, Malm C, Oldenborg Per-Arne. Transfusion of cryopreserved human red blood cells into healthy humans is associated with rapid extravascular hemolysis without a proinflammatory cytokine response. Transfusion. 2013;53:28-33.

84. Hunfeld MA, Hoitsma HF, Meijer S, van Haeringen H, Rietveld FW. The role of A-O-incompatible blood transfusions in porcine orthotopic liver transplantations. Eur Surg Res. 1984;16:354-9.

85. Jackman RP. Immunomodulation in transfused trauma patients. Curr Opin Anaesthesiol. 2013; 26:196-203.

86. Jakobsen CJ, Ryhammer PK, Tang M, Andreasen JJ, Mortensen PE. Transfusion of blood during cardiac surgery is associated with higher long-term mortality in low-risk patients. Eur J Cardiothorac Surg. 2012;42:114-20.

87. Jiwaji Z, Nunn KP, Conway-Morris A, Simpson AJ, Wyncoll, Rossi AG, Walsh TS; RELIEVE Trial Investigators. Leukoreduced blood transfusion does not increase circulating soluble markers of inflammation: a randomized controlled trial. Transfusion. 2014;54:2404-11. 
88. Johnson JL, Moore EE, Gonzalez RJ, Fedel N, Partrick DA, Silliman CC. Alteration of the postinjury hyperinflammatory response by means of resuscitation with a red cell substitute. J Trauma. 2003; 54:133-9; discussion $139-40$.

89. Karam O, Tucci M, Bateman ST, Ducruet T, Spinella PC, Randolph AG, Lacroix $\mathrm{J}$. Association between length of storage of red blood cell units and outcome of critically ill children: a prospective observational study. Crit Care. 2010;14:R57.

90. Karkouti K, Wijeysundera DN, Yau TM, McCluskey SA, Chan CT, Wong PY, Beattie WS. Influence of erythrocyte transfusion on the risk of acute kidney injury after cardiac surgery differs in anemic and nonanemic patients. Anesthesiology. 2011;115:523-30.

91. Kato GJ. Understanding the erythrocyte storage lesion. Anesthesiology. 2012; 117:1159-61.

92. Kaukonen KM, Bailey M, Ady B, Aubron C, French C, Gantner D, Irving D, Murray L, Nichol A, Pettilä V, McQuilten Z, Cooper A randomised controlled trial of standard transfusion versus fresher red blood cell use in intensive care(TRANSFUSE): protocol and statistical analysis plan.DJCrit Care Resusc. 2014 Dec;16(4):255-61.

93. Keir AK, McPhee AJ, Andersen CC, Stark MJ. Plasma cytokines and markers of endothelial activation increase after packed red blood cell transfusion in the preterm infant. Pediatr Res. 2013;73:75-9.

94. Kenz HE, Van der Linden P. Transfusion-related acute lung injury. Eur $J$ Anaesthesiol. 2014;31:345-50.

95. Kim-Shapiro DB, Schechter AN, Gladwin MT. Unraveling the reactions of nitric oxide, nitrite, and hemoglobin in physiology and therapeutics. Arterioscler Thromb Vasc Biol. 2006; 26:697-705

96. Kim-Shapiro DB, Lee J, Gladwin MT. Storage lesion: role of red blood cell breakdown. Transfusion. 2011; 51:844-51.

97. Klein HG, Spahn DR, Carson JL. Red blood cell transfusion in clinical practice. Lancet. 2007;370(9585):415-26. 
98. Kleinman S, Caulfield T, Chan P, Davenport R, McFarland J, McPhedran S, Meade $M$, Morrison D, Pinsent T, Robillard P, Slinger P. Toward an understanding of transfusion-related acute lung injury: statement of a consensus panel. Transfusion. 2004; 44:1774-89.

99. Knotzer H, Pajk W, Maier S, Dünser MW, Ulmer H, Schwarz B, Salak N, Hasibeder WR. Comparison of lactated Ringer's, gelatine and blood resuscitation on intestinal oxygen supply and mucosal tissue oxygen tension in haemorrhagic shock. Br J Anaesth. 2006; 97:509-16.

100. Koch CG, Li L, Sessler DI, Figueroa P, Hoeltge GA, Mihaljevic T, Blackstone $\mathrm{EH}$. Duration of red-cell storage and complications after cardiac surgery. $N$ Engl J Med. 2008;358:1229-39.

101. Kopko P, Silva M, Shulman I, Kleinman S. AABB survey of transfusion-related acute lung injury policies and practices in the United States. Transfusion. 2007; 47:1679-85.

102. Kopko PM, Marshall CS, MacKenzie MR, Holland PV, Popovsky MA. Transfusion-related acute lung injury: report of a clinical look-back investigation. JAMA. 2002;287:1968-71.

103. Kor DJ, Kashyap R, Weiskopf RB, Wilson GA, van Buskirk CM, Winters JL, Malinchoc M, Hubmayr RD, Gajic O. Fresh red blood cell transfusion and shortterm pulmonary, immunologic, and coagulation status: a randomized clinical trial. Am J Respir Crit Care Med. 2012;185:842-50.

104. Lacroix J, Hébert P, Fergusson D, Tinmouth A, Blajchman MA, Callum J, Cook $\mathrm{D}$, Marshall JC, Mclntyre L, Turgeon AF; ABLE study group. The Age of Blood Evaluation (ABLE) randomized controlled trial: study design. Transfus Med Rev. $2011 ; 25: 197-205$.

105. Leal-Noval SR, Jara-López I, García-Garmendia JL, Marín-Niebla A, HerruzoAvilés A, Camacho-Laraña $\mathrm{P}$, Loscertales J. Influence of erythrocyte concentrate storage time on postsurgical morbidity in cardiac surgery patients. Anesthesiology. 2003; 98:815-22.

106. Lee MT, Small T, Khan MA et al. Doppler-defined pulmonary hypertension and the risk of death in children with sicckle Cell disease followed fo a mean of three years. Br J Haematol. 2009;146:437-41. 
107. Lei C, Yu B, Shahid M, Beloiartsev A, Bloch KD, Zapol WM. Inhaled nitric oxide attenuates the adverse effects of transfusing stored syngeneic erythrocytes in mice with endothelial dysfunction after hemorrhagic shock. Anesthesiology. $2012 ; 117: 1190-202$.

108. Lelubre C, Piagnerelli M, Vincent JL. Association between duration of storage of transfused red blood cells and morbidity and mortality in adult patients: myth or reality? Transfusion. 2009; 49:1384-94.

109. Levy JH, Steiner ME; Transfusion Medicine and Hemostasis Clinical Trials Network. Clinical studies of erythrocyte outcomes and mortality: size really counts. Anesthesiology. 2013; 118:10-2.

110. Liu C, Zhao W, Christ GJ, Gladwin MT, Kim-Shapiro DB. Nitric oxide scavenging by red cell microparticles. Free Radic Biol Med. 2013;65:1164-73.

111. Liu C, Liu X, Janes J, Stapley R, Patel RP, Gladwin MT, .Kim-Shapiro DB. Mechanism of faster NO scavenging by older stored red blood cells. Redox Biol. 2014; 2:211-9.

112. Lorente JA, Landín L, De Pablo R, Renes E, Rodríguez-Díaz R, Liste D. Effects of blood transfusion on oxygen transport variables in severe sepsis. Crit Care Med. 1993; 21:1312-8.

113. MacDonald VW, Hill H, Mongan P. Inosine allows long-term storage of swine red blood cells for autologous transfusion in experimental trauma. Transfusion. 2003;40(9 Suppl):69A.

114. Machado RF, Farber HW. Pulmonary hypertension associated with chronic hemolytic anemia and other blood disorders. Clin Chest Med. 2013; 34:739-75.

115. Mangalmurti NS, Xiong Z, Hulver $M$, Ranganathan $M$, Liu XH, Oriss $T$, Fitzpatrick M, Rubin M, Triulzi D, Choi A, Lee JS. Loss of red cell chemokine scavenging promotes transfusion-related lung inflammation. Blood. 2009; 113:1158-66. 
116. Marcus CS, Myhre BA, Angulo MC, Salk RD, Essex CE, Demianew SH. Radiolabeled red cell viability. I. Comparison of $51 \mathrm{Cr}$, $99 \mathrm{mTc}$, and $111 \mathrm{ln}$ for measuring the viability of autologous stored red cells. Transfusion. 1987;27:415-9.

117. Marik PE, Sibbald WJ. Effect of stored-blood transfusion on oxygen delivery in patients with sepsis. JAMA. 1993;269:3024-9.

118. Marik PE, Corwin HL. Efficacy of red blood cell transfusion in the critically ill: a systematic review of the literature. Crit Care Med. 2008;36:2667-74.

119. Martin CM, Sibbald WJ, Lu X, Hebert P. Age of transfused red blood cells is associated with ICU length of stay. Clin Invest Med. 1994;17(suppl 4):124.

120. Matthay MA, Ware LB, Zimmerman GA. The acute respiratory distress syndrome. J Clin Invest. 2012;122:2731-40.

121. Mollison PL, Engelfriet CP, Contreras M. Blood transfusion in clinical medicine. $9^{\text {th }}$ ed. London: Blackwell Science; 1993. chapt 9, p.379.

122. Mollison PL. Further observations on the normal survival curve of $51 \mathrm{Cr}$-labelled red cells. Clin Sci. 1961;21:21-36.

123. Mollison PL, Veall N. The use of the isotope ${ }^{51} \mathrm{Cr}$ as a label for red cells. $\mathrm{Br} \mathrm{J}$ Haematol. 1955;1:62-74.

124. Mollision PL, Polley MJ, Crome P. Temporary suppression of Lewis bloodgroup antibodies to permit incompatible transfusion. Lancet. 1963;1(7287):90912.

125. Moore FA, Moore EE, Sauaia A. Blood transfusion. An independent risk factor for postinjury multiple organ failure. Arch Surg. 1997; 132:620-4; discussion 624-5. 
126. Morisawa K, Fujitani S, Taira Y, Kushimoto S, Kitazawa Y, Okuchi K, Ishikura $\mathrm{H}$, Sakamoto T, Tagami T, Yamaguchi J, Sugita M, Kase $Y$, Kanemura T, Takahashi H, Kuroki Y, Izumino H, Rinka H, Seo R, Takatori M, Kaneko T, Nakamura T, Irahara T, Saitou N, Watanabe A; PiCCO Pulmonary Edema Study Group. Difference in pulmonary permeability between indirect and direct acute respiratory distress syndrome assessed by the transpulmonary thermodilution technique: a prospective, observational, multi-institutional study. J Intensive Care. 2014;2:24.

127. Moroff G, Sohmer PR, Button LN. Proposed standardization of methods for determining the 24-hour survival of stored red cells. Transfusion. 1984;24:10914.

128. Mowbray JF, Gibbings C, Liddell H, Reginald PW, Underwood JL, Beard RW. Controlled trial of treatment of recurrent spontaneous abortion by immunization with paternal cells. Lancet. 1985;1(8435):941-3.

129. Mulder JB, Brown RV, Corwin LA Jr. 51-chromium labeled erythrocyte half-time disappearance from miniature swine. Can J Comp Med. 1972; 36:103-7.

130. Murphy WG. Of mad cows and bolted horses: the economics of blood safety. Transfusion. 2012; 52:2278-81.

131. Nathens $A B$. Massive transfusion as a risk factor for acute lung injury: association or causation? Crit Care Med. 2006; 34(5 Suppl):S144-50.

132. Netzer G, Shah CV, Iwashyna TJ, Lanken PN, Finkel B, Fuchs B, Guo W, Christie JD. Association of RBC transfusion with mortality in patients with acute lung injury. Chest. 2007; 132:1116-23.

133. Noguchi, K., Gel, Y. R., Brunner, E. \& Konietschke, F. (2012). nparld: An r software package for the nonparametric analysis of longitudinal data in factorial experiments, Journal of Statistical Software 50(12): 1-23).

134. Offner PJ, Moore EE, Biffl WL, Johnson JL, Silliman CC. Increased rate of infection associated with transfusion of old blood after severe injury. Arch Surg. 2002; 137:711-6; discussion 716-7. 
135. Offner PJ. Age of blood: does it make a difference? Crit Care. 2004; 8(Suppl 2):S24-6.

136. Opelz G, Sengar DP, Mickey MR, Terasaki PI. Effect of blood transfusions on subsequent kidney transplants. Transplant Proc. 1973;5:253-9.

137. Paone G, Likosky DS, Brewer R, Theurer PF, Bell GF, Cogan CM, Prager RL; Membership of the Michigan Society of Thoracic and Cardiovascular Surgeons. Transfusion of 1 and 2 units of red blood cells is associated with increased morbidity and mortality. Ann Thorac Surg. 2014;97:87-94.

138. Pape A, Meier J, Kertscho H, Steche M, Laout M, Schwerdel F, Wedel M, Zwissler B, Habler O. Hyperoxic ventilation increases the tolerance of acute normovolemic anemia in anesthetized pigs. Crit Care Med. 2006; 34:1475-82.

139. Patel NN, Lin H, Jones C, Walkden G, Ray P, Sleeman PA, Angelini GD, Murphy GJ. Interactions of cardiopulmonary bypass and erythrocyte transfusion in the pathogenesis of pulmonary dysfunction in Swine. Anesthesiology. 2013; 119:365-78.

140. Patel NN, Lin H, Toth T, Welsh GI, Jones C, Ray P, Satchell SC, Sleeman P, Angelini GD, Murphy GJ. Reversal of anemia with allogenic RBC transfusion prevents post-cardiopulmonary bypass acute kidney injury in swine. $A m \mathrm{~J}$ Physiol Renal Physiol. 2011; 301:F605-14.

141. Pereira A. Deleterious consequences of allogenic blood transfusion on postoperative infection: really a transfusion-related immunomodulation effect? Blood. 2001; 98:498-500.

142. Piagnerelli M, Boudjeltia KZ, Brohee D, Piro P, Carlier E, Vincent JL, Lejeune P, Vanhaeverbeek M. Alterations of red blood cell shape and sialic acid membrane content in septic patients. Crit Care Med. 2003; 31:2156-62.

143. Purdy FR, Tweeddale MG, Merrick PM. Association of mortality with age of blood transfused in septic ICU patients. Can J Anaesth. 1997; 44:1256-61. 
144. Raat NJ, Verhoeven AJ, Mik EG, Gouwerok CW, Verhaar R, Goedhart PT, de Korte $\mathrm{D}$, Ince $\mathrm{C}$. The effect of storage time of human red cells on intestinal microcirculatory oxygenation in a rat isovolemic exchange model. Crit Care Med. 2005; 33:39-45; discussion 238-9.

145. Refaai MA, Blumberg N. The transfusion dilemma - weighing the known and newly proposed risks of blood transfusions against the uncertain benefits. Best Pract Res Clin Anaesthesiol. 2013; 27:17-35.

146. Roback JD, Neuman RB, Quyyumi A, Sutliff R. Insufficient nitric oxide bioavailability: a hypothesis to explain adverse effects of red blood cell transfusion. Transfusion. 2011;51:859-66.

147. Rogers CS, Abraham WM, Brogden KA, Engelhardt JF, Fisher JT, McCray PB Jr, McLennan G, Meyerholz DK, Namati E, Ostedgaard LS, Prather RS, Sabater JR, Stoltz DA, Zabner J, Welsh MJ. The porcine lung as a potential model for cystic fibrosis. Am J Physiol Lung Cell Mol Physiol. 2008; 295:L24063.

148. Rosário AL, Park M, Brunialti MK, Mendes $M$, Rapozo $M$, Fernandes $D$, Salomão R, Laurindo FR, Schettino GP, Azevedo LC. SvO(2)-guided resuscitation for experimental septic shock: effects of fluid infusion and dobutamine on hemodynamics, inflammatory response, and cardiovascular oxidative stress. Shock. 2011; 36:604-12.

149. Roubinian NH, Escobar GJ, Liu V, Gardner MN, Carson JL, Kleinman SH, Murphy EL; NHLBI Recipient Epidemiology and Donor Evaluation Study (REDS-III): decreased red blood cell use and mortality in hospitalized patients. JAMA Intern Med. 2014;174:1405-7.

150. Sasidharan $\mathrm{P}$, HeimLer R. Alterations in pulmonary mechanics after transfusion in anemic preterm infants. Crit Care Med. 1990; 18:1360-2.

151. Schaer DJ, Buehler PW, Alayash AL; Belcher JD, Vercellotti GM. Hemolysis and free hemoglobin revisited: exploring hemoglobin and hemin scavengers as a novel class of therapeutic proteins. Blood. 2013; 121(8):1276-84 
152. Schroeder TH, Hansen M. Effects of fresh versus old stored blood in the priming solution on whole blood lactate levels during paediatric cardiac surgery. Perfusion. 2005; 20:17-9.

153. Schönhofer B, Wenzel M, Geibel M, Köhler D. Blood transfusion and lung function in chronically anemic patients with severe chronic obstructive pulmonary disease. Crit Care Med. 1998; 26:1824-8.

154. Serious Hazards of Transfusion. Annual SHOT Report 2012. Manchester, UK; 2012. [cited 2013 Out]. Available from: http://www.shotuk.org/wpcontent/uploads/2013/08/SHOT-Annual-Report-2012.pdf

155. Shander A, Hofmann A, Ozawa S, Theusinger OM, Gombotz H, Spahn DR. Activity-based costs of blood transfusions in surgical patients at four hospitals. Transfusion. 2010; 50:753-65.

156. Shander A, Javidroozi M, Ozawa $S$ and Hare GMT. What is really dangerous: anaemia or transfusion? Br J Anaesth. 2011; 107(suppl 1):i41-i59.

157. Shanwell A, Kristiansson M, Remberger M, Ringdén O. Generation of cytokines in red cell concentrates during storage is prevented by prestorage white cell reduction. Transfusion. 1997; 37:678-84.

158. Sheil AG, Halliday JP, Drummond JM, Bookallil MJ, Gaudry PL, Yezerski SD. A modified technique for orthotopic liver transplantation. Arch Surg. 1972; 104:720-4.

159. Silliman CC, Moore EE, Kelher MR, Khan SY, Gellar L, Elzi DJ. Identification of lipids that accumulate during the routine storage of prestorage leukoreduced red blood cells and cause acute lung injury. Transfusion. 2011; 51:2549-54.

160. Simonova G, Tung JP, Fraser JF, Do HL, Staib A, Chew MS, Dunster KR, Glenister KM, Jackson DE, Fung YL. A comprehensive ovine model of blood transfusion. Vox Sang. 2014;106:153-60. 
161. Sitniakowsky LS, Later AF, van de Watering LM, Bogaerts M, Brand A, Klautz RJ, Smit NP, van Hilten JA. The effect of RBC transfusions on cytokine gene expression after cardiac surgery in patients developing post-operative multiple organ failure. Transfus Med. 2011; 21:236-46.

162. Smith DM, Newhouse M, Naziruddin B, Kresie L. Blood groups and transfusions in pigs. Xenotransplantation. 2006; 13:186-94.

163. Sparrow RL. Red blood cell storage and transfusion-related immunomodulation. Blood Transfus. 2010; 8(Suppl 3):s26-30.

164. Spinella PC, Carroll CL, Staff I, Gross R, Mc Quay J, Keibel L, Wade CE, Holcomb JB. Duration of red blood cell storage is associated with increased incidence of deep vein thrombosis and in hospital mortality in patients with traumatic injuries. Crit Care. 2009;13:R151.

165. Spinella PC, Doctor A, Blumberg N, Holcomb JB. Does the storage duration of blood products affect outcomes in critically ill patients? Transfusion. 2011;51:1644-50.

166. Spitalnik SL. Stored red blood cell transfusions: iron, inflammation, immunity, and infection. Transfusion. 2014;54:2365-2371.

167. Spolski R, Kim HP, Zhu W, Levy DE, Leonard WJ. IL-21 mediates suppressive effects via its induction of IL-10. J Immunol. 2009;182:2859-67.

168. Steiner ME, Assmann SF, Levy JH, Marshall J, Pulkrabek S, Sloan SR, Triulzi $\mathrm{D}$, Stowell CP. Addressing the question of the effect of RBC storage on clinical outcomes: the Red Cell Storage Duration Study (RECESS) (Section 7). Transfus Apher Sci. 2010; 43:107-16.

169. Steiner ME, Triulzi DJ , Assmann SF, Sloan SR, Delaney M, Blajchman MA, Granger S, D'Andrea PA, Pulkrabek S, Stowell CP. Randomized Trial Results: Red Cell Storage Age is Not Associated with a Significant Difference in Multiple-Organ Dysfunction Score or Mortality in Transfused Cardiac Surgery Patients [abstract]. Transfusion. 2014; 54(suppl 2):15A. 
170. Strauss RG, Mock DM, Widness JA, Johnson K, Cress G, Schmidt RL. Posttransfusion 24-hour recovery and subsequent survival of allogeneic red blood cells in the bloodstream of newborn infants. Transfusion. 2004; 44:871-6.

171. Surgenor SD, Kramer RS, Olmstead EM, Ross CS, Sellke FW, Likosky DS, Marrin CA, Helm RE Jr, Leavitt BJ, Morton JR, Charlesworth DC, Clough RA, Hernandez F, Frumiento C, Benak A, DioData C, O'Connor GT; Northern New England Cardiovascular Disease Study Group. The association of perioperative red blood cell transfusions and decreased long-term survival after cardiac surgery. Anesth Analg. 2009;108(6):1741-6.

172. Takei T, Amin NA, Schmid G, Dhingra-Kumar N, Rugg D. Progress in global blood safety for HIV. J Acquir Immune Defic Syndr. 2009; 52(Suppl 2):S127-31.

173. Talbot RB, Andresen E. Influence of blood group antibodies on survival of transfused erythrocytes in pigs. Am $J$ Vet Res. 1964; 25:1556-9.

174. Talbot RB, Swenson MJ. Survival of Cr-51 labeled erythrocytes in swine. Proc Soc Exp Biol Med. 1963; 112:573-6.

175. Tartter PI, Driefuss RM, Malon AM, Heimann TM, Aufses AH. Relationship of posperative septic complications and blood transfusions in patients with Crohn's disease. Am J Surg. 1988;155:43-7.

176. The ProCESS Investigators. A Randomized Trial of Protocol-Based Care for Early Septic Shock. N Engl J Med 2014;370:1683-93.

177. Tinmouth A, Fergusson D, Yee IC, Hébert PC; ABLE Investigators; Canadian Critical Care Trials Group. Clinical consequences of red cell storage in the critically ill. Transfusion. 2006;46:2014-27.

178. Tsai AG, Cabrales $P$, Intaglietta M. Microvascular perfusion upon exchange transfusion with stored red blood cells in normovolemic anemic conditions. Transfusion. 2004;44:1626-34. 
179. Tsai AG, Cabrales $P$, Manjula BN, Acharya SA, Winslow RM, Intaglietta M. Dissociation of local nitric oxide concentration and vasoconstriction in the presence of cell-free hemoglobin oxygen carriers. Blood. 2006;108:3603-10.

180. Tsai AG, Hofmann A, Cabrales P. Perfusion vs. oxygen delivery in Transfusion with "fresh" and "old" red blood cells: The experimental evidence. Transf Apher Sci. 2010;4391:69-78.

181. Toy P, Popovsky MA, Abraham E, Ambruso DR, Holness LG, Kopko PM, McFarland JG, Nathens AB, Silliman CC, Stroncek D; National Heart, Lung and Blood Institute Working Group on TRALI. Transfusion-related acute lung injury: definition and review. Crit Care Med. 2005; 33:721-6.

182. Toy P, Gajic O, bachetti P, Looney MR, Gropper MA, Hubmayr R, Lowell CA, Noris PJ, Murphy EL, Weiskopf RB, Wilson G, Koenigsbrerg M, lee D, Schuller R, Wu P, Grimes P, Gangdhi MU, Winters JL,Mair D, Hirschler N, Sanchez Rosen R, Mattay MA. Transfusion-related acute lung injury: incidence and risk factors. Blood. 2012; 119:1757-67.

183. Triulzi DJ, Yazer MH. Clinical studies of the effect of blood storage on patient outcomes. Transfus Apher Sci. 2010; 43:95-106.

184. Tuinman PR, Vlaar AP, Cornet AD, Hofstra JJ, Levi M, Meijers JC, Beishuizen A, Schultz MJ, Groeneveld AJ, Juffermans NP. Blood transfusion during cardiac surgery is associated with inflammation and coagulation in the lung: a case control study. Crit Care. 2011;15:R59.

185. Tung JP, Fraser JF, Nataatmadja M, Colebourne KI, Barnett AG, Glenister KM, Zhou AY, Wood P, Silliman CC, Fung YL. Age of blood and recipient factors determine the severity of transfusion-related acute lung injury (TRALI). Crit Care. 2012;16:R19.

186. Tung JP, Fung YL, Nataatmadja M, Colebourne KI, Esmaeel HM, Wilson K, Barnett AG, Wood P, Silliman CC, Fraser JF. A novel in vivo ovine model of transfusion-related acute lung injury (TRALI). Vox Sang. 2011; 100:219-30. 
187. United States. Food and Drug Administration. Fatalities Reported to FDA Following Blood Collection and Transfusion: Annual Summary for Fiscal Year 2011. [cited 2014 Dez]. Available from: $<$ http://www.fda.gov/biologicsbloodvaccines/safetyavailability/reportaproblem/tra nsfusiondonationfatalities/ucm302847.htm>.

188. United States. Food and Drug Administration. Workshop on red cells stored in additive solution systems. Bethesda, MD; 1985.

189. Urner M, Herrmann IK, Buddeberg F, Schuppli C, Roth Z'graggen B, Hasler M, Schanz U, Mehr M, Spahn DR, Beck Schimmer B. Effects of blood products on inflammatory response in endothelial cells in vitro. PLoS One. 2012;7:e33403.

190. Vamvakas EC, Blajchman MA. Blood still kills: six strategies to further reduce allogeneic blood transfusion-related mortality. Transfus Med Rev. 2010; 24:77124.

191. Vamvakas EC, Blajchman MA. Deleterious clinical effects of transfusionassociated immunomodulation: fact or fiction? Blood. 2001; 97:1180-95.

192. Vamvakas EC, Blajchman MA. Transfusion -related mortality: the ongoing risks of allogeneiv blood transfusion and the available strategies for their prevention. Blood 2009; 113: 3406-3417)

193. Vamvakas EC, Carven JH. Allogeneic blood transfusion, hospital charges, and length of hospitalization: a study of 487 consecutive patients undergoing colorectal cancer resection. Arch Pathol Lab Med. 1998; 122:145-51.

194. Vamvakas EC, Carven JH. Length of storage of transfused red cells and postoperative morbidity in patients undergoing coronary artery bypass graft surgery. Transfusion. 2000; 40:101-9.

195. Van der Horst-Bruinsma IE, Huizinga TWJ, Lagaay EM, et al. The influence of a partially HLA-matched blood transfusion on the disease activity of rheumatoid arthritis. Rheumatology . 1999;38:53-58.

196. Van de Watering L. Red cell storage and prognosis. Vox Sang. 2011;100:36-45. 
197. Van de Watering L, Lorinser J, Versteegh M, Westendord R, Brand A. Effects of storage time of red blood cell transfusions on the prognosis of coronary artery bypass graft patients. Transfusion. 2006; 46:1712-8.

198. Van de Watering L; Biomedical Excellence for Safer Transfusion (BEST) Collaborative. Pitfalls in the current published observational literature on the effects of red blood cell storage. Transfusion. 2011; 51:1847-54.

199. Van de Watering LM, Hermans J, Houbiers JG, van den Broek PJ, Bouter H, Boer F, Harvey MS, Huysmans HA, Brand A. Beneficial effects of leukocyte depletion of transfused blood on postoperative complications in patients undergoing cardiac surgery: a randomized clinical trial. Circulation. 1998;97:562-8.

200. Villanueva C, Colomo A, Bosch A, Concepción M, Hernandez-Gea V, Aracil C, Graupera I, Poca M, Alvarez-Urturi C, Gordillo J, Guarner-Argente C, Santaló M, Muñiz E, Guarner C. Transfusion strategies for acute upper gastrointestinal bleeding. N Engl J Med. 2013;368(1):11-21.

201. Vincent JL, Baron JF, Reinhart K, Gattinoni L, Thijs L, Webb A, Meier-Hellmann A, Nollet G, Peres-Bota D; ABC (Anemia and Blood Transfusion in Critical Care) Investigators. Anemia and blood transfusion in critically ill patients. JAMA. 2002; 288:1499-507.

202. Vincent JL, Sakr Y, Sprung C, Harboe S, Damas P; Sepsis Occurrence in Acutely III Patients (SOAP) Investigators. Are blood transfusions associated with greater mortality rates? Results of the Sepsis Occurrence in Acutely III Patients study. Anesthesiology. 2008; 108:31-9.

203. Vincent JL, Sakr Y, Lelubre C. The future of observational research and randomized controlled trials in red blood cell transfusion medicine. Shock. 2014;41(suppl 1):98-101

204. Vlaar AP, Cornet AD, Hofstra JJ, Porcelijn L, Beishuizen A, Kulik W, Vroom MB, Schultz MJ, Groeneveld AB, Juffermans NP. The effect of blood transfusion on pulmonary permeability in cardiac surgery patients: a prospective multicenter cohort study. Transfusion. 2012; 52:82-90. 
205. Vlaar AP, Hofstra JJ, Levi M, Kulik W, Nieuwland R, Tool AT, Schultz MJ, de Korte D, Juffermans NP. Supernatant of aged erythrocytes causes lung inflammation and coagulopathy in a "two-hit" in vivo syngeneic transfusion model. Anesthesiology. 2010; 113:92-103.

206. Voorhuis FT, Dieleman JM, de Vooght KM, van Dijk D, van Herwerden LA, Peelen LM, van Klei WA. Storage time of red blood cell concentrates and adverse outcomes after cardiac surgery: a cohort study. Ann Hematol. 2013;92:1701-6

207. Walker RH. Technical Manual. $11^{\text {th }}$ ed. Bethesda, MD: American Association of Blood Banks; 1993. Sect.2, p.622.

208. Walsh TS, McArdle F, McLellan SA, Maciver C, Maginnis M, Prescott RJ, McClelland DB. Does the storage time of transfused red blood cells influence regional or global indexes of tissue oxygenation in anemic critically ill patients? Crit Care Med. 2004; 32:364-71.

209. Walsh TS, Boyd JA, Watson D, Hope D, Lewis S, Krishan A, Forbes JF, Ramsay $P$, Pearse R, Wallis C, Cairns C, Cole S, Wyncoll D, for the RELIEVE Investigators. Restrictive versus liberal transfusion strategies for older mechanically ventilated critically ill patients: a randomized pilot trial. Crit Care Med. 2013;41:2354-63.

210. Wang D, Sun J, Solomon SB, Klein HG, Natanson C. Transfusion of older stored blood and risk of death: a meta-analysis. Transfusion. 2012;52:1184-95.

211. Weiskopf RB, Feiner J, Hopf H, Lieberman J, Finlay HE, Quah C, Kramer JH, Bostrom A, Toy P. Fresh blood and aged stored blood are equally efficacious in immediately reversing anemia-induced brain oxygenation deficits in humans. Anesthesiology. 2006; 104:911-20.

212. Weiskopf RB, Feiner J, Toy P, Twiford J, Shimabukuro D, Lieberman J, Looney MR, Lowell CA, Gropper MA. Fresh and stored red blood cell transfusion equivalently induce subclinical pulmonary gas exchange deficit in normal humans. Anesth Analg. 2012; 114:511-9. 
213. Williams JG, Hughes LE. Effects of perioperative blood transfusion on recurrence of Crohn's disease. Lancet 1989;2:131-3.

214. Yeo TW, Lampah DA, Gitawati $R$ et al. Impaired nitric oxide biovaibility and Larginine reversible endotelial dysfunction in adults with falciparum malária. $J$ Exp Med. 2007; 204:2693-704.

215. Yu B, Shahid M. Egorina EM, Sovershaev MA, . Raher MJ, Lei C, Wu MX, Bloch KD Zapol WM. Endothelial dysfunction enhances vasoconstriction dueto scavenging of nitric oxide by a hemoglobin-based oxygen carrier. Anesthesiology. 2010;112: 586-94.

216. Yu B, Lei C, Baron DM, Steinbicker AU, Bloch KD, Zapol WM. Diabetes augments and inhaled nitric oxide prevents the adverse hemodynamic effects of transfusing syngeneic stored blood in mice. Transfusion 2012; 52:1410-22.

217. Zallen G, Moore EE, Ciesla DJ, Brown M, Biffl WL, Silliman CC. Stored red blood cells selectively activate human neutrophils to release IL-8 and secretory PLA2. Shock. 2000; 13:29-33.

218. Zallen G, Offner PJ, Moore EE, Blackwell J, Ciesla DJ, Gabriel J, Denny C, Silliman CC. Age of transfused blood is an independent risk factor for postinjury multiple organ failure. Am J Surg. 1999; 178:570-2.

219. Zhang Z, Xu X, Yao M, Chen H, Ni H, Fan H. Use of the PiCCO system in critically ill patients with septic shock and acute respiratory distress syndrome: a study protocol for a randomized controlled trial. Trials. 2013; 14:32.

220. Zilberberg MD, Carter C, Lefebvre P, Raut M, Vekeman F, Duh MS, Shorr AF. Red blood cell transfusions and the risk of acute respiratory distress syndrome among the critically ill: a cohort study. Crit Care. 2007;11:R63.

221. Zimrin $A B$, Hess JR. Current issues relating to the transfusion of stored red blood cells. Vox Sang. 2009; 96:93-103. 
222. Zimring JC, Smith N, Stowell SR, Johnsen JM, Bell LN, Francis RO, Hod EA, hendrickson JE, Roback JD, Spitalnik SL. Strain- specific red blood cell storage, metabolism, and eicosanoid generation in a mouse model. Transfusion. 2014;54:137-48.

223. Zimring JC, Spitalnik SL. On the appropriate use and interpretation of animal models in transfusion medicine research. Transfusion. 2013;53:2334-9. 